\title{
Novel strategies for making myasthenia less gravis : targeting plasma cells and the neuromuscular junction
}

Citation for published version (APA):

Gomez, A. M. (2013). Novel strategies for making myasthenia less gravis : targeting plasma cells and the neuromuscular junction. [Doctoral Thesis, Maastricht University]. Maastricht University. https://doi.org/10.26481/dis.20131122ag

Document status and date:

Published: 01/01/2013

DOI:

10.26481/dis.20131122ag

Document Version:

Publisher's PDF, also known as Version of record

\section{Please check the document version of this publication:}

- A submitted manuscript is the version of the article upon submission and before peer-review. There can be important differences between the submitted version and the official published version of record.

People interested in the research are advised to contact the author for the final version of the publication, or visit the DOI to the publisher's website.

- The final author version and the galley proof are versions of the publication after peer review.

- The final published version features the final layout of the paper including the volume, issue and page numbers.

Link to publication

\footnotetext{
General rights rights.

- You may freely distribute the URL identifying the publication in the public portal. please follow below link for the End User Agreement:

www.umlib.nl/taverne-license

Take down policy

If you believe that this document breaches copyright please contact us at:

repository@maastrichtuniversity.nl

providing details and we will investigate your claim.
}

Copyright and moral rights for the publications made accessible in the public portal are retained by the authors and/or other copyright owners and it is a condition of accessing publications that users recognise and abide by the legal requirements associated with these

- Users may download and print one copy of any publication from the public portal for the purpose of private study or research.

- You may not further distribute the material or use it for any profit-making activity or commercial gain

If the publication is distributed under the terms of Article $25 \mathrm{fa}$ of the Dutch Copyright Act, indicated by the "Taverne" license above, 
MAASTRICHT UNIVERSITY

Novel strategies for making myasthenia less gravis

Targeting plasma cells and the neuromuscular junction

Alejandro Martin Gomez 
Novel strategies for making myasthenia less gravis: targeting plasma cells and the neuromuscular junction

Copyright (C) Alejandro Martin Gomez, Maastricht, 2013

ISBN:978-90-5335-753-8

Thesis with summary in English, Dutch and Spanish

All rights reserved. No part of this thesis may be reproduced or transmitted in any form or by any means, electronic or mechanical, including photocopying, recording or by any information storage and retrieval system, without permission in writing from the copyright holder.

Cover design: Linda van Zijp (StudioLIN Graphic Design, Rotterdam)

Typesetting and layout: Alejandro M. Gomez

Production and printing: Ridderprint BV (Ridderkerk, the Netherlands) 


\title{
Novel strategies for making myasthenia less gravis: targeting plasma cells and the neuromuscular junction
}

\author{
DISSERTATION \\ To obtain the degree of Doctor at \\ Maastricht University,
}

on the authority of the Rector Magnificus, Prof. Dr. L.L.G. Soete

in accordance with the decision of the Board of Deans,

to be defended in public

on Friday $22^{\text {nd }}$ of November 2013 at 10.00 hours

by

\section{Alejandro Martin Gomez}




\section{Supervisor:}

Prof. Dr. M.H. De Baets

\section{Co-supervisors:}

Dr. M. Losen

Dr. P. Martínez-Martínez

\section{Assessment Committee:}

Prof. Dr. H.W.M. Steinbusch (Chairman)

Dr. J.G.M.C. Damoiseaux

Prof. Dr. N. Hellings (Hasselt University, Belgium)

Dr. V.H.J.M. van Kranen-Mastenbroek

Prof. Dr. J.J.G.M. Verschuuren (Leiden University)

Financial support for the completion of this thesis was kindly provided by:

\section{PRINSES BEATRIX \\ SPIER

FONDS

KRACHTIG TEGEN SPIERZIEKTEN

Prinses Beatrix Fonds voor Spierziekten

(Project WAR 2008-12)

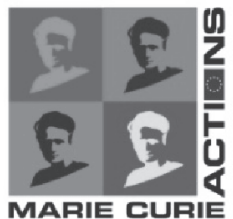

Marie-Curie Actions

Fellowship for Early Stage Research Networks

(European Commission, FP6-MOBILITY) 
"It always seems impossible until it's done"

N. Mandela 



\section{Contents}

Abbreviations $\quad 6$

General Introduction 9

$\begin{array}{ll}\text { Chapter } 1 & 31\end{array}$

Antibody effector mechanisms in myasthenia gravis - Pathogenesis at the neuromuscular junction

Chapter 2

69

Proteomic analysis of rat tibialis anterior muscles at different stages of experimental autoimmune myasthenia gravis

\section{Chapter 3}

Silencing of Dok-7 in adult rat muscle increases susceptibility to experimental autoimmune myasthenia gravis

\section{Chapter 4}

Targeting plasma cells with proteasome inhibitors: possible roles in treating myasthenia gravis?

\section{Chapter 5}

Proteasome inhibition with bortezomib depletes plasma cells and autoantibodies in experimental autoimmune myasthenia gravis

\section{Chapter 6}

Proteasome inhibition with bortezomib depletes plasma cells and specific autoantibody production in primary thymic cell cultures from early-onset myasthenia gravis patients

General Discussion

Summary

Samenvatting

Resumen

About the author 


\section{Abbreviations}

2D-DIGE

ACh

AChE

AChR

AMR

Btz or Bz

Bw

C5

CAIII

CFA

CMAP

CMS

Dok-7

EAMG

EM

EMG

EOMG

EPP

ER

FACS

FSC

GALT

GAPDH

GFP

HRP

IF

iFBS

IVIg

Lrp4

mAb

MAC

MEPP

MG

MGFA

MIR

MM

MMF

MUSK

NMJ

PBMC

PEX

PI
Two-dimensional difference in-gel electrophoresis

Acetylcholine

Acetylcholinesterase

Acetylcholine receptor

Antibody-mediated transplant rejection

Bortezomib

Body weight

Complement factor 5

Carbonic anhydrase III

Complete Freund's adjuvant

Compound muscle action potential

Congenital myasthenic syndromes

Downstream of kinase 7

Experimental autoimmune myasthenia gravis

Electron microscopy

Electromyography

Early-onset myasthenia gravis

Endplate potential

Endoplasmic reticulum

Fluorescence-activated cell sorting

Forward scatter

Gut-associated lymphoid tissue

Glyceraldehyde 3-phosphate dehydrogenase

Green fluorescent protein

Horseradish peroxidase

Immunofluorescence

Heat-inactivated fetal bovine serum

Intravenous immunoglobulin

Low-density lipoprotein receptor-related protein 4

Monoclonal antibody

Membrane attack complex

Miniature endplate potential

Myasthenia gravis

Myasthenia gravis foundation of America

Main immunogenic region

Multiple myeloma

Mycophenolate mofetil

Muscle specific kinase

Neuromuscular junction

Peripheral blood mononuclear cell

Plasma exchange

Propidium iodide 


$\begin{array}{ll}\text { PN } & \text { Peripheral neuropathy } \\ \text { PTB } & \text { Phosphotyrosine binding } \\ \text { PWM } & \text { Pokeweed mitogen } \\ \text { Rapsyn } & \text { Receptor-associated protein of the synapse } \\ \text { RIA } & \text { Radioimmunoassay } \\ \text { SEM } & \text { Standard error of the mean } \\ \text { shRNA } & \text { Short hairpin RNA } \\ \text { SiRNA } & \text { Small interfering RNA } \\ \text { SLE } & \text { Systemic lupus erythematosus } \\ \text { SSC } & \text { Side scatter } \\ \text { SV2 } & \text { Synaptic vesicle protein 2 } \\ \text { tAChR } & \text { Torpedo acetylcholine receptor } \\ \text { Tid1 } & \text { Tumorous imaginal disk 1 } \\ \text { TMB } & \text { Tetramethylbenzidine } \\ \text { TNF } & \text { Tumor necrosis factor } \\ \text { TTP } & \text { Thrombotic thrombocytopenic purpura } \\ \text { VGSC } & \text { Voltage-gated sodium channels }\end{array}$




\section{General Introduction}

Alejandro M. Gomez 


\section{Myasthenia gravis, an archetypal autoimmune disease}

The complex adaptive immune system of vertebrates has evolved to specifically recognize foreign antigens (mainly proteins from microbes and parasites) and eliminate them upon infection. The effector cells responsible for this task, B- and T-lymphocytes, have the potential of recognizing virtually any antigen by expressing randomly-mutated receptors at their surface, a feature that also poses risk for self-antigen recognition [1]. Consequently, the immune system developed fine selection processes to eliminate or inactivate lymphocytes that could react against host proteins; in other words, the adaptive immune system only allows in the circulation lymphocytes that "tolerates" the host antigens [2]. However, as with most of biological processes, these tolerance mechanisms can fail and, in such cases, self-reactive immune responses are mounted against "self"tissues, which is the basis for the development of autoimmune diseases [3].

Myasthenia gravis (MG) is one of the best characterized autoimmune diseases. Patients affected by MG mount an immune response against the postsynaptic component of the neuromuscular junction (NMJ), which is the synapse between a motor nerve terminal and the muscle; thereby blocking neuromuscular transmission and, thus, impairing muscle contraction. In this regard, the clinical presentation of MG is well explained by its own name: "myasthenia" means muscle weakness (one of the main symptoms, in addition to fatigability), and "gravis" means severe (because in some cases the weakness can be incapacitating or even lethal). One important aspect of MG is that the targets for the autoimmune response are well defined, with responses against the muscle acetylcholine receptor (AChR, 85\%), or muscle specific kinase (MuSK, 10\%), or low density lipoprotein receptor-related protein 4 (Lrp4, about 1-2\%), which also facilitates its clinical diagnosis [4]; the rest of patients ( $4 \%)$ have no detectable antibodies and are termed "seronegative" or idiopathic MG-patients. Moreover, several lines of evidence have demonstrated that these antibodies, particularly anti-AChR antibodies, are the sole mediators of the clinical symptoms. They bind and activate complement at the NMJ [5], they accelerate AChR degradation [6], they can passively transfer the disease to animals [7] or to neonates (neonatal MG) [8], and their removal by plasmapheresis and 
immunosuppression ameliorates muscle weakness [9]. This is usually not the case for many of the autoimmune diseases so far recognized, which tend to react against several auto-antigens and, in many of them, it is also difficult to clearly individualize the causal relationship between autoimmune response and pathology.

For the abovementioned reasons, MG has been traditionally regarded as a one of the prototypical antibody-mediated autoimmune diseases [10]. In addition, its target organ (the NMJ) is relatively accessible and easy to manipulate for both research in MG patients and animal models, which helped to boost research in the pathophysiology of MG already in the late 70's. This was also fostered by its early recognition as an autoimmune condition in the 60 's, when the concept of autoimmune diseases was just emerging [11].

\section{Historical overview of myasthenia gravis}

The first reports of myasthenia gravis date back to the $17^{\text {th }}$ century, with the description in England and the American colonies of a debilitating condition of the bulbar muscles that did not involve the central nervous system. One such case was the Native American chief Openchancanough, from whom it was accounted by early colonists that "was unable to walk and his eyelids were so heavy that he could not see unless they were lifted up by his attendants" [12]. More comprehensively documented is the report of the Oxford-born physician Thomas Willis who, in 1672, described the case of a woman with recurrent weakness in her bulbar muscles that prevented her from speaking after prolonged use of her voice; he referred to this condition as some kind of "spurious palsy" [13].

By the end of the $19^{\text {th }}$ century several cases of the spurious palsy were documented, which were usually regarded as atypical presentations of bulbar paralysis due to the lack of neuronal loss. However, in 1893, MG gained recognition as a condition distinct from bulbar paralysis when the Polish physician Samuel Goldflam provided a complete account of the symptoms, after carefully reviewing the cases described until then [14]. The name of this novel muscle disease emerged a few years later when Friederich Jolly, reporting two cases in a conference in Berlin, referred to his patients as suffering from "myasthenia gravis pseudo-paralytica" [15]. In the upcoming years, the relation between MG and the impairment of neuromuscular transmission, instead of the 
central nervous system, would become more evident. Initial observations indicated that repetitive nerve stimulation could trigger muscle weakness in MG and later, in the 1930's, Dr. Mary Walker successfully treated MG patients in London's St. Alfege's Hospital by enhancing neuromuscular transmission with acetylcholinesterase inhibitors [16]. The story goes that she attempted this treatment after noticing that the clinical picture of MG patients resembled that of curare poisoning, which was usually treated with cholinesterase inhibitors [17].

In the early $20^{\text {th }}$ century, the immunological nature of MG started to be slowly unveiled. Despite the fact that early physicians, such as Willis, tried to explain its possible causes by referring to fluctuations of a circulating substance called "explosive copula", which could be associated with immune components, one of the first empiric observations pointing at the immune system was made by Edward Buzzard; he reported an accumulation of lymphocytes in both the affected muscles and the thymus of MG patients [18]. Subsequently, several papers exposed that MG patients frequently presented thymic alterations [19-22], driving attention to the thymus as a key organ in the pathogenesis of MG. Shortly thereafter, the first thymectomy was successfully performed in Switzerland in 1911 and, by 1944, the heart surgeon Alfred Blalock had thymectomized 20 MG patients at the Johns Hopkins hospital in Baltimore, reporting his findings in an original paper [23]. Since the 1960's, thymectomy has been one of the standard treatments for MG, along with cholinesterase inhibitors.

It was not until the 1950-1960's that the first theories of an autoimmune component in the pathology of MG were formulated. John Simpson, a Scottish physician, is credited for publishing the seminal paper arguing that MG was caused by an autoimmune reaction to the motor endplates, after studying the transient effects of neonatal myasthenia in children of MG mothers and the association of MG with other autoimmune diseases [24]. This hypothesis received fundamental support about a decade later when Patrick and Lindstrom, in an attempt to generate antibodies against purified acetylcholine receptors (AChRs) by injecting the purified protein into rabbits, serendipitously created the first animal model for MG (experimental autoimmune myasthenia gravis, EAMG) [25]. This model was also crucial to define that MG was 
mediated by the autoantibodies, since the disease could be transferred by serum to naive animals [26]. A few years later, the development of a radioimmunoassay in which radioactive-labeled AChRs were immunoprecipitated by anti-AChR antibodies, allowed for measurement of autoantibody titers in serum of MG patients and helped to confirm that anti-AChR antibodies were indeed pathogenic [27].

In the last decades of the $20^{\text {th }}$ century, immunological research in MG unfolded. The contribution of different immunoglobulin subclasses to the pathological changes was well-characterized and complement-mediated damage at the neuromuscular junction was more clearly defined as one of the hallmarks in MG [28]. Also, increased internalization of cross-linked AChRs by bivalent antibodies [29] and blockade of acetylcholine-binding sites [30] were regarded as important pathological mechanisms of the disease. Most importantly, the increased knowledge of the pathology behind MG helped to diversify the treatment available for patients. In particular, immunosuppressive therapy, which started already in the 1960's with the use of corticosteroids and azathioprine, consolidated as the standard treatment for MG, while research on new immunosuppressive drugs started to flourish [31]. In the 2000's, the discovery of new autoimmune targets in seronegative patients, muscle specific kinase (MuSK) [32] and low density lipoprotein receptor-related protein 4 (Lrp4) [33], revealed that $M G$ in fact encompassed distinct autoimmune conditions and paved the way for a more specific treatment of patients.

\section{$\underline{\text { Treatment of myasthenia gravis }}$}

The incidence (30 cases/1,000,000/year; all ages, worldwide) [34] and prevalence (20/100,000, in USA, 2003 [35]; and 10/100,000 in the Netherlands, 2007 [36]) of MG are relatively low, but it still represents a considerable number of patients in the general population (about 60,000 patients in USA; and 1,500 patients in the Netherlands) $[35,36]$. As with most of autoimmune diseases, the risk for development of MG is higher in females below 40 years of age (early-onset MG) and is almost equal for both sexes after 40 years (late-onset MG) [37]. Taking into consideration that MG is a chronic and potentially disabling condition, adequate and efficient treatment strategies are important for both improving the quality of life of the patients and reducing the economic burden of 
treatment.

For the most part, MG patients are managed by a neurologist, who will perform the electrophysiological tests to detect alterations in neuromuscular transmission that are typical of MG, and later confirm the diagnosis by testing for autoantibodies. In most cases, one of the first clinical signs of MG is ptosis, which is the drooping of one or both eyelids due to ocular muscle weakness. In some cases, symptoms will be confined to the ocular muscles (ocular MG) but, in the majority of patients, muscle weakness will eventually spread to other muscles as well; such as the limbs, neck, bulbar and respiratory muscles (generalized MG). When respiratory muscles are involved, MG poses a potentially lifethreatening risk to the patient, since severe weakness in such muscles usually requires hospitalization and assisted ventilation, a so-called "myasthenic crisis", which also increases the risk of respiratory track infections. According to muscle involvement and severity, MG patients are classified following the recommendations of the Myasthenia Gravis Foundation of America (MGFA) in five different classes (Table 1) [38], what also helps to define which treatment is the more adequate to follow.

One of the first-line and most frequently used treatments for MG patients is thymectomy, the removal of the thymus; though it is only indicated in patients $<60$ years old, or older patients with an associated thymoma [31]. Thymectomy usually improves the clinical outcome of MG patients after immunosuppressive treatment, particularly in newly-diagnosed and severely affected patients; although a randomized controlled clinical trial to assess the real benefits of thymectomy in MG is still missing [39]. Moreover, the precise mechanisms by which thymectomy ameliorates MG remain largely unknown, even though the links between thymus and MG stretch back to almost 100 years ago. Possible explanations are an impaired central tolerance for T-cells that is ameliorated by thymectomy [40,41] and, since both epithelial thymic cells and myoid thymic cells express AChR, the elimination of a potential site for constant activation of autoreactive B- and Tcells [42]. 
Table 1. MGFA Clinical Classification

\begin{tabular}{|c|c|}
\hline Class I & $\begin{array}{l}\text { Any ocular muscle weakness } \\
\text { May have weakness of eye closure } \\
\text { All other muscle strength is normal }\end{array}$ \\
\hline Class II & $\begin{array}{l}\text { Mild weakness affecting other than ocular muscles } \\
\text { May also have ocular muscle weakness of any severity }\end{array}$ \\
\hline Ila & $\begin{array}{l}\text { Predominantly affecting limb, axial muscles, or both } \\
\text { May also have lesser involvement of oropharyngeal muscles }\end{array}$ \\
\hline ilb & $\begin{array}{l}\text { Predominantly affecting oropharyngeal, respiratory muscles, or both } \\
\text { May also have lesser or equal involvement of limb, axial muscles, or both }\end{array}$ \\
\hline Class III & $\begin{array}{l}\text { Moderate weakness affecting other than ocular muscles } \\
\text { May also have ocular muscle weakness of any severity }\end{array}$ \\
\hline IIla & $\begin{array}{l}\text { Predominantly affecting limb, axial muscles, or both } \\
\text { May also have lesser involvement of oropharyngeal muscles }\end{array}$ \\
\hline IIIb & $\begin{array}{l}\text { Predominantly affecting oropharyngeal, respiratory muscles, or both } \\
\text { May also have lesser or equal involvement of limb, axial muscles, or both }\end{array}$ \\
\hline Class IV & $\begin{array}{l}\text { Severe weakness affecting other than ocular muscles } \\
\text { May also have ocular muscle weakness of any severity }\end{array}$ \\
\hline IVa & $\begin{array}{l}\text { Predominantly affecting limb and/or axial muscles } \\
\text { May also have lesser involvement of oropharyngeal muscles }\end{array}$ \\
\hline IVb & $\begin{array}{l}\text { Predominantly affecting oropharyngeal, respiratory muscles, or both } \\
\text { May also have lesser or equal involvement of limb, axial muscles, or both }\end{array}$ \\
\hline Class V & $\begin{array}{l}\text { Defined by intubation, with or without mechanical ventilation, except when } \\
\text { employed during routine postoperative management. } \\
\text { The use of a feeding tube without intubation places the patient in class IVb. }\end{array}$ \\
\hline
\end{tabular}

\section{* Adapted from [38]}

Newly-diagnosed AChR-MG patients will usually receive symptomatic treatment in the form of pyridostigmine (Mestinon), regardless of their MGFA classification [43, 44]. This drug inhibits the activity of acetylcholinesterase (AChE) at the synaptic cleft and, therefore, delays the breakdown of acetylcholine and prolongs the stimulation of AChRs at the muscle membrane. In most cases, however, AChE-inhibitors treatment will be combined with certain form of immunosuppression, from which several options exist according to clinical severity and responsiveness to previous treatments. The most widely 
used immunosuppressive drugs in MG are corticosteroids, prednisone/prednisolone in particular, because they improve the clinical condition in about $70 \%$ of patients (observational studies, no double-blinded placebo controlled trial) albeit usually after 3-6 months after initiation of treatment, and they are orally-administered and relatively inexpensive [43, 45]. However, corticosteroid treatment carries complications and side effects: first, severely affected patients will initially receive high doses of prednisone, which can worsen the muscle weakness and, consequently, hospitalization is required during the first days of treatment; second, long-term treatment with prednisone can lead to severe adverse effects such as osteoporosis (particularly in the elderly), weight gain, glucose intolerance, hypertension and gastrointestinal complications [46]; and third, patients might be or become unresponsive to corticosteroids treatment [47]. In order to reduce the dose of corticosteroids, physicians usually combine prednisone with a second immunosuppressant that, in most cases, is azathioprine. Azathioprine is a purine analogue that inhibits the de novo synthesis of purines and therefore prevents the proliferation of both T- and B- lymphocytes rather specifically, because they lack a salvage pathway for purine recycling [48]. The main advantage of azathioprine treatment is that it is welltolerated and easy to administrate, the most common adverse effects are a flu-like syndrome and transient hepatotoxicity, though in rare cases bone marrow suppression has been associated with long-term treatment. The main disadvantage of azathioprine is its long induction period for improvement of the clinical status, with initial responses starting at about 6 months and peaking at 12-24 months [46, 49]. Still, the combination prednisone/azathioprine is the most commonly used immunosuppressive treatment for MG patients, and it is likely to remain this way in the upcoming years.

Alternatively, different "second line" immunosuppressants can be combined with prednisone instead of azathioprine, or used instead of prednisone for corticosteroidunresponsive patients. One of such is mycophenolate mofetil (MMF), which, like azathioprine, inhibits the proliferation of T- and B- lymphocytes by blocking purine synthesis, though it does so more specifically than azathioprine, and targeting activated lymphocytes in particular [50]. MMF is still frequently used in MG patients because of its mild adverse-effect profile and good tolerability [49], despite not having shown beneficial 
effects on randomized-controlled trials [51, 52]; probably because these trials had drawbacks in their design (such as duration of the study and pre-treatment history of the patients) that undermined the prednisone-sparing effects of MMF [53]. Other second line treatments include: cyclosporine $A$ and tacrolimus, both calcineurin inhibitors that block cytokine signaling (specially IL-2) in activated T-cells [54, 55]; cyclosphosphamide, a nitrogen mustard alkylating agent that induces cell death and prevents cell replication by DNA modification; and methotrexate, a folate analog that inhibits the metabolism of folic acid and impairs the synthesis of thymidine and purines, thereby blocking cell replication, in addition to exerting anti-inflammatory effects [56]. The majority of these drugs have been proven beneficial in MG when combined with corticosteroids, though their adverseeffects tend to be more frequent and severe than with azathioprine and MMF (particularly for cyclosporine A and cyclophosphamide) [46] and, therefore, their use is reserved only for steroid-resistant patients.

In the event of a myasthenic crisis, one of the therapeutic goals is to rapidly clear the serum from the pathogenic autoantibodies and, therefore, the preferred treatment of choice is either plasma exchange (PEx) or intravenous immunoglobulin (IVIg). PEx leads to a transient fall of anti-AChR antibody titers that translates into a rapid improvement of clinical symptoms, but this effect is short-lived and autoantibody titers will rise again about 2 weeks after a course of PEx [57]. In general, the procedure is well tolerated and the side effects are mild (chills, nausea, and vomiting), though complications such as pulmonary embolism, hypotension and sepsis may occur. Moreover, given its requirement for sophisticated apparatuses and technical expertise, it is an expensive procedure and is normally unavailable in small community hospitals [58]. Alternatively, IVIg can be used for the management of myasthenic crisis, or in refractory patients, since it has been demonstrated that its efficacy for improving clinical symptoms is similar to that of PEX [59]; additionally, side effects are considered to be fewer and less severe with IVIg [60]. The immunomodulatory mechanisms that might contribute to the improvement of clinical symptoms with IVIg are various and include: Fc receptor blockade, anti-idiotypic antibodies, modulation of cytokine production, and inhibition of complement deposition on target tissues [61]. Still, as with PEx, the benefits from IVIg therapy are transient and, 
therefore, repeated infusions are needed to avoid relapses $[62,63]$. In addition, antigenspecific plasma apheresis of anti-AChR antibodies is another interesting treatment alternative for severely-affected MG patients, though it is still experimental [64].

In the past decades, a large number of new immunosuppressive agents have been tested or are currently under investigation as potential new therapies for MG. Examples of these agents are: etanercept, a recombinant tumor necrosis factor- $\alpha$ (TNF- $\alpha$ ) receptor blocker [65]; terbutaline, a $\beta 2$ agonist [66]; eculizumab, a monoclonal antibody against the complement factor 5 (C5) [67]; and the C5 inhibitor rEV576 [68]. The majority of them showed significant improvement of muscle strength in MG, though with varying degrees, in small clinical trials or animal models. One of these new agents, however, stands out from the crowd in terms of efficacy and experience in the clinics: rituximab. This chimeric mouse-human monoclonal antibody directed against CD20 eliminates circulating B-cells and has proven to be efficacious in the treatment of MuSK-MG. B-cell depletion with rituximab was originally intended for the treatment of B-cell malignancies but in the last years its use expanded also to autoimmune diseases [69]. The main advantages of rituximab treatment are its quick onset of action (as early as 2 weeks) [70] and relatively good safety profile. Rituximab's main adverse effect is infusion-related reactions, though severe neurological complications (e.g. multifocal leukoencephalopathy) and systemic infections have been also described in lupus and rheumatoid arthritis patients [69]. However, despite the initial enthusiasm for using rituximab to treat refractory MG, it has been recently reported that its long-term efficacy for refractory AChR-MG is not outstanding; since patients improve their clinical condition only moderately and anti-AChR autoantibody titers are not very much reduced by rituximab [70]. Nevertheless, rituximab reduces autoantibody titers and significantly improve clinical symptoms in MuSK-MG, making it a promising treatment alternative for this subgroup of patients [70].

\section{The problem of treatment-refractory myasthenia gravis}

The prognosis of MG has improved remarkably since the initial immunosuppressive treatments in the 1960's and, currently, it is more or less accepted that myasthenia gravis 
is not as "gravis" as it was in the pre-immunosuppressant drugs era. In addition, the widespread use of thymectomy for EOMG patients has increased the rate of patients with clinical improvement and lower doses of corticosteroids as maintenance therapy, and even increased the rate of patients with complete stable remission (absence of symptoms without immunosuppressive treatment) [71, 72]. However, despite the wide array of efficacious treatment options available, some MG patients remain unresponsive to immunosuppression and are in need of novel therapeutic alternatives. These "refractory" MG patients usually undergo chronic palliative treatments, such as PEx or IVIg, which are scheduled according to disease severity and grade of response to other treatments; or they are treated with more experimental drugs with severe side effects. As a consequence, refractory patients are at a higher risk for experiencing severe complications or myasthenic crises and, in such a case, effective treatment alternatives are virtually nil, which increases the chances of fatal complications.

As mentioned, the number of novel immunosuppressive/immunomodulatory agents has expanded and has increased the options for treating refractory MG patients. Nevertheless, most of these novel immunosuppressive agents are not primarily intended for the reduction of the pathological anti-AChR autoantibodies and, those who do directly target the humoral immune system, such as rituximab, have not shown effective autoantibody reduction in AChR-MG. In this regard, the rather poor of effects of rituximab in antibody titers can be possibly explained by the survival of long-lived plasma cells to this treatment: these cells lack CD20 on their surface, can live up to several years at survival niches in the bone marrow, are the main producers of antibodies, and resist most of the currently available treatments for MG. Long-lived plasma cells are, thus, an attractive candidate to explain the resistance of some MG patients to treatment and, consequently, they are also a promising therapeutic target. Additionally, elimination of autoreactive plasma cells in patients with high autoantibody titers might be an effective approach to rapidly reduce titers until standard immunosuppression with corticosteroids and azathioprine takes effect. 


\section{Targeting the immune system and the target organ}

Diseases, and by extension autoimmune diseases, result from the interaction of an infective agent (e.g. pathogen) and the body's effector agent (i.e. immune system), in the context of a specific target organ, tissue, or cell. The effects of both the pathogen trying to replicate and the immune system attempting to eliminate it will influence the homeostasis of the target organ, inducing phenotypic changes that are the signs of a disease. In evolutionary terms, there are roughly two main strategies for avoiding disease once a host has been infected. One strategy is the "resistance" to an infection, which refers to the capacity of the immune system to eliminate or prevent the infection. The second strategy is the "tolerance" of the host to the infection, which reduces the negative impact of the pathogen (or the immune response to eliminate the pathogen) in the overall fitness of the target organ [73].

The idea of disease tolerance in animal immunology has emerged primarily in the past decade and it has not been comprehensively addressed by the scientific community. Research on disease tolerance mechanisms has potential applications to both increase our knowledge about pathophysiology of diseases and, more importantly, to develop new tools for novel therapies [74]. For instance, it has been recently demonstrated that hemoglobin mutations in Plasmodium-resistant individuals confer a survival advantage not much by impairing the parasite's replication in red blood cells, but mainly by inducing resistance to the toxic effects of hemolytic by-products in malaria [75]. Thus, such mutations seem to have been evolutionary selected for enhancing the host's tolerance to the infection rather than for preventing it. In this regard, manipulations of the enzymatic machinery that is activated by mutated hemoglobin can be a promising therapeutic alternative to improve symptoms in severe malaria [76, 77].

Traditionally, autoimmune diseases have been treated by a rather unspecific modulation of the immune system, in an attempt to concomitantly decrease the autoimmune response or its effector mechanisms. In other words, treatment of autoimmune conditions has been largely focused on diminishing the capacity for infectionresistance of the immune system, either as a whole or only in a certain fraction of it. Because of the success of these immunomodulatory treatments, little attention has been 
paid to the response of the target organ to the autoimmune attack. As a consequence, manipulating the tolerance of the host to the autoimmune attack has, for the most part, been neglected as a therapeutic alternative in autoimmune diseases.

In order to apply concepts of disease tolerance for understanding autoimmune diseases, it is important to consider the tolerance capacity of different organs to an immune attack. Organs such as the brain and the heart have a low tolerance capacity since their ability for tissue regeneration is poor and they have a low resistance to hypoxia; consequently, they are very susceptible to inflammation-induced damage. Also, tissues with poor repair mechanisms (i.e. low cell turnover, high sensitivity to oxidative stress and slow tissue regeneration, susceptibility to fibrosis, among others) are predisposed to experience autoimmunity-related sequels [73].

When it comes to muscle tissue, the embryonic development of NMJs is well characterized, but very little is known about their maintenance and repair mechanisms during adulthood. Such knowledge might provide new tools for understanding and treating MG. For instance, it has been shown that the expression of the AChR-anchoring protein rapsyn is increased in the muscle of EAMG animals [78], and increasing its levels at the NMJ of rats reduces their susceptibility to the autoantibody attack in EAMG $[79,80]$. In addition, mutations in AChR-clustering proteins of the NMJ cause of a group of conditions characterized by impaired neuromuscular transmission and muscle weakness, which are termed congenital myasthenic syndromes (CMS) [81]. This also implies that the loss of these AChR-clustering proteins in MG could aggravate even more the disease by facilitating the loss of AChRs or delaying the recovery from the autoantibody damage. It is plausible to consider, thus, that such proteins are intrinsically important for the tolerance capacity of the NMJ. Consequently, their manipulation could offer new treatment strategies that could be valuable for improving symptoms in MG patients, particularly those who are severely affected.

\section{Aim and outline of this thesis}

The six chapters presented on this thesis are aimed at investigating new strategies for a more holistic treatment of MG, focusing not only on the immune system, but also on the 
target organ (the muscle). In our search for novel therapies, we explored the effects of the autoimmune attack in the muscle and evaluated the therapeutic potential of the, so far neglected, plasma cells.

Chapter 1 gives a comprehensive introduction to the normal structure, organization and physiology of the NMJ, and the pathological alterations in both MuSKand AChR-MG. Emphasis is given to the contribution of different IgG isotypes to the pathophysiology of MG and particular interest is placed on explaining how the loss of AChR-associated proteins can contribute to disease severity. In addition, the main animal models of MG are described.

Chapter $\mathbf{2}$ characterizes the response of the muscle to an autoimmune attack in the chronic EAMG model. For this purpose, we studied the differentially expressed proteins in tibialis anterior muscles of chronic EAMG rats. The muscle's proteome was analyzed by two-dimensional difference in-gel electrophoresis (2D-DIGE) technology and the changes in relevant proteins were confirmed by Western blotting.

Chapter 3 investigates the role of the muscle protein Dok-7 in both the susceptibility to and the recovery from a passive-transfer EAMG model. Since Dok-7 is fundamental for the development of the NMJ, and its mutations are one of the major causes of CMS, we hypothesized that silencing its expression with siRNAs would increase the susceptibility to EAMG and delay the recovery of the NMJ from the autoantibody attack.

Chapter 4 elaborates on the importance of the main antibody-producing cell, the plasma cells, in the treatment of autoimmune diseases, with emphasis in the treatment of MG. It also provides an overview of the in vitro and in vivo experience with the proteasome inhibitor bortezomib in non-neoplastic conditions; one of the few compounds that can kill plasma cells and is also approved for clinical use in patients. Additionally, it discusses the rationale of bortezomib's potential applications for the treatment of MG.

Chapter 5 investigates the effects of proteasome inhibition with bortezomib in the treatment of chronic EAMG rats. It demonstrates the toxic effects of bortezomib on plasma cells in vivo and shows that depletion of plasma cells can significantly reduce autoantibody titers and, thus, improve the clinical condition. 
Chapter 6 studies the in vitro effects of proteasome inhibition on cultured thymic cells from early onset MG patients. It shows that administration of bortezomib, but not corticosteroids, eliminates autoimmune human plasma cells from the cultured thymic cells, thereby blocking autoantibody and IgG production.

The main contents of these chapters are summarized and illustrated in Figure 1.

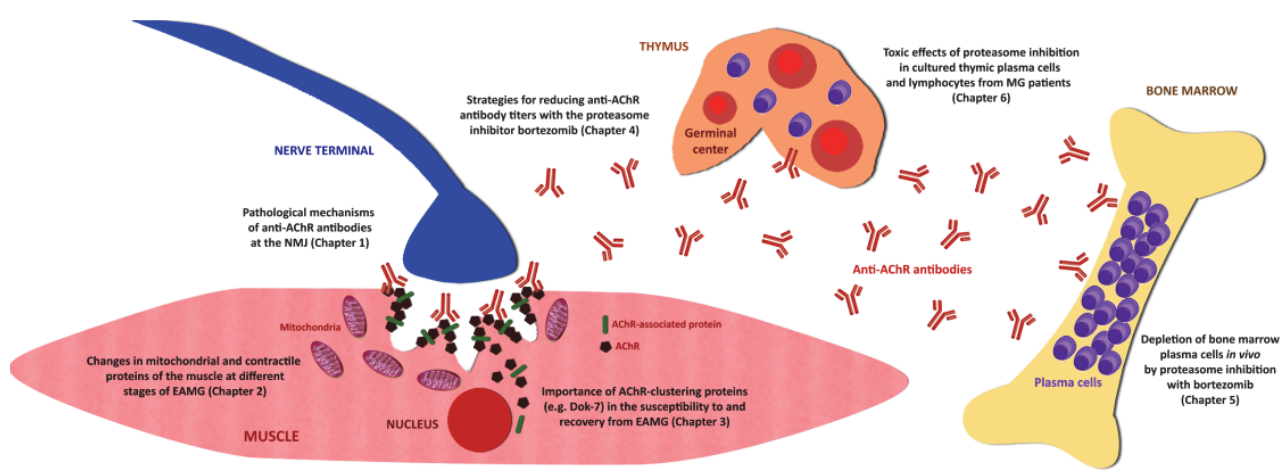

Figure 1. Illustrative overview of the different chapters presented in this thesis. This simplified representation of the features of MG most directly related to this thesis includes: the generation of germinal centers and autoimmune plasma cells in the thymus of MG patients, which were used to test the efficacy of the proteasome inhibitor bortezomib (Chapter 6); the accumulation and prolonged survival of autoimmune plasma cells in the bone marrow, which were depleted by treatment with bortezomib in the EAMG rat model (Chapter 5); high levels of anti-AChR antibodies in serum and novel strategies for reducing them (Chapter 4); pathological changes at the NMJ due to the binding of autoantibodies in MG (Chapter 1); changes in the proteomic profile of muscle fibers at different disease stages of EAMG (Chapter 2); relative importance of the AChR-clustering machinery (in particular the cytoplasmic protein Dok-7) in the susceptibility to and recovery from the autoantibody attack in EAMG (Chapter 3). 


\section{$\underline{\text { References }}$}

1. Cooper, M.D., Herrin, B.R. 2010. How did our complex immune system evolve? Nat Rev Immunol, 10: 2-3.

2. Goodnow, C.C., Sprent, J., Fazekas de St Groth, B., Vinuesa, C.G. 2005. Cellular and genetic mechanisms of self tolerance and autoimmunity. Nature, 435: 590-7.

3. Mackay, I.R. 2000. Science, medicine, and the future: Tolerance and autoimmunity. BMJ, 321: 93-6.

4. Meriggioli, M.N., Sanders, D.B. 2012. Muscle autoantibodies in myasthenia gravis: beyond diagnosis? Expert Rev Clin Immunol, 8: 427-38.

5. Lennon, V.A., Seybold, M.E., Lindstrom, J.M., Cochrane, C., Ulevitch, R. 1978. Role of complement in the pathogenesis of experimental autoimmune myasthenia gravis. J Exp Med, 147: 973-83.

6. Kao, I., Drachman, D.B. 1977. Myasthenic immunoglobulin accelerates acetylcholine receptor degradation. Science, 196: 527-9.

7. Toyka, K.V., Brachman, D.B., Pestronk, A., Kao, I. 1975. Myasthenia gravis: passive transfer from man to mouse. Science, 190: 397-9.

8. Morel, E., Eymard, B., Vernet-der Garabedian, B., Pannier, C., Dulac, O., Bach, J.F. 1988. Neonatal myasthenia gravis: a new clinical and immunologic appraisal on 30 cases. Neurology, 38: 138-42.

9. Dau, P.C., Lindstrom, J.M., Cassel, C.K., Denys, E.H., Shev, E.E., Spitler, L.E. 1977. Plasmapheresis and immunosuppressive drug therapy in myasthenia gravis. $N$ Engl J Med, 297: 1134-40.

10. Hoedemaekers, A.C., van Breda Vriesman, P.J., De Baets, M.H. 1997. Myasthenia gravis as a prototype autoimmune receptor disease. Immunol Res, 16: 341-54.

11. Mackay, I.R. 2010. Travels and travails of autoimmunity: a historical journey from discovery to rediscovery. Autoimmun Rev, 9: A251-8.

12. Marsteller, H.B. 1988. The first American case of myasthenia gravis. Arch Neurol, 45: 1857.

13. Pordage, S. 1971. An English translation of the works of Willis published in 1681. Fascimile of the 1683 translation of "The Soul of the Brutes", Gainesville, Florida: Scholars' Facsimilies \& Reprints.

14. Goldflam, S. 1893. Ueber einen scheinbar heilbaren bulbarparalytischen symptomencomplex mit beheiligung der extremitaten. Dtsch Z Nervenheilk, 4: 312-52.

15. Jolly, F. 1895. Ueber myasthenia gravis pseudoparalytica. Berlin Klin. Wochenschr, 32: 1-7.

16. Walker, M.B. 1934. Treatment of myasthenia gravis with physostigmine. Lancet, 1: 12001201.

17. Hughes, T. 2005. The early history of myasthenia gravis. Neuromuscul Disord, 15: 878-86.

18. Buzzard, E.F. 1905. The clinical history and post-mortem examination of five cases of myasthenia gravis. Brain, 28: 438-83.

19. Lacquer, L., Weigert, C. 1901. Beitrage zur Lehre von der Erb'schen Krankheit. Neurol Centralbl, 20: 594-601.

20. Bell, E.J. 1917. Tumours of the thymus gland in myasthenia gravis. J Nerv Ment Dis, 45: 130-43.

21. Holmes, G. 1923. Discussion of a case presented to the Royal Society of Medicine. Brain, 46: 237-41.

22. Norris, E.H. 1936. The thymoma and thymic hyperplasia in myasthenia gravis with observations on the general pathology. Am J Cancer, 27: 421-33. 
23. Blalock, A. 1944. Thymectomy in the treatment of myasthenia gravis, report of 20 cases. $J$ Thoracic Surg, 13: 316-39.

24. Simpson, J.A. 1960. Myasthenia gravis, a new hypothesis. Scott. Med. J., 5: 419-436.

25. Patrick, J., Lindstrom, J. 1973. Autoimmune response to acetylcholine receptor. Science, 180: 871-2.

26. Lindstrom, J.M., Engel, A.G., Seybold, M.E., Lennon, V.A., Lambert, E.H. 1976. Pathological mechanisms in experimental autoimmune myasthenia gravis. II. Passive transfer of experimental autoimmune myasthenia gravis in rats with anti-acetylcholine recepotr antibodies. J Exp Med, 144: 739-53.

27. Lindstrom, J.M., Seybold, M.E., Lennon, V.A., Whittingham, S., Duane, D.D. 1976. Antibody to acetylcholine receptor in myasthenia gravis. Prevalence, clinical correlates, and diagnostic value. Neurology, 26: 1054-9.

28. Sahashi, K., Engel, A.G., Lambert, E.H., Howard, F.M., Jr. 1980. Ultrastructural localization of the terminal and lytic ninth complement component (C9) at the motor end-plate in myasthenia gravis. J Neuropathol Exp Neurol, 39: 160-72.

29. Drachman, D.B., Angus, C.W., Adams, R.N., Michelson, J.D., Hoffman, G.J. 1978. Myasthenic antibodies cross-link acetylcholine receptors to accelerate degradation. $N$ Engl J Med, 298: 1116-22.

30. Gomez, C.M., Richman, D.P. 1983. Anti-acetylcholine receptor antibodies directed against the alpha-bungarotoxin binding site induce a unique form of experimental myasthenia. Proc Natl Acad Sci U S A, 80: 4089-93.

31. Diaz-Manera, J., Rojas Garcia, R., Illa, I. 2012. Treatment strategies for myasthenia gravis: an update. Expert Opin Pharmacother, 13: 1873-83.

32. Scuderi, F., Marino, M., Colonna, L., Mannella, F., Evoli, A., Provenzano, C., Bartoccioni, E. 2002. Anti-p110 autoantibodies identify a subtype of "seronegative" myasthenia gravis with prominent oculobulbar involvement. Lab Invest, 82: 1139-46.

33. Higuchi, O., Hamuro, J., Motomura, M., Yamanashi, Y. 2011. Autoantibodies to low-density lipoprotein receptor-related protein 4 in myasthenia gravis. Ann Neurol, 69: 418-22.

34. McGrogan, A., Sneddon, S., de Vries, C.S. 2010. The incidence of myasthenia gravis: a systematic literature review. Neuroepidemiology, 34: 171-83.

35. Phillips, L.H., 2nd. 2003. The epidemiology of myasthenia gravis. Ann N Y Acad Sci, 998: 407-12.

36. Niks, E.H., Kuks, J.B., Verschuuren, J.J. 2007. Epidemiology of myasthenia gravis with antimuscle specific kinase antibodies in The Netherlands. J Neurol Neurosurg Psychiatry, 78: 417-8.

37. Vincent, A. 2002. Unravelling the pathogenesis of myasthenia gravis. Nat Rev Immunol, 2: 797-804.

38. Jaretzki, A., 3rd, Barohn, R.J., Ernstoff, R.M., Kaminski, H.J., Keesey, J.C., Penn, A.S., Sanders, D.B. 2000. Myasthenia gravis: recommendations for clinical research standards. Task Force of the Medical Scientific Advisory Board of the Myasthenia Gravis Foundation of America. Ann Thorac Surg, 70: 327-34.

39. Gronseth, G.S., Barohn, R.J. 2000. Practice parameter: thymectomy for autoimmune myasthenia gravis (an evidence-based review): report of the Quality Standards Subcommittee of the American Academy of Neurology. Neurology, 55: 7-15.

40. Cavalcante, P., Cufi, P., Mantegazza, R., Berrih-Aknin, S., Bernasconi, P., Le Panse, R. 2013. Etiology of myasthenia gravis: Innate immunity signature in pathological thymus. Autoimmun Rev.

41. Gerli, R., Paganelli, R., Cossarizza, A., Muscat, C., Piccolo, G., Barbieri, D., Mariotti, S., Monti, D., Bistoni, O., Raiola, E. et al. 1999. Long-term immunologic effects of thymectomy in patients with myasthenia gravis. J Allergy Clin Immunol, 103: 865-72. 
42. Leite, M.I., Jones, M., Strobel, P., Marx, A., Gold, R., Niks, E., Verschuuren, J.J., BerrihAknin, S., Scaravilli, F., Canelhas, A. et al. 2007. Myasthenia gravis thymus: complement vulnerability of epithelial and myoid cells, complement attack on them, and correlations with autoantibody status. Am J Pathol, 171: 893-905.

43. Skeie, G.O., Apostolski, S., Evoli, A., Gilhus, N.E., Hart, I.K., Harms, L., Hilton-Jones, D., Melms, A., Verschuuren, J., Horge, H.W. 2006. Guidelines for the treatment of autoimmune neuromuscular transmission disorders. Eur J Neurol, 13: 691-9.

44. Mehndiratta, M.M., Pandey, S., Kuntzer, T. 2011. Acetylcholinesterase inhibitor treatment for myasthenia gravis. Cochrane Database Syst Rev: CD006986.

45. Schneider-Gold, C., Gajdos, P., Toyka, K.V., Hohlfeld, R.R. 2005. Corticosteroids for myasthenia gravis. Cochrane Database Syst Rev: CD002828.

46. Sathasivam, S. 2008. Steroids and immunosuppressant drugs in myasthenia gravis. Nat Clin Pract Neurol, 4: 317-27.

47. Palace, J., Newsom-Davis, J., Lecky, B. 1998. A randomized double-blind trial of prednisolone alone or with azathioprine in myasthenia gravis. Myasthenia Gravis Study Group. Neurology, 50: 1778-83.

48. Maltzman, J.S., Koretzky, G.A. 2003. Azathioprine: old drug, new actions. J Clin Invest, 111: 1122-4.

49. Sanders, D.B., Evoli, A. 2010. Immunosuppressive therapies in myasthenia gravis. Autoimmunity, 43: 428-35.

50. Allison, A.C., Eugui, E.M. 2000. Mycophenolate mofetil and its mechanisms of action. Immunopharmacology, 47: 85-118.

51. Sanders, D.B., Hart, I.K., Mantegazza, R., Shukla, S.S., Siddiqi, Z.A., De Baets, M.H., Melms, A., Nicolle, M.W., Solomons, N., Richman, D.P. 2008. An international, phase III, randomized trial of mycophenolate mofetil in myasthenia gravis. Neurology, 71: 400-6.

52. Group, T.M.S. 2008. A trial of mycophenolate mofetil with prednisone as initial immunotherapy in myasthenia gravis. Neurology, 71: 394-9.

53. Sanders, D.B., Siddiqi, Z.A. 2008. Lessons from two trials of mycophenolate mofetil in myasthenia gravis. Ann N Y Acad Sci, 1132: 249-53.

54. Matsuda, S., Koyasu, S. 2000. Mechanisms of action of cyclosporine. Immunopharmacology, 47: 119-25.

55. Brazelton, T.R., Morris, R.E. 1996. Molecular mechanisms of action of new xenobiotic immunosuppressive drugs: tacrolimus (FK506), sirolimus (rapamycin), mycophenolate mofetil and leflunomide. Curr Opin Immunol, 8: 710-20.

56. Tian, H., Cronstein, B.N. 2007. Understanding the mechanisms of action of methotrexate: implications for the treatment of rheumatoid arthritis. Bull NYU Hosp Jt Dis, 65: 168-73.

57. Newsom-Davis, J., Wilson, S.G., Vincent, A., Ward, C.D. 1979. Long-term effects of repeated plasma exchange in myasthenia gravis. Lancet, 1: 464-8.

58. Silvestri, N.J., Wolfe, G.I. 2012. Myasthenia gravis. Semin Neurol, 32: 215-26.

59. Gajdos, P., Chevret, S., Toyka, K.V. 2012. Intravenous immunoglobulin for myasthenia gravis. Cochrane Database Syst Rev, 12: CD002277.

60. Gajdos, P., Chevret, S., Clair, B., Tranchant, C., Chastang, C. 1997. Clinical trial of plasma exchange and high-dose intravenous immunoglobulin in myasthenia gravis. Myasthenia Gravis Clinical Study Group. Ann Neurol, 41: 789-96.

61. Ballow, M. 2011. The IgG molecule as a biological immune response modifier: mechanisms of action of intravenous immune serum globulin in autoimmune and inflammatory disorders. J Allergy Clin Immunol, 127: 315-23; quiz 324-5.

62. Barth, D., Nabavi Nouri, M., Ng, E., Nwe, P., Bril, V. 2011. Comparison of IVIg and PLEX in patients with myasthenia gravis. Neurology, 76: 2017-23.

63. Zinman, L., Ng, E., Bril, V. 2007. IV immunoglobulin in patients with myasthenia gravis: a 
randomized controlled trial. Neurology, 68: 837-41.

64. Lazaridis, K., Zisimopoulou, P., Lagoumintzis, G., Skriapa, L., Trakas, N., Evangelakou, P., Kanelopoulos, I., Grapsa, E., Poulas, K., Tzartos, S. 2012. Antigen-specific apheresis of autoantibodies in myasthenia gravis. Ann N Y Acad Sci, 1275: 7-12.

65. Rowin, J., Meriggioli, M.N., Tuzun, E., Leurgans, S., Christadoss, P. 2004. Etanercept treatment in corticosteroid-dependent myasthenia gravis. Neurology, 63: 2390-2.

66. Soliven, B., Rezania, K., Gundogdu, B., Harding-Clay, B., Oger, J., Arnason, B.G. 2009. Terbutaline in myasthenia gravis: a pilot study. J Neurol Sci, 277: 150-4.

67. Zhou, Y., Gong, B., Lin, F., Rother, R.P., Medof, M.E., Kaminski, H.J. 2007. Anti-C5 antibody treatment ameliorates weakness in experimentally acquired myasthenia gravis. J Immunol, 179: 8562-7.

68. Soltys, J., Kusner, L.L., Young, A., Richmonds, C., Hatala, D., Gong, B., Shanmugavel, V., Kaminski, H.J. 2009. Novel complement inhibitor limits severity of experimentally myasthenia gravis. Ann Neurol, 65: 67-75.

69. Gurcan, H.M., Keskin, D.B., Stern, J.N., Nitzberg, M.A., Shekhani, H., Ahmed, A.R. 2009. A review of the current use of rituximab in autoimmune diseases. Int Immunopharmacol, 9: 10-25.

70. Diaz-Manera, J., Martinez-Hernandez, E., Querol, L., Klooster, R., Rojas-Garcia, R., SuarezCalvet, X., Munoz-Blanco, J.L., Mazia, C., Straasheijm, K.R., Gallardo, E. et al. 2012. Longlasting treatment effect of rituximab in MuSK myasthenia. Neurology, 78: 189-93.

71. Nieto, I.P., Robledo, J.P., Pajuelo, M.C., Montes, J.A., Giron, J.G., Alonso, J.G., Sancho, L.G. 1999. Prognostic factors for myasthenia gravis treated by thymectomy: review of 61 cases. Ann Thorac Surg, 67: 1568-71.

72. Buckingham, J.M., Howard, F.M., Jr., Bernatz, P.E., Payne, W.S., Harrison, E.G., Jr., O'Brien, P.C., Weiland, L.H. 1976. The value of thymectomy in myasthenia gravis: a computerassisted matched study. Ann Surg, 184: 453-8.

73. Medzhitov, R., Schneider, D.S., Soares, M.P. 2012. Disease tolerance as a defense strategy. Science, 335: 936-41.

74. Ayres, J.S., Schneider, D.S. 2012. Tolerance of infections. Annu Rev Immunol, 30: 271-94.

75. Ferreira, A., Marguti, I., Bechmann, I., Jeney, V., Chora, A., Palha, N.R., Rebelo, S., Henri, A., Beuzard, Y., Soares, M.P. 2011. Sickle hemoglobin confers tolerance to Plasmodium infection. Cell, 145: 398-409.

76. Walther, M., De Caul, A., Aka, P., Njie, M., Amambua-Ngwa, A., Walther, B., Predazzi, I.M., Cunnington, A., Deininger, S., Takem, E.N. et al. 2012. HMOX1 gene promoter alleles and high HO-1 levels are associated with severe malaria in Gambian children. PLoS Pathog, 8: e1002579.

77. Rosenthal, P.J. 2011. Lessons from sickle cell disease in the treatment and control of malaria. N Engl J Med, 364: 2549-51.

78. Asher, O., Kues, W.A., Witzemann, V., Tzartos, S.J., Fuchs, S., Souroujon, M.C. 1993. Increased gene expression of acetylcholine receptor and myogenic factors in passively transferred experimental autoimmune myasthenia gravis. J Immunol, 151: 6442-50.

79. Losen, M., Stassen, M.H., Martinez-Martinez, P., Machiels, B.M., Duimel, H., Frederik, P., Veldman, H., Wokke, J.H., Spaans, F., Vincent, A. et al. 2005. Increased expression of rapsyn in muscles prevents acetylcholine receptor loss in experimental autoimmune myasthenia gravis. Brain, 128: 2327-37.

80. Martinez-Martinez, P., Losen, M., Duimel, H., Frederik, P., Spaans, F., Molenaar, P., Vincent, A., De Baets, M.H. 2007. Overexpression of rapsyn in rat muscle increases acetylcholine receptor levels in chronic experimental autoimmune myasthenia gravis. Am J Pathol, 170: 644-57.

81. Finlayson, S., Beeson, D., Palace, J. 2013. Congenital myasthenic syndromes: an update. 
Pract Neurol, 13: 80-91. 


\section{Chapter 1}

\section{Antibody effector mechanisms in myasthenia gravis - Pathogenesis at the neuromuscular junction}

Alejandro M. Gomez*, Joost Van den Broeck*, Kathleen Vrolix*, Sofie P. Janssen, Marijke A. M. Lemmens, Eline van der Esch, Hans Duimel, Peter Frederik, Peter C. Molenaar, Pilar Martínez-Martínez, Marc H. De Baets and Mario Losen

* These authors contributed equally to this work

Autoimmunity (2010); 43 (5-6):353-370. 


\section{Abstract}

Myasthenia gravis (MG) is an autoimmune disorder caused by autoantibodies that are either directed to the muscle nicotinic acetylcholine receptor (AChR) or to the muscle specific tyrosine kinase (MuSK). These autoantibodies define two distinct subforms of the disease - AChR-MG and MuSK-MG. Both AChR and MuSK are expressed on the postsynaptic membrane of the neuromuscular junction (NMJ), which is a highly specialized region of the muscle dedicated to receive and process signals from the motor nerve. Autoantibody binding to proteins of the postsynaptic membrane leads to impaired neuromuscular transmission and muscle weakness. Pro-inflammatory antibodies of the human $\operatorname{lgG} 1$ and IgG3 subclass modulate the AChR, cause complement activation and attract lymphocytes; together acting to decrease levels of the AChR and AChR-associated proteins and to reduce postsynaptic folding. In patients with anti-MuSK antibodies there is no evidence of loss of junctional folds and no apparent loss of AChR density. Anti-MuSK antibodies are predominantly of the IgG4 isotype which functionally differs from other IgG subclasses in its anti-inflammatory activity. Moreover, IgG4 undergoes a posttranslational modification termed Fab arm exchange which prevents cross-linking of antigens. These findings suggest that MuSK-MG may be different in etiological and pathological mechanisms from AChR-MG. The effector functions of IgG subclasses on synapse structure and function are discussed in this review. 


\section{Introduction}

Myasthenia gravis (MG) is an autoimmune disease caused by autoantibodies against proteins in the postsynaptic membrane of the neuromuscular junction (NMJ) [1,2]. Several lines of evidence have clearly demonstrated that antibodies against the acetylcholine receptor (AChR) cause the disease in approximately $85 \%$ of MG patients [1]. Autoantibodies against the muscle specific tyrosine kinase (MuSK) have been detected in up to $70 \%$ of MG patients without autoantibodies against the AChR [2]. MuSK is essential for the development and maintenance of the NMJ [2-4] since it is required for AChR clustering. Together, AChR-MG and MuSK-MG cover more than $90 \%$ of MG cases.

The remaining patients also have an autoimmune disorder, since they, too, benefit from immunosuppression or plasmapheresis [5]. Historically, the term "seronegative MG" was used for MG without anti-AChR antibodies, but with the discovery of MUSK antibodies in many seronegative patients, this term has become confusing. Therefore, we will use the following nomenclature in this review: "AChR-MG" for myasthenia gravis with anti-AChR antibodies; “MuSK-MG" for myasthenia gravis with antiMuSK antibodies; "idiopathic MG" for patients with (autoimmune) myasthenia gravis, but (so-far) undetectable levels of anti-AChR or anti-MuSK antibodies (Table 1.1).

In AChR-MG patients, antibodies against many other antigens can be found [6]. Their role in the pathogenesis and their contribution to the clinical symptoms of MG are not completely understood yet. Many of these antibodies are not specific for MG and they also occur in patients with other autoimmune diseases. Some autoantibodies are associated with malignancies of the thymus [7]. Thymic abnormalities such as hyperplasia and thymoma are significant risk factors for AChR-MG $[8,9]$.

Idiopathic MG is more similar to AChR-MG than to MuSK-MG regarding thymic pathology [10] and clinical features [11]. Since idiopathic MG patients have the same clinical presentation as patients with AChR-MG, it is possible that they produce AChR autoantibodies at a very low level or with low affinity, which makes these autoantibodies undetectable for conventional AChR antibody assays [12-14]. Alternatively, autoantibodies might be directed against other neuromuscular proteins in idiopathic MG patients. 
Table 1.1. MG and related animal models

\begin{tabular}{|c|c|c|c|c|}
\hline \multicolumn{2}{|c|}{ MG in humans } & \multirow{2}{*}{$\begin{array}{c}\text { MG in } \\
\text { animals } \\
\text { Chronic }\end{array}$} & \multicolumn{2}{|c|}{ Animal models } \\
\hline Chronic & Transient & & Active immunization & Passive immunization \\
\hline AChR-MG & $\begin{array}{l}\text { Neonatal } \\
\text { AChR-MG }\end{array}$ & AChR-MG & AChR-EAMG & $\begin{array}{l}\text { Passive transfer } \\
\text { AChR-MG }\end{array}$ \\
\hline $\begin{array}{l}\text { human IgG1, } \\
\text { human IgG3 }\end{array}$ & [140-143] & $\begin{array}{l}\text { cats }[144], \\
\text { dogs }[145]\end{array}$ & $\begin{array}{l}\text { rabbit [121], rats, guinea } \\
\text { pigs [123], rhesus } \\
\text { monkeys [124] }\end{array}$ & $\begin{array}{c}\text { mice [115], rhesus } \\
\text { monkeys [49], rats [146] }\end{array}$ \\
\hline MuSK-MG & $\begin{array}{l}\text { Neonatal } \\
\text { MuSK-MG }\end{array}$ & & MuSK-EAMG & $\begin{array}{c}\text { Passive transfer } \\
\text { MuSK-MG }\end{array}$ \\
\hline human IgG4 & {$[147,148]$} & & $\begin{array}{l}\text { rabbits [116], } \\
\text { mice [117] }\end{array}$ & mice [118] \\
\hline \multicolumn{5}{|l|}{ Idiopathic MG } \\
\hline $\begin{array}{c}\text { "seronegative } \\
\text { MG" }\end{array}$ & & & & \\
\hline
\end{tabular}

The structure and physiology of the NMJ is complex, but well understood. The pathogenic changes at the NMJ in MG are interesting also from an immunological point of view, since it provides a clear example of autoantibody effector functions on the target tissue. Immunotherapies for MG patients do not only depend on suppressing or modulating the autoimmune processes, but also on the repair processes and plasticity of the NMJ. Therefore, we first review the normal structure and function of the NMJ and secondly discuss the changes at the NMJ as a function of IgG isotype and specificity.

\section{Organization and physiology of the NMJ}

For understanding the pathophysiology in MG, it will be useful to recall some basic facts of neuromuscular transmission. The NMJ is a chemical synapse that transmits a signal from the motor nerve to the postsynaptic region of the muscle fiber (Fig. 1.1 and 1.2). The postsynaptic membrane contains a high density of AChR (Fig. 1.3) which is a ligand-gated 
ion channel [15]. The impairment of the neuromuscular function in MG is a result of changes in the physiology, biochemistry and structure of the NMJ.

\section{Physiology}

At the nerve terminal, ACh is stored in synaptic vesicles. Occasionally a vesicle undergoes spontaneous exocytosis so that a so-called quantum of released ACh, consisting of about 10,000 molecules, causes a miniature endplate potential (MEPP), about $1 \mathrm{mV}$ in amplitude, by interaction with the AChRs. MEPPs occur in the human endplate at a frequency of a few per minute and their amplitude is a good measure of the density of the AChRs.

When a nerve action potential reaches the nerve terminal, P/Q-type calcium channels open and as a result of inflowing calcium ions a number of vesicles release their ACh into the synaptic cleft. The evoked release of ACh is thus dependent on the presence of calcium in the surrounding medium. The number of ACh quanta released by the nerve action potential is called the quantal content in human muscle around 30 whereas in rodents it is between 50 and 100 .

The ACh that is released upon a stimulus (in man $30 \times 10,000=300,000$ molecules of ACh) causes a depolarization called the endplate potential or EPP. The EPP has a more or less constant value since the nerve action potential is a standard event causing a standard inflow of calcium into the nerve terminal. The EPP shows a little variation, however, which is largely dependent on the variation in the quantal content and the variation in diameter of the muscle fiber. 

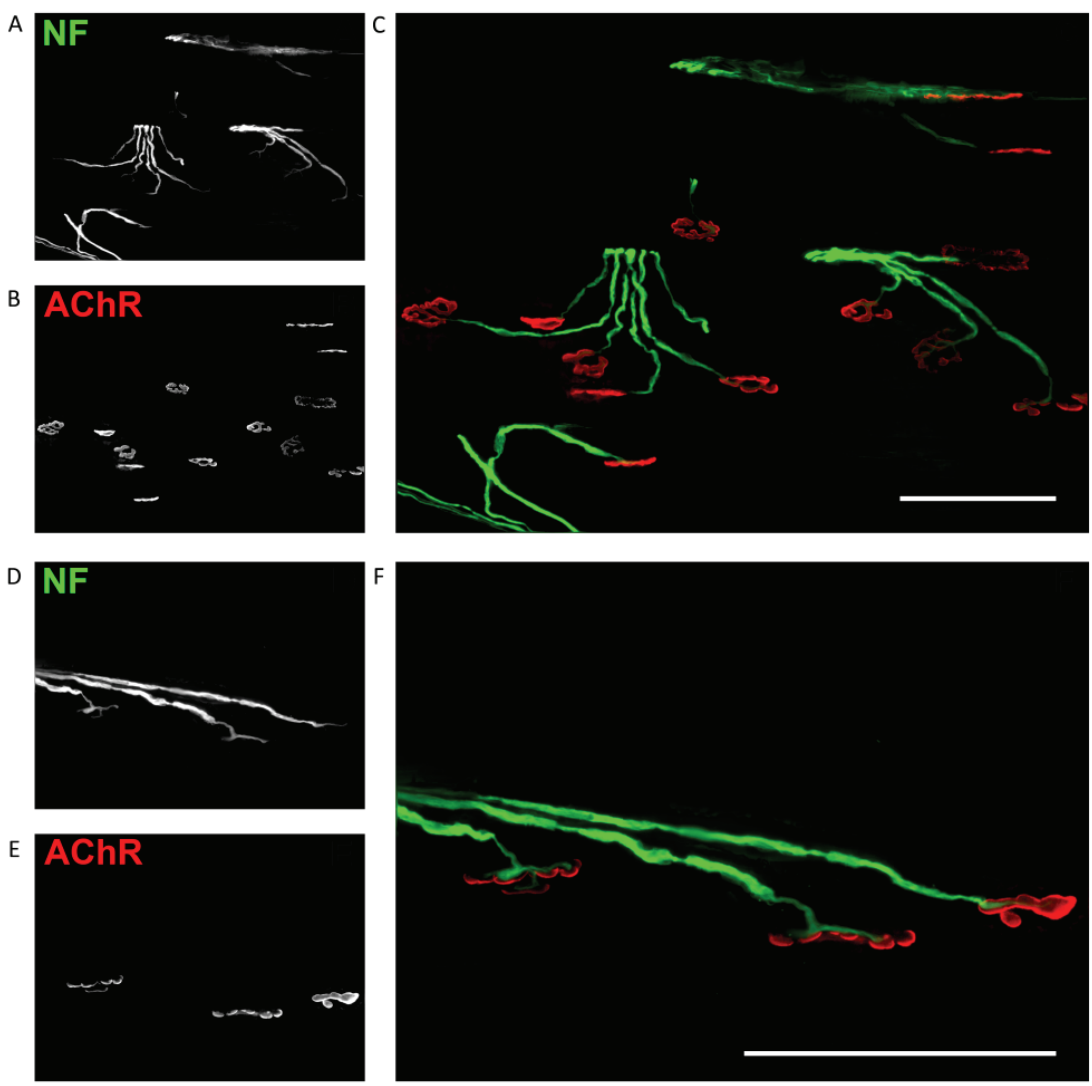

Figure 1.1. Immunohistochemical staining of $\mathbf{2 0 0} \boldsymbol{\mu m}$ cryosections of rat tibialis anterior muscle. Nerves are stained with mouse anti-neurofilament $A b(A, D)$ and $A C h R s$ are stained with Alexa $594 \alpha$-bungarotoxin (B, E). Merged pictures (C, F) show the AChR clusters (red) at the site of contact with the nerve terminals (green). Generally, each muscle fiber is only innervated by a single nerve branch. Scale bars are $100 \mu \mathrm{m}$.

Normally, the EPP is so large that surrounding voltage-gated sodium channels (VGSCs) in the muscle membrane near the endplate are activated so that the muscle action potential is generated [16]. As soon as the action potential is generated, it completely overshadows the EPP (Fig. 1.4). If EPPs have to be recorded, this can only be done after blocking specifically the sodium channels of the muscle. Neuromuscular transmission has a large so-called safety factor, meaning that the EPP is considerably larger than the threshold membrane potential for opening of VGSC, so that nerve stimuli elicit muscle action potentials with $100 \%$ efficiency. This safety factor is about 3 in human muscle and about 5 in rodents [17]. 


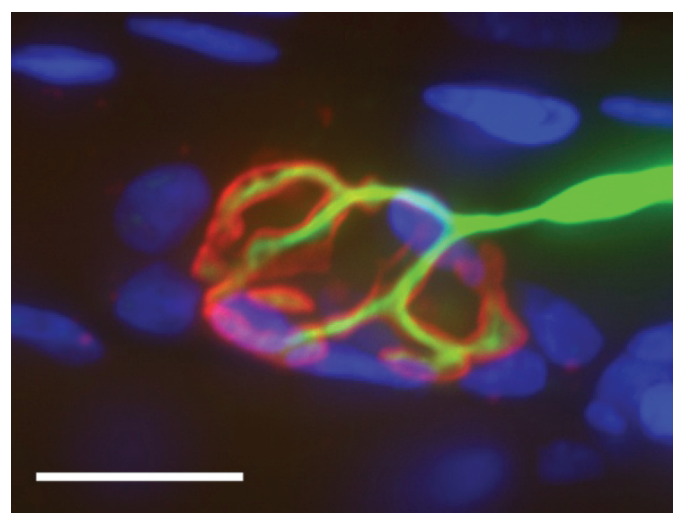

Figure 1.2. High power confocal photomicrograph of a rat NMJ. The AChR is stained in red with Alexa 594labelled $\alpha$-bungarotoxin and the nerve terminal is stained in green (Alexa 488) with an antibody directed against neurofilament and synaptic vesicle protein 2 (SV2). Nuclei are labeled with Hoechst DNA stain in blue. The image was taken with a MBF Bioscience Stereo Investigator Confocal Spinning Disk (SI-SD) system (MBF Bioscience, Williston, VT), with a modified Olympus BX51 fluorescence microscope (Olympus, Tokyo, Japan). Scale bar is 20 $\mu \mathrm{m}$.

The muscle action potential spreads along the muscle fiber from the endplate area towards the tendons. The action potential activates L-type calcium channels causing the release of calcium from intracellular stores though ryanodine-type calcium channels. As a result, the concentration of cytosolic calcium rises dramatically, which leads finally to the contraction of the muscle fiber.

\section{Biochemistry and structure}

The nerve terminal produces agrin and neuregulin which induce expression of postsynaptic proteins in subsynaptic nuclei (Fig. 1.2 and 1.3) of the muscle fiber. Among the molecules that are concentrated at the endplate are the acetylcholine esterase, the membrane receptors for agrin [MUSK and low-density lipoprotein receptor-related protein 4 (Lrp4)] and the cytoskeletal-associated proteins utrophin and receptor-associated protein of the synapse (rapsyn) [18]. During development, AChRs are diffusely distributed on embryonic myotubes but become highly concentrated (approximately $10,000 / \mu \mathrm{m}^{2}$ ) in the postsynaptic membrane a few weeks after birth, whereas the density of the extrasynaptical AChRs falls to $10 / \mu \mathrm{m}^{2}$ [19]. 


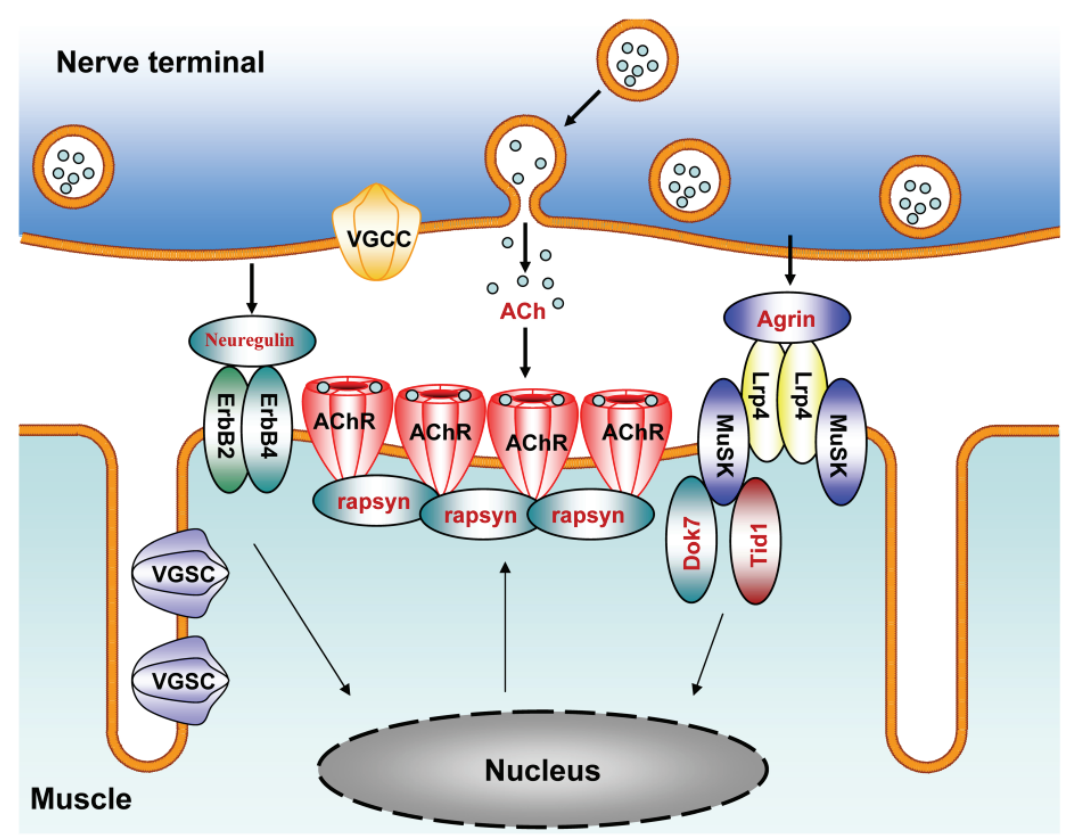

Figure 1.3. Scheme of the NMJ. ACh, neuregulin and agrin are released from the nerve terminal. ACh is a neurotransmitter that binds and opens the $A C h R$ ion channel, inducing depolarization of the membrane. Neuregulins bind to ErbB receptors and enhance the transcription of AChR, utrophin and acetylcholine esterase genes at the postsynaptic nuclei. Lrp4-MuSK-Dok-7-Tid1 are the main mediators of agrin-signaling in the postsynaptic membrane, activating intracellular cascades that lead to dense AChR clustering at the top of the junctional folds. ACh, acetylcholine; AChR, acetylcholine receptor; Dok-7, downstream of tyrosine kinase 7; ErbB2/4, erythroblastic leukemia viral oncogene homolog 2/4; Lrp4, low-density lipoprotein receptor-related protein 4; MuSK, muscle specific tyrosine kinase; rapsyn, receptor-associated protein of the synapse; Tid1, tumorous imaginal disk 1; VGSC, voltage gated sodium channel; VGCC, voltage gated calcium channel.

At least two distinct processes contribute to this accumulation. First, subsynaptic muscle nuclei transcribe AChR subunit genes at higher rates than extra-synaptic nuclei, so AChR messenger RNA is concentrated near synaptic sites [20, 21]. Second, once AChRs have been inserted into the membrane, they form high-density clusters by tethering to a subsynaptic cytoskeletal complex. A key component of this complex is rapsyn, a $43 \mathrm{kDa}$ membrane-associated protein, which is precisely colocalized with AChRs at synaptic sites (Fig. 1.5) as soon as clusters form [22]. Rapsyn anchors the AChR via ß-dystroglycan and utrophin to the contractile protein F-actin and is thus essential for the AChR clustering in the endplate region [23-28]. No AChR clusters are formed in muscles of rapsyn-deficient mice or in myotubes cultured from the mutants [22]. 


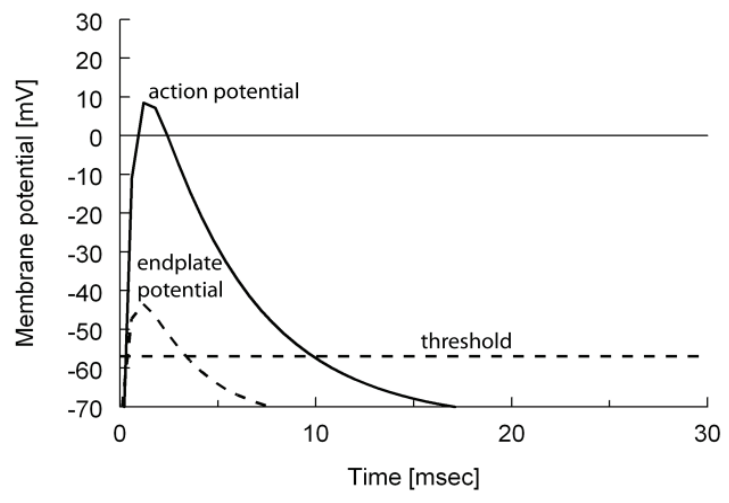

Figure 1.4. Schematic representation of an intracellular microelectrode recording at the endplate of the muscle action potential. The stippled line indicates the shape of the EPP (which can only be seen after blocking the action potential of the muscle with $\mu$-conotoxin). The firing threshold of the muscle is indicated by the horizontal stippled line. Nota bene: in most recordings the electrode is dislodged from the cell because of the contraction of the muscle, but sometimes it stays put and it is possible, as illustrated in this chart, to follow the whole event of the muscle action potential.
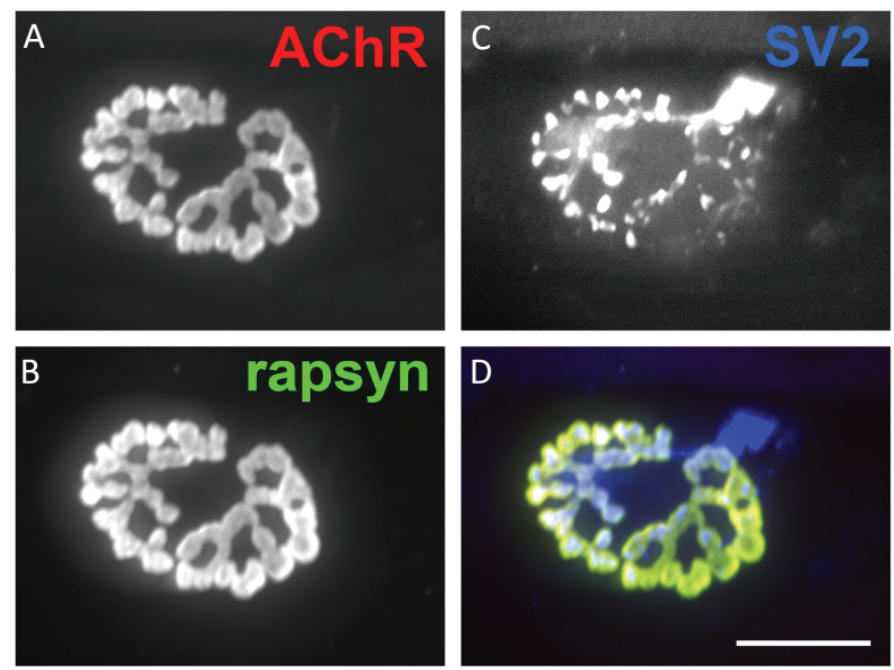

Figure 1.5. Confocal photomicrographs demonstrating colocalization of rapsyn and the AChR. Rat tibialis anterior cryosections of $30 \mu \mathrm{m}$ were stained with Alexa 594 labeled $\alpha$-bungarotoxin for the AChR in red $(A)$, mouse anti-rapsyn mAb 1234 in green $(B)$ and SV2 for the nerve terminal in blue $(C)$. The merged picture $(D)$ shows the precise colocalization of rapsyn and the AChR (yellow color). Images were taken with a MBF Bioscience Stereo Investigator Confocal Spinning Disk (SI-SD) system (MBF Bioscience, Williston, VT) with a modified Olympus BX51 fluorescence microscope (Olympus, Tokyo, Japan). Scale bar is $20 \mu \mathrm{m}$. 
The structure of the postsynaptic membrane is also highly specialized. The nerve and the nerve terminal area are covered by Schwann cells as shown in the scanning electron micrograph in Fig. 1.6A. Chemical removal of the Schwann cell and partial removal of the nerve (Fig. 1.6B) reveal that the branched nerve endings are embedded in the gutter-like depression of the muscle plasma membrane (sarcolemma). Between the nerve endings (synaptic boutons) and the sarcolemma lies the primary synaptic cleft. Adjacent to synaptic boutons, the sarcolemma is folded and thereby creates secondary clefts (hereafter referred to as synaptic folds of the postsynaptic membrane, Fig. 1.6B, arrowhead). The postsynaptic folds enlarge the surface and contain a high density of AChR at the top of the folds facing the nerve and voltage gated sodium channels in the troughs of the secondary folds.

A

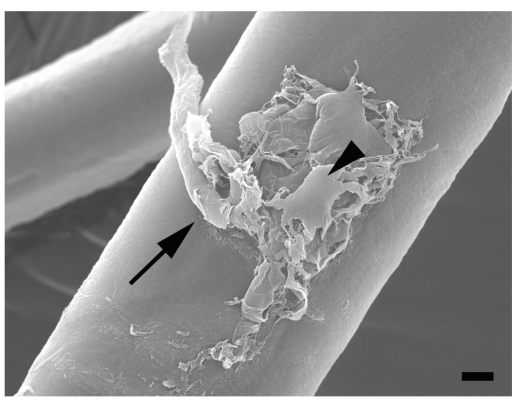

C

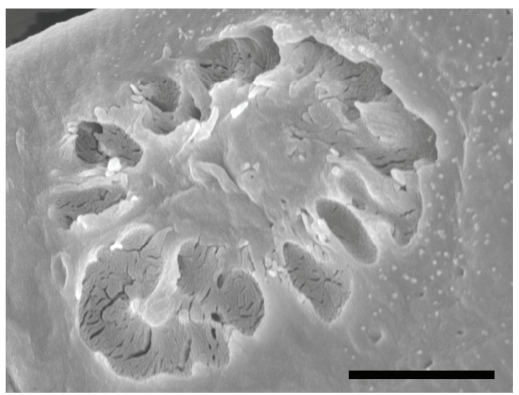

B

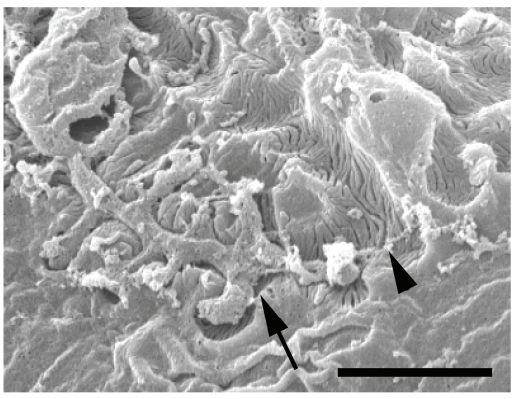

D

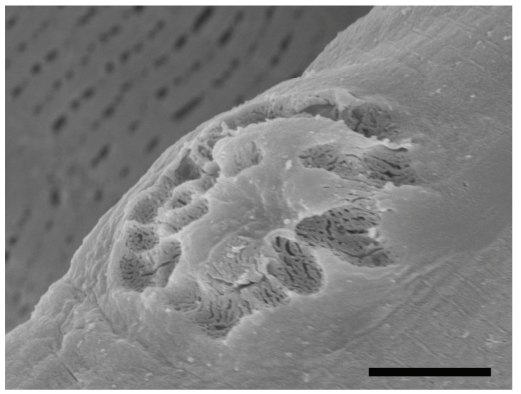

Figure 1.6. Scanning electron micrographs of the NMJ of a rat. (A) The myelinated motor axon (arrow) branches at the NMJ. The NMJ is covered by perisynaptic (terminal) Schwann cells (arrowhead). (B) Chemical removal of the Schwann cells exposes the nerve terminals (arrow) which are embedded in gutter-like depressions. Where the nerve terminal is removed as well, the folded postsynaptic membrane is visible (arrowhead). (C) Complete chemical removal of the presynaptic structures reveals the postsynaptic structure of a normal rat NMJ. (D) Postsynaptic membrane with slightly widened postsynaptic clefts in a rat with EAMG. Scale bars are $5 \mu \mathrm{m}$. 


\section{Pathophysiology of the neuromuscular junction in AChR-MG}

Anti-AChR antibodies induce the loss of the AChRs, leading to impaired neuromuscular transmission with muscle weakness as a result [29]. Due to the reduced number of AChRs, the sensitivity of the endplate to released ACh is reduced. Consequently, the amplitude of the MEPPs is reduced with approximately the same proportion as the loss of the AChRs. However, the loss of AChRs is partly compensated by an increase in ACh release in AChRMG [30, 31].

As a consequence of the reduced AChR levels in MG, the EPPs can be so low that the threshold for activating VGSCs is not reached and consequently no action potential is generated (blocking of neuromuscular transmission; Fig. 1.7D). If the EPP is just above the threshold, a delayed action potential is produced because the threshold is reached later. The reduced AChR levels, in combination with the variability of the quantal content, leads to a variation of the time at which an action potential is generated after motor nerve stimulation. This variation (jitter) can be measured by single fiber electromyography and is a sensitive measure for impaired neuromuscular transmission (Fig. 1.7B). This method also allows the detection of neuromuscular blockings.

The quantal content decreases as a function of time (and frequency) during repetitive stimulation. Due to the great safety factor of the NMJ, this does not normally impair neuromuscular transmission; but in MG, because of the decreased sensitivity of the endplate to $\mathrm{ACh}$, this decreased output leads to an increased likelihood of neuromuscular blockings. In electromyography recordings in MG patients, the decreasing amount of released ACh during repetitive nerve stimulation (generally measured at $3 \mathrm{~Hz}$ ) leads to increased number of neuromuscular blockings and to decrementing amplitudes of the compound muscle action potentials. 
A

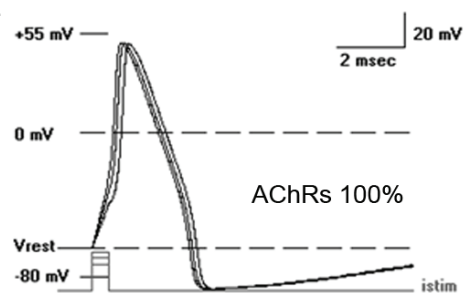

C

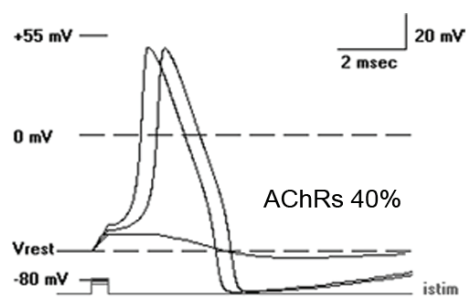

B

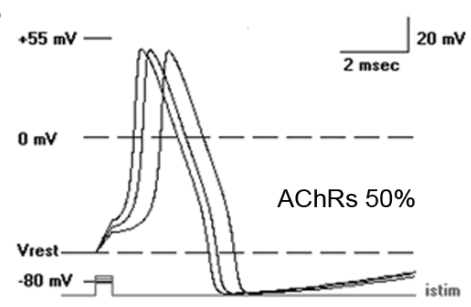

D

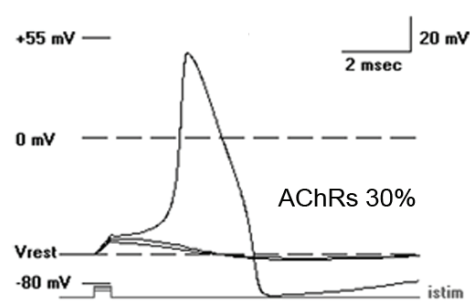

Figure 1.7. Computer simulation of muscle action potentials. Action potentials were elicited by nerve stimulation under conditions of increasing degree of AChR loss using the program NeuralSim/APSimv1.0 by Steven A. Siegelbaum. The basis of the simulation settings is the assumption of the value of the safety factor 3.0 for neuromuscular transmission in man. In each frame, $(A)-(D)$, three traces are shown to indicate the variability of the quantal output of ACh upon each stimulus: the mean; the mean minus 1SD; and the mean plus 1SD (the coefficient of variation of the transmitter release of the human endplate with a quantal content of 30 is 0.18 ). Panel $A, 100 \%$ AChRs. Panel $B, 50 \%$ AChRs; notice the increased delay in response time to the nerve stimulus and also the greater variation of response time (jitter). Panel $C, 40 \%$ AChRs; notice the further delay in response time and one failure (blocking) where stimulation failed to elicit an action potential. Panel $D, 30 \% \mathrm{AChRs}$; a further delay in response time and two failures.

\section{Ultrastructural changes at the NMJ in AChR-MG}

In transmission electron micrographs, the ultrastructure of the postsynaptic membrane can be analyzed in detail. Normal NMJs show a complex pattern of postsynaptic folds near the nerve bouton (Fig. 1.8). In contrast, a high concentration of anti-AChR antibodies causes lysis of the postsynaptic membrane. Fig. 1.9A shows this lysis after passive transfer of the anti-AChR monoclonal antibody (mAb) 35. In this model, also infiltration of granulocytes occurs (Fig. 1.9B). Ultimately, the chronic exposure of the NMJ to anti-AChR antibodies leads to a simplified postsynaptic membrane without postsynaptic folds. This change also occurs in experimental autoimmune MG (EAMG) models (Fig. 1.9C), as discussed below. 


\section{Pathophysiology of the NMJ in MuSK-MG}

The main effect of MuSK antibodies at the endplate is still unclear. MuSK is known to initiate aggregation of the AChR during synapse formation via the agrin/Lrp4/MuSK/rapsyn/AChR clustering pathway (Fig. 1.3), but MuSK is also expressed at the mature NMJ. MuSK autoantibodies have the potential to alter MuSK function at the adult NMJ, and they may not only inhibit MuSK function directly, but also increase the turnover of MuSK, thereby further reducing its activity $[2,3]$. In contrast with AChR antibody-positive patients, there is no evidence of loss of junctional folds, no apparent loss of AChR density, and generally no complement deposition [32, 33] in muscle biopsies of MuSK-MG patients. These findings suggest that MuSK-MG may be different in etiological and pathological mechanisms, compared to AChR-MG [34].
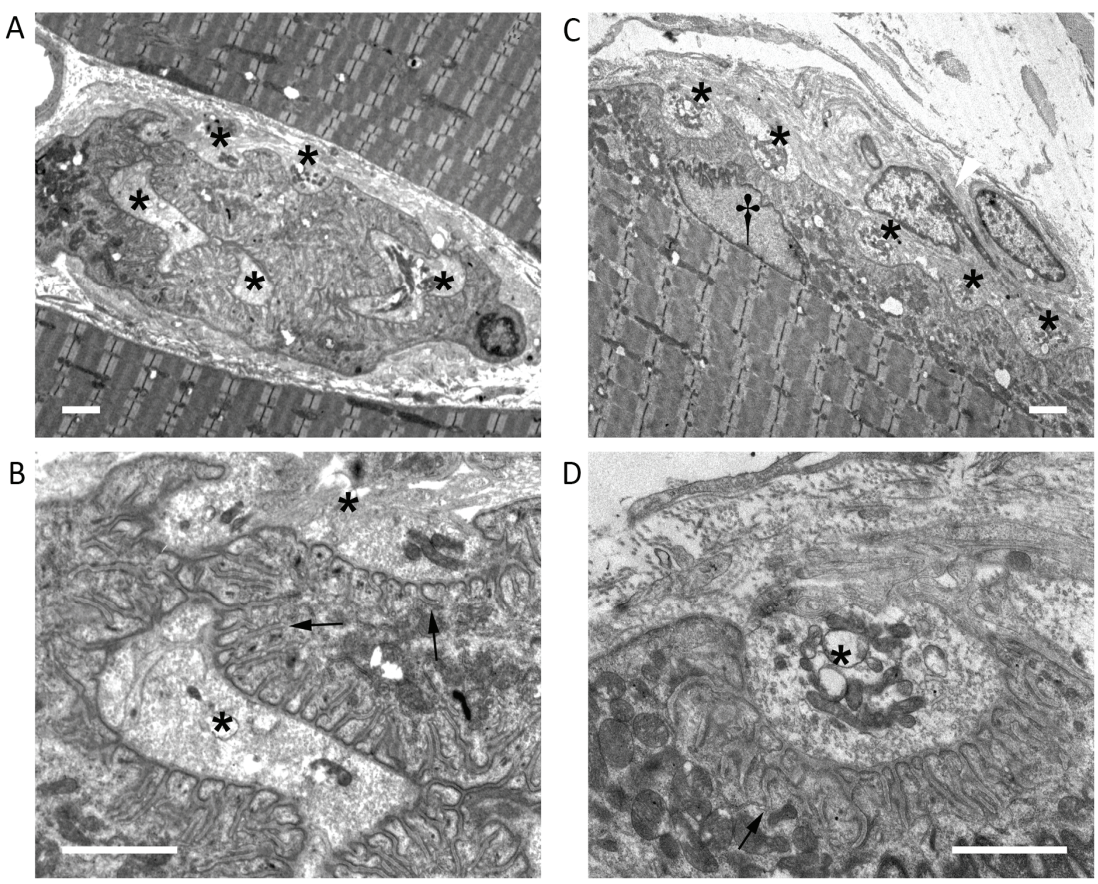

Figure 1.8. Transmission electron micrographs of the NMJ in rat tibialis anterior muscles. The asterisks indicate nerve terminals, the arrows point at the postsynaptic membrane $(A, B)$ Section cutting the NMJ parallel to the muscle fiber surface (i.e. similar to the orientation of the scanning electron micrographs shown in Fig. 1.6). Abundant postsynaptic membrane folds are arranged around multiple nerve boutons. $(C, D)$ Section cutting parallel to the axis of the muscle fiber. In this orientation, both the subsynaptic nuclei (dagger) and the perisynaptic Schwann cell (arrowhead) covering the nerve terminal. Scale bars are $2 \mu \mathrm{m}$. 
Although some muscles may remain unaffected, other, particularly facial, muscles show abnormalities such as increased jitter and atrophy [35-37]. In vitro investigations revealed reduced amplitudes of MEPPs but no concomitant reduction in the number of AChRs $[32,33]$. Studies using active immunization with MuSK or passive transfer of antiMuSK antibodies from MuSK-MG patients to mice have shed some light into the effects on the NMJ and are discussed below.

\section{IgG isotypes in MG}

MG is mediated by circulating antibodies of the IgG class directed to the AChR, MuSK, or possibly other, still unidentified autoantigens in the NMJ of striated muscle. In humans, four different IgG isotypes exist which have similar amino acid sequences (more than $95 \%$ sequence homology), but differ in their ability to activate the complement system. These differences are mainly due to structural differences at the $\mathrm{CH}_{2}$ domains (the site of $\mathrm{C} 1 \mathrm{q}$ binding) and variability of the hinge regions [38, 39]. IgG1 and IgG3 are effective complement activators, IgG2 poorly fixes complement, and IgG4 is completely deficient in the ability to activate complement via the classical pathway $[40,41]$. The structure mainly responsible for the differential ability of human IgG isotypes to activate complement is located at the carboxy-terminal part (residues 292-340) of the $\mathrm{CH}_{2}$ domain [42] (Fig. $1.10 A)$, but the hinge region also has a minor contribution to the complement activation [43].

In AChR-MG patients, the complement-fixing IgG1 and IgG3 isotype AChR-specific antibodies predominate, whereas $\lg G 2$ and $\lg G 4$ are only present in lower concentrations [44-46]. Generally, the anti-AChR autoantibody concentration does not correlate well with the severity of disease [47], although in individual patients there is a relation between antibody titer and clinical condition after immunosuppression [48]. Since IgG autoantibody subclasses have distinct immunological properties, a possible explanation for this weak correlation could be found in variations in the isotype distribution. Interestingly, anti-AChR $\lg G 1$ (but not $\lg G 2, \lg G 3$, and $\lg G 4$ ) concentration was found to be significantly correlated with severity of disease [44]. These results suggest that binding of IgG1 may play a key role in the pathogenesis of AChR-MG [44]. In rhesus monkeys, passive transfer of human IgG1, 




B

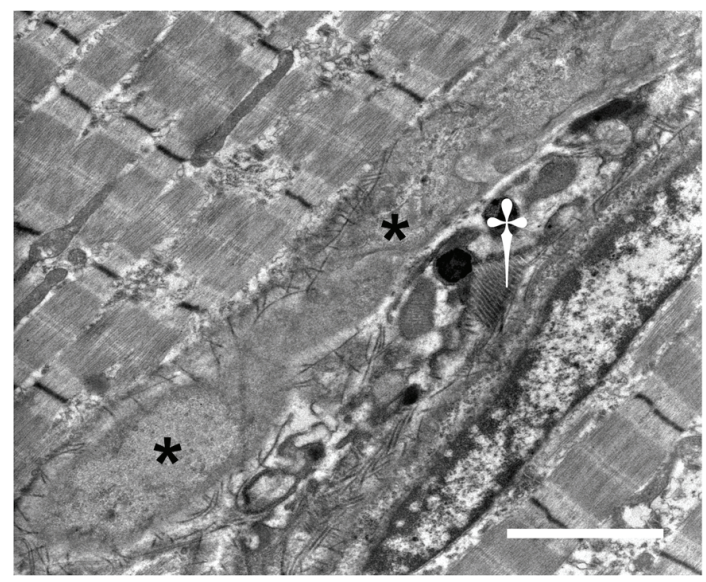

C

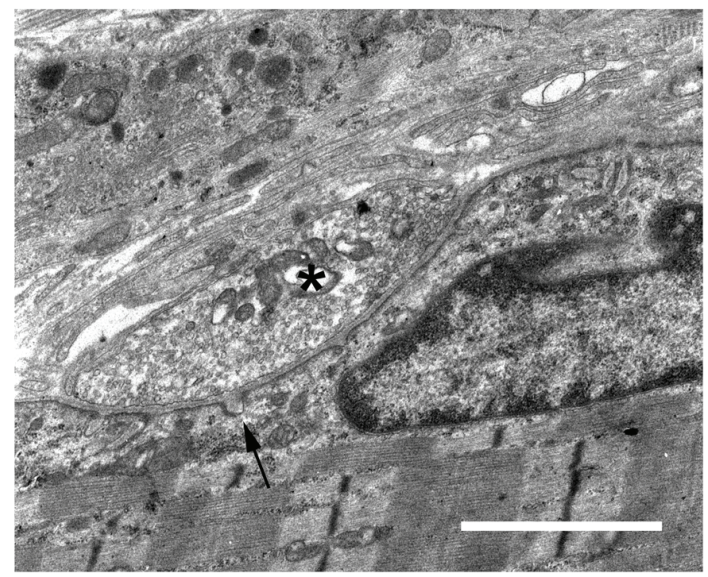

Figure 1.9. Morphological changes at the postsynaptic membrane after autoantibody attack. Transmission electron microscopy pictures of the NMJ in tibialis anterior sections. The asterisks indicate nerve terminals, the arrows point at the postsynaptic membrane. (A) Lysis of postsynaptic structure after passive transfer of anti-AChR mAb35. (B) Infiltrating granulocyte (see dagger) at the NMJ after passive transfer of mAb35. The synaptic boutons are dislocated from the sarcolemma. (C) In chronic AChR-EAMG, many endplates show a simplified postsynaptic membrane with a few shallow postsynaptic folds. Scale bars are $2 \mu \mathrm{m}$. 
In contrast to the anti-AChR antibodies, anti-MuSK antibodies are predominantly of the IgG4 isotype [34] and therefore they do not cause substantial complement deposition, morphological damage, or AChR loss at the NMJ $[32,33]$. These findings imply important differences between MUSK-MG and AChR-MG in their pathological mechanisms. The mechanism in MuSK-MG may involve downstream changes in the function and distribution of key molecules at the NMJ. Based on cell culture experiments using AChR-expressing rhabdomyosarcoma cells, it has been suggested that the postsynaptic machinery becomes structurally and functionally disorganized by a significant reduction of AChR clustering [50].

A

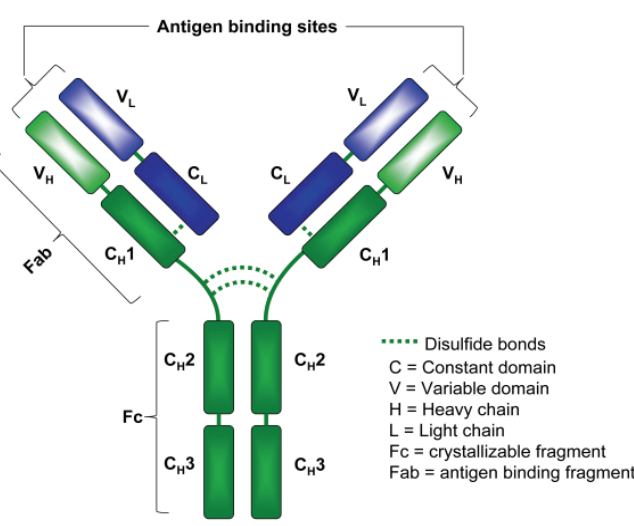

B

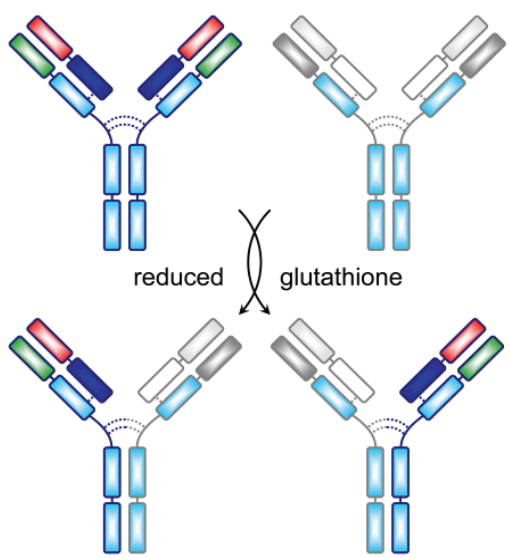

Figure 1.10. A) Structure of IgG. B) Fab arm exchange reaction. IgG4 molecules with different specificity interchange half-molecules resulting in chimeric bispecific antibodies [156].

Finally, in idiopathic MG patients, it has been shown that the autoantibodies belong to the IgG1 subclass. In addition, they induced complement deposition on the AChR clusters, which demonstrated C1q binding and activation of the classical complement pathway [13]. This suggests that the autoantibodies of idiopathic MG can be directed toward the AChR, but bind only when the AChRs are clustered densely [13].

\section{IgG4 Fab arm exchange}

All IgGs are composed of two heavy chain/light chain pairs (half-molecules), which are connected via inter-heavy chain disulfide bonds situated in the hinge region (Fig. 1.10A), 
as well as by non-covalent bonds mostly situated between the third constant domains $\left(\mathrm{CH}_{3}\right)$. IgG antibodies mediate pro-inflammatory activities, with the exception of IgG4 which has anti-inflammatory activities. IgG4 represents approximately $4 \%$ of the total IgG in serum of adults and significant IgG4 titers are generated by prolonged antigenic stimulation [51].

The anti-inflammatory activity includes a poor ability to induce complement and cell activation because of a low affinity for $\mathrm{C} 1 \mathrm{q}$ and Fc receptors. Moreover, IgG4 does not form immune complexes due to a posttranslational modification, known as Fab arm exchange. IgG4 exchanges Fab arms by swapping a heavy chain and attached light chain with a half-molecule from another antibody (Fig. 1.10B). Antibodies from the IgG4 subclass have been shown to be dynamic molecules, undergoing Fab arm exchange both in vivo and in vitro. The ability to engage in Fab arm exchange appears to be an inherent feature of IgG4 that involves the third constant domain in addition to the hinge region and this posttranslational modification only requires a reducing environment to be activated [49].

Kinetic studies on the inter-heavy chain disulfide bond formation of the IgG4 molecule showed that these bonds were formed slowly and that they were unstable [52]. Inter- and intra-heavy chain disulfide bonds are in equilibrium. This phenomenon is facilitated by a substitution of single amino acid in the hinge of IgG4 compared to IgG1: a proline in IgG1 is replaced by a serine in IgG4 [53]. Nevertheless, simply mixing IgG4 molecules in vitro does not result in Fab arm exchange. The mechanism by which IgG4 Fab arm exchange occurs in vivo likely requires the reducing environment in blood or at cell surfaces to facilitate the breaking of bonds between half-molecules [49].

When polyclonal IgG4 is derived from plasma, the Fab arm exchange reaction usually produces IgG4 molecules with two different antigen-binding sites. The resulting asymmetric antibodies are bispecific, and thus are directed against two different and generally unrelated antigens. Moreover, they are unable to cross-link two identical antigens [54] and are therefore functionally monovalent [51]. Fab arm exchange, furthermore, is dynamic, and combinations of certain specific Fab arms are therefore expected to exist only transiently. This protein modification challenges the commonly 
accepted one antibody-one antigen paradigm and redefines our thinking about the role of IgG4 in antibody-mediated immunity and the application of IgG4 monoclonal antibodies to immunotherapy.

Functionally monovalent IgG4 antibodies directed to the AChR that do not modulate the AChR or block the ACh binding are not pathogenic. Moreover, they have the potential to protect the NMJ against complement fixing IgG1 anti-AChR-autoantibodies [49] by competition for binding. Therefore, IgG4 has an important anti-inflammatory property and protects tissues against the biological effects of the complement-fixing IgG subclasses [54].

\section{Effector functions of IgG autoantibody subclasses in AChR-MG}

The breakdown of the AChR is mainly caused by complement-mediated lysis of the postsynaptic membrane [55] and by cross-linking of AChRs in the membrane. Cross-linking antibodies are believed to initiate a conformational change of the AChR (antigenic modulation) which induces accelerated AChR internalization and degradation [56]. The different properties and effector functions of IgG antibodies are discussed below.

\section{$\underline{\text { Antigenic modulation }}$}

Antibodies from patients with AChR-MG accelerate the degradation of AChRs in cultured muscles and in vivo at intact NMJs [56-58]. The antibody-accelerated degradation of the AChR by antigenic modulation is a consequence of the bivalent nature of the $\lg G 1, \lg \operatorname{lo} 2$ and IgG3 autoantibodies. These AChR-specific antibodies are able to cross-link adjacent AChR molecules which are rapidly internalized by endocytosis and then degraded [59]. Serum IgG from approximately $90 \%$ of patients increased the degradation rate of the AChR two to threefold [60]. Thus, if accelerated degradation is not sufficiently compensated by increased AChR synthesis, it will lead to a reduction of the available AChR molecules at the NMJ. This reduction of AChR at the NMJ can be used as a useful diagnostic test for MG [61]. However, not all anti-AChR antibodies cause antigenic modulation. The epitope location on the AChR surface may restrict the ability of antibodies to cross-link a second AChR molecule [62]. Moreover, IgG4 antibodies are 
functionally monovalent, which means that they do not cross-link two identical antigens.

\section{Complement activation}

Binding of anti-AChR antibodies to the tightly packed AChRs in the postsynaptic membrane folds results in very high density of bound antibody and, hence, very tightly packed Fc regions of these antibodies. Since anti-AChR antibodies belong mainly to the $\operatorname{lgG1}$ and IgG3 class, this causes a highly efficient activation of the complement system and consequently the formation of the membrane attack complex (MAC) in the postsynaptic membrane. In combination with antigenic modulation of the AChR, MAC causes severe endplate membrane damage $[63,64]$. Stabilization of the AChR by increasing rapsyn expression prevents modulation of the AChR, even in the presence of activated complement $[65,66]$.

Different lines of indirect evidence support complement activation at the NMJ as a fundamental cause of AChR loss and failure of neuromuscular transmission: complement depletion with cobra venom factor [67], administration of antibodies that block a complement component [68], complement inhibitors [69], or genetic deficits of complement components [70] make animals resistant or less susceptible to EAMG. IL-12 deficient mice develop minimal EAMG symptoms after AChR immunization in spite of robust anti-AChR antibody synthesis [71]. The lack of IL-12 prevents the production of the complement-fixing IgG2a antibodies in the mouse (Table 1.2). NMJs in these mice contain only IgG1 antibodies, which unlike human IgG1 antibodies do not activate complement; indicating that anti-AChR antibodies, which do not activate complement, do not effectively compromise neuromuscular transmission.

Complement activation damages the postsynaptic membrane by multiple mechanisms. The MAC leads to loss of postsynaptic folding [72], loss of membrane potential [73] and, in conjunction with antigenic modulation of the AChR, to loss of AChRassociated proteins [74].

\section{Functional AChR blockade}

Serum IgG from 50 to $88 \%$ of patients with MG has been shown to block the ACh-binding sites of AChRs in cultured mammalian muscle cells [61]. Antibodies with the ability to 
block the ACh-binding site of the AChR cause acute and severe muscle weakness in rodents without inflammation or necrosis at the NMJ [75]. Many MG patients have low levels of these antibodies. They might block the AChR in spite of their low concentrations and contribute to acute myasthenic crisis [76].

\section{$\underline{\text { Loss of AChR-associated proteins }}$}

The attack of anti-AChR antibodies at the NMJ does not only lead to a reduction in the density of AChR, but also affects other AChR-associated proteins [77, 78]. Research on the significance of postsynaptic proteins for the maintenance of the adult endplate and the reorganization of the NMJ after injuries are promising, showing that some postsynaptic proteins are not just crucial for fetal development but also play an important role in the dynamics of the organization of adult endplates. This premise is in agreement with the deterioration of neuromuscular transmission observed in patients with mutations in genes of the NMJ. This group of patients is gathered under the term "congenital myasthenic syndromes" (CMS) [79]. CMS mutations can occur in genes of presynaptic, synaptic, or postsynaptic proteins, though the latter is far more common [80].

The importance of the synaptic proteins is further illustrated in the knock-down models for MuSK [81], rapsyn [22], Dok-7 [82], Lrp4 [83], or agrin [23], where animals die prematurely around birth, primarily due to respiratory distress, and with a severely underdeveloped NMJ.

Among the NMJ proteins affected in CMS patients, the AChR is the most prominent, with mutations in $\alpha, \beta, \delta$ or $\varepsilon$ subunits that generate an MG-like clinical picture of the patients. Several mutations that lead to muscular weakness have been identified in rapsyn, MuSK, laminin and Dok-7 genes [84-88]. CMS patients display a variable range of MG-like symptoms that are normally present at birth or develop during early life.

In AChR-MG, it seems likely that loss of AChR-associated proteins, including rapsyn, utrophin and voltage gated sodium channels aggravate the disease and delays repair processes $[74,89]$. The function of key postsynaptic proteins is reviewed below, because we believe that this knowledge is helpful for evaluating the possible consequences resulting from loss of these proteins in AChR-MG. 
Table 1.2. IgG isotype profile and complement activation in relation to $T$ helper subsets and cytokine production.

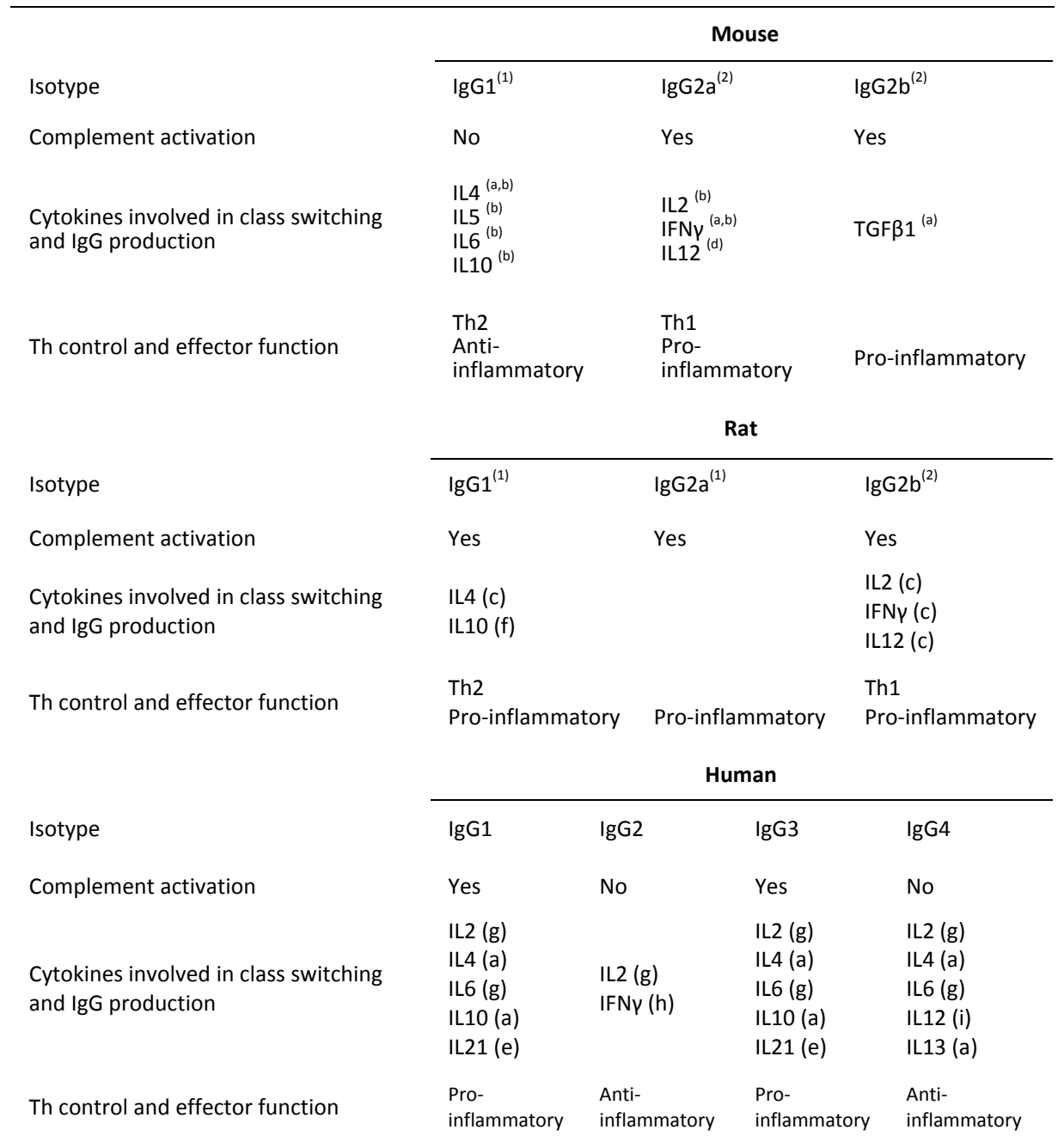

(1) Mouse IgG1 is homologous to rat IgG1 and rat IgG2a [149]. (2) Mouse IgG2a and mouse IgG2b are homologous to rat IgG2b [149]. (a) [150]; (b) [151]; (c) [127]; (d) [129]; (e) [152]; (f) [153]; (g) [154]; (h) [155]; (i) [156].

\section{Utrophin}

Utrophin is localized primarily at the NMJ [90], while the homologous protein dystrophin [91] is expressed throughout the muscle fiber [92]. Utrophin is found closely colocalized to the AChR both in the adult NMJ [93] and throughout development [94], suggesting that it helps to stabilize the AChR clusters [95]. However, studies of utrophin-deficient mice 
indicate that utrophin is not essential for NMJ formation or for precise localization of AChRs at the NMJ [96, 97]. The reduction of utrophin in MG patients is probably secondary to the loss of AChR, but in the presence of autoantibodies against the AChR, it is likely that utrophin-loss curbs anchoring of newly produced AChRs to the cytoskeleton [74].

\section{Rapsyn}

Rapsyn is required for anchoring and stabilizing the AChR in the postsynaptic membrane of the NMJ during development. The AChR clustering by rapsyn is activated by agrin [98], which acts via Lrp4 and MuSK [99]. The expression of rapsyn increases with age and thereby stabilizes the AChR [100]. In a passive-transfer rat model for MG, increased expression of rapsyn at the NMJ induced resistance against anti-AChR antibodies [66] by reducing antibody-induced $A C h R$ internalization. Conversely, rapsyn overexpression has a detrimental effect in chronic EAMG where endplates are already substantially damaged. In chronic EAMG, increased rapsyn expression increases the postsynaptic membrane turnover by anti-AChR antibodies [74]. It is of interest that a modest reduction in rapsyn expression already causes substantial changes, showing that the amount of rapsyn is critically related to the AChR levels and to the structure of the endplate [89].

These findings support the idea of rapsyn as a stabilizing protein for the AChR in the membrane, as previously shown in vitro when AChR half-life was increased and its degradation rate reduced by the presence of rapsyn in cultured myotubes [28], or when AChR turnover was augmented in rapsyn-deficient myotubes [27]. In intercostal muscle biopsies from AChR-MG patients rapsyn levels are significantly reduced relative to control biopsies (unpublished results).

\section{MUSK}

The role of MuSK has been discussed above. In addition it is important to mention the findings of Hesser et al. [101] who demonstrated the relevance of MuSK for the maintenance of the postsynaptic structure using a transgenic mouse model with a conditional knock-out of MuSK. Upon inactivation of MuSK expression, the AChR clusters became disassembled with evident disorganization of the NMJ and sprouting of the nerve 
terminals. This further supports the notion that MuSK expression is necessary for maintaining the integrity of the NMJ [4].

Lrp4

Lrp4 is localized in the postsynaptic membrane and has a large extracellular region [102, 103]. New born mice with null alleles of Lrp4 are cyanotic, unable to breathe, and have defects in distal limbs, indicating that Lrp4 is required for the development of the NMJ [83]. The absence of AChR clusters at the postsynaptic membrane of Lrp4 null mutant animals resemble the phenotype observed in MuSK -/- mice and suggest a role for Lrp4 upstream or at the same level of MuSK. Lrp4 selectively binds to neural agrin [99, 104], which is necessary for the activation of MuSK.

\section{Dok-7}

The family of Dok proteins works as docking platforms for the formation of signaling complexes at the cell membrane. They actively regulate signal transduction and recruit other proteins by their phosphotyrosine binding (PTB) domain and a C-terminal domain, which contains multiple potential tyrosine phosphorylation sites and proline-rich sequences for SH2 and SH3-containing proteins [105]. Dok-7 interacts with the cytoplasmic domain of MuSK and induces its autophosphorylation. MuSK-deficient myotubes do not form AChR clusters when mutated forms of MuSK, which cannot interact with Dok-7, are reintroduced [82]. Silencing of Dok-7 in C2 myotubes suppressed MuSK phosphorylation and, therefore, impaired the formation of AChR clusters. Dok-7 knock-out mice are immobile and die at birth. No detectable AChR clusters on the endplate area are developed in these mice, which resembles the phenotype of MuSK -/- mice [82].

\section{Tid1}

When screening for proteins that interact with MuSK, Linnoila and colleagues [106] encountered a rat homolog of the Drosophila tumor suppressor Tid56 and the heat shock protein hsp40 that was constitutively associated with MuSK, and was denominated tumorous imaginal disk 1 (Tid1). Tid1 is colocalized with MuSK and the AChR at the postsynaptic membrane. The relevance of Tid1 for AChR clustering was demonstrated 
when silencing of Tid1 expression in cultured myotubes caused a marked disruption in the AChR clusters, a situation that could be rescued by transfecting the normal Tid1 gene [106]. However, transfection of a mutated variant of Tid1 did not rescue AChR clustering. These findings suggest that Tid1 orchestrates the cascade that leads to AChR clustering by interactions with other regulatory proteins downstream of MuSK, since Tid1 had been documented to activate a variety of intracellular mediators like the small GTPases RAc1 and RhoA [107] or NFKB [108]. Some of these mediators were directly related with AChR phosphorylation and rapsyn stabilization like Hsp90ß [109] and, therefore, it is likely that the effect of Tid1 on the AChR clustering occurs downstream of MuSK $[106,110]$.

In vivo studies have also supported the role of Tid1 for the development and maintenance of the NMJ. Tid1 knock-out mice die at embryonic day 7. Since Tid1 is localized in many cells types and tissues [111] and is involved in a wide range of intracellular processes such as DNA repair [112] and senescence [113] or signaling pathways like those of NF-KB [108], interferon [114] and ras [107], it is not surprising that suppression of this gene resulted in death at an early developmental stage. Furthermore, focalized siRNA-mediated downregulation of Tid1 in adult mouse muscles led to a profound disorganization of the AChR clusters at the NMJ and also impaired neuromuscular transmission, showing that Tid1 expression is essential for the maintenance of normal endplates [106].

Although MuSK still remains a key molecule for AChR clustering, it is more adequate at the moment to refer to a MuSK-Dok7-Tid1 complex in the agrin-induced pathway for synapse development.

\section{IgG isotypes in animal models for MG}

Animal models have contributed significantly to elucidate the pathogenesis of MG. AChRimmunization is used as an MG animal model termed EAMG. Moreover, injection of MG patient sera or monoclonal anti-AChR antibodies also induce muscle weakness in animals and this model is termed passive transfer MG [115].

Similarly, MG can be induced in animals by active immunization with MuSK [116, 117] or by passive transfer with serum from MuSK-MG patients $[118,119]$. Here, we refer 
to these models as "MuSK-EAMG" and "passive transfer MuSK-MG", respectively (Table 1.1).

MG models have been crucial for understanding the role of the different IgG isotypes in the pathology and severity of MG. This knowledge provides a basis to improve the current therapies for MG patients and to develop more specific treatment approaches [120]. Strategies that use this knowledge to curb the pathogenic effects of proinflammatory IgG subclasses are briefly discussed next.

\section{$\underline{A C h R-E A M G}$}

Patrick and Lindstrom were the first to induce MG in rabbits by immunization with AChR from the electric organ of electric eels (Electrophorus electricus) in complete Freund's adjuvant. They immunized these rabbits with purified AChR to obtain antibodies for the biochemical analysis of the AChR, but all animals became paralyzed and eventually died [121]. Active immunization of experimental animals (including mice, rats, guinea pigs, and monkeys) with AChR -with or without adjuvant- induced chronic EAMG within 30 days after immunization [122-124]. The animals mount an active immune response against injected AChR. The disease is caused by antibodies cross-reacting with the animals' own muscle AChR.

The production of the pathogenic antibodies by B cells depends on Thelper cells. The pathogenic anti-AChR antibodies are high-affinity IgGs, whose synthesis requires interaction of activated T cells with B cells [125]. T cells can be divided into T helper-one (Th1) and T helper-two cells (Th2) depending upon their cytokine profile. Cytokine signaling is crucial for development, modulation, and downregulation of immune responses, and therefore influences the initiation and evolution of the anti-AChR response in EAMG. The regulation of Th cells by cytokines is important, because it affects the isotype profile of stimulated B cells. Th1 cells have a pathogenic role in EAMG because they stimulate the synthesis of anti-AChR antibodies that fix complement and therefore cause destruction of the NMJ [126]. In contrast, Th2 cells induce anti-AChR antibodies that do not fix complement in mice (Table 1.2). In rats, both Th1 and Th2 cells are able to induce pathogenic anti-AChR antibodies [127]. 
In AChR-EAMG models, the isotype profile of autoantibodies can be altered by experimental treatments. Cytokines such as IL-4 stimulate Th2 cells and antagonize the action of Th1 cells, possibly by inducing regulatory T cells [128]. In mice, manipulation of the balance in favor of Th2 cells protects against EAMG [129], because only Th1-related cytokines induce the complement activating IgG2b antibodies. In rats, both Th1 and Th2 cells are able to induce pathogenic anti-AChR antibodies (see Table 1.2) and manipulation of the Th1/Th2 balance does not affect the severity of disease [127]. The different requirements for Th1-dependent responses in rats and mice are therefore correlated to the capacity of complement activation by antibody subclasses. In humans, it is not yet clear if the Th1/Th2 balance affects the production of complement-binding antibodies. It would be interesting to study how an isotype switch of IgG1 towards IgG4 can be induced in autoreactive $B$ cells for the treatment of AChR-MG.

\section{Passive transfer $A C h R-M G$}

Toyka and colleagues have transferred purified IgG from MG patients to mice, which subsequently developed MG symptoms [115]. This passive transfer EAMG model is relevant for MG in order to study the effector phase of the disease. Antibodies against the main immunogenic region (MIR) of the AChR induce myasthenia within 8 to 48 hours, depending on the dose and affinity of the antibody for AChR [130]. The source of antibodies can be serum of MG patients, serum from chronic EAMG animals, or monoclonal antibodies produced in cell culture [131]. The immunopathological mechanisms are antigenic modulation [132] and complement-mediated focal lysis of the postsynaptic membrane for anti-MIR antibodies [67]. Antibodies against the ACh-binding sites induce an acute paralysis within 15-30 minutes [133]. It has been shown that also anti-MIR antibodies can functionally inhibit AChR [134], and the role of the MIR for AChR activity has recently been demonstrated [135].

Monovalent anti-AChR antibodies or antibody fragments without complement binding capacity are not pathogenic. Since they can compete with pathogenic autoantibodies for binding to the AChR, they can prevent autoantibody binding at the NMJ [136]. In passive transfer AChR-MG mouse models, monovalent Fab fragments have been 
demonstrated to protect the AChR against the action of intact pathogenic antibodies [137, 138]. Monovalent binding to antigens is not limited to Fab fragments, but also human IgG4 antibodies are functionally monovalent. IgG4 has favorable properties for potential immunotherapy, such as long half-life in vivo, low immunogenicity, no capacity of complement activation, and inability to cross-link antigens. In a passive transfer MG model in rhesus monkeys, a monoclonal human anti-AChR IgG4 antibody derived from an MG patient [139] was not pathogenic, while the corresponding IgG1 isotype induced muscle weakness [49]. Interestingly, also Fab arm exchange of IgG4 anti-AChR antibodies occurred in this model, suggesting that the rhesus monkey has an IgG4 like subclass.

\section{$\underline{\text { MUSK-EAMG }}$}

Mice actively immunized with MuSK also showed the characteristic symptoms of MG [117]. However, the pro-inflammatory (i.e. complement-fixing and cross-linking) antiMuSK antibodies that are produced in MuSK-EAMG do not closely resemble human MuSKMG with anti-inflammatory IgG4 antibodies. Therefore, the pathological mechanisms of the MuSK-EAMG model might differ from MuSK-MG.

\section{Passive transfer MuSK-MG}

The presence of a pathogenic antibody in MuSK-MG was demonstrated by a passive transfer of IgG from anti-MuSK-positive MG patients into adult mice. In this passive transfer model, reduced levels of AChRs were observed at the postsynaptic membrane and changes in the presynaptic and postsynaptic elements of the synapse led to muscle weakness [118]. Treatment of mice with blood plasma from MuSK patients led to reduced endplate sizes and caused a decrease in the safety factor of neuromuscular transmission in regenerating adult muscles [119]. With high doses of anti-MuSK IgG in passive transfer experiments, the number of AChRs is reduced as well [118]. It is possible that MuSK antibodies in patients primarily cause a reduction in the size of the presynaptic ending while leaving the postsynaptic part and the AChRs intact, although the function of the AChRs may be altered [119]. In this case, the value of the quantal content would be decreased leading to increased jitter in single fiber EAMG. Reduced endplate sizes have been observed in pathogenic mutations of both MuSK and Dok7 [85, 86], which predict 
that the pathophysiological cause of muscle weakness is primarily a small value of the quantal content because of small nerve terminals.

\section{Conclusion}

The symptoms of AChR-MG and MuSK-MG are a result of dysregulation of the immune system and the NMJ. Antigen-specific therapies for MG can make use of biological mechanisms such as the Th1/Th2 balance or the IgG1/IgG4 antibody isotype distribution. Similarly, the NMJ offers potential therapeutic targets to make the postsynaptic membrane more resilient to autoantibody attack. Hopefully, a better understanding of the mechanisms of immune regulation in MG and the pathogenesis at the NMJ as a result of autoantibody attack will lead to the development of antigen-specific therapies.

\section{Acknowledgements}

The micrographs in this paper were taken with a confocal spinning disk microscope financed by The Netherlands Organisation for Scientific Research (NWO), grant number 911-06-003. The authors' experimental work was supported by grants from the Prinses Beatrix Fonds, L'Association Française contre les Myopathies, the European Union Sixth Framework Program (FP6) MYASTAID LSHM-CT-2006-037833, Genmab and Aspreva. The authors report no conflicts of interest. The authors alone are responsible for the content and writing of the paper. 


\section{$\underline{\text { References }}$}

1. Lindstrom, J.M., Seybold, M.E., Lennon, V.A., Whittingham, S., Duane, D.D. 1976. Antibody to acetylcholine receptor in myasthenia gravis. Prevalence, clinical correlates, and diagnostic value. Neurology, 26: 1054-9.

2. Hoch, W., McConville, J., Helms, S., Newsom-Davis, J., Melms, A., Vincent, A. 2001. Autoantibodies to the receptor tyrosine kinase MuSK in patients with myasthenia gravis without acetylcholine receptor antibodies. Nat Med, 7: 365-8.

3. Evoli, A., Tonali, P.A., Padua, L., Monaco, M.L., Scuderi, F., Batocchi, A.P., Marino, M., Bartoccioni, E. 2003. Clinical correlates with anti-MuSK antibodies in generalized seronegative myasthenia gravis. Brain, 126: 2304-11.

4. Kong, X.C., Barzaghi, P., Ruegg, M.A. 2004. Inhibition of synapse assembly in mammalian muscle in vivo by RNA interference. EMBO Rep, 5: 183-8.

5. Sanders, D.B., Evoli, A. 2009. Immunosuppressive Therapies in Myasthenia Gravis. Autoimmunity, In press.

6. Kathleen Vrolix, J.F., Peter C. Molenaar, Mario Losen, Veerle Somers, Piet Stinissen, Marc H. De Baets, Pilar Martínez-Martínez. 2009. The auto-antigen repertoire in myasthenia gravis. autoimmunity, In press.

7. Marx, A., Willcox, N., Leite, M.I., Chuang, W., Schalke, B., Nix, W., Ströbel, P. 2009. Thymoma and paraneoplastic myasthenia gravis. autoimmunity, In press.

8. Shiono, H., Wong, Y.L., Matthews, I., Liu, J.L., Zhang, W., Sims, G., Meager, A., Beeson, D., Vincent, A., Willcox, N. 2003. Spontaneous production of anti-IFN-alpha and anti-IL-12 autoantibodies by thymoma cells from myasthenia gravis patients suggests autoimmunization in the tumor. Int Immunol, 15: 903-13.

9. Le Panse, R., Bismuth, J., Cizeron-Clairac, G., Weiss, J.M., Cufi, P., Dartevelle, P., Kerlero de Rosbo, N., Berrih-Aknin, S. 2009. Thymic remodeling associated with hyperplasia in myasthenia gravis. Autoimmunity, In press.

10. Leite, M.I., Strobel, P., Jones, M., Micklem, K., Moritz, R., Gold, R., Niks, E.H., Berrih-Aknin, S., Scaravilli, F., Canelhas, A. et al. 2005. Fewer thymic changes in MuSK antibody-positive than in MuSK antibody-negative MG. Ann Neurol, 57: 444-8.

11. Romi, F., Skeie, G.O., Gilhus, N.E., Aarli, J.A. 2005. Striational antibodies in myasthenia gravis: reactivity and possible clinical significance. Arch Neurol, 62: 442-6.

12. Vincent, A., Leite, M.I. 2005. Neuromuscular junction autoimmune disease: muscle specific kinase antibodies and treatments for myasthenia gravis. Curr Opin Neurol, 18: 519-25.

13. Leite, M.I., Jacob, S., Viegas, S., Cossins, J., Clover, L., Morgan, B.P., Beeson, D., Willcox, N., Vincent, A. 2008. IgG1 antibodies to acetylcholine receptors in 'seronegative' myasthenia gravis. Brain, 131: 1940-52.

14. Leite, M.I., Waters, P., Vincent, A. 2009. Diagnostic use of auto-antibodies in myasthenia gravis. autoimmunity, In press.

15. Changeux, J.P., Devillers-Thiery, A., Chemouilli, P. 1984. Acetylcholine receptor: an allosteric protein. Science, 225: 1335-45.

16. Katz, B., Miledi, R. 1964. Further Observations on the Distribution of Actylcholine-Reactive Sites in Skeletal Muscle. J Physiol, 170: 379-88.

17. Wood, S.J., Slater, C.R. 2001. Safety factor at the neuromuscular junction. Prog Neurobiol, 64: 393-429.

18. Schaeffer, L., de Kerchove d'Exaerde, A., Changeux, J.P. 2001. Targeting transcription to the neuromuscular synapse. Neuron, 31: 15-22.

19. Bevan, S., Steinbach, J.H. 1977. The distribution of alpha-bungarotoxin binding sites of 
mammalian skeletal muscle developing in vivo. J Physiol, 267: 195-213.

20. Jessell, T.M., Siegel, R.E., Fischbach, G.D. 1979. Induction of acetylcholine receptors on cultured skeletal muscle by a factor extracted from brain and spinal cord. Proc Natl Acad Sci U S A, 76: 5397-401.

21. Goldman, D., Staple, J. 1989. Spatial and temporal expression of acetylcholine receptor RNAs in innervated and denervated rat soleus muscle. Neuron, 3: 219-28.

22. Gautam, M., Noakes, P.G., Mudd, J., Nichol, M., Chu, G.C., Sanes, J.R., Merlie, J.P. 1995. Failure of postsynaptic specialization to develop at neuromuscular junctions of rapsyndeficient mice. Nature, 377: 232-6.

23. Glass, D.J., Bowen, D.C., Stitt, T.N., Radziejewski, C., Bruno, J., Ryan, T.E., Gies, D.R., Shah, S., Mattsson, K., Burden, S.J. et al. 1996. Agrin acts via a MuSK receptor complex. Cell, 85: 513-23.

24. Moransard, M., Borges, L.S., Willmann, R., Marangi, P.A., Brenner, H.R., Ferns, M.J., Fuhrer, C. 2003. Agrin regulates rapsyn interaction with surface acetylcholine receptors, and this underlies cytoskeletal anchoring and clustering. J Biol Chem, 278: 7350-9.

25. Cartaud, A., Coutant, S., Petrucci, T.C., Cartaud, J. 1998. Evidence for in situ and in vitro association between beta-dystroglycan and the subsynaptic 43K rapsyn protein. Consequence for acetylcholine receptor clustering at the synapse. J Biol Chem, 273: 113216.

26. Rybakova, I.N., Humston, J.L., Sonnemann, K.J., Ervasti, J.M. 2006. Dystrophin and utrophin bind actin through distinct modes of contact. J Biol Chem, 281: 9996-10001.

27. Wang, Z.Z., Mathias, A., Gautam, M., Hall, Z.W. 1999. Metabolic stabilization of muscle nicotinic acetylcholine receptor by rapsyn. J Neurosci, 19: 1998-2007.

28. Phillips, W.D., Vladeta, D., Han, H., Noakes, P.G. 1997. Rapsyn and agrin slow the metabolic degradation of the acetylcholine receptor. Mol Cell Neurosci, 10: 16-26.

29. Drachman, D.B. 1994. Myasthenia gravis. N Engl J Med, 330: 1797-810.

30. Plomp, J.J., Van Kempen, G.T., De Baets, M.B., Graus, Y.M., Kuks, J.B., Molenaar, P.C. 1995. Acetylcholine release in myasthenia gravis: regulation at single end-plate level. Ann Neurol, 37: 627-36.

31. Molenaar, P.C., Polak, R.L., Miledi, R., Alema, S., Vincent, A., Newsom-Davis, J. 1979. Acetylcholine in intercostal muscle from myasthenia gravis patients and in rat diaphragm after blockade of acetylcholine receptors. Prog Brain Res, 49: 449-58.

32. Shiraishi, H., Motomura, M., Yoshimura, T., Fukudome, T., Fukuda, T., Nakao, Y., Tsujihata, M., Vincent, A., Eguchi, K. 2005. Acetylcholine receptors loss and postsynaptic damage in MuSK antibody-positive myasthenia gravis. Ann Neurol, 57: 289-93.

33. Selcen, D., Fukuda, T., Shen, X.M., Engel, A.G. 2004. Are MuSK antibodies the primary cause of myasthenic symptoms? Neurology, 62: 1945-50.

34. McConville, J., Farrugia, M.E., Beeson, D., Kishore, U., Metcalfe, R., Newsom-Davis, J., Vincent, A. 2004. Detection and characterization of MuSK antibodies in seronegative myasthenia gravis. Ann Neurol, 55: 580-4.

35. Kuwabara, S., Nemoto, Y., Misawa, S., Takahashi, H., Kawaguchi, N., Hattori, T. 2007. AntiMuSK-positive myasthenia gravis: neuromuscular transmission failure in facial and limb muscles. Acta Neurol Scand, 115: 126-8.

36. Stickler, D.E., Massey, J.M., Sanders, D.B. 2005. MuSK-antibody positive myasthenia gravis: clinical and electrodiagnostic patterns. Clin Neurophysiol, 116: 2065-8.

37. Farrugia, M.E., Kennett, R.P., Newsom-Davis, J., Hilton-Jones, D., Vincent, A. 2006. Singlefiber electromyography in limb and facial muscles in muscle-specific kinase antibody and acetylcholine receptor antibody myasthenia gravis. Muscle Nerve, 33: 568-70.

38. Tao, M.H., Smith, R.I., Morrison, S.L. 1993. Structural features of human immunoglobulin G that determine isotype-specific differences in complement activation. J Exp Med, 178: 661- 
7.

39. Michaelsen, T.E., Sandlie, I., Bratlie, D.B., Sandin, R.H., Ihle, O. 2009. Structural difference in the complement activation site of human IgG1 and IgG3. Scand J Immunol, 70: 553-64.

40. Bruggemann, M., Williams, G.T., Bindon, C.I., Clark, M.R., Walker, M.R., Jefferis, R., Waldmann, H., Neuberger, M.S. 1987. Comparison of the effector functions of human immunoglobulins using a matched set of chimeric antibodies. J Exp Med, 166: 1351-61.

41. Dangl, J.L., Wensel, T.G., Morrison, S.L., Stryer, L., Herzenberg, L.A., Oi, V.T. 1988. Segmental flexibility and complement fixation of genetically engineered chimeric human, rabbit and mouse antibodies. Embo J, 7: 1989-94.

42. Tao, M.H., Canfield, S.M., Morrison, S.L. 1991. The differential ability of human IgG1 and IgG4 to activate complement is determined by the $\mathrm{COOH}$-terminal sequence of the $\mathrm{CH} 2$ domain. J Exp Med, 173: 1025-8.

43. Tan, L.K., Shopes, R.J., Oi, V.T., Morrison, S.L. 1990. Influence of the hinge region on complement activation, $\mathrm{C} 1 \mathrm{q}$ binding, and segmental flexibility in chimeric human immunoglobulins. Proc Natl Acad Sci U S A, 87: 162-6.

44. Rodgaard, A., Nielsen, F.C., Djurup, R., Somnier, F., Gammeltoft, S. 1987. Acetylcholine receptor antibody in myasthenia gravis: predominance of IgG subclasses 1 and 3. Clin Exp Immunol, 67: 82-8.

45. Vincent, A., Newsom-Davis, J. 1982. Acetylcholine receptor antibody characteristics in myasthenia gravis. I. Patients with generalized myasthenia or disease restricted to ocular muscles. Clin Exp Immunol, 49: 257-65.

46. Lefvert, A.K., Cuenoud, S., Fulpius, B.W. 1981. Binding properties and subclass distribution of anti-acetylcholine receptor antibodies in myasthenia gravis. $J$ Neuroimmunol, 1: 125-35.

47. Takeo, G., Motomura, M., Mats, H., Ohishi, K., Yoshimura, T., Tsujihata, M., Nagataki, S. 1993. Effect of myasthenic IgG on degradation of junctional acetylcholine receptor. Muscle Nerve, 16: 840-8.

48. Newsom-Davis, J., Wilson, S.G., Vincent, A., Ward, C.D. 1979. Long-term effects of repeated plasma exchange in myasthenia gravis. Lancet, 1: 464-8.

49. van der Neut Kolfschoten, M., Schuurman, J., Losen, M., Bleeker, W.K., Martinez-Martinez, P., Vermeulen, E., den Bleker, T.H., Wiegman, L., Vink, T., Aarden, L.A. et al. 2007. Antiinflammatory activity of human IgG4 antibodies by dynamic Fab arm exchange. Science, 317: 1554-7.

50. Boneva, N., Frenkian-Cuvelier, M., Bidault, J., Brenner, T., Berrih-Aknin, S. 2006. Major pathogenic effects of anti-MuSK antibodies in myasthenia gravis. J Neuroimmunol, 177: 119-31.

51. Schuurman, J., Van Ree, R., Perdok, G.J., Van Doorn, H.R., Tan, K.Y., Aalberse, R.C. 1999. Normal human immunoglobulin G4 is bispecific: it has two different antigen-combining sites. Immunology, 97: 693-8.

52. Petersen, J.G., Dorrington, K.J. 1974. An in vitro system for studying the kinetics of interchain disulfide bond formation in immunoglobulin G. J Biol Chem, 249: 5633-41.

53. Angal, S., King, D.J., Bodmer, M.W., Turner, A., Lawson, A.D., Roberts, G., Pedley, B., Adair, J.R. 1993. A single amino acid substitution abolishes the heterogeneity of chimeric mouse/human (IgG4) antibody. Mol Immunol, 30: 105-8.

54. van der Zee, J.S., van Swieten, P., Aalberse, R.C. 1986. Inhibition of complement activation by IgG4 antibodies. Clin Exp Immunol, 64: 415-22.

55. Sahashi, K., Engel, A.G., Lambert, E.H., Howard, F.M., Jr. 1980. Ultrastructural localization of the terminal and lytic ninth complement component (C9) at the motor end-plate in myasthenia gravis. J Neuropathol Exp Neurol, 39: 160-72.

56. Drachman, D.B., Angus, C.W., Adams, R.N., Michelson, J.D., Hoffman, G.J. 1978. Myasthenic antibodies cross-link acetylcholine receptors to accelerate degradation. $N$ Engl 
J Med, 298: 1116-22.

57. Kao, I., Drachman, D.B. 1977. Myasthenic immunoglobulin accelerates acetylcholine receptor degradation. Science, 196: 527-9.

58. Stanley, E.F., Drachman, D.B. 1978. Effect of myasthenic immunoglobulin on acetylcholine receptors of intact mammalian neuromuscular junctions. Science, 200: 1285-7.

59. Pumplin, D.W., Drachman, D.B. 1983. Myasthenic patients' IgG causes redistribution of acetylcholine receptors: freeze-fracture studies. J Neurosci, 3: 576-84.

60. Drachman, D.B., Adams, R.N., Josifek, L.F., Self, S.G. 1982. Functional activities of autoantibodies to acetylcholine receptors and the clinical severity of myasthenia gravis. $N$ Engl J Med, 307: 769-75.

61. Howard, F.M., Jr., Lennon, V.A., Finley, J., Matsumoto, J., Elveback, L.R. 1987. Clinical correlations of antibodies that bind, block, or modulate human acetylcholine receptors in myasthenia gravis. Ann N Y Acad Sci, 505: 526-38.

62. Conti-Tronconi, B., Tzartos, S., Lindstrom, J. 1981. Monoclonal antibodies as probes of acetylcholine receptor structure. 2. Binding to native receptor. Biochemistry, 20: 2181-91.

63. Corey, A.L., Richman, D.P., Agius, M.A., Wollmann, R.L. 1987. Refractoriness to a second episode of experimental myasthenia gravis. Correlation with AChR concentration and morphologic appearance of the postsynaptic membrane. J Immunol, 138: 3269-75.

64. Engel, A.G., Arahata, K. 1987. The membrane attack complex of complement at the endplate in myasthenia gravis. Ann N Y Acad Sci, 505: 326-32.

65. Losen, M., Martinez-Martinez, P., Phernambucq, M., Schuurman, J., Parren, P.W., De Baets, M.H. 2008. Treatment of myasthenia gravis by preventing acetylcholine receptor modulation. Ann N Y Acad Sci, 1132: 174-9.

66. Losen, M., Stassen, M.H., Martinez-Martinez, P., Machiels, B.M., Duimel, H., Frederik, P., Veldman, H., Wokke, J.H., Spaans, F., Vincent, A. et al. 2005. Increased expression of rapsyn in muscles prevents acetylcholine receptor loss in experimental autoimmune myasthenia gravis. Brain, 128: 2327-37.

67. Lennon, V.A., Seybold, M.E., Lindstrom, J.M., Cochrane, C., Ulevitch, R. 1978. Role of complement in the pathogenesis of experimental autoimmune myasthenia gravis. J Exp Med, 147: 973-83.

68. Biesecker, G., Gomez, C.M. 1989. Inhibition of acute passive transfer experimental autoimmune myasthenia gravis with Fab antibody to complement C6. J Immunol, 142: 2654-9.

69. Piddlesden, S.J., Jiang, S., Levin, J.L., Vincent, A., Morgan, B.P. 1996. Soluble complement receptor 1 (sCR1) protects against experimental autoimmune myasthenia gravis. J Neuroimmunol, 71: 173-7.

70. Christadoss, P. 1988. C5 gene influences the development of murine myasthenia gravis. J Immunol, 140: 2589-92.

71. Karachunski, P.I., Ostlie, N.S., Monfardini, C., Conti-Fine, B.M. 2000. Absence of IFNgamma or IL-12 has different effects on experimental myasthenia gravis in C57BL/6 mice. J Immunol, 164: 5236-44.

72. Engel, A.G., Lambert, E.H., Howard, F.M. 1977. Immune complexes (IgG and C3) at the motor end-plate in myasthenia gravis: ultrastructural and light microscopic localization and electrophysiologic correlations. Mayo Clin Proc, 52: 267-80.

73. Mozrzymas, J.W., Lorenzon, P., Riviera, A.P., Tedesco, F., Ruzzier, F. 1993. An electrophysiological study of the effects of myasthenia gravis sera and complement on rat isolated muscle fibres. J Neuroimmunol, 45: 155-62.

74. Martinez-Martinez, P., Losen, M., Duimel, H., Frederik, P., Spaans, F., Molenaar, P., Vincent, A., De Baets, M.H. 2007. Overexpression of rapsyn in rat muscle increases acetylcholine receptor levels in chronic experimental autoimmune myasthenia gravis. Am J 
Pathol, 170: 644-57.

75. Gomez, C.M., Richman, D.P. 1983. Anti-acetylcholine receptor antibodies directed against the alpha-bungarotoxin binding site induce a unique form of experimental myasthenia. Proc Natl Acad Sci U S A, 80: 4089-93.

76. Whiting, P.J., Vincent, A., Newsom-Davis, J. 1983. Acetylcholine receptor antibody characteristics in myasthenia gravis. Fractionation of alpha-bungarotoxin binding site antibodies and their relationship to IgG subclass. J Neuroimmunol, 5: 1-9.

77. Ito, H., Yoshimura, T., Satoh, A., Takino, H., Tsujihata, M., Nagataki, S. 1996. Immunohistochemical study of utrophin and dystrophin at the motor end-plate in myasthenia gravis. Acta Neuropathol, 92: 14-8.

78. Slater, C.R., Young, C., Wood, S.J., Bewick, G.S., Anderson, L.V., Baxter, P., Fawcett, P.R., Roberts, M., Jacobson, L., Kuks, J. et al. 1997. Utrophin abundance is reduced at neuromuscular junctions of patients with both inherited and acquired acetylcholine receptor deficiencies. Brain, 120 (Pt 9): 1513-31.

79. Engel, A.G., Sine, S.M. 2005. Current understanding of congenital myasthenic syndromes. Curr Opin Pharmacol, 5: 308-21.

80. Palace, J., Beeson, D. 2008. The congenital myasthenic syndromes. J Neuroimmunol, 201202: 2-5.

81. DeChiara, T.M., Bowen, D.C., Valenzuela, D.M., Simmons, M.V., Poueymirou, W.T., Thomas, S., Kinetz, E., Compton, D.L., Rojas, E., Park, J.S. et al. 1996. The receptor tyrosine kinase MuSK is required for neuromuscular junction formation in vivo. Cell, 85: 501-12.

82. Okada, K., Inoue, A., Okada, M., Murata, Y., Kakuta, S., Jigami, T., Kubo, S., Shiraishi, H., Eguchi, K., Motomura, M. et al. 2006. The muscle protein Dok-7 is essential for neuromuscular synaptogenesis. Science, 312: 1802-5.

83. Weatherbee, S.D., Anderson, K.V., Niswander, L.A. 2006. LDL-receptor-related protein 4 is crucial for formation of the neuromuscular junction. Development, 133: 4993-5000.

84. Burke, G., Cossins, J., Maxwell, S., Owens, G., Vincent, A., Robb, S., Nicolle, M., HiltonJones, D., Newsom-Davis, J., Palace, J. et al. 2003. Rapsyn mutations in hereditary myasthenia: distinct early- and late-onset phenotypes. Neurology, 61: 826-8.

85. Chevessier, F., Faraut, B., Ravel-Chapuis, A., Richard, P., Gaudon, K., Bauche, S., Prioleau, C., Herbst, R., Goillot, E., loos, C. et al. 2004. MUSK, a new target for mutations causing congenital myasthenic syndrome. Hum Mol Genet, 13: 3229-40.

86. Beeson, D., Higuchi, O., Palace, J., Cossins, J., Spearman, H., Maxwell, S., Newsom-Davis, J., Burke, G., Fawcett, P., Motomura, M. et al. 2006. Dok-7 mutations underlie a neuromuscular junction synaptopathy. Science, 313: 1975-8.

87. Noakes, P.G., Gautam, M., Mudd, J., Sanes, J.R., Merlie, J.P. 1995. Aberrant differentiation of neuromuscular junctions in mice lacking s-laminin/laminin beta 2. Nature, 374: 258-62.

88. Maselli, R.A., Ng, J.J., Anderson, J.A., Cagney, O., Arredondo, J., Williams, C., Wessel, H.B., Abdel-Hamid, H., Wollmann, R.L. 2009. Mutations in LAMB2 causing a severe form of synaptic congenital myasthenic syndrome. J Med Genet, 46: 203-8.

89. Martinez-Martinez, P., Phernambucq, M., Steinbusch, L., Schaeffer, L., Berrih-Aknin, S., Duimel, H., Frederik, P., Molenaar, P., De Baets, M.H., Losen, M. 2009. Silencing rapsyn in vivo decreases acetylcholine receptors and augments sodium channels and secondary postsynaptic membrane folding. Neurobiol Dis, 35: 14-23.

90. Tanaka, H., Ishiguro, T., Eguchi, C., Saito, K., Ozawa, E. 1991. Expression of a dystrophinrelated protein associated with the skeletal muscle cell membrane. Histochemistry, 96: 15.

91. Tinsley, J.M., Blake, D.J., Roche, A., Fairbrother, U., Riss, J., Byth, B.C., Knight, A.E., Kendrick-Jones, J., Suthers, G.K., Love, D.R. et al. 1992. Primary structure of dystrophinrelated protein. Nature, 360: 591-3. 
92. Huard, J., Fortier, L.P., Labrecque, C., Dansereau, G., Tremblay, J.P. 1991. Is dystrophin present in the nerve terminal at the neuromuscular junction? An immunohistochemical study of the heterozygote dystrophic (mdx) mouse. Synapse, 7: 135-40.

93. Bewick, G.S., Nicholson, L.V., Young, C., O'Donnell, E., Slater, C.R. 1992. Different distributions of dystrophin and related proteins at nerve-muscle junctions. Neuroreport, 3: 857-60.

94. Bewick, G.S., Young, C., Slater, C.R. 1996. Spatial relationships of utrophin, dystrophin, beta-dystroglycan and beta-spectrin to acetylcholine receptor clusters during postnatal maturation of the rat neuromuscular junction. J Neurocytol, 25: 367-79.

95. Phillips, W.D., Noakes, P.G., Roberds, S.L., Campbell, K.P., Merlie, J.P. 1993. Clustering and immobilization of acetylcholine receptors by the $43-\mathrm{kD}$ protein: a possible role for dystrophin-related protein. J Cell Biol, 123: 729-40.

96. Grady, R.M., Merlie, J.P., Sanes, J.R. 1997. Subtle neuromuscular defects in utrophindeficient mice. J Cell Biol, 136: 871-82.

97. Deconinck, A.E., Potter, A.C., Tinsley, J.M., Wood, S.J., Vater, R., Young, C., Metzinger, L., Vincent, A., Slater, C.R., Davies, K.E. 1997. Postsynaptic abnormalities at the neuromuscular junctions of utrophin-deficient mice. J Cell Biol, 136: 883-94.

98. Brockhausen, J., Cole, R.N., Gervasio, O.L., Ngo, S.T., Noakes, P.G., Phillips, W.D. 2008. Neural agrin increases postsynaptic ACh receptor packing by elevating rapsyn protein at the mouse neuromuscular synapse. Dev Neurobiol, 68: 1153-69.

99. Kim, N., Stiegler, A.L., Cameron, T.O., Hallock, P.T., Gomez, A.M., Huang, J.H., Hubbard, S.R., Dustin, M.L., Burden, S.J. 2008. Lrp4 is a receptor for Agrin and forms a complex with MuSK. Cell, 135: 334-42.

100. Gervasio, O.L., Phillips, W.D. 2005. Increased ratio of rapsyn to ACh receptor stabilizes postsynaptic receptors at the mouse neuromuscular synapse. J Physiol, 562: 673-85.

101. Hesser, B.A., Henschel, O., Witzemann, V. 2006. Synapse disassembly and formation of new synapses in postnatal muscle upon conditional inactivation of MuSK. Mol Cell Neurosci, 31: 470-80.

102. Johnson, E.B., Hammer, R.E., Herz, J. 2005. Abnormal development of the apical ectodermal ridge and polysyndactyly in Megf7-deficient mice. Hum Mol Genet, 14: 352338.

103. Tian, Q.B., Suzuki, T., Yamauchi, T., Sakagami, H., Yoshimura, Y., Miyazawa, S., Nakayama, K., Saitoh, F., Zhang, J.P., Lu, Y. et al. 2006. Interaction of LDL receptor-related protein 4 (LRP4) with postsynaptic scaffold proteins via its C-terminal PDZ domain-binding motif, and its regulation by $\mathrm{Ca} / \mathrm{calmodulin}$-dependent protein kinase II. Eur J Neurosci, 23: 286476.

104. Zhang, B., Luo, S., Wang, Q., Suzuki, T., Xiong, W.C., Mei, L. 2008. LRP4 serves as a coreceptor of agrin. Neuron, 60: 285-97.

105. Zhang, Y., Yan, Z., Farooq, A., Liu, X., Lu, C., Zhou, M.M., He, C. 2004. Molecular basis of distinct interactions between Dok1 PTB domain and tyrosine-phosphorylated EGF receptor. J Mol Biol, 343: 1147-55.

106. Linnoila, J., Wang, Y., Yao, Y., Wang, Z.Z. 2008. A mammalian homolog of Drosophila tumorous imaginal discs, Tid1, mediates agrin signaling at the neuromuscular junction. Neuron, 60: 625-41.

107. Trentin, G.A., Yin, X., Tahir, S., Lhotak, S., Farhang-Fallah, J., Li, Y., Rozakis-Adcock, M. 2001. A mouse homologue of the Drosophila tumor suppressor I(2)tid gene defines a novel Ras GTPase-activating protein (RasGAP)-binding protein. J Biol Chem, 276: 13087-95.

108. Cheng, H., Cenciarelli, C., Tao, M., Parks, W.P., Cheng-Mayer, C. 2002. HTLV-1 Taxassociated hTid-1, a human DnaJ protein, is a repressor of Ikappa B kinase beta subunit. J Biol Chem, 277: 20605-10. 
109. Luo, S., Zhang, B., Dong, X.P., Tao, Y., Ting, A., Zhou, Z., Meixiong, J., Luo, J., Chiu, F.C., Xiong, W.C. et al. 2008. HSP90 beta regulates rapsyn turnover and subsequent AChR cluster formation and maintenance. Neuron, 60: 97-110.

110. Song, Y., Balice-Gordon, R. 2008. New dogs in the dogma: Lrp4 and Tid1 in neuromuscular synapse formation. Neuron, 60: 526-8.

111. Yin, X., Rozakis-Adcock, M. 2001. Genomic organization and expression of the human tumorous imaginal disc (TID1) gene. Gene, 278: 201-10.

112. Catlett, M.G., Forsburg, S.L. 2003. Schizosaccharomyces pombe Rdh54 (TID1) acts with Rhp54 (RAD54) to repair meiotic double-strand breaks. Mol Biol Cell, 14: 4707-20.

113. Tarunina, M., Alger, L., Chu, G., Munger, K., Gudkov, A., Jat, P.S. 2004. Functional genetic screen for genes involved in senescence: role of Tid1, a homologue of the Drosophila tumor suppressor I(2)tid, in senescence and cell survival. Mol Cell Biol, 24: 10792-801.

114. Sarkar, S., Pollack, B.P., Lin, K.T., Kotenko, S.V., Cook, J.R., Lewis, A., Pestka, S. 2001. hTid-1, a human DnaJ protein, modulates the interferon signaling pathway. $J$ Biol Chem, 276: 49034-42.

115. Toyka, K.V., Brachman, D.B., Pestronk, A., Kao, I. 1975. Myasthenia gravis: passive transfer from man to mouse. Science, 190: 397-9.

116. Shigemoto, K., Kubo, S., Maruyama, N., Hato, N., Yamada, H., Jie, C., Kobayashi, N., Mominoki, K., Abe, Y., Ueda, N. et al. 2006. Induction of myasthenia by immunization against muscle-specific kinase. J Clin Invest, 116: 1016-24.

117. Jha, S., Xu, K., Maruta, T., Oshima, M., Mosier, D.R., Atassi, M.Z., Hoch, W. 2006. Myasthenia gravis induced in mice by immunization with the recombinant extracellular domain of rat muscle-specific kinase (MuSK). J Neuroimmunol, 175: 107-17.

118. Cole, R.N., Reddel, S.W., Gervasio, O.L., Phillips, W.D. 2008. Anti-MuSK patient antibodies disrupt the mouse neuromuscular junction. Ann Neurol, 63: 782-9.

119. ter Beek, W.P., Martinez-Martinez, P., Losen, M., de Baets, M.H., Wintzen, A.R., Verschuuren, J.J., Niks, E.H., van Duinen, S.G., Vincent, A., Molenaar, P.C. 2009. The effect of plasma from muscle-specific tyrosine kinase myasthenia patients on regenerating endplates. Am J Pathol, 175: 1536-44.

120. Souroujon, M.C., Brenner, T., Fuchs, S. 2009. Development of novel therapies for MG: studies in animal models. Autoimmunity, In press.

121. Patrick, J., Lindstrom, J. 1973. Autoimmune response to acetylcholine receptor. Science, 180: 871-2.

122. Berman, P.W., Patrick, J. 1980. Experimental myasthenia gravis. A murine system. J Exp Med, 151: 204-23.

123. Lennon, V.A., Lindstrom, J.M., Seybold, M.E. 1975. Experimental autoimmune myasthenia: A model of myasthenia gravis in rats and guinea pigs. J Exp Med, 141: 1365-75.

124. Tarrab-Hazdai, R., Aharonov, A., Silman, I., Fuchs, S., Abramsky, O. 1975. Experimental autoimmune myasthenia induced in monkeys by purified acetylcholine receptor. Nature, 256: 128-30.

125. Conti-Fine, B.M., Milani, M., Wang, W. 2008. CD4+ T cells and cytokines in the pathogenesis of acquired myasthenia gravis. Ann N Y Acad Sci, 1132: 193-209.

126. Balasa, B., Deng, C., Lee, J., Bradley, L.M., Dalton, D.K., Christadoss, P., Sarvetnick, N. 1997. Interferon gamma (IFN-gamma) is necessary for the genesis of acetylcholine receptorinduced clinical experimental autoimmune myasthenia gravis in mice. J Exp Med, 186: 38591.

127. Saoudi, A., Bernard, I., Hoedemaekers, A., Cautain, B., Martinez, K., Druet, P., De Baets, M., Guery, J.C. 1999. Experimental autoimmune myasthenia gravis may occur in the context of a polarized Th1- or Th2-type immune response in rats. J Immunol, 162: 7189-97.

128. Ostlie, N., Milani, M., Wang, W., Okita, D., Conti-Fine, B.M. 2003. Absence of IL-4 facilitates 
the development of chronic autoimmune myasthenia gravis in C57BL/6 mice. J Immunol, 170: 604-12.

129. Moiola, L., Galbiati, F., Martino, G., Amadio, S., Brambilla, E., Comi, G., Vincent, A., Grimaldi, L.M., Adorini, L. 1998. IL-12 is involved in the induction of experimental autoimmune myasthenia gravis, an antibody-mediated disease. Eur J Immunol, 28: 248797.

130. Hoedemaekers, A.C., van Breda Vriesman, P.J., De Baets, M.H. 1997. Myasthenia gravis as a prototype autoimmune receptor disease. Immunol Res, 16: 341-54.

131. Richman, D.P., Gomez, C.M., Berman, P.W., Burres, S.A., Fitch, F.W., Arnason, B.G. 1980. Monoclonal anti-acetylcholine receptor antibodies can cause experimental myasthenia. Nature, 286: 738-9.

132. Tzartos, S.J., Sophianos, D., Efthimiadis, A. 1985. Role of the main immunogenic region of acetylcholine receptor in myasthenia gravis. An Fab monoclonal antibody protects against antigenic modulation by human sera. J Immunol, 134: 2343-9.

133. Balass, M., Heldman, Y., Cabilly, S., Givol, D., Katchalski-Katzir, E., Fuchs, S. 1993. Identification of a hexapeptide that mimics a conformation-dependent binding site of acetylcholine receptor by use of a phage-epitope library. Proc Natl Acad Sci U S A, 90: 10638-42.

134. Sterz, R., Hohlfeld, R., Rajki, K., Kaul, M., Heininger, K., Peper, K., Toyka, K.V. 1986. Effector mechanisms in myasthenia gravis: end-plate function after passive transfer of IgG, Fab, and $\mathrm{F}\left(\mathrm{ab} \mathrm{b}^{\prime}\right) 2$ hybrid molecules. Muscle Nerve, 9: 306-12.

135. Luo, J., Taylor, P., Losen, M., de Baets, M.H., Shelton, G.D., Lindstrom, J. 2009. Main immunogenic region structure promotes binding of conformation-dependent myasthenia gravis autoantibodies, nicotinic acetylcholine receptor conformation maturation, and agonist sensitivity. J Neurosci, 29: 13898-908.

136. Lagoumintzisa, G., Zisimopouloua, P., Kordas, G., Lazaridisa, K., Poulas, K., Tzartos, S.J. 2009. Recent approaches to the development of antigen-specific immunotherapies for myasthenia gravis. Autoimmunity, In Press.

137. Papanastasiou, D., Poulas, K., Kokla, A., Tzartos, S.J. 2000. Prevention of passively transferred experimental autoimmune myasthenia gravis by Fab fragments of monoclonal antibodies directed against the main immunogenic region of the acetylcholine receptor. $J$ Neuroimmunol, 104: 124-32.

138. Toyka, K.V., Lowenadler, B., Heininger, K., Besinger, U.A., Birnberger, K.L., FatehMoghadam, A., Heilbronn, E. 1980. Passively transferred myasthenia gravis: protection of mouse endplates by Fab fragments from human myasthenic IgG. I Neurol Neurosurg Psychiatry, 43: 836-42.

139. Graus, Y.F., de Baets, M.H., Parren, P.W., Berrih-Aknin, S., Wokke, J., van Breda Vriesman, P.J., Burton, D.R. 1997. Human anti-nicotinic acetylcholine receptor recombinant Fab fragments isolated from thymus-derived phage display libraries from myasthenia gravis patients reflect predominant specificities in serum and block the action of pathogenic serum antibodies. J Immunol, 158: 1919-29.

140. Eymard, B., Vernet-der Garabedian, B., Berrih-Aknin, S., Pannier, C., Bach, J.F., Morel, E. 1991. Anti-acetylcholine receptor antibodies in neonatal myasthenia gravis: heterogeneity and pathogenic significance. J Autoimmun, 4: 185-95.

141. Morel, E., Eymard, B., Vernet-der Garabedian, B., Pannier, C., Dulac, O., Bach, J.F. 1988. Neonatal myasthenia gravis: a new clinical and immunologic appraisal on 30 cases. Neurology, 38: 138-42.

142. Papazian, O. 1992. Transient neonatal myasthenia gravis. J Child Neurol, 7: 135-41.

143. Vernet-der Garabedian, B., Lacokova, M., Eymard, B., Morel, E., Faltin, M., Zajac, J., Sadovsky, O., Dommergues, M., Tripon, P., Bach, J.F. 1994. Association of neonatal 
myasthenia gravis with antibodies against the fetal acetylcholine receptor. J Clin Invest, 94: 555-9.

144. Shelton, G.D. 1999. Acquired myasthenia gravis: what we have learned from experimental and spontaneous animal models. Vet Immunol Immunopathol, 69: 239-49.

145. Shelton, G.D., Schule, A., Kass, P.H. 1997. Risk factors for acquired myasthenia gravis in dogs: 1,154 cases (1991-1995). J Am Vet Med Assoc, 211: 1428-31.

146. Lindstrom, J.M., Engel, A.G., Seybold, M.E., Lennon, V.A., Lambert, E.H. 1976. Pathological mechanisms in experimental autoimmune myasthenia gravis. II. Passive transfer of experimental autoimmune myasthenia gravis in rats with anti-acetylcholine recepotr antibodies. J Exp Med, 144: 739-53.

147. Behin, A., Mayer, M., Kassis-Makhoul, B., Jugie, M., Espil-Taris, C., Ferrer, X., Chatenoud, L., Laforet, P., Eymard, B. 2008. Severe neonatal myasthenia due to maternal anti-MuSK antibodies. Neuromuscul Disord, 18: 443-6.

148. Niks, E.H., Verrips, A., Semmekrot, B.A., Prick, M.J., Vincent, A., van Tol, M.J., Jol-van der Zijde, C.M., Verschuuren, J.J. 2008. A transient neonatal myasthenic syndrome with antimusk antibodies. Neurology, 70: 1215-6.

149. Bazin, H. 1990. Rat Immunoglobulins. In Rat Hybridomas and Rat Monoclonal Antibodies. Bazin, H., ed. CRC press, Boca Raton, pp. 5-42.

150. Zhang, K. 2003. Accessibility control and machinery of immunoglobulin class switch recombination. J Leukoc Biol, 73: 323-32.

151. Saoudi, A., Kuhn, J., Huygen, K., de Kozak, Y., Velu, T., Goldman, M., Druet, P., Bellon, B. 1993. Role of the TH1-TH2 balance in the development of autoimmunity in rats. Transplant Proc, 25: 2824-5.

152. Avery, D.T., Bryant, V.L., Ma, C.S., de Waal Malefyt, R., Tangye, S.G. 2008. IL-21-induced isotype switching to $\lg G$ and $\operatorname{IgA}$ by human naive B cells is differentially regulated by IL-4. J Immunol, 181: 1767-79.

153. Zhang, G.X., Xiao, B.G., Yu, L.Y., van der Meide, P.H., Link, H. 2001. Interleukin 10 aggravates experimental autoimmune myasthenia gravis through inducing Th2 and B cell responses to AChR. J Neuroimmunol, 113: 10-8.

154. Kawano, Y., Noma, T. 1996. Role of interleukin-2 and interferon-gamma in inducing production of IgG subclasses in lymphocytes of human newborns. Immunology, 88: 40-8.

155. Kawano, Y., Noma, T., Yata, J. 1994. Regulation of human IgG subclass production by cytokines. IFN-gamma and IL-6 act antagonistically in the induction of human IgG1 but additively in the induction of IgG2. J Immunol, 153: 4948-58.

156. de Boer, B.A., Kruize, Y.C., Rotmans, P.J., Yazdanbakhsh, M. 1997. Interleukin-12 suppresses immunoglobulin E production but enhances immunoglobulin $\mathrm{G} 4$ production by human peripheral blood mononuclear cells. Infect Immun, 65: 1122-5. 


\section{Chapter}

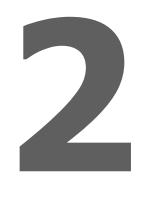

\section{Proteomic analysis of rat tibialis anterior muscles at different stages of experimental autoimmune myasthenia gravis}

Alejandro M. Gomez*, Annelies Vanheel*, Mario Losen, Peter C. Molenaar, Marc H. De Baets, Jean-Paul Noben, Niels Hellings, Pilar Martinez-Martinez

* These authors contributed equally to this work

Journal of Neuroimmunology (2013); 10.1016/j.jneuroim.2013.05.008. 


\section{Abstract}

Myasthenia gravis (MG) is an autoimmune disease in which autoantibodies, most commonly directed against the acetylcholine receptor (AChR), impair neuromuscular transmission and cause muscle weakness. In this study, we utilized two-dimensional difference in-gel electrophoresis (2D-DIGE) to analyze the muscle's proteomic profile at different stages of experimental autoimmune myasthenia gravis (EAMG). We identified twenty-two differentially expressed proteins, mainly related to metabolic and stressresponse pathways. Interestingly, these identified proteins have also been associated with other contraction-impairing muscle pathologies (e.g. inclusion body myositis), suggesting a similar response of the muscle to such conditions. 


\section{Introduction}

Myasthenia gravis (MG) is one of the best characterized antibody-mediated autoimmune diseases, and its symptoms include muscle weakness and fatigability. The autoantibodies in MG are primarily directed to proteins of the neuromuscular junction (NMJ), such as the acetylcholine receptor (AChR-MG, 85\% cases), muscle-specific kinase (MuSK-MG, 10\% cases) and low-density lipoprotein receptor-related protein 4 (Lrp4-MG, 2\% cases) [1, 2]. In AChR-MG, autoantibodies cause extensive damage at the NMJ, mainly by activation of the complement system and by antigenic modulation of the AChR [3]. This autoimmune attack leads to a reduction of AChRs and other AChR-related proteins $[4,5]$, which further contributes to the severity of symptoms. Consequently, such AChR-related proteins could represent novel targets for symptomatic treatments. However, the precise number and identity of muscle proteins affected by the autoimmune attack in MG remains largely unknown.

In recent years, the advent of the two-dimensional difference in-gel electrophoresis (2D-DIGE) technology has allowed a more sensitive and accurate quantification of differential protein expression and/or protein modifications affecting size and charge in biological samples [6]. In this study, we used the experimental autoimmune myasthenia gravis model (EAMG) rat model and 2D-DIGE to evaluate the muscle's proteomic profile at different disease stages of EAMG.

\section{Materials and Methods}

\section{Animals, induction of EAMG and tissue preparation}

Seven-week-old female Lewis rats were obtained from Charles River laboratories (Cologne, Germany). Chronic EAMG was induced by immunization with AChRs purified from $T$. californica, the severity of EAMG symptoms was assessed three times a week with the paw-grip test for muscle weakness as described [7]. Animals were sacrificed between 5 and 8 weeks after immunization according to their disease score, to have a 
representative number of muscles from each score $(0$, no weakness; $0 / 1$, mild weakness after testing; 1, weakness after testing; 2, clinical signs of EAMG present before testing; 3, severe clinical signs of EAMG, moribund). Animals were perfused to obtain blood-free tibialis anterior muscle [5 mM EDTA in PBS pH 7.2, containing Complete Protease Inhibitor Cocktail (Roche, Almere, the Netherlands)]. Muscles were processed to remove their connective membranes and tendons, frozen in liquid nitrogen and subsequently stored at $-80^{\circ} \mathrm{C}$. All experiments were done with permission from the Committee on Animal Welfare of Maastricht University, according to Dutch governmental rules.

\section{$\underline{\text { Protein Extraction }}$}

Proteins were extracted as described [8]. Briefly, muscle samples were lyophilized, crushed (GentleMACS, Miltenyi Biotec, Leiden, the Netherlands) and proteins solubilized before ultracentrifugation. Samples were then desalted and the buffer was exchanged to labeling buffer ( $7 \mathrm{M}$ urea, $2 \mathrm{M}$ thiourea, $4 \% \mathrm{w} / \mathrm{v}$ CHAPS in $30 \mathrm{mM}$ Tris $\mathrm{HCl} \mathrm{pH}$ 8.5) using Amicon Ultra filters (Millipore, 3 kDa cut-off). Protein concentration was determined using the 2D Quant kit (GE Healthcare, Diegem, Belgium) and aliquots were stored at $-80^{\circ} \mathrm{C}$. For Western blotting experiments, additional muscles from animals described in [7] were homogenized with a Mini BeadBeater (Biospec Products, Bartlesville, OK) in lysis buffer (30 mM triethanolamine, $50 \mathrm{mM} \mathrm{NaCl}, 5 \mathrm{mM}$ EDTA, 5 mM EGTA, $50 \mathrm{mM} \mathrm{NaF}, 1 \mathrm{mM} \mathrm{Na}-$ orthovanadate, $1 \mathrm{mM}$ benzamidine, $1 \mathrm{mM}$ Na-tetrathionate, $1 \mathrm{mM}$ PMSF, pH 9.5) containing HALT Protease Inhibitor Cocktail (Thermo Scientific, Rockford, IL) and Triton X$100(1 \%)$.

\section{$\underline{2 D-D I G E}$}

Minimal labeling with N-hydroxysuccinimidyl-ester dyes Cy2, Cy3 and Cy5 (GE Healthcare, Diegem, Belgium) and 2D-GE were performed as described in [9]. CyDye-labeled 2D-DIGE gels were scanned on the Ettan DIGE imager (GE Healthcare). Gel images from all three CyDyes were loaded into DeCyder 7.0 software (GE Healthcare) and analyzed. Statistical significance was calculated using analysis of variance (ANOVA) and multiple comparison test. Spots present in $85 \%$ of the gel images, and with $p \leq 0.05$, were considered for further analysis. 


\section{Spotpicking, protein digestion and identification}

For spot picking (ProPicll, Isogen Life Science, PW De Meern, The Netherlands) a $12.5 \%$ acrylamide gel was loaded with $200 \mu \mathrm{g}$ of an unlabeled internal standard and $50 \mu \mathrm{g}$ of the Cy2 labeled internal standard. In-gel digestion using trypsin (Promega, Leiden, the Netherlands) [10] was performed followed by protein identification by mass spectrometry [9].

\section{Western blotting}

To validate the results obtained by 2D-DIGE, we performed Western blotting both with muscle extracts used for the 2D-DIGE analysis and muscle extracts from control and EAMG animals characterized in a previous study [7]. Protein extracts were separated by SDS polyacrylamide gel electrophoresis (SDS-PAGE) and membranes were incubated with either rabbit anti- $\beta$-enolase (W-25, Santa Cruz Biotechnology, CA; $1: 800)$ or goat anticarbonic anhydrase III (CAIII) (E-19, Santa Cruz Biotechnology; 1:800), and mouse antiGAPDH (10R-G109a, Fitzgerald, MA; 1:5000000). Secondary antibodies were donkey antimouse IgG IRDye 680, goat anti-rabbit IgG IRDye 800 and donkey anti-goat IgG IRDye 800 (926-32222, 926-32211 and 926-32214 respectively; LI-COR Biosciences, Lincoln, NE), diluted 1:10000. Membranes were imaged with Odyssey Infrared Imaging System (LI-COR Biosciences) and bands were quantified with ImageJ software (mean intensity), normalizing for GAPDH mean intensity. Protein levels were compared between groups with an unpaired $t$-test using GraphPad Prism 4 software.

\section{$\underline{\text { Results }}$}

A 2D-DIGE proteomics experiment was performed to identify proteins that are affected at various disease stages of EAMG. Proteins were extracted from blood-free tibialis anterior muscles from each of the experimental groups (control, clinical scores $0,0-1,1,2,3 ; n=$ 4). A 2D spotmap with an average of 3342 protein spots per sample was obtained and analyzed in the DeCyder 7.0 software. 


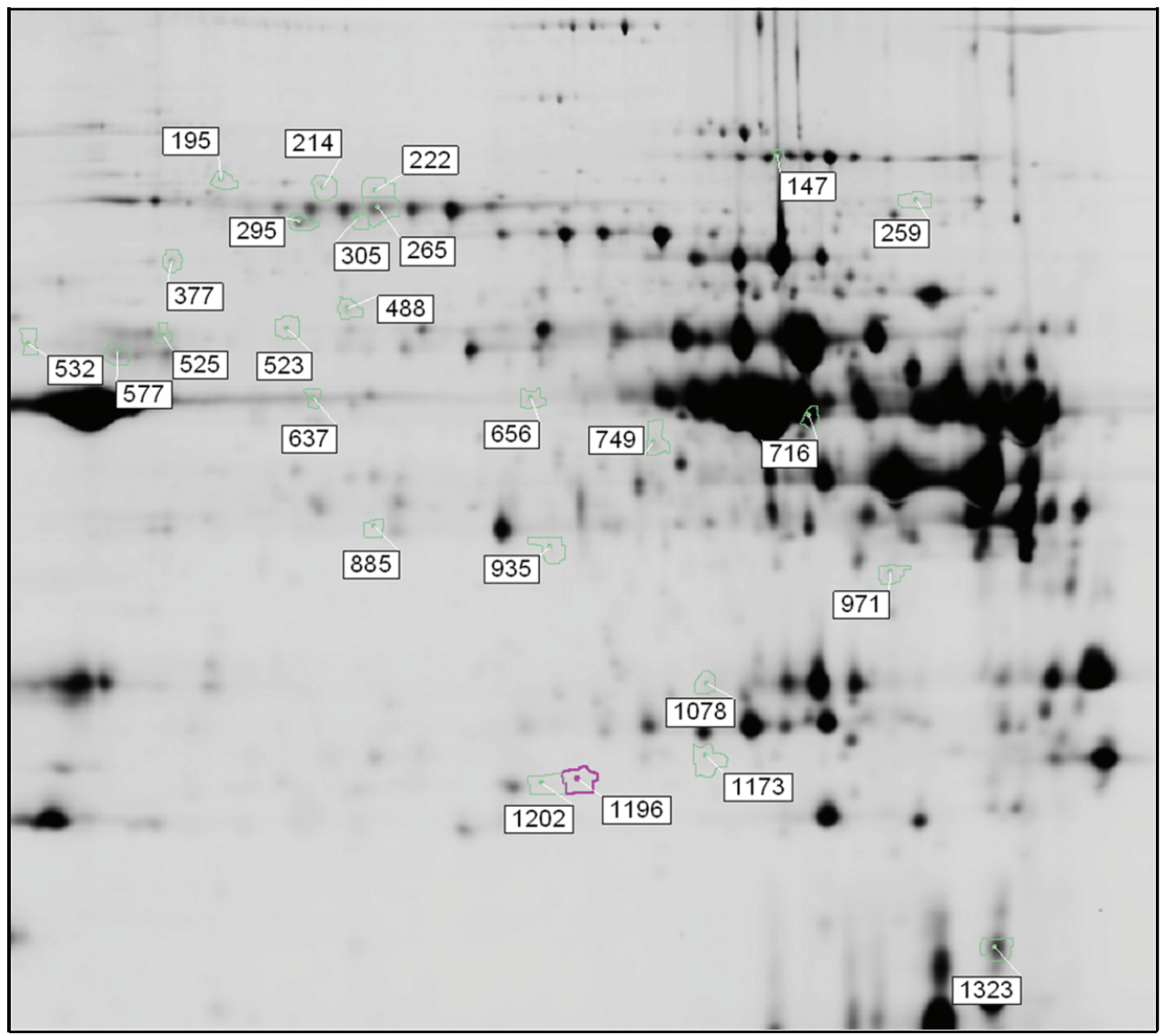

Figure 2.1S. 2D-DIGE gel image. The twenty-six protein spots that are differentially expressed in EAMG are shown (1w-ANOVA, $p \leq 0.05$ ). Seventeen of these spots were successfully identified by mass spectrometry (significant MASCOT and SEQUEST scores). 
Table 2.1. Protein identification

\begin{tabular}{|c|c|c|c|c|}
\hline $\begin{array}{l}\text { Spot } \\
\text { number }\end{array}$ & $\begin{array}{l}1 w- \\
\text { ANOVA }\end{array}$ & $\begin{array}{l}\text { Relative } \\
\text { fluorescence } \\
\text { intensity }\end{array}$ & $\begin{array}{l}\text { Protein } \\
\text { identification }\end{array}$ & Protein accession numbers \\
\hline \multirow[t]{3}{*}{147} & 0.0233 & decreased & $\begin{array}{l}\text { Pyruvate kinase } \\
\text { isozymes } \mathrm{M} 1 / \mathrm{M} 2\end{array}$ & IPI00231929 \\
\hline & & & Serotransferrin & IPI00679202 \\
\hline & & & $\begin{array}{l}\text { Aconitate } \\
\text { hydratase, } \\
\text { mitochondrial }\end{array}$ & IPI00421539 IPI00950672 \\
\hline \multirow[t]{2}{*}{195} & 0.0255 & $\begin{array}{l}\text { depends on } \\
\text { experimental } \\
\text { group }\end{array}$ & Myosin-4 & IPI00476111 IPI00948572 \\
\hline & & & $\begin{array}{l}\text { mitochondrial } \\
\text { inner membrane } \\
\text { protein }\end{array}$ & IPI00364895 IPI00566985 IPI00777695 IPI00948331 \\
\hline 214 & 0.015 & decreased & $\begin{array}{l}\text { mitochondrial } \\
\text { inner membrane } \\
\text { protein }\end{array}$ & IPI00364895 IPI00566985 IPI00948331 \\
\hline 265 & 0.00177 & decreased & Serum albumin & IPI00191737 \\
\hline 295 & 0.0318 & decreased & $\begin{array}{l}\text { Dihydrolipoylly } \\
\text { sine-residue } \\
\text { acetyltransferase } \\
\text { component of } \\
\text { pyruvate } \\
\text { dehydrogenase } \\
\text { complex, } \\
\text { mitochondrial } \\
\text { Serum albumin }\end{array}$ & IPI00191737 \\
\hline 305 & 0.000398 & decreased & Serum albumin & IPI00191737 \\
\hline 377 & 0.0131 & decreased & $\begin{array}{l}60 \mathrm{kDa} \text { heat shock } \\
\text { protein, } \\
\text { mitochondrial }\end{array}$ & IPI00339148 \\
\hline 488 & 0.0406 & decreased & $\begin{array}{l}\text { Dihydrolipoylly } \\
\text { sine-residue } \\
\text { succinyltrans } \\
\text { ferase component } \\
\text { of 2-oxoglutarate } \\
\text { dehydrogenase } \\
\text { complex, } \\
\text { mitochondrial }\end{array}$ & IPI00551702 IPI00948493 \\
\hline 523 & 0.0373 & $\begin{array}{l}\text { depends on } \\
\text { experimental } \\
\text { group }\end{array}$ & $\begin{array}{l}\text { Pyruvate kinase } \\
\text { isozymes M1/M2 }\end{array}$ & IPI00231929 \\
\hline \multirow[t]{2}{*}{577} & 0.0241 & decreased & Beta-enolase & IPI00231631 \\
\hline & & & $\begin{array}{l}\text { Cytochrome b-c1 } \\
\text { complex subunit } \\
1 \text {, mitochondrial }\end{array}$ & IPI00471577 \\
\hline
\end{tabular}




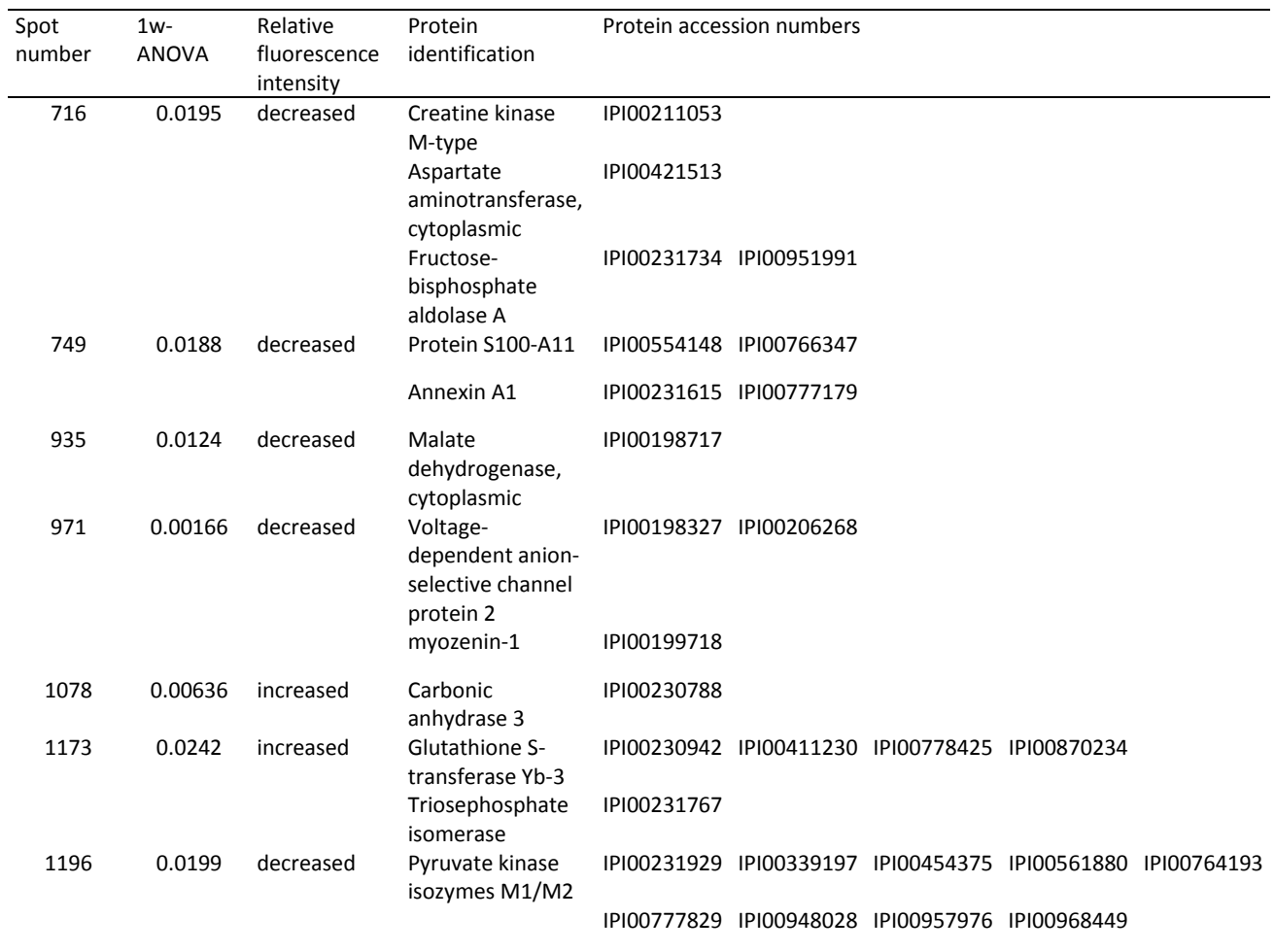

Muscle proteome was analyzed, differential protein spots were picked and in-gel digestion was performed. Proteins were identified by mass spectrometry. For each spot: the 1way-ANOVA value, spot relative fluorescence intensity, protein identification, and protein accession numbers are presented.

Twenty-six protein spots with significantly different fluorescence intensities, at least between two of the experimental groups, were identified (1w-ANOVA, $p \leq 0.05$ ) (Fig. 2.1S). Unequivocal protein identification by mass spectrometry was achieved for seventeen of the selected spots. There were spots containing more than one protein due to co-migration, so a total of twenty-seven proteins were identified. In this study, a maximum of three proteins per spot were found. Two proteins, serum albumin and pyruvate kinase, were present in three spots, leading to the identification of twenty two unique proteins in EAMG (Table 2.1).

As expected, most identified proteins detected by 2D-DIGE were cytoplasmic, probably due to the bias of detecting soluble proteins using this technique. We observed 
changes by 2D-DIGE in $\beta$-enolase and carbonic anhydrase III (CAIII) (Fig. 2.1A, B), and quantified their protein levels in control and EAMG animals by Western blotting. Protein levels of $\beta$-enolase were significantly reduced in EAMG muscles compared with controls ( $n$ $=6$ for both groups, $p<0.05$ ), with an average reduction of approximately 25\% (Fig. 2.1C). CAIII protein levels were increased in all EAMG stages when quantified by immunoblotting (data not shown). Interestingly, only severely affected animals (score 3 ) had significantly higher levels of CAIII protein compared with controls. In such muscles, average levels of CAIII were increased by approximately $35 \%$ compared with control muscles $(p<0.01 ; n=5$ for score 3 EAMG and $n=10$ for control) (Fig. 2.1D).

A

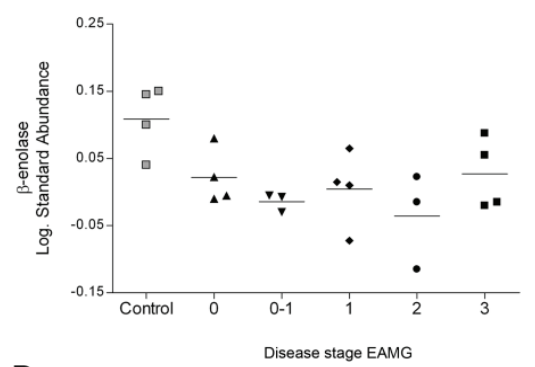

B

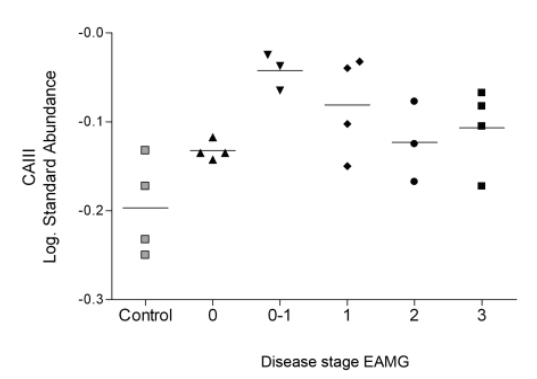

C
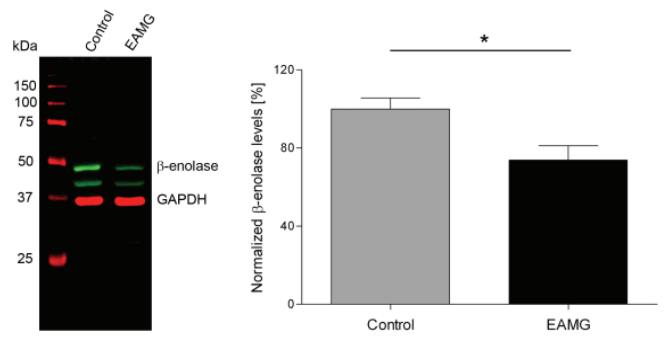

D
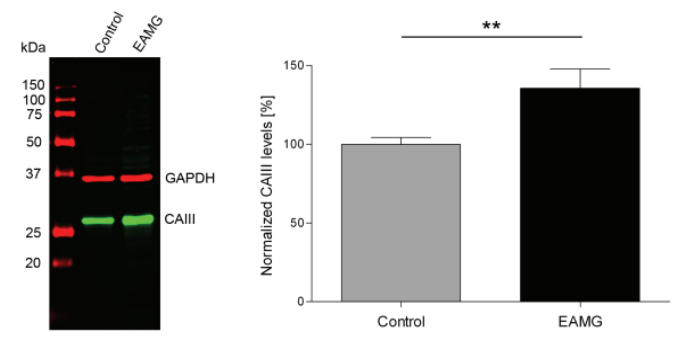

Figure 2.1. $\beta$-enolase and CAIII protein levels in tibialis anterior muscles of EAMG and control rats. Both a reduction of $\beta$-enolase (A) and an increase of CAIII (B) levels were detected by 2D-DIGE in all EAMG disease stages. Reduction in $\beta$-enolase protein levels were corroborated by Western blotting (C). A significant reduction in muscle homogenates from EAMG animals compared with controls ( ${ }^{*} \mathrm{p}<0.05, \mathrm{n}=6$ per condition) was observed. CAlll protein levels measured by Western blotting (D) were significantly increased in muscle homogenates from severely affected EAMG animals compared with controls ( $* * p<0.01$; score 3 EAMG, $n=5$, control $n=10$ ). $\beta$-enolase ( $C$ upper green band) / CAlll intensity ( $D$ green band) were normalized with GAPDH intensity (red band). 


\section{Discussion}

We analyzed the muscle proteome at different EAMG disease stages by 2D-DIGE and identified twenty-two differentially expressed proteins. The majority of these identified proteins are involved in metabolic pathways (glycolysis and the citric-acid cycle), while others are related to cellular-stress responses (e.g. glutathione S-transferase Yb3, $60 \mathrm{KDa}$ heat shock protein), or are contractile proteins (myosin-4 and myozenin-1). Overall, we observed a reduction of the glycolytic capacity and of fast-twitch myosin isoforms in EAMG tibialis anterior muscles, which suggests a switch from fast- to slow-twitch fibers. Similar proteomic profiles were previously described in conditions that impair muscle contraction both in animals and in human diseases, such as denervation [11, 12], inclusion body myositis [13], immobilization [14] and aging [15]. In such studies, relatively few differentially expressed proteins were identified (between 17 and 73), most of them also related to cellular-stress responses and to changes in the type of muscle fibers. Therefore, it appears that the most evident protein alterations in EAMG are a consequence of the impaired muscle-nerve signaling and, possibly, of the atrophy (or loss) of fast-twitch fibers; as it was previously demonstrated in muscle biopsies from MG patients [16-18]. In this connection it might be relevant that enhancing the response of fast-twitch muscle cells with a selective troponin activator improves muscle strength in EAMG [19].

Most of the proteins found in our study are not specific for MG, since they are also affected in other pathological (and physiological) conditions of the muscle. Nonetheless, $\beta$-enolase and CAIII have been associated with muscle regeneration and autoimmunity respectively. $\beta$-enolase is a muscle-specific metabolic enzyme very sensible to physiological stimuli [20], with an important role in developing and regenerating muscles [21]. Moreover, its deficiency leads to severe myalgias, muscle weakness and fatigability in affected individuals [22]. CAIII is a muscle-specific enzyme that catalyzes the hydration of carbon dioxide and can protect the cell from oxidative damage [23]. It has been described as an auto-antigen in several autoimmune diseases, e.g. rheumatoid arthritis and systemic lupus erythematosus [24], and its expression is reduced in pectoralis muscle biopses of MG patients [25]. The discrepancy in CAlll expression between our experiment (increased) and MG biopses (decreased) is probably explained by differences 
in the experimental design. In this regard, timing seems essential because it has been reported that CAIII levels are reduced immediately after denervation, but they subsequently increase over basal levels six days after the procedure [12].

The NMJ area, with a width of $10 \mu \mathrm{m}$, is no more than $1 / 3000$ of the $30 \mathrm{~mm}$ total length of the tibialis anterior fiber and, even in such an imaginary transverse $10 \mu \mathrm{m}$ section, the NMJ proteins would still be vastly outnumbered by the proteins of the muscle. Therefore, it is not unexpected that we could not identify any changes in well-known NMJrelated protein between EAMG and control muscles [26, 27]. Moreover, membrane proteins are considerably less abundant than cytoplasmic proteins and, since they usually have several hydrophobic domains, they are poorly soluble in the aqueous buffers required for isoelectric focusing [28, 29]. Furthermore, there is high inter-individual variation within the EAMG model, which also limits the robustness of 2D-DIGE for detecting differentially expressed proteins, especially those present at low quantities.

At present, the response of muscle fibers to the autoimmune attack in MG remains poorly understood. This study describes alterations in cytoplasmic proteins that are not intuitively considered to be involved in the pathogenesis of MG, and it suggests that AChR-MG shares similar intracellular disease mechanisms with other muscle pathologies. 


\section{$\underline{\text { References }}$}

1. Silvestri, N.J., Wolfe, G.I. 2012. Myasthenia gravis. Semin Neurol, 32: 215-26.

2. Richman, D.P. 2012. Antibodies to low density lipoprotein receptor-related protein 4 in seronegative myasthenia gravis. Arch Neurol, 69: 434-5.

3. Gomez, A.M., Van Den Broeck, J., Vrolix, K., Janssen, S.P., Lemmens, M.A., Van Der Esch, E., Duimel, H., Frederik, P., Molenaar, P.C., Martinez-Martinez, P. et al. 2010. Antibody effector mechanisms in myasthenia gravis-pathogenesis at the neuromuscular junction. Autoimmunity, 43: 353-70.

4. Martinez-Martinez, P., Losen, M., Duimel, H., Frederik, P., Spaans, F., Molenaar, P., Vincent, A., De Baets, M.H. 2007. Overexpression of rapsyn in rat muscle increases acetylcholine receptor levels in chronic experimental autoimmune myasthenia gravis. Am J Pathol, 170: 644-57.

5. Conti-Fine, B.M., Milani, M., Kaminski, H.J. 2006. Myasthenia gravis: past, present, and future. J Clin Invest, 116: 2843-54.

6. Lilley, K.S., Friedman, D.B. 2004. All about DIGE: quantification technology for differentialdisplay 2D-gel proteomics. Expert Rev Proteomics, 1: 401-9.

7. Gomez, A.M., Vrolix, K., Martinez-Martinez, P., Molenaar, P.C., Phernambucq, M., van der Esch, E., Duimel, H., Verheyen, F., Voll, R.E., Manz, R.A. et al. 2011. Proteasome inhibition with bortezomib depletes plasma cells and autoantibodies in experimental autoimmune myasthenia gravis. J Immunol, 186: 2503-13.

8. Sizova, D., Charbaut, E., Delalande, F., Poirier, F., High, A.A., Parker, F., Van Dorsselaer, A., Duchesne, M., Diu-Hercend, A. 2007. Proteomic analysis of brain tissue from an Alzheimer's disease mouse model by two-dimensional difference gel electrophoresis. Neurobiol Aging, 28: 357-70.

9. Vanheel, A., Daniels, R., Plaisance, S., Baeten, K., Hendriks, J.J., Leprince, P., Dumont, D., Robben, J., Brone, B., Stinissen, P. et al. 2012. Identification of protein networks involved in the disease course of experimental autoimmune encephalomyelitis, an animal model of multiple sclerosis. PLoS One, 7: e35544.

10. Shevchenko, A., Wilm, M., Vorm, O., Mann, M. 1996. Mass spectrometric sequencing of proteins silver-stained polyacrylamide gels. Anal Chem, 68: 850-8.

11. Li, Z.B., Lehar, M., Samlan, R., Flint, P.W. 2005. Proteomic analysis of rat laryngeal muscle following denervation. Proteomics, 5: 4764-76.

12. Isfort, R.J., Hinkle, R.T., Jones, M.B., Wang, F., Greis, K.D., Sun, Y., Keough, T.W., Anderson, N.L., Sheldon, R.J. 2000. Proteomic analysis of the atrophying rat soleus muscle following denervation. Electrophoresis, 21: 2228-34.

13. Parker, K.C., Kong, S.W., Walsh, R.J., Salajegheh, M., Moghadaszadeh, B., Amato, A.A., Nazareno, R., Lin, Y.Y., Krastins, B., Sarracino, D.A. et al. 2009. Fast-twitch sarcomeric and glycolytic enzyme protein loss in inclusion body myositis. Muscle Nerve, 39: 739-53.

14. Isfort, R.J., Wang, F., Greis, K.D., Sun, Y., Keough, T.W., Bodine, S.C., Anderson, N.L. 2002. Proteomic analysis of rat soleus and tibialis anterior muscle following immobilization. $J$ Chromatogr B Analyt Technol Biomed Life Sci, 769: 323-32.

15. Ohlendieck, K. 2011. Proteomic Profiling of Fast-To-Slow Muscle Transitions during Aging. Front Physiol, 2: 105.

16. Martignago, S., Fanin, M., Albertini, E., Pegoraro, E., Angelini, C. 2009. Muscle histopathology in myasthenia gravis with antibodies against MuSK and AChR. Neuropathol Appl Neurobiol, 35: 103-10.

17. Zamecnik, J., Vesely, D., Jakubicka, B., Cibula, A., Pitha, J., Schutzner, J., Mazanec, R. 2009. 
Atrophy of type II fibres in myasthenia gravis muscle in thymectomized patients: steroidinduced change with prognostic impact. J Cell Mol Med, 13: 2008-18.

18. Coers, C., Telerman-Toppet, N. 1976. Morphological and histochemical changes of motor units in myasthenia. Ann N Y Acad Sci, 274: 6-19.

19. Russell, A.J., Hartman, J.J., Hinken, A.C., Muci, A.R., Kawas, R., Driscoll, L., Godinez, G., Lee, K.H., Marquez, D., Browne, W.F.t. et al. 2012. Activation of fast skeletal muscle troponin as a potential therapeutic approach for treating neuromuscular diseases. Nat Med, 18: 452-5.

20. Keller, A., Rouzeau, J.D., Farhadian, F., Wisnewsky, C., Marotte, F., Lamande, N., Samuel, J.L., Schwartz, K., Lazar, M., Lucas, M. 1995. Differential expression of alpha- and betaenolase genes during rat heart development and hypertrophy. Am J Physiol, 269: H184351.

21. Merkulova, T., Dehaupas, M., Nevers, M.C., Creminon, C., Alameddine, H., Keller, A. 2000. Differential modulation of alpha, beta and gamma enolase isoforms in regenerating mouse skeletal muscle. Eur J Biochem, 267: 3735-43.

22. Comi, G.P., Fortunato, F., Lucchiari, S., Bordoni, A., Prelle, A., Jann, S., Keller, A., Ciscato, P., Galbiati, S., Chiveri, L. et al. 2001. Beta-enolase deficiency, a new metabolic myopathy of distal glycolysis. Ann Neurol, 50: 202-7.

23. Raisanen, S.R., Lehenkari, P., Tasanen, M., Rahkila, P., Harkonen, P.L., Vaananen, H.K. 1999. Carbonic anhydrase III protects cells from hydrogen peroxide-induced apoptosis. FASEB J, 13: 513-22.

24. Robert-Pachot, M., Desbos, A., Moreira, A., Becchi, M., Tebib, J., Bonnin, M., Aitsiselmi, T., Bienvenu, J., Fabien, N. 2007. Carbonic anhydrase III: a new target for autoantibodies in autoimmune diseases. Autoimmunity, 40: 380-9.

25. Du, A.L., Ren, H.M., Lu, C.Z., Tu, J.L., Xu, C.F., Sun, Y.A. 2009. Carbonic anhydrase III is insufficient in muscles of myasthenia gravis patients. Autoimmunity, 42: 209-15.

26. Guyon, T., Levasseur, P., Truffault, F., Cottin, C., Gaud, C., Berrih-Aknin, S. 1994. Regulation of acetylcholine receptor alpha subunit variants in human myasthenia gravis. Quantification of steady-state levels of messenger RNA in muscle biopsy using the polymerase chain reaction. J Clin Invest, 94: 16-24.

27. Asher, O., Fuchs, S., Zuk, D., Rapaport, D., Buonanno, A. 1992. Changes in the expression of mRNAs for myogenic factors and other muscle-specific proteins in experimental autoimmune myasthenia gravis. FEBS Lett, 299: 15-8.

28. Santoni, V., Molloy, M., Rabilloud, T. 2000. Membrane proteins and proteomics: un amour impossible? Electrophoresis, 21: 1054-70.

29. Tan, S., Tan, H.T., Chung, M.C. 2008. Membrane proteins and membrane proteomics. Proteomics, 8: 3924-32. 


\section{Chapter}

\section{Silencing of Dok-7 in adult rat muscle increases susceptibility to experimental autoimmune myasthenia gravis}

Alejandro M. Gomez, Jo Stevens, Mario Losen, Peter C. Molenaar, Hans Duimel, Fons Verheyen, Marc H. De Baets, Pilar Martinez-Martinez 


\section{$\underline{\text { Abstract }}$}

Myasthenia gravis (MG) is an autoimmune disease mediated by autoantibodies that target proteins at the neuromuscular junction (NMJ); primarily the acetylcholine receptor (AChR) or the muscle-specific kinase (MuSK). In MG, the muscle responds to an autoimmune attack by up-regulating proteins that can compensate for the loss of function (e.g. AChR, MuSK, rapsyn, Dok-7). Since Dok-7 is essential for the full activation of MuSK and consequently for dense clustering of AChRs, we hypothesized that reduced levels of Dok-7 increases the susceptibility to passive transfer experimental autoimmune myasthenia gravis (EAMG) and impairs recovery after the antibody attack. Dok-7 expression was silenced by transfecting shRNA coding plasmids into the tibialis anterior muscle of adult rats by in vivo electroporation. Mild/subclinical MG was subsequently induced with 5 pmol/100 g body weight of anti-AChR monoclonal antibody (mAb) 35. Neuromuscular transmission was significantly impaired in Dok-7-silenced legs when compared with the contralateral control legs. This was correlated with a reduction of AChR levels ( $25 \%)$ in Dok-7 silenced muscles, as measured by quantitative immunohistochemistry. Furthermore, we examined the effects of Dok-7 silencing in the recovery from passive transfer EAMG (20 pmol mAb35/100 g body weight) by performing electromyography 2, 7, or 14 days after electroporation. Neuromuscular transmission was equally impaired in both Dok-7 silenced and non-silenced legs at all time points studied. These results suggest that a reduced expression of Dok-7 is not fundamental for the recovery of the NMJ after damage but may play a role in the susceptibility to EAMG, by rendering AChR clusters less resistant to the autoantibody attack. 


\section{Introduction}

The neuromuscular junction (NMJ) is the synaptic connection between a motor nerve terminal and the skeletal muscle membrane. For an efficient neuromuscular transmission to occur, acetylcholine receptors (AChRs) must be densely clustered on the top of postsynaptic-membrane folds facing the nerve terminal, in a process primarily mediated by the activation of muscle-specific kinase (MUSK). To be activated, MuSK requires two signals: one from nerve-derived agrin and one from the muscle cytoplasmic protein downstream of kinase 7 (Dok-7) [1, 2]. Once released from the nerve terminal, agrin binds to its receptor, the low-density lipoprotein receptor-related protein 4 (Lrp4), and this, in association with basal activation by Dok-7, activates MuSK at the muscle's postsynaptic membrane. This ultimately leads to dense AChR clustering by the receptor associated protein (rapsyn). All knock-out models of the main AChR-clustering proteins (rapsyn, MuSK, Dok-7 and Lrp4) die at birth due to an absence of mature NMJs that causes respiratory failure [2-5], demonstrating the crucial role of each of these proteins during embryonic synaptogenesis $[2,6,7]$.

The adaptor protein Dok-7 is the most recently described member of the AChRclustering pathway, and it is localized in the intracellular face of the postsynaptic membrane in close association with MuSK. Recessive mutations in the DOK7 gene are a frequent cause of congenital myasthenic syndromes (CMS) [8, 9]. Patients with such mutations develop a "limb girdle" pattern of muscle weakness at an early age. In muscle biopsies of these patients simplified endplates with reduced postsynaptic folding and impaired neuromuscular transmission are found [10-12]. These observations suggest the possibility that Dok-7 could also have an important role in the pathophysiology (and treatment) of acquired diseases that affect the NMJ in adulthood, such as myasthenia gravis (MG).

In AChR-MG, autoantibodies cause complement-mediated damage at the NMJ, leading to loss of AChR and AChR-associated proteins [13]. Loss of synaptic proteins may impair the clustering of newly-synthesized AChR and delay the NMJ recovery from antibody-mediated damage. Thus, it can contribute to the severity of symptoms in MG. 
Silencing the expression of rapsyn in adult muscles with small interfering RNAs (siRNAs) impaired neuromuscular transmission [14], while its over-expression protected the NMJ from antibody-mediated damage in the experimental autoimmune myasthenia gravis model (EAMG) [15]. In addition, adult NMJs were disrupted when MuSK expression was reduced by siRNAs [16], or by its conditional inactivation in transgenic mice [17], which further implies an important role for AChR-associated proteins in the maintenance of the NMJ.

In order to obtain further insight into the role of Dok-7 in adult NMJs, we studied the effect of down-regulation of Dok-7 by RNA interference in control and EAMG muscles. Adult muscles of rats were transfected by in vivo electroporation using the mammalian expression vector pSUPER that directs the synthesis of short hairpin RNA (shRNA) transcripts. The results suggest that reduced Dok-7 expression is not crucial for the recovery from the damage caused by autoantibodies, but it increases the susceptibility to EAMG.

\section{Materials and Methods}

\section{shRNA constructs and evaluation of silencing efficiency}

Dok-7 siRNA sequence selection was performed following Tuschl rules [18, 19], using the SiRNA design interface from the University of Hong Kong (http://i.cs.hku.hk/ sirna/software/sirna.php). A total of 5 different siRNAs, targeting nucleotides sequences conserved between rat (NM_001130062) and mouse (NM_172708) Dok-7, plus 1 scrambled siRNA (negative control designed by random mutations in the sequence of Dok-7 siRNA5), were cloned in the PSUPER vector [20] and subsequently verified by sequencing as described [14].

Dok-7 silencing efficiency was measured in vitro by co-transfecting the shRNAPSUPER and scrambled constructs with a rat Dok7-GFP expression vector (rat Dok-7, NM_001130062 in a pEGFP-N1 vector, cloned by Geneart AG, Regensburg, Germany) in HEK 293 cells. HEK cells were cultured in DMEM medium with 10\% heat-inactivated fetal bovine serum (iFBS) and transfected with $2.5 \mu \mathrm{g}$ of each plasmid using the 
polyethylenimine (PEI) transfection method [21], in the presence of D-glucose $(6.5 \% \mathrm{w} / \mathrm{v})$. Dok-7 silencing efficiency in transfected cells was estimated by measuring GFP intensity with an Olympus IX-81 inverted fluorescence microscope (Olympus Nederland B.V., Zoeterwoude, the Netherlands), and by quantification of Dok-7 protein levels in cell extracts by Western blotting. Dok-7 intensity levels were quantified using ImageJ software (http://rsb.info.nih.gov/ij/); each condition was analyzed in triplo.

C2C12 myoblast cells were co-transfected with Dok-7 shRNAs and Dok7-GFP using a NEON transfection system (Invitrogen, Paisley, UK), and were cultured in DMEM medium plus $15 \%$ iFBS until confluence. Cells were then switched to DMEM medium plus $5 \%$ iFBS for differentiation and, once myotubes were formed, AChR clusters were stained with alpha-bungarotoxin Alexa 594 (B-13423, Invitrogen, Paisley, UK; 1:1000 diluted), as described [9]. A total surface of $4.25 \mathrm{~mm}^{2}$ was imaged per condition (from 3 replicates) with an Olympus IX71 fluorescence microscope (Olympus UK, Southend-on-Sea, UK) and the average AChR cluster length was estimated with ImageJ.

Based on their in vitro silencing efficiency, we selected 2 shRNAs, in addition to the scrambled shRNA, for muscle electroporation in vivo (Table 3.1).

Table 3.1. Primer sequences for silencing Dok-7 expression using pSUPER plasmid.

\begin{tabular}{|l|l|}
\hline shRNA1 (S-1) fwd & 5'-GATCCCCGCAGATCAGCTTCCTGTTTttcaagagaAAACAGGAAGCTGATCTGCTTTTTGGAAA-3' \\
\hline shRNA1 (S-1) rev & 5'-AGCTTTTCCAAAAAGCAGATCAGCTTCCTGTTTtctcttgaaAAACAGGAAGCTGATCTGCGGG-3' \\
\hline shRNA5 (S-5) fwd & 5'-GATCCCCGATCAGCTTCCTGTTTGACttcaagagaGTCAAACAGGAAGCTGATCTTTTTGGAAA-3' \\
\hline shRNA5 (S-5) rev & 5'-AGCTTTTCCAAAAAGATCAGCTTCCTGTTTGACtctcttgaaGTCAAACAGGAAGCTGATCGGG-3' \\
\hline Scrambled shRNA fwd & 5'-GATCCCCGAGATGGTCCCTGTTTGACAGttcaagagaCTGTCAAACAGGGACCATCTCTTTTTA-3' \\
\hline Scrambled shRNA rev & 5'-AGCTTAAAAAGAGATGGTCCCTGTTTGACAGtctcttgaaCTGTCAAACAGGGACCATCTCGGG-3' \\
\hline
\end{tabular}

\section{Animals and tissue processing}

7-week-old female Lewis rats were obtained from Charles River laboratories (Cologne, Germany), with permission from the Committee on Animal Welfare, according to Dutch governmental rules. For electroporation, induction of passive-transfer EAMG and electromyography, animals were anesthetized and later euthanized as described [14]. Frozen muscles were cut in a cryostat (CM3050 S, Leica Biosystems, Wetzlar, Germany) in $10 \mu \mathrm{m}$ sections (for immunohistochemistry and immunofluorescence) and $50 \mu \mathrm{m}$ sections (for protein and RNA extraction). For electron microscopy analysis, animals were 
euthanized as previously described $[15,22]$ with the following modifications: fixation buffer was $3 \%$ glutaraldehyde plus $1.4 \%$ sucrose buffered in $0.09 \mathrm{M} \mathrm{KH}_{2} \mathrm{PO}_{4}, \mathrm{pH} 7.4$; a mix of ketamine $(100 \mathrm{mg} / \mathrm{kg}) / x y l a z i n e(15 \mathrm{mg} / \mathrm{kg})$ was used for anesthesia; and fixed muscles were sectioned at $500 \mu \mathrm{m}$ with a VT1200S vibratome (Leica Biosystems, Wetzlar, Germany).

\section{Electroporation and optimization of Dok-7 silencing in vivo}

Dok-7-shRNAs plasmids were prepared with the Qiagen Gigaprep DNA purification kit (cat. 12191), according to manufacturer's manual, and dissolved at a concentration of $2 \mu \mathrm{g} / \mu \mathrm{l}$ in $0.9 \% \mathrm{NaCl}$. Electroporation of the tibialis anterior muscle was performed with the same parameters as described previously [14, 15], using the Electro Square Porator ECM 830 (BTX, San Diego, USA). Dok-7-silencing was performed by injecting muscles with $50 \mu \mathrm{g}$ of each of the two silencing vectors (S-1 and S-5, see table 3.1) and, for the contralateral control leg, $100 \mu \mathrm{g}$ of the scrambled shRNA vector in a final volume of $50 \mu \mathrm{l}$. To estimate the transfection and silencing efficiency, a group of 18 rats were injected with a DNA solution containing $100 \mu \mathrm{g}$ of S-1 or S-5, plus $50 \mu \mathrm{g}$ of pVAX1-LacZ in a volume of $75 \mu \mathrm{l}$. These rats were later sacrificed at 7, 14 or 28 days after electroporation ( 3 animals per time point). The reporter gene ß-galactosidase was highly expressed 7 days after electroporation in approximately $60 \%$ of the muscle fibers and it was still detectable at day 28 after electroporation (Fig. 3.1A). Dok-7 protein levels were 16\% reduced in Dok-7 silenced legs compared with non-silenced legs 28 days after electroporation. Importantly, this reduction was not observed at early time points (supplementary Fig. 3.1), indicating that the in vivo down-regulation of Dok-7 with shRNAs is likely to require, at least, 14 days to manifest, as previously described also for down-regulation of MuSK [16]. 
A

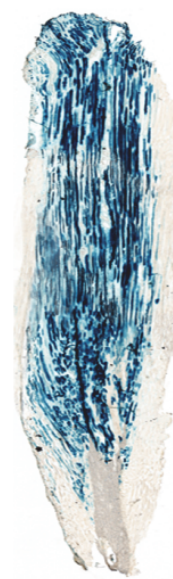

Day 7

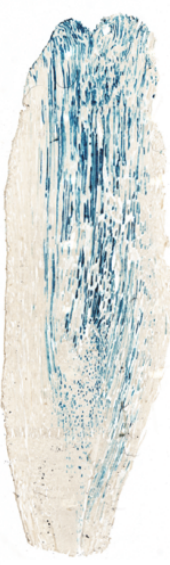

Day 14

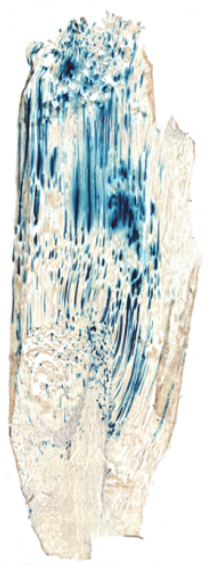

Day 28

B

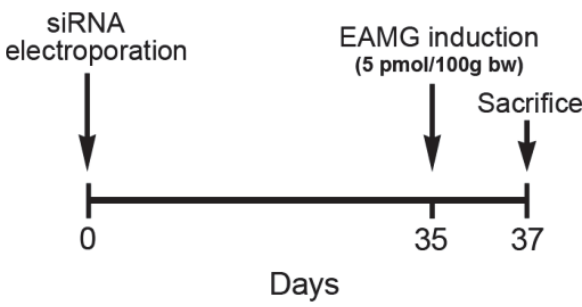

C

$$
\text { SiRNA }
$$
electroporation

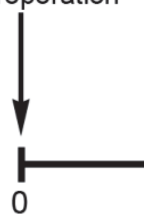

EAMG induction

(20 pmol/100g bw)

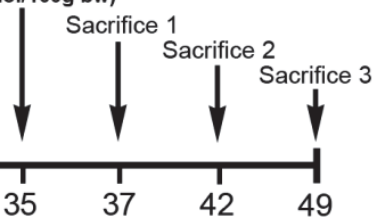

Days

Figure 3.1. (A) In vivo electroporation of shRNA plasmids. The transfection efficiency was analyzed using $\mathrm{X}$-gal as a substrate for the reporter $\beta$-galactosidase. The sections are spaced $500 \mu \mathrm{m}$. ßgalactosidase expression was observed in muscle fibers at all analyzed time points $(7,14$ and 28 days after electroporation), indicating stable plasmid expression. Scheme of the experimental set up for investigating the effects of in vivo Dok-7 silencing in (B) the susceptibility to EAMG, and (C) the recovery from autoantibody damage in EAMG. 


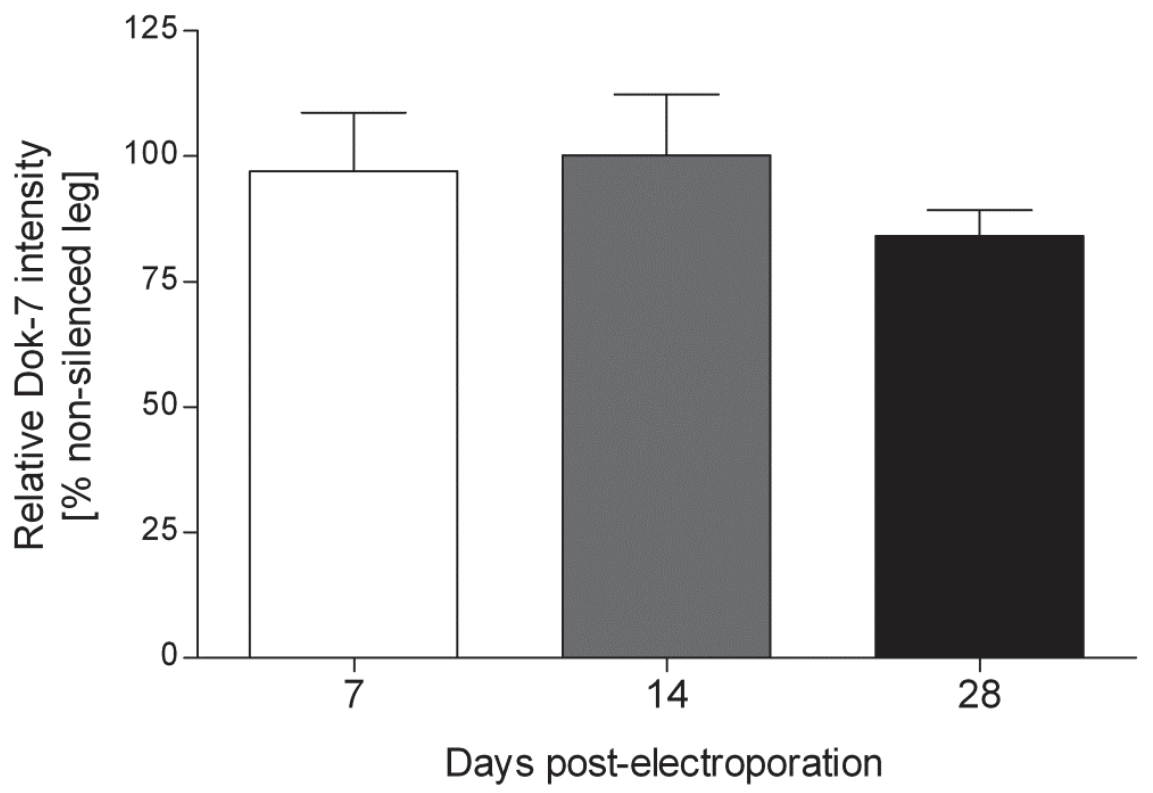

Figure 3.1S. In vivo silencing efficiency of Dok-7 shRNAs by muscle electroporation. Dok-7 levels were analyzed by Western blotting in muscle protein extracts from animals electroporated with Dok-7 shRNAs at 7, 14 or 28 days after electroporation ( $n=3$ per time point). Relative Dok-7 and GAPDH intensities were quantified by Image and results are expressed as the percentage of Dok-7/GAPDH ratio in the Dok-7 silenced leg compared with the contralateral non-silenced leg. Dok-7 protein levels were not reduced at 7 or 14 days after electroporation, but they were decreased by $16 \%$ in Dok-7 silenced legs, compared with the contralateral no-silenced leg, at day 28.

\section{Induction of EAMG and experimental set-up}

The effects of Dok-7 silencing at the NMJ were subsequently investigated in EAMG animals following two different experimental set-ups. In both cases, animals were electroporated on day 0 and, on day 35, EAMG was induced by intraperitoneal injection of anti-AChR monoclonal antibody (mAb) 35 [23], while control animals were untreated. One EAMG group received $5 \mathrm{pmol} / 100 \mathrm{~g}$ body weight (bw) mAb35 (subclinical dose, see supplementary Fig. 3.2) and was sacrificed $48 \mathrm{~h}$ later ( $n=5$ EAMG and $n=3$ control rats) in order to evaluate the importance of Dok-7 for the susceptibility to EAMG (Fig. 3.1B). The other EAMG group received $20 \mathrm{pmol} / 100 \mathrm{~g}$ bw mAb35 (standard dose) and was sacrificed at 2, 7 or 14 days after induction of EAMG ( $n=5$ EAMG and $n=3$ control rats per time point) for assessing the relevance of Dok-7 in the recovery from the damage induced by 
autoantibodies (Fig. 3.1C). This standard dose of mAb35 leads to acute muscle weakness and severely impaired neuromuscular transmission [24], which normally fully recover within 1 week after induction of passive-transfer EAMG [25, 26]. Clinical scoring was evaluated daily with the paw-grip test as previously described [15, 22].

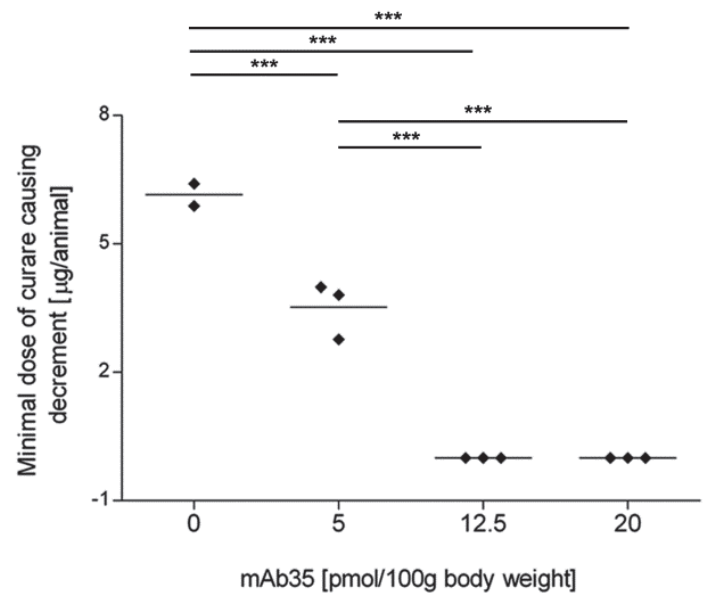

Figure 3.2S. Assessment of the minimal curare dose that induced decrement (subclinical EAMG). Rats were injected with $5,12.5$ or $20 \mathrm{pmol} / 100 \mathrm{~g}$ bw mAb35 ( $\mathrm{n}=3$ per dose), and neuromuscular transmission was assessed by EMG 2 days later, in the presence of continuous i.p. injections of curare. Animals that received either 12.5 or $20 \mathrm{pmol} / 100 \mathrm{~g}$ bw mAb35 had a decrement already before the injection of curare solution, while those injected with $5 \mathrm{pmol} / 100 \mathrm{~g}$ bw required approximately $3.5 \mu \mathrm{g}$ curare to show a decremental response. This was significantly less curare than what was needed to induce decrement in control animals $(5 \mu \mathrm{g})$, indicating that injection of $5 \mathrm{pmol} / 100 \mathrm{~g}$ bw mAb35 significantly impaired neuromuscular transmission, though to a lesser extent than injection of 12.5 or $20 \mathrm{pmol} / 100 \mathrm{~g}$ bw mAb35. Additionally, at 2 days after induction of EAMG, animals that received 12.5 or $20 \mathrm{pmol} / 100 \mathrm{~g}$ bw mAb35 had clinical scores ranging from 0 to 2 , while control animals and animals injected with $5 \mathrm{pmol} / 100 \mathrm{~g}$ bw mAb35 had no clinical signs of muscle weakness (score 0 , data not shown). ${ }^{* * *} \mathrm{p}<0.001 ; 1$-way ANOVA.

\section{Electromyography (EMG)}

Decrement of compound muscle action potential (CMAP) was measured simultaneously in both tibialis anterior muscles of $n=5 \mathrm{EAMG}$ and $n=3$ control rats (per time point) at the day of sacrifice, as described $[14,15]$. If no decrement was observed initially, neuromuscular transmission was challenged by a continuous i.p. infusion of a $20 \mu \mathrm{g} / \mathrm{ml}$ solution of curare 
[(+)-tubocurarine, T2379; Sigma-Aldrich], at a rate of $1 \mathrm{ml} / \mathrm{h}(0.33 \mu \mathrm{g}$ curare/min) with a syringe pump (SP210CZ, World Precision Instruments Germany GmbH, Berlin). During curare infusion, CAMP measurements were repeated at intervals of $1 \mathrm{~min}$ (for each leg), until a reproducible decrement was observed. All EMG studies were performed by the same investigators.

\section{$\underline{\text { Immunohistochemistry }}$}

Muscle cryosections of $10 \mu \mathrm{m}$ from pVAX-ß-galactosidase transfected animals were stained for ß-galactosidase activity as described [14], dehydrated in a series of ethanol dilutions (70-100\%), immersed in Ultraclear (J.T Baker, the Netherlands), and coverslipped with Pertex (Histolab Products AB, Göteborg, Sweden). Sections were imaged with an Olympus BX50 microscope (Tokyo, Japan) and the Stereo Investigator software (Microbrightfield Bioscience, VT).

To visualize NMJs, $10 \mu \mathrm{m}$ frozen muscle sections were fluorescently stained. Cryosections were fixed in cold acetone for $15 \mathrm{~min}$ at $4^{\circ} \mathrm{C}$ and, subsequently, muscle slides were delimited with a PAP hydrophobic pen. Sections were blocked for $30 \mathrm{~min}$ with donkey serum (1:500 in TBS-T), while endogenous biotin-binding sites in the muscle were blocked with a streptavidin/biotin blocking kit (SP-2002, Vector Laboratories, Burlingame, $\mathrm{CA})$, following the manufacturer's instructions. Slides were then incubated for $1 \mathrm{~h}$ with the following primary antibodies: rabbit anti-MuSK (1:1,000; kind gift from Steven J. Burden, New York University, NY) and mouse anti-SV2 (directed against synaptic vesicles; 1:2,000; DS Hybridoma Bank, IA). Alexa-647 conjugated alpha-bungarotoxin (1:300; B35450, Invitrogen/Molecular Probes, Bleiswijk, the Netherlands) was utilized for detection of AChRs. Subsequently, slides were incubated $1 \mathrm{~h}$ with the following secondary antibodies: biotin-conjugated goat anti-rabbit IgG (1:1,000; 111-065-144, Jackson ImmunoResearch, West Grove, PA) and Alexa 594 donkey anti-mouse IgG (1:300; A21203, Invitrogen/Molecular Probes), followed by incubation with Alexa 488 streptavidin (1:2,000; S11223 Invitrogen/Molecular Probes) for another hour at RT. Finally, slides were mounted in $80 \%$ glycerol-TBS. All antibodies and reagents were diluted in TBSA ( $2 \%$ bovine serum albumin in TBS) and all washing steps were performed with TBS-T. 


\section{Quantitative immunofluorescence analysis}

The relative concentrations of AChR and MuSK at the NMJ were analyzed as previously described $[14,15]$. Muscle sections from $n=5$ EAMG and $n=3$ control rats (16 muscles in total) were stained for visualization of AChR, MuSK and SV2 as described above. For each muscle, 2 sets of sections from 2 different regions of the tissue were stained, each set containing 3 muscle sections of $10 \mu \mathrm{m}$. Endplate regions were identified based on their morphology and positive staining for SV2, and they were imaged for the quantification of SV2, AChR and MuSK intensities with an Olympus Provis AX70 fluorescence microscope (Olympus Nederland B.V.). Approximately 50 endplate regions per muscle (with 3-10 endplates each) were imaged and the fluorescence intensities were quantified using ImageJ. For each single endplate, both AChR and MuSK mean intensities were normalized to the SV2 mean intensity, to allow comparisons between different postsynaptic regions. The average of the normalized intensities from all endplates in a set of muscle sections was used for comparison between conditions.

\section{Electron microscopy}

Electron micrographs were obtained from endplate regions of the tibialis anterior muscles of $n=5$ EAMG rats and $n=3$ control rats with unilateral Dok-7 silencing. Sections of glutaraldehyde-perfused muscles $(500 \mu \mathrm{m})$ were processed for EM imaging as described $[15,22]$. Ultra-thin sections $(80 \mathrm{~nm})$ were viewed with a Philips CM 100 electron microscope. At least 15 endplate regions (including between 1 to 3 endplates) were imaged from each muscle and the morphometric analysis of each micrograph was performed using the ImageJ software, as described [15, 22, 27, 28].

\section{Protein extraction and immunoblotting}

Muscle sections $(50 \mu \mathrm{m})$ were homogenized in approximately $5 \mathrm{~mL}$ of protein extraction buffer A $(10 \mathrm{mmol} / \mathrm{L}$ ethylenediaminetetraacetic acid, $10 \mathrm{mmol} / \mathrm{L} \mathrm{NaN3}, 10 \mathrm{mmol} / \mathrm{L}$ iodoacetamide, and $1 \mathrm{mmol} / \mathrm{L}$ phenylmethyl sulfonyl fluoride in PBS) by vortexing 3 times for $1 \mathrm{~min}$ (with $1 \mathrm{~min}$ intervals), in the presence of glass beads $(0.5 \mathrm{~mm})$. The extraction buffer also contained protease inhibitors (Complete Cocktail Tablets, Roche Diagnostics, 
the Netherlands) and phosphatase inhibitors (PhosSTOP, Roche Diagnostics, the Netherlands). Next, the homogenate was centrifuged at $22,000 \mathrm{~g}$ for $30 \mathrm{~min}$ and the supernatant was recovered as a cytoplasmic-protein enriched sample. The resulting pellet was resuspended in $1.8 \mathrm{ml}$ of buffer B (buffer A with an additional 2\% Triton X-100) for extracting membrane-bound proteins. Extraction was performed for $1 \mathrm{~h}$ at $4^{\circ} \mathrm{C}$ on a reciprocal shaker followed by centrifugation $(22,000 \mathrm{~g}, 30 \mathrm{~min})$ and collection of the supernatant (membrane-enriched protein sample).

Protein extracts from tibialis anterior muscles and from transfected HEK cells were separated by SDS 10\% polyacrylamide gel electrophoresis (SDS-PAGE) for $1 \mathrm{~h}$ at 160$200 \mathrm{~V}$, transferred to a nitrocellulose membrane (Bio-Rad Laboratories, CA) for $1 \mathrm{~h}$ at 100V and blocked with 1:2 PBS-diluted blocking buffer (Odyssey blocking buffer, LI-COR Biosciences, NE) for $1 \mathrm{~h}$ at room temperature. Membranes were then incubated with either rabbit anti-Dok-7 (H-77, Santa Cruz Biotechnology, CA; 1:400) or rabbit anti-MuSK sera (kind gift from Judy Cossins, Oxford, UK; 1:20,000), and mouse anti-GAPDH (10RG109a, Fitzgerald, MA; 1:3,000,000), overnight at $4^{\circ} \mathrm{C}$. Secondary antibodies were donkey anti-mouse IgG IRDye 680 and goat anti-rabbit IgG IRDye 800 (926-32222 and 926-32211, respectively; LI-COR Biosciences, NE), diluted 1:10,000. Finally, the membranes were imaged with the Odyssey Infrared Imaging System (LI-COR Biosciences, NE) and bands were quantified with the ImageJ software (mean intensity), normalizing for GAPDH expression.

\section{$\underline{\text { Statistics }}$}

GraphPad Prism 4 was used to perform statistical analyses. Comparison between normally distributed values was performed using either a 1-way or 2-way ANOVA, and Bonferroni post hoc test. A two-sided probability value $(p)<0.05$ was considered significant. Values are expressed as mean \pm standard error of the mean (SEM), unless stated otherwise. 
A

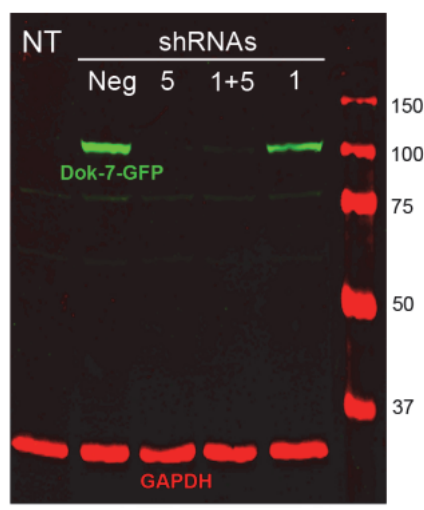

C
B

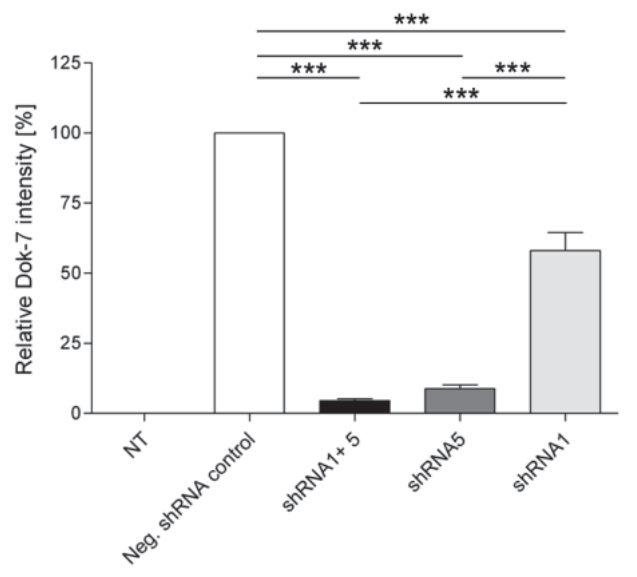

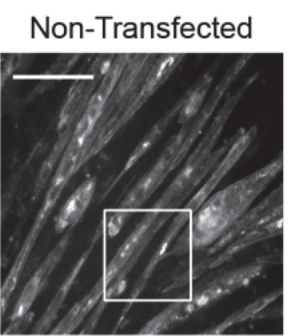

Neg. shRNA control

shRNA5

shRNA1
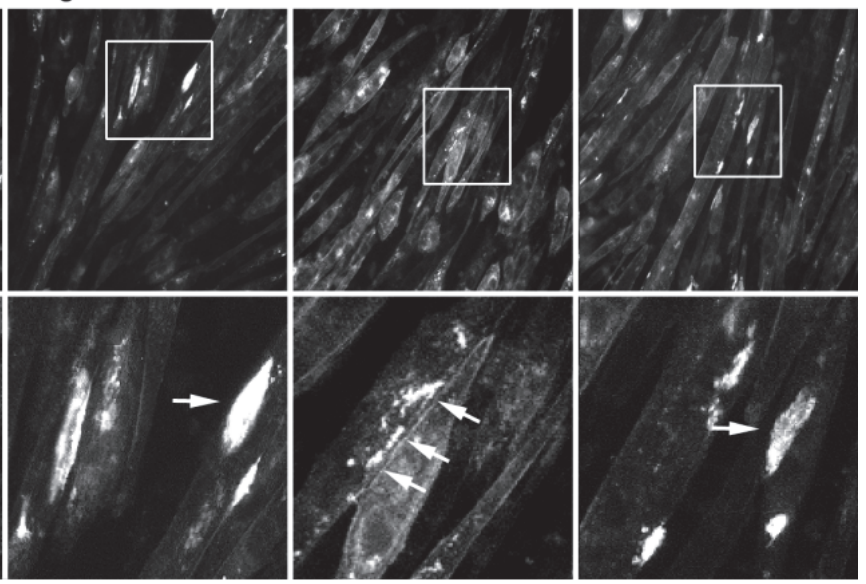

D
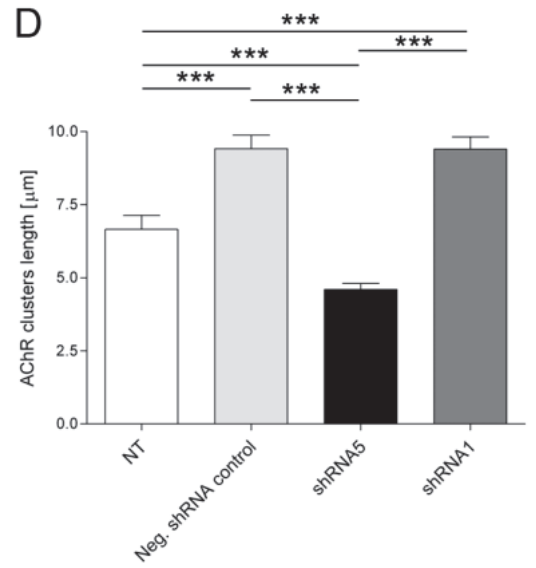
Figure 3.2. In vitro analysis of shRNA efficiency. (A) HEK 293 cells were co-transfected with plasmids for the expression of Dok-7-GFP (MW= $91 \mathrm{kDa}$ ), and anti-Dok-7 shRNAs (S-1, S-5 and S-1 + S-5) or a scrambled shRNA expression plasmid pSUPER. $48 \mathrm{~h}$ later, cells were harvested and protein extracts were separated by SDS-PAGE, followed by immunoblotting for Dok-7 (green band) and GAPDH (red band). (B) Western blotting quantification of Dok-7 silencing efficiency using ImageJ densitometry software. Co-transfection of Dok-7-GFP with anti- Dok-7 shRNAs (S-1+ S-5 and S-5) strongly reduced Dok-7 expression compared to cells transfected with the scrambled ShRNA pSUPER plasmid. Dok-7 band intensities were normalized for GAPDH intensity and results are expressed as the percentage of Dok-7 intensity compared with the negative control shRNA (scrambled). Error bars indicate the standard error of the means of 3 independent experiments. (C) In vitro analysis of Dok-7 shRNA efficiency in C2C12 cells. C2C12 myoblasts were co-transfected with plasmids for the expression of Dok-7-GFP, and anti-Dok-7 shRNAs (S-1 and S-5) or the scrambled shRNA expression plasmid pSUPER. Upon myotube differentiation, Dok-7GFP transfected cells had large AChR clusters when no Dok-7 shRNA was co-transfected (see neg. shRNA control). AChR clusters in S-5 co-transfected myotubes were small and disperse, and even smaller than in non-transfected cells. Squares in the upper row delimitate the region enlarged in the lower row, arrows in the lower row point at AChR clusters (D) The average AChR cluster length was increased after co-transfection of Dok-7-GFP with the scrambled shRNA, but it was significantly reduced when Dok-7-GFP was co-transfected with shRNA S-5. ImageJ densitometry software was used for quantification of clusters length. ${ }^{* * *} p<0.001$; 1-way ANOVA.

\section{$\underline{\text { Results }}$}

Dok-7 shRNAs reduced Dok-7 levels and induced smaller and simplified AChR clusters in vitro

In order to knock-down the expression of Dok-7 in vitro and in vivo in adult rat muscles, we designed five shRNA oligonucleotides (S-1-S-5) targeting Dok-7 which were cloned into the pSUPER expression vector and initially tested in vitro by co-transfection with Dok-7GFP in HEK 293 cells. Following transfection, two pSUPER constructs (S-1 and S-5, table 3.1) efficiently reduced the levels of Dok-7-GFP (between $40 \%$ and $90 \%$ ) compared with Dok-7-GFP co-transfected with the scrambled pSUPER vector, as measured by Western blotting ( $p<0.001,1$ w-ANOVA) (Fig. 3.2A, B). The combination of these 2 shRNAs had additive effects and showed a reduction of Dok-7-GFP levels of $95 \%(p<0.001,1 \mathrm{w}$ ANOVA) (Fig. 3.2A, B). Similar Dok-7 silencing efficiencies were measured by fluorescence activated cell sorting (FACS) and by fluorescence microscopy in separate experiments (data not shown).

Since over-expression of Dok-7 leads to increased AChR clustering in muscle cells [2], we tested if shRNAs S-1 and S-5 affected clustering of AChRs in differentiated myotubes of the mouse muscle cell line C2C12. Co-transfection of Dok-7 with S-5 impaired the Dok-7 induced clustering of AChRs in C2C12 cells and led to smaller and simplified AChR clusters ( $51 \%$ smaller than in neg. control shRNA transfected cells, $p<0.001$; Fig. 
3.2C, D). In contrast co-transfection of Dok-7 with the scrambled shRNA or S-1 promoted the formation of larger AChR clusters (41\% larger than in non-transfected cells, $p<0.001$ ). Interestingly, clusters in S-5-transfected C2C12 cells were even smaller than those in Dok7 non-transfected cells $(31 \%, p<0.001 ;$ Fig. 3.2C, D).

\section{Effects of Dok-7 silencing in neuromuscular transmission}

In order to evaluate the importance of Dok-7 for the susceptibility to EAMG, we reduced levels of Dok-7 in the tibialis anterior muscle by electroporation, subsequently induced EAMG in some animals by injection of $5 \mathrm{pmol} / 100 \mathrm{~g}$ bw mAb35 (subclinical dose), and sacrificed them 2 days later. Silencing of Dok-7 in tibialis anterior muscles of control animals did not impair neuromuscular transmission, as measured by the resistance to curare with EMG ( $n=3$; Fig. 3.3A). However, Dok-7 silenced muscles in subclinical EAMG animals were less resistant to curare ( $26 \%$ less), when compared with the non-silenced contralateral leg ( $n=5) ; p<0.05$; Fig. 3.3A).

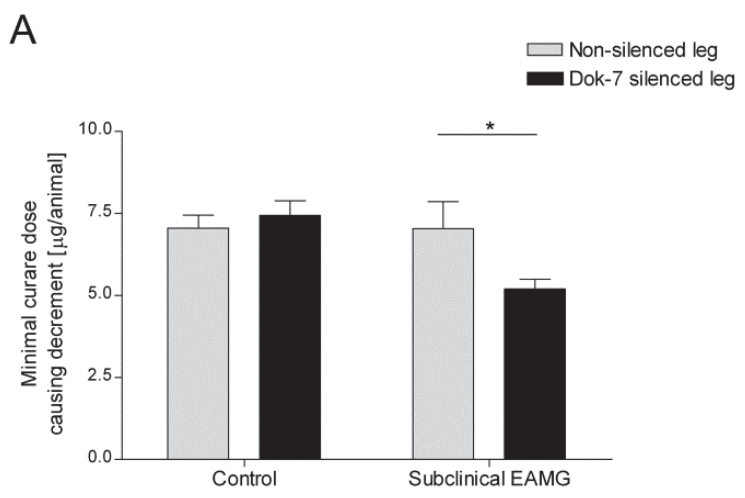

B

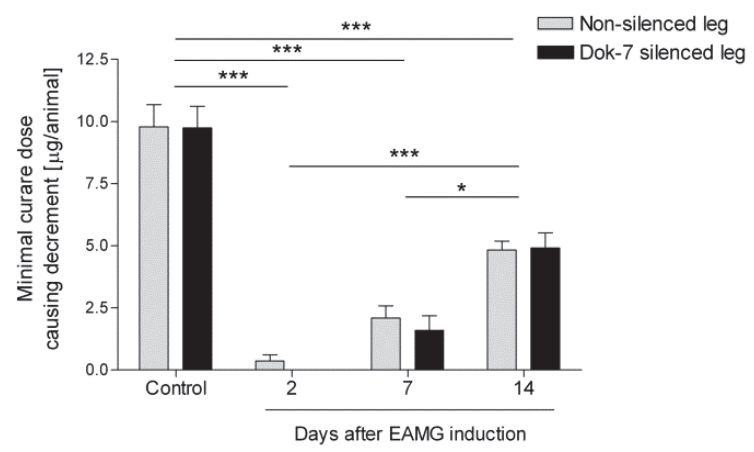

Figure 3.3. Silencing of Dok-7 impairs neuromuscular transmission in subclinical EAMG (induced with $5 \mathrm{pmol} / 100 \mathrm{~g}$ bw). CMAP was measured bilaterally in transfected muscles by EMG, in the presence of continuous curare i.p infusion. (A) Silencing of Dok-7 did not affect the resistance to curare of control animals, but it significantly decreased curare resistance in subclinical EAMG animals. Control $n=3$, EAMG $n=5$. (B) Dok-7 silencing had no significant effect on the recovery from autoantibody damage up to 14 days after injection of $20 \mathrm{pmol} / 100 \mathrm{~g}$ bw of mAb35. At this time point, curare resistance was still significantly lower than in control animals, indicating that neuromuscular transmission was not fully recovered yet. Control $n=3$, EAMG $n=5$ per time point.*** $\mathrm{p}<0.001, * \mathrm{p}<0.05 ; 2$-way ANOVA. 
For evaluating the effects of Dok-7 silencing in the recovery from EAMG, we measured neuromuscular transmission at 2, 7 and 14 days after injection of mAb35 to induce a full-blown disease $(20 \mathrm{pmol} / 100 \mathrm{~g} \mathrm{bw})$. As anticipated from the abovementioned experiment, no differences were observed in the curare resistance of Dok-7 silenced and non-silenced legs in control animals $(n=3)$. Unexpectedly, this was also the case for EAMG animals in all the time points evaluated. There were no significant differences in the resistance to curare between Dok-7 silenced and non-silenced legs at 2, 7, or 14 days after induction of EAMG ( $n=5$ per time point; Fig. 3.3B). A tendency for less curare resistance in the Dok-7 silenced leg was observed at 2 and 7 days time points, although it was not statistically significant. This suggests that a lower expression of Dok-7 at the NMJ is possibly not crucial for the recovery from the damage caused by autoantibodies. However, it is important to note that, 14 days after the induction of EAMG, both Dok-7 silenced and non-silenced legs had a lower curare resistance than that of control animals, suggesting that NMJs were not totally regenerated after the structural damage.

\section{Dok-7 silencing reduces AChR protein levels in EAMG rat muscles}

To further characterize the effects of Dok-7 silencing in AChR and AChR-associated proteins, we stained for AChR, MuSK and SV2 in muscles of rats injected with 5 pmol/100 g bw mAb35 ( $n=5)$ and in untreated animals $(n=3)$, and estimated their relative abundance at the NMJ by quantitative immunofluorescence. The majority of endplates in subclinical EAMG animals had a normal morphology in both Dok-7 silenced and non-silenced legs (Fig. 3.4A). The intensities of AChR and MuSK were quantified in approximately 300 endplates per muscle and normalized for their corresponding SV2 intensity, because this presynaptic marker is typically unaffected by EAMG [14]. In control animals, both AChR/SV2 and MuSK/SV2 ratios were not changed by Dok-7 silencing, and they were not significantly different from those in subclinical EAMG (Fig. 3.4B, C). By contrast, Dok-7 silenced legs in subclinical EAMG animals had a significantly lower AChR/SV2 ratio at their NMJs compared with non-silenced legs (25\% less; $p<0.01$, Fig. 3.4B), while MuSK levels were not significantly affected by Dok-7 down-regulation (Fig. 3.4C). These findings are in line with the impaired neuromuscular transmission observed by EMG in Dok-7 silenced 
legs of subclinical EAMG animals, but not controls. Altogether, they suggest that functional AChR molecules are more likely to be reduced by the relatively low amount of autoantibodies in subclinical EAMG when there is less Dok-7 available in the muscle.

A

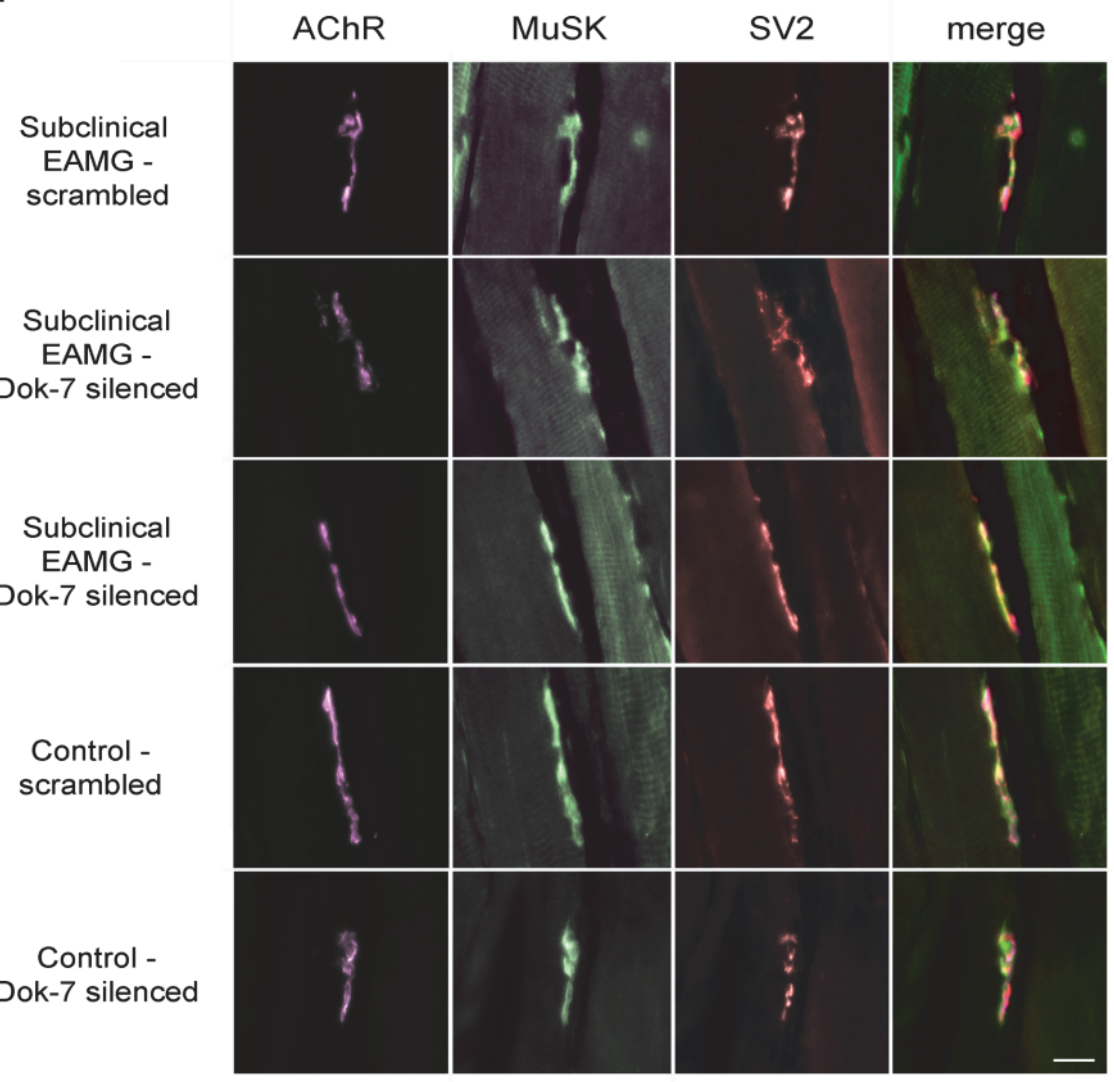

B

C
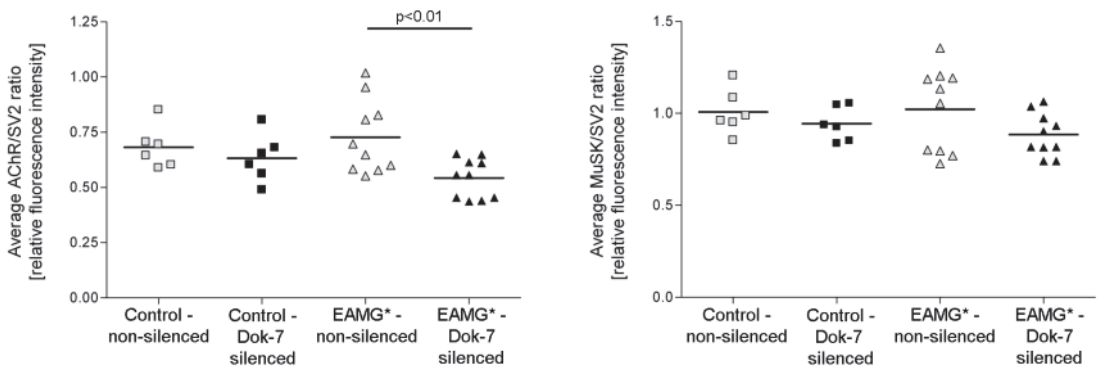
Figure 3.4. Fluorescent microscopy images of representative endplates and quantitative immunohistochemistry analysis. Muscle sections were triple stained for AChR (magenta), MuSK (green) and the presynaptic protein SV2 (red) as a reference. (A) Representative images of endplates from control and subclinical EAMG muscles. No evident differences in morphology or AChR clusters size were observed between Dok-7 silenced and non-silenced legs in control animals. The majority of endplates were normal in subclinical EAMG muscles, though in Dok-7 silenced legs some endplates were disrupted and had less AChR intensity (as representatively shown in the panel). Scale bar is $10 \mu \mathrm{m}$. Quantification of the relative intensity of AChR (B) and MuSK (C), normalized for SV2 intensity. The average AChR/SV2 ratio was significantly lower in Dok-7 silenced legs, compared with the contralateral non-silenced legs, in subclinical EAMG animals but not in controls. MuSK levels were not significantly affected by Dok-7 silencing. Approximately 300 endplates per muscle were quantified from 5 EAMG animals and 3 controls. 2-way ANOVA was used for comparisons.

\section{Effects of Dok-7 silencing in NMJ ultrastructure}

In addition, we examined the ultrastructure of the NMJ by electron microscopy. Control animals had morphologically normal NMJs in both Dok-7 silenced and non-silenced legs (Fig. 3.5A, B), and no particular endplate abnormalities were observed due to Dok-7 silencing. Resembling control animals, most endplates in subclinical EAMG rats also had a normal morphology in both Dok-7 silenced and non-silenced legs. However, some endplates were clearly disrupted at the postsynaptic membrane, with wider junctional folds and enlarged synaptic clefts or simplified postsynaptic foldings, which are usually signs of complement-mediated damage in EAMG (Fig. 3.5C,D). Such endplates were equally observed in both Dok-7 silenced and non-silenced legs. For statistical comparisons between conditions, we performed quantitative morphometric analysis of the folding index (ratio between the post- and presynaptic membrane length [29]) in control and subclinical EAMG animals ( $n=3$ and $n=5$, respectively; approximately 25 endplates per muscle were analyzed). The folding index was not significantly different either between these two conditions (averages per group: control=7; EAMG=6.1) or between Dok-7 silenced and non-silenced legs (averages per group: EAMG non-silenced=6.1; EAMG Dok-7 silenced=5.5). 


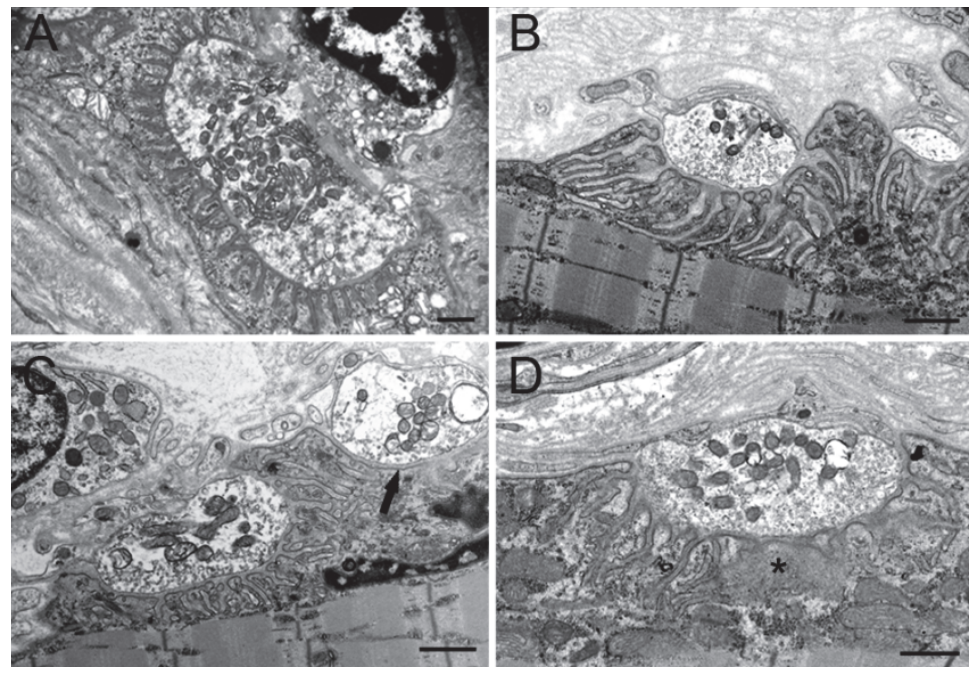

Figure 3.5. Electron microscopic analysis of endplate morphology. (A) Normal endplate region in a non-silenced control muscle, with an elaborate postsynaptic folding facing the nerve terminal. (B) Normal endplate region in a Dok-7 silenced control muscle, no particular morphological alterations were observed in the majority of Dok-7 silenced endplates. (C) Muscles injected with 5 pmol/100 g anti-AChR antibodies (subclinical EAMG) contained both normal endplate regions and endplates showing reduction of postsynaptic folding (see arrow) and widening of the synaptic cleft [see asterisk in (D)]. Ultra-thin muscle sections from 5 EAMG and 3 control animals were imaged with an electron microscope (at least 15 endplate regions per muscle). Scale bars are $1 \mu \mathrm{m}$.

\section{Discussion}

In this study, we have examined the effects of silencing Dok-7 in order to obtain further insight into the function of Dok-7 in healthy and EAMG adult muscles. Down-regulation of Dok-7 led to an increased susceptibility to mAb35. Unexpectedly, it did not impair the recovery from autoantibody damage up to 14 days after the induction of EAMG. Additionally, silencing of Dok-7 did not affect neuromuscular transmission or led to loss of AChRs in control animals, which suggests that down-regulation of Dok-7 in adult muscle does not affect per se the functionality of the NMJ, but it does renders AChR clusters less resistant to autoantibodies in EAMG.

The efficiency of neuromuscular transmission is directly related to the number and degree of clustering of AChRs at the surface of the postsynaptic membrane. The high density of $A C h R$ at the NMJ ensures that every nerve stimuli will elicit muscle action potentials, what is also called "the safety factor" of neuromuscular transmission $[13,30]$. 
Since in rodents the safety factor is several folds larger than the minimum threshold needed to induce an action potential (about 5 folds) [31], it is more likely that the effects of reduced Dok-7 expression are only evident when neuromuscular transmission in challenged by an autoimmune attack or a neuromuscular toxin. Indeed, in our experiment we observed a significant impairment in neuromuscular transmission due to Dok-7 silencing only in the presence of autoantibodies, and not in control animals. This impairment, however, was detectable in subclinical EAMG animals but not in rats that received the standard mAb35 dose, most likely because the latter model causes a very extensive damage at the NMJ. Therefore, when analyzed by EMG, standard EAMG animals had typically a decrement in their CMAP without the need for curare injections which, in turn, prevented the detection of small differences in curare sensitivity between Dok-7 silenced and non-silenced legs. In this regard, the mild impairment of neuromuscular transmission in subclinical EAMG animals allowed us to detect these subtle, but significant, differences in the resistance to AChR loss. Moreover, our EMG findings are in good correlation with the quantification of AChRs at the endplate by immunohistochemistry. We observed a significant reduction in AChR content in Dok-7 silenced legs of subclinical EAMG animals, further supporting the importance of Dok-7 in the stabilization of AChR clusters at the NMJ. In this regard, previous studies have demonstrated that Dok-7 is particularly relevant for the pre-patterning of AChR clusters during development $[6,32]$ and Dok-7 knock-down zebrafish generated fewer and smaller AChR clusters [32]. Additionally, our ultrastructural analysis by electron microscopy did not reveal morphological abnormalities at the endplates of Dok-7 silenced muscles. Thus, it seems that Dok-7 does not play a crucial role in maintaining the ultrastructure of the mature NMJ in the short-term (unlike when rapsyn is silenced, which resulted in increased folding of the postsynaptic membrane [14]) and morphological alterations are probably not responsible for the increased sensitivity to curare of Dok-7 silenced legs.

Dok-7 is a crucial member of the MuSK signaling pathway. Its binding to the juxtamembrane region of MUSK allows for trans-autophosphorylation of the kinase activation loops of MuSK [1], thereby acting as the muscle factor that ensures basal activation of this kinase for full responsiveness to agrin signaling [33]. During embryonic 
development, the agrin-MuSK-Dok-7 triad is widely recognized as the main organizer of neuromuscular synapses $[2,6,34,35]$ and, in adulthood, is fundamental for the maintenance and stability of AChR clusters at the NMJ. The latter has been demonstrated by both siRNA down-regulation [16] and conditional inactivation [17] of MuSK expression and, more extensively, by studies that investigated the effects of anti-MuSK antibodies at the NMJ [36-39]. In such studies, the most consistently reported finding was a significant reduction of AChR clustering that follows the decrease in MuSK levels at the endplate; in addition to increased nerve branching, disassembly of endplates, and formation of aberrant NMJs. Although a link between Dok-7 and MuSK expression has been demonstrated by several studies (both proteins share the transcription factor Sp1 [40], Dok-7 levels are the limiting factor for the formation of ectopic AChR clusters when MuSK is overexpressed in muscle fibers [41], and the two proteins increase their expression upon denervation $[41,42])$, we did not find significantly changed MuSK levels at the NMJ because of Dok-7 silencing. Given that Dok-7 is required for activation of MuSK and, consequently, for dense and stable NMJs, it seems likely that the loss of AChR clusters by autoantibodies in Dok-7 silenced legs was a result of reduced MuSK activation rather than of reduced MuSK levels.

Induction of EAMG with $20 \mathrm{pmol} / 100 \mathrm{~g}$ body weight is known to cause extensive damage at the NMJ [24], and the clinical and electrophysiological features of passivetransfer EAMG typically recover in about 7 days $[25,26]$. Given the previously discussed key role of Dok-7 in neuromuscular synaptogenesis, and its requirement for full activation of MuSK [6], we hypothesized that Dok-7 silencing at the adult NMJ could impair endplate recovery after passive-transfer EAMG. Silencing of Dok-7 in this scenario, however, did not result in a delayed recovery of neuromuscular transmission in any of the time points studied (2, 7, and 14 days), as measured by EMG; even though a trend for an impaired neuromuscular transmission in Dok7-silenced legs was observed. One possibility is that the damage at the NMJ caused by $20 \mathrm{pmol} / 100 \mathrm{~g}$ of mAb35 is so extensive that it overshadows the relatively mild effect of Dok-7 silencing. This is supported by the fact that, even 14 days after mAb35 injection, and in contrast to what was expected, neuromuscular transmission was still not fully recovered in any of the animals' 
electroporated muscles. In this regard, it was reported that endplates in passive-transfer EAMG animals require at least 10 days (and possibly up to 54) to fully recover their normal morphology and junctional AChR content after a single injection with autoantibodies [28]. Had we studied the recovery of neuromuscular transmission at later time points (e.g. 21 or 28 days), we might have had a better chance of effectively assessing the effects of Dok-7 silencing on NMJ recovery.

In summary, our results indicate a relevant role for Dok-7 in the susceptibility to damage at the NMJ and, therefore, implicate this protein in the maintenance of a functional NMJ. Taking into account that several well-characterized mutations of the DOK7 gene in humans have been involved in the development of CMS [9-11], it is tempting to speculate that, in the general population, minor variations in the sequence of this gene, its promoter, and the upstream regulators, could also mildly impair the levels or activity of Dok-7. Such carriers would then be more susceptible to damage at the NMJ and, therefore, Dok-7 could be a promising marker to predict the severity of conditions that challenge neuromuscular transmission, such as MG.

\section{Acknowledgements}

We would like to thank Jochen De Vry for helping with the cloning of shRNAs, Judith Cossins and David Beeson for their collaboration in the C2C12 experiments, and Marjan Philippens for her technical assistance in immunohistochemistry. Special thanks also to Laura Van Dam, Sonny Sliepen and Christian Paylor-Smith for the processing of muscle samples. 


\section{$\underline{\text { References }}$}

1. Bergamin, E., Hallock, P.T., Burden, S.J., Hubbard, S.R. 2010. The cytoplasmic adaptor protein Dok7 activates the receptor tyrosine kinase MuSK via dimerization. Mol Cell, 39: 100-9.

2. Okada, K., Inoue, A., Okada, M., Murata, Y., Kakuta, S., Jigami, T., Kubo, S., Shiraishi, H., Eguchi, K., Motomura, M. et al. 2006. The muscle protein Dok-7 is essential for neuromuscular synaptogenesis. Science, 312: 1802-5.

3. Gautam, M., Noakes, P.G., Mudd, J., Nichol, M., Chu, G.C., Sanes, J.R., Merlie, J.P. 1995. Failure of postsynaptic specialization to develop at neuromuscular junctions of rapsyndeficient mice. Nature, 377: 232-6.

4. DeChiara, T.M., Bowen, D.C., Valenzuela, D.M., Simmons, M.V., Poueymirou, W.T., Thomas, S., Kinetz, E., Compton, D.L., Rojas, E., Park, J.S. et al. 1996. The receptor tyrosine kinase MuSK is required for neuromuscular junction formation in vivo. Cell, 85: 501-12.

5. Weatherbee, S.D., Anderson, K.V., Niswander, L.A. 2006. LDL-receptor-related protein 4 is crucial for formation of the neuromuscular junction. Development, 133: 4993-5000.

6. Inoue, A., Setoguchi, K., Matsubara, Y., Okada, K., Sato, N., Iwakura, Y., Higuchi, O., Yamanashi, Y. 2009. Dok-7 activates the muscle receptor kinase MuSK and shapes synapse formation. Sci Signal, 2: ra7.

7. Shi, L., Fu, A.K., Ip, N.Y. 2012. Molecular mechanisms underlying maturation and maintenance of the vertebrate neuromuscular junction. Trends Neurosci, 35: 441-53.

8. Engel, A.G. 2011. Current status of the congenital myasthenic syndromes. Neuromuscul Disord, 22: 99-111.

9. Cossins, J., Liu, W.W., Belaya, K., Maxwell, S., Oldridge, M., Lester, T., Robb, S., Beeson, D. 2012. The spectrum of mutations that underlie the neuromuscular junction synaptopathy in DOK7 congenital myasthenic syndrome. Hum Mol Genet, 21: 3765-75.

10. Beeson, D., Higuchi, O., Palace, J., Cossins, J., Spearman, H., Maxwell, S., Newsom-Davis, J., Burke, G., Fawcett, P., Motomura, M. et al. 2006. Dok-7 mutations underlie a neuromuscular junction synaptopathy. Science, 313: 1975-8.

11. Muller, J.S., Herczegfalvi, A., Vilchez, J.J., Colomer, J., Bachinski, L.L., Mihaylova, V., Santos, M., Schara, U., Deschauer, M., Shevell, M. et al. 2007. Phenotypical spectrum of DOK7 mutations in congenital myasthenic syndromes. Brain, 130: 1497-506.

12. Selcen, D., Milone, M., Shen, X.M., Harper, C.M., Stans, A.A., Wieben, E.D., Engel, A.G. 2008. Dok-7 myasthenia: phenotypic and molecular genetic studies in 16 patients. Ann Neurol, 64: 71-87.

13. Gomez, A.M., Van Den Broeck, J., Vrolix, K., Janssen, S.P., Lemmens, M.A., Van Der Esch, E., Duimel, H., Frederik, P., Molenaar, P.C., Martinez-Martinez, P. et al. 2010. Antibody effector mechanisms in myasthenia gravis-pathogenesis at the neuromuscular junction. Autoimmunity, 43: 353-70.

14. Martinez-Martinez, P., Phernambucq, M., Steinbusch, L., Schaeffer, L., Berrih-Aknin, S., Duimel, H., Frederik, P., Molenaar, P., De Baets, M.H., Losen, M. 2009. Silencing rapsyn in vivo decreases acetylcholine receptors and augments sodium channels and secondary postsynaptic membrane folding. Neurobiol Dis, 35: 14-23.

15. Losen, M., Stassen, M.H., Martinez-Martinez, P., Machiels, B.M., Duimel, H., Frederik, P., Veldman, H., Wokke, J.H., Spaans, F., Vincent, A. et al. 2005. Increased expression of rapsyn in muscles prevents acetylcholine receptor loss in experimental autoimmune myasthenia gravis. Brain, 128: 2327-37.

16. Kong, X.C., Barzaghi, P., Ruegg, M.A. 2004. Inhibition of synapse assembly in mammalian 
muscle in vivo by RNA interference. EMBO Rep, 5: 183-8.

17. Hesser, B.A., Henschel, O., Witzemann, V. 2006. Synapse disassembly and formation of new synapses in postnatal muscle upon conditional inactivation of MuSK. Mol Cell Neurosci, 31: 470-80.

18. Elbashir, S.M., Harborth, J., Lendeckel, W., Yalcin, A., Weber, K., Tuschl, T. 2001. Duplexes of 21-nucleotide RNAs mediate RNA interference in cultured mammalian cells. Nature, 411: 494-8.

19. Tuschl, T., Zamore, P.D., Lehmann, R., Bartel, D.P., Sharp, P.A. 1999. Targeted mRNA degradation by double-stranded RNA in vitro. Genes Dev, 13: 3191-7.

20. Brummelkamp, T.R., Bernards, R., Agami, R. 2002. A system for stable expression of short interfering RNAs in mammalian cells. Science, 296: 550-3.

21. Boussif, O., Lezoualc'h, F., Zanta, M.A., Mergny, M.D., Scherman, D., Demeneix, B., Behr, J.P. 1995. A versatile vector for gene and oligonucleotide transfer into cells in culture and in vivo: polyethylenimine. Proc Natl Acad Sci U S A, 92: 7297-301.

22. Martinez-Martinez, P., Losen, M., Duimel, H., Frederik, P., Spaans, F., Molenaar, P., Vincent, A., De Baets, M.H. 2007. Overexpression of rapsyn in rat muscle increases acetylcholine receptor levels in chronic experimental autoimmune myasthenia gravis. Am J Pathol, 170: 644-57.

23. Tzartos, S., Hochschwender, S., Vasquez, P., Lindstrom, J. 1987. Passive transfer of experimental autoimmune myasthenia gravis by monoclonal antibodies to the main immunogenic region of the acetylcholine receptor. J Neuroimmunol, 15: 185-94.

24. Graus, Y.M., Verschuuren, J.J., Spaans, F., Jennekens, F., van Breda Vriesman, P.J., De Baets, M.H. 1993. Age-related resistance to experimental autoimmune myasthenia gravis in rats. J Immunol, 150: 4093-103.

25. Gomez, C.M., Wollmann, R.L., Richman, D.P. 1984. Induction of the morphologic changes of both acute and chronic experimental myasthenia by monoclonal antibody directed against acetylcholine receptor. Acta Neuropathol, 63: 131-43.

26. Lindstrom, J.M., Engel, A.G., Seybold, M.E., Lennon, V.A., Lambert, E.H. 1976. Pathological mechanisms in experimental autoimmune myasthenia gravis. II. Passive transfer of experimental autoimmune myasthenia gravis in rats with anti-acetylcholine recepotr antibodies. J Exp Med, 144: 739-53.

27. Engel, A.G., Tsujihata, M., Lindstrom, J.M., Lennon, V.A. 1976. The motor end plate in myasthenia gravis and in experimental autoimmune myasthenia gravis. A quantitative ultrastructural study. Ann N Y Acad Sci, 274: 60-79.

28. Engel, A.G., Sakakibara, H., Sahashi, K., Lindstrom, J.M., Lambert, E.H., Lennon, V.A. 1979. Passively transferred experimental autoimmune myasthenia gravis. Sequential and quantitative study of the motor end-plate fine structure and ultrastructural localization of immune complexes (IgG and C3), and of the acetylcholine receptor. Neurology, 29: 179-88.

29. Slater, C.R., Lyons, P.R., Walls, T.J., Fawcett, P.R., Young, C. 1992. Structure and function of neuromuscular junctions in the vastus lateralis of man. A motor point biopsy study of two groups of patients. Brain, 115 ( Pt 2): 451-78.

30. Wood, S.J., Slater, C.R. 2001. Safety factor at the neuromuscular junction. Prog Neurobiol, 64: 393-429.

31. Wood, S.J., Slater, C.R. 1997. The contribution of postsynaptic folds to the safety factor for neuromuscular transmission in rat fast- and slow-twitch muscles. J Physiol, 500 ( Pt 1): 165-76.

32. Muller, J.S., Jepson, C.D., Laval, S.H., Bushby, K., Straub, V., Lochmuller, H. 2010. Dok-7 promotes slow muscle integrity as well as neuromuscular junction formation in a zebrafish model of congenital myasthenic syndromes. Hum Mol Genet, 19: 1726-40.

33. Yamanashi, Y., Tezuka, T., Yokoyama, K. 2012. Activation of receptor protein-tyrosine 
kinases from the cytoplasmic compartment. J Biochem, 151: 353-9.

34. Misgeld, T., Kummer, T.T., Lichtman, J.W., Sanes, J.R. 2005. Agrin promotes synaptic differentiation by counteracting an inhibitory effect of neurotransmitter. Proc Natl Acad Sci U S A, 102: 11088-93.

35. Kim, N., Burden, S.J. 2008. MuSK controls where motor axons grow and form synapses. Nat Neurosci, 11: 19-27.

36. Cole, R.N., Ghazanfari, N., Ngo, S.T., Gervasio, O.L., Reddel, S.W., Phillips, W.D. 2010. Patient autoantibodies deplete postsynaptic muscle-specific kinase leading to disassembly of the ACh receptor scaffold and myasthenia gravis in mice. J Physiol, 588: 3217-29.

37. Klooster, R., Plomp, J.J., Huijbers, M.G., Niks, E.H., Straasheijm, K.R., Detmers, F.J., Hermans, P.W., Sleijpen, K., Verrips, A., Losen, M. et al. 2012. Muscle-specific kinase myasthenia gravis IgG4 autoantibodies cause severe neuromuscular junction dysfunction in mice. Brain, 135: 1081-101.

38. ter Beek, W.P., Martinez-Martinez, P., Losen, M., de Baets, M.H., Wintzen, A.R., Verschuuren, J.J., Niks, E.H., van Duinen, S.G., Vincent, A., Molenaar, P.C. 2009. The effect of plasma from muscle-specific tyrosine kinase myasthenia patients on regenerating endplates. Am J Pathol, 175: 1536-44.

39. Punga, A.R., Lin, S., Oliveri, F., Meinen, S., Ruegg, M.A. 2011. Muscle-selective synaptic disassembly and reorganization in MuSK antibody positive MG mice. Exp Neurol, 230: 20717.

40. Hamuro, J., Hishida, Y., Higuchi, O., Yamanashi, Y. 2011. The transcription factor Sp1 plays a crucial role in dok-7 gene expression. Biochem Biophys Res Commun, 408: 293-9.

41. Punga, A.R., Maj, M., Lin, S., Meinen, S., Ruegg, M.A. 2011. MuSK levels differ between adult skeletal muscles and influence postsynaptic plasticity. Eur J Neurosci, 33: 890-8.

42. Valenzuela, D.M., Stitt, T.N., DiStefano, P.S., Rojas, E., Mattsson, K., Compton, D.L., Nunez, L., Park, J.S., Stark, J.L., Gies, D.R. et al. 1995. Receptor tyrosine kinase specific for the skeletal muscle lineage: expression in embryonic muscle, at the neuromuscular junction, and after injury. Neuron, 15: 573-84. 


\section{Chapter 4}

\section{Targeting plasma cells with proteasome inhibitors: possible roles in treating myasthenia gravis?}

Alejandro M. Gomez, Nick Willcox, Peter C. Molenaar, Wim Buurman, Pilar MartinezMartinez, Marc H. De Baets, and Mario Losen

Annals of the New York Academy of Sciences (2012); 1274:48-59. 


\section{Abstract:}

Myasthenia gravis (MG) is treated primarily with broad-spectrum immunosuppressants, such as prednisone or azathioprine, which normally require several months to reduce auto-antibody titers significantly. This delay may be caused by the resistance of the main antibody-producing cells, the plasma cells, to these drugs. In particular, long-lived plasma cells are resistant to the immunosuppressive treatments and can produce (auto-) antibodies for months. Bortezomib is a proteasome inhibitor approved for treating patients with multiple myeloma, a plasma cell malignancy. Recent preclinical studies in cell cultures and animal models, and clinical studies in organ-transplant recipients, have demonstrated that bortezomib can kill non-neoplastic plasma cells within hours. This suggests that proteasome inhibitors could also be used for rapidly reducing auto-antibody production in autoimmune diseases. We have begun to assess their potential in MG. 


\section{Introduction}

Myasthenia gravis (MG) is an autoimmune disease characterized by muscle weakness caused by autoantibodies against postsynaptic proteins of the neuromuscular junction. In most MG-patients, they recognize the acetylcholine receptor (AChR) [1], but, in others, the muscle-specific kinase (MuSK) [2] or the low-density lipoprotein receptor-related protein (LRP4) [3] instead. Even though these antibodies cause similar clinical features (muscle weakness and fatigability), they are in fact the result of distinct autoimmune processes. For instance, in early-onset AChR-MG patients, the frequent thymic abnormalities include lymph node-type infiltrates with AChR-specific plasma cells $[4,5]$, whereas the MuSK-MG thymus hardly differs from that in age-matched controls [6]. Moreover, MuSK-MG is mediated by auto-antibodies of the IgG4 subclass [7], while those in AChR-MG are mainly complement-binding IgG1s and IgG3s [8].

Many aspects of the underlying etiologies of these conditions remain to be defined, but different treatment responses to immunosuppressive drugs and monoclonal antibodies suggest that distinct antibody-producing cell populations are involved [9]. Plasma cells are the main antibody-producing cell type; they can be either short- or longlived, and they do not divide. Importantly, they survive most immunosuppressive treatments, rendering them relevant targets for therapies aimed at reducing antibody production.

In this review, we focus on the importance of plasma cells as targets for therapy in autoimmune diseases, and on the potential applications of proteasome inhibitors for eliminating these high-rate antibody-producing cells, emphasizing the potential benefits of such therapies for treating MG patients.

\section{Plasma cells in autoimmunity}

Plasma cells are one vital end-product of B cell differentiation; unlike their immediate precursor plasmablasts, they do not proliferate or migrate into the circulation. Therefore, they are very rare in the blood and reside predominantly in the bone marrow and secondary lymphoid tissues such as spleen and lymph nodes, where they are embedded in 
special niches. Their function is high-rate secretion of antibodies (3700 times more than by B lymphocytes [10]; i.e., >3,000 molecules/cell/second). Consequently, they are essential for maintaining antibody levels in serum and thus for humoral immune responses. Although antibody-producing cells were shown to survive for many months already in the 1960s [11], long-lived plasma cells, and their contribution to humoral memory, have only been described accurately in the last decade [12-14]. Recent studies have demonstrated that their maintenance is largely independent of continuous regeneration from memory $B$ cells $[15,16]$. Moreover, the cellular and molecular components of the survival niches, where plasma cells must reside in the longer term, have been defined [17]; they include interactions via VCAM-1/VLA4, CXCL12/CXCR4 and IL-6/IL-6R [18]. While differentiating terminally, plasma cells almost completely downregulate most B cell markers (CD19, CD20, CD22 and MHC class II), though most do express CD38 and CD138. Crucial to their specialization is the upregulation of proteins related to endoplasmic reticulum (ER) stress and the unfolded protein response, including Blimp-1 and XBP1 $[19,20]$. The resulting intracellular differentiation is characterized by formation of extensive amounts of rough ER with densely arranged cisternae (Fig. 4.1) typical of professional secretory cells.

In recent years, long-lived plasma cells have proved to play a key role in antibodymediated autoimmune diseases. For instance, in a mouse model of systemic lupus erythematosus (SLE), they produced substantial amounts of auto-antibodies and were resistant to standard immunosuppression [21]. Furthermore, they appear to maintain the autoimmune response in Sjögren's syndrome [22] and in rheumatoid arthritis patients [23].

Persisting long-lived plasma cells are probably also responsible for the typically slow time course of serum autoantibody decline seen in most MG patients during treatment with steroids and/or other immunosuppressive drugs. Convincing evidence implicating them in MG comes from retrospective studies of rituximab-treated MGpatients. In their long-term follow-up of a cohort of refractory MG-patients treated with the anti-CD20 antibody rituximab, Diaz-Manera et al. showed almost complete elimination of anti-MuSK autoantibodies, whereas anti-AChR levels did not change significantly [9]. Apparently therefore, autoantibodies against MuSK are made mainly by short-lived 
plasma cells that are continuously regenerated from autoreactive CD20 positive B cells. By contrast, those against the AChR most likely derive from long-lived plasma cells; so do total circulating IgGs and anti-tetanus toxoid antibodies, which also remained constant after CD20 depletion therapy, again implicating the long-lived plasma cell compartment that is expected to resist it [9]. Similarly, in a randomized phase II/III trial with rituximab in SLE patients [24], autoantibody titers remained unchanged for at least one year, probably because they are maintained by long-lived plasma cells, even if circulating B cells are depleted completely.

Clearly, therefore, drugs targeting plasma cells may have a place in the therapy of autoimmune diseases [25].

\section{Bortezomib targets non-neoplastic plasma cells: in vivo studies}

Most of the available immunosuppressive drugs are designed to halt proliferation of immune cells, but plasma cells are terminally differentiated and there are very few drugs that target them. Long-lived plasma cells are even resistant to whole-body irradiation [26]. Until recently, their neoplasms (in particular multiple myeloma) were notoriously hard to treat. Even benign plasma cells are typically resistant to most standard immunosuppressant treatments, including such novel drugs as mycophenolate mofetil (MMF) [15, 27, 28], and they express very few targets for therapeutic monoclonal antibodies. At present, one of the most effective FDA-approved drugs for plasma cell malignancies is the proteasome inhibitor bortezomib (also known as Velcade or PS-341). It is currently used for treating patients with mantle cell lymphoma as well as multiple myeloma [29, 30]. However, peripheral neuropathy (PN) is a major side effect of bortezomib - when used repeatedly. PN can be very disabling in up to $30 \%$ of treated patients and has seriously discouraged off-label testing of bortezomib in clinical conditions other than cancers. Recent advances in its use (e.g., subcutaneous instead of intravenous administration [31] and lower but effective dose regimens [32]) are showing promise for reducing these risks and thus for broadening its future applicability in other diseases. Recently, a second proteasome inhibitor, carfilzomib (also known as Kyprolis or PR-171), has been approved for the treatment of multiple myeloma. By analogy, it is likely to be 
effective against autoimmune plasma cells as well. Since carfilzomib does not increase the risk of PN in multiple myeloma patients [33], this particular side effect of bortezomib may not be proteasome specific [34].

Proteasome inhibition is toxic for myeloma cells because it (a) causes accumulation of misfolded proteins in the ER, triggering the terminal unfolded protein response that ultimately leads to apoptosis [35]; (b) prevents the activation of the transcription factor NF-KB that is crucial for expression of cytokines, chemokines and their receptors, which ensure plasma cell survival [36]. In fact, it is now clear that it is mainly the high-rate production of proteins that sensitizes certain cell types towards proteasome inhibition [37]. That is why Neubert et al. predicted that bortezomib would be toxic to non-neoplastic plasma cells too, since they also secrete antibodies in large amounts [38].

Initial studies in animal models demonstrated that proteasome inhibition could indeed kill non-neoplastic plasma cells (Table 4.1). In an SLE model, plasma cells (whether short- or long-lived) were depleted as early as 48 hours after treatment by inducing apoptosis in them [38]. Moreover, long-term treatment (>30 weeks) decreased autoantibody titers almost to background levels, while approximately halving total IgG levels (possibly reflecting partial recovery of plasma cells after the treatment was stopped). Hence, proteasome inhibition ameliorated the lupus-like nephritis signs in these mice and prolonged their survival. Similarly, we have demonstrated that bortezomib significantly depletes bone marrow plasma cells in an animal model of MG (experimental autoimmune myasthenia gravis, EAMG) [39]. In that study, we treated EAMG-rats with bortezomib twice weekly for four weeks, starting four weeks after immunization with Torpedo AChR (by when serum autoantibodies against rat AChR were present). At the end of the experiment, plasma cell numbers and autoantibody titers were significantly lower in bortezomib-treated rats than in saline-injected controls; titers were reduced by $60 \%$ after four weeks of treatment. Interestingly, in bone marrow plasma cells, bortezomib induced ultrastructural changes (swelling of the endoplasmic reticulum) characteristic of ER stress (Fig. 4.1B, C). 


\section{Control}
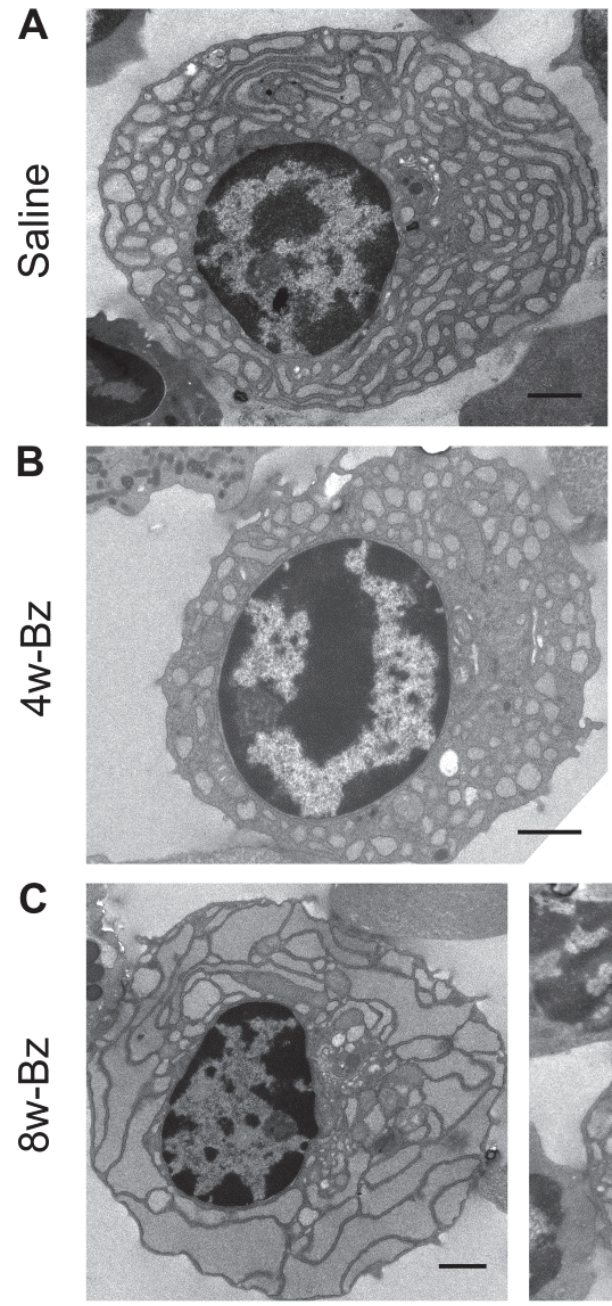

\section{EAMG}
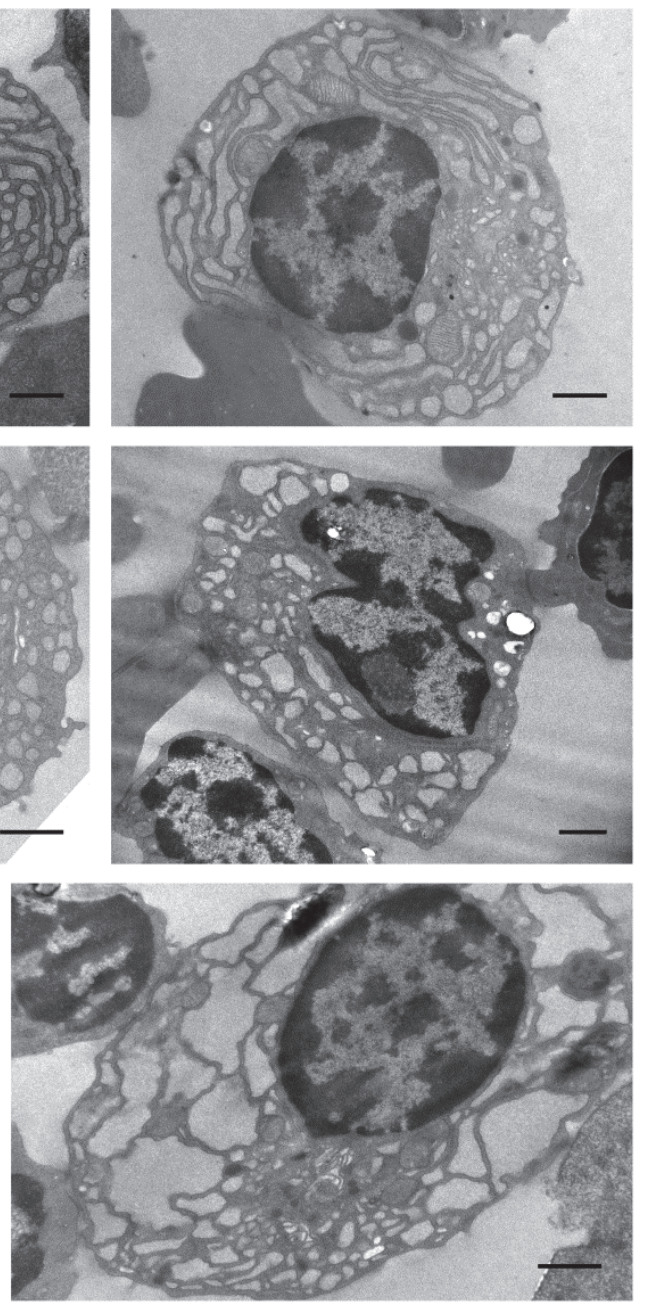

Figure 4.1. Electron micrographs of plasma cells from rat bone marrow. $(A)$ Morphologically normal plasma cells after eight weeks of saline treatment. These cells are characterized by an elaborate endoplasmic reticulum (ER), which occupies most of the cytoplasm, and by an eccentric nucleus that contains patches of condensed chromatin (resembling a "cart-wheel" configuration). The Golgi apparatus is easy to distinguish. (B) Plasma cells from four-week bortezomib-treated animals. During bortezomib treatment, plasma cells frequently show morphological alterations, including distension of the ER cisternae, with disorganization of its normal structure and derangement of the Golgi complex. (C) Plasma cells from eight-week bortezomib-treated animals. Morphological alterations were similar to those in four-week treated animals, with more pronounced dilatation of the ER cisternae. Cells were stained with osmium tetroxide and contrasted with uranyl acetate and lead citrate. Scale bars, $1 \mu \mathrm{m}$. Reproduced, with permission, from Reference 39. 
Table 4.1. Summary of in vitro and in vivo studies with bortezomib (Btz) in non-neoplastic models of disease

\begin{tabular}{|c|c|c|c|c|}
\hline Reference & $\begin{array}{l}\text { Disease } \\
\text { model }\end{array}$ & $\begin{array}{l}\text { Btz dose and } \\
\text { schedule(s) }\end{array}$ & Effects on PC & Main findings \\
\hline \multicolumn{5}{|c|}{ In vitro studies } \\
\hline $\begin{array}{l}\text { Perry et al. } \\
{[27]}\end{array}$ & $\begin{array}{l}\text { PC from the } \\
\text { BM of renal- } \\
\text { transplant } \\
\text { recipients }\end{array}$ & $\begin{array}{l}1 \mathrm{mg} / \mathrm{L} \text { for } 24 \mathrm{~h} \text { or } \\
72 \mathrm{~h}\end{array}$ & $\begin{array}{l}\text { Btz induced apoptosis } \\
\text { in more than } 60 \% \text { of } \\
\text { PC already after } 24 \mathrm{~h}\end{array}$ & $\begin{array}{l}\text { Btz, but not Rtx or IVIg, } \\
\text { blocked the production of } \\
\text { allo-antibodies by PC after } 72 \\
\text { hours. } \\
\text { A dose-response curve } \\
\text { showed that Btz is effective at } \\
\text { concentrations } \geq 1 \mathrm{mg} / \mathrm{L}\end{array}$ \\
\hline $\begin{array}{l}\text { Gomez et al., } \\
\text { unpublished } \\
\text { data }\end{array}$ & $\begin{array}{l}\text { Thymic cells } \\
\text { from MG } \\
\text { patients }\end{array}$ & $\begin{array}{l}1 \mathrm{mg} / \mathrm{L} \text { twice (days } \\
7 \text { and } 11 \text { ) in a 14- } \\
\text { day culture } \\
\text { schedule }\end{array}$ & $\begin{array}{l}\text { No Btz-exposed PC } \\
\text { survived to day } 14 . \text { In } \\
\text { cultures with Dx, Len } \\
\text { or saline, significantly } \\
\text { more PC survived } \\
\text { until day } 14\end{array}$ & $\begin{array}{l}\text { Autoantibody and IgG } \\
\text { production were completely } \\
\text { blocked by Btz, but not by } \mathrm{Dx} \text {, } \\
\text { Len, or saline. } \\
\text { On dose-response testing, Btz } \\
\text { eliminated PC at } \\
\text { concentrations } \geq 4 \mu \mathrm{g} / \mathrm{L}\end{array}$ \\
\hline
\end{tabular}

\section{In vivo studies}

\begin{tabular}{|c|c|c|c|c|}
\hline $\begin{array}{l}\text { Neubert et al. } \\
\text { [38] }\end{array}$ & $\begin{array}{l}\text { SLE-like mice } \\
\text { (NZB/W F1; } \\
\text { MRL/lpr) }\end{array}$ & $\begin{array}{l}0.75 \mathrm{mg} / \mathrm{kg} \\
\text { - Twice at } 36 \mathrm{~h} \\
\text { interval (A) } \\
\text { - } 3 \text { times in } 1 \text { week } \\
\text { (B) } \\
\text { - Twice weekly for } \\
40 \text { weeks (C) }\end{array}$ & $\begin{array}{l}>60 \% \text { reduction of } \\
\text { both short- and long- } \\
\text { lived } P C \text { in the BM, } \\
\text { from } 48 \mathrm{~h} \text { after the } \\
\text { first dose }(\mathrm{A})\end{array}$ & $\begin{array}{l}\text { Significant reduction of anti- } \\
\text { ds-DNA antibody titers only } \\
\text { with Btz treatment (not Dx or } \\
\text { Cy) (B). } \\
\text { Long-term treatment with Btz } \\
\text { improved the clinical } \\
\text { condition of these mice (C) }\end{array}$ \\
\hline $\begin{array}{l}\text { Gomez et al. } \\
\text { [39] }\end{array}$ & EAMG rats & $\begin{array}{l}0.2 \mathrm{mg} / \mathrm{kg} \\
\text { - For prevention: } \\
\text { twice weekly for } \\
\text { eight weeks ( } 8 \mathrm{w}- \\
\text { Btz) } \\
\text { - For treatment: } \\
\text { four weeks Btz, } \\
\text { starting four weeks } \\
\text { after induction of } \\
\text { the model ( } 4 \mathrm{w}-\mathrm{Btz})\end{array}$ & $\begin{array}{l}\text { Strong reduction of } \\
\text { total PC in the BM, } \\
\text { with both regimens }\end{array}$ & $\begin{array}{l}\text { Significant reduction of anti- } \\
\text { AChR antibody titers and total } \\
\text { IgG levels in both the } 8 w-B t z \\
\text { and } 4 w \text {-Btz groups, i. e., also } \\
\text { when autoantibodies were } \\
\text { already present ( } 4 \text { w-Btz) }\end{array}$ \\
\hline
\end{tabular}


Table 4.1. Continued

\begin{tabular}{|c|c|c|c|c|}
\hline Reference & Disease model & $\begin{array}{l}\text { Btz dose and } \\
\text { schedule(s) }\end{array}$ & Effects on PC & Main findings \\
\hline $\begin{array}{l}\text { Vogelbacher } \\
\text { et al. [40] }\end{array}$ & $\begin{array}{l}\text { Chronic allograft } \\
\text { nephropathy } \\
\text { model in rats }\end{array}$ & $\begin{array}{l}0.2 \mathrm{mg} / \mathrm{kg} \\
\text { - Twice weekly } \\
\text { for nine weeks }\end{array}$ & $\begin{array}{l}\text { Significant depletion of PC } \\
\text { in the BM and the spleen }\end{array}$ & $\begin{array}{l}\text { Significant reduction of } \\
\text { allo-antibody titers and } \\
\text { IgG-producing cells. } \\
\text { Some additive actions } \\
\text { were suggested for Btz } \\
\text { and the mTOR-inhibitor } \\
\text { sirolimus }\end{array}$ \\
\hline $\begin{array}{l}\text { Meslier et al. } \\
\text { [41] }\end{array}$ & $\begin{array}{l}\text { Experimental } \\
\text { hemophilia-A } \\
\text { mice that develop } \\
\text { anti-factor VIII } \\
\text { antibodies }\end{array}$ & $\begin{array}{l}0.75 \mathrm{mg} / \mathrm{kg} \\
\text { - For prevention: } \\
\text { Btz twice weekly } \\
\text { for four weeks } \\
\text { - For treatment: } \\
\text { Btz twice weekly } \\
\text { for } 10 \text { weeks }\end{array}$ & $\begin{array}{l}\text { Both short- and long-lived } \\
\text { PC were strongly reduced } \\
\text { by Btz in the spleen, but } \\
\text { not in the BM, with the } \\
\text { preventive schedule. The } \\
\text { number of autoreactive PC } \\
\text { in BM was not reduced by } \\
\text { Btz treatment }\end{array}$ & $\begin{array}{l}\text { Btz was effective in } \\
\text { preventing anti-factor } \\
\text { VIII antibody responses } \\
\text { but hardly reduced } \\
\text { them once they were } \\
\text { established }\end{array}$ \\
\hline $\begin{array}{l}\text { Ichikawa et } \\
\text { al. [42] }\end{array}$ & $\begin{array}{l}\text { SLE-like mice } \\
\text { (NZB/W F1, ONX } \\
\text { 0914, NZB/NZW) }\end{array}$ & $\begin{array}{l}0.5 \mathrm{mg} / \mathrm{kg} \\
\text { - Twice weekly } \\
\text { for } 13 \text { weeks }\end{array}$ & $\begin{array}{l}\text { Btz decreased by }>90 \% \text { the } \\
\text { number of PC in the spleen } \\
\text { and the BM }\end{array}$ & $\begin{array}{l}\text { Greater sensitivity of } \\
\text { autoantibody- than } \\
\text { total IgG- secreting PC } \\
\text { to proteasome } \\
\text { inhibition. } \\
\text { New proteasome } \\
\text { inhibitors (carfilzomib } \\
\text { and ONX 0914) also } \\
\text { gave positive results }\end{array}$ \\
\hline $\begin{array}{l}\text { Bontscho et } \\
\text { al. [43] }\end{array}$ & $\begin{array}{l}\text { Mouse model of } \\
\text { vasculitis due to } \\
\text { anti-neutrophil } \\
\text { cytoplasmic } \\
\text { antibodies (ANCA) }\end{array}$ & $\begin{array}{l}0.75 \mathrm{mg} / \mathrm{kg} \\
\text { twice weekly } \\
\text { - Early } \\
\text { treatment: } 5 \\
\text { weeks of Btz, } \\
\text { starting } 3 \text { weeks } \\
\text { after induction } \\
\text { of the model } \\
\text { - Late } \\
\text { treatment: } 3 \\
\text { weeks of Btz, } \\
\text { starting } 5 \text { weeks } \\
\text { after induction } \\
\text { of the model }\end{array}$ & $\begin{array}{l}\text { Spleen and BM PC were } \\
\text { significantly reduced by } \\
\text { Btz. } \\
\text { Auto-reactive PCs were } \\
\text { more susceptible to Btz } \\
\text { treatment }\end{array}$ & $\begin{array}{l}\text { Btz significantly } \\
\text { reduced autoantibody } \\
\text { titers already one week } \\
\text { into early treatment, } \\
\text { and protected against } \\
\text { development of clinical } \\
\text { signs. } \\
\text { Late treatment reduced } \\
\text { antibody titers at the } \\
\text { endpoint but did not } \\
\text { improve the clinical } \\
\text { condition. } \\
\text { Combined steroid/Cy } \\
\text { significantly reduced PC } \\
\text { numbers in the spleen, } \\
\text { but not in BM }\end{array}$ \\
\hline
\end{tabular}

AMR, antibody-mediated transplant rejection; BM, bone marrow; Btz, bortezomib; Cy, cyclophosphamide; Dx, dexamethasone; EAMG, experimental autoimmune myasthenia gravis; IVIg, intravenous immunoglobulin; Len, lenalidomide; PC, plasma cell; Rtx, rituximab. 


\section{Bortezomib is toxic for non-neoplastic plasma cells: in vitro studies}

Recent in vitro studies have focused on the sensitivity of nonmalignant plasma cells to proteasome inhibition (Table 4.1) [27, 38-43], and especially - in antibody-mediated kidney transplant rejection - on its potential for depleting allo-reactive (anti-HLA) plasma cells. In one of the first such studies [27], bortezomib, but not rituximab or IVIg, induced apoptosis within 72 hours in plasma cells cultured from the bone marrow of transplant recipients. In addition, it completely blocked allo-antibody production in these cultures, while rituximab had no significant effect. These results, along with pilot clinical studies in vivo [44], prompted the off-label use of bortezomib for preventing transplant rejection in patients, as discussed later in this review.

To extend this approach to autoimmune diseases, we took advantage of the very prevalent lymph node-like infiltration into the early-onset MG thymus [4-6, 45, 46], where germinal centers form close to rare muscle-like myoid cells [4], and plasma cells spontaneously secrete anti-AChR antibodies $[5,45,46]$. Since the thymus is removed surgically in many of these patients as part of treatment, it is an accessible and valuable source of specific autoreactive plasma cells for research [5]. In culture, these continue spontaneously secreting substantial amounts of AChR autoantibodies for several weeks (at least) - even after irradiation, a feature unique to plasma cells [5]. They are apparently sustained by "feeder effects" from accessory thymic cell types (e.g., fibroblasts and macrophages) $[5,45,46]$.

We therefore exploited this source of autoimmune plasma cells as a test-bed for evaluating their sensitivity to drugs used against myelomas. These included bortezomib, dexamethasone, and the thalidomide derivative lenalidomide (now also approved for myeloma therapy); we measured (auto-) antibody and total IgG production and plasma cell survival after two weeks in culture (unpublished results). Bortezomib proved to target plasma cells with surprising efficiency; they were already almost undetectable after $24 \mathrm{~h}$, and even at 60 times lower concentrations than those reached in patients' plasma [31]. Plasma cells appeared apoptotic as soon as eight hours after adding bortezomib to the cultures. Moreover, autoantibody and total IgG production were completely blocked upon addition of bortezomib, whereas dexamethasone caused a mild but statistically significant 
reduction and lenalidomide had no significant effect. Importantly, at the doses used, none of these drugs caused extra death of thymic cells by day 14 (i.e., above the rate of apoptosis expected of thymocytes). Thus, bortezomib's toxicity seems selective for plasma cells.

\section{Experience with bortezomib in transplantation and autoimmune}

\section{disorders}

Since its introduction, there have been many clinical trials and case reports of bortezomib's benefits and side effects in multiple myeloma patients [47], but few on its off-label use in non-neoplastic diseases (Table 4.2) [44, 48-52]. However, there are reports of positive outcomes in the treatment of autoimmune hemolytic anemia [48, 53], rheumatoid arthritis [54], and SLE [55]. The most extensive studies have focused on the prevention of antibody-mediated rejection in renal transplant recipients [56]. Initially, bortezomib was only used as a last resort in patients who were refractory to several immunosuppressive drugs [44]; subsequently, in combination with plasma exchange, it also proved effective as primary treatment for rapidly reducing anti-HLA antibody levels in hyper acute transplant rejection [57]. Bortezomib reduced both numbers of allo-reactive plasma cells in the bone marrow and serum allo-antibody titers in strongly allo-sensitized renal patients prior to transplantation [49]. Moreover, it significantly increased graft survival in comparison to rituximab [52]. However, despite these positive findings, there is one other report that a single cycle of bortezomib as a monotherapy was not beneficial in sub-acute rejection when given after transplantation [51]. Moreover, it seems more effective in early than in late acute rejection [58].

By contrast, there is much less published experience with proteasome inhibition in autoimmune diseases. To date, two reports have described a reduction of autoantibody titers and a clear increase of hemoglobin levels in cases of steroid/rituximab-refractory autoimmune hemolytic anemia $[48,53]$. In addition, in one multiple myeloma patient, the coincidental SLE improved substantially and anti-dsDNA titers declined significantly after just 3 cycles of bortezomib [55]. Similarly, Hiepe et al. recently reported significant clinical improvements and autoantibody titer reductions in four patients with refractory SLE after 
treatment with bortezomib plus dexamethasone [59]. Protective vaccine-specific antibodies and total IgG levels were also decreased in these patients, suggesting that longlived plasma cells were indeed depleted by proteasome inhibition. However, since repeated treatments were necessary to achieve sustained responses, combinations of bortezomib with agents that can also eliminate plasma cell precursors (i.e., rituximab) were recommended.

Table 4.2. Summary of clinical studies with bortezomib in transplantation and autoimmune disorders

\begin{tabular}{|c|c|c|c|}
\hline Reference & Patients & Btz dose and schedule(s) & Main findings \\
\hline $\begin{array}{l}\text { Carson et al. } \\
\text { [48] }\end{array}$ & $\begin{array}{l}\text { Case report of refractory } \\
\text { IgM-mediated autoimmune } \\
\text { hemolytic anemia }\end{array}$ & $\begin{array}{l}1.3 \mathrm{mg} / \mathrm{m}^{2} \\
\text { - Three doses of Btz }\end{array}$ & $\begin{array}{l}\text { Improvement of symptoms and } \\
\text { increase of hemoglobin levels after } \\
\text { Btz treatment. IgM autoantibodies } \\
\text { were significantly decreased }\end{array}$ \\
\hline $\begin{array}{l}\text { Hiepe et al. } \\
\text { [59] }\end{array}$ & Four refractory SLE patients & $\begin{array}{l}1.3 \mathrm{mg} / \mathrm{m}^{2} \\
\text { - Four cycles of Btz (days } 1 \text {, } \\
4,8,11 \text { ) with } 10 \text {-day } \\
\text { treatment-free intervals } \\
\text { - } 20 \mathrm{mg} \text { Dx was given in } \\
\text { combination }\end{array}$ & $\begin{array}{l}\text { Significant clinical improvement } \\
\text { and reduction of lupus-associated } \\
\text { antibodies. } \\
\text { Total IgG levels and vaccine- } \\
\text { specific antibodies were } \\
\text { decreased, suggesting that the } \\
\text { bone marrow PCs were affected. } \\
\text { The authors recommend a } \\
\text { combination therapy of Btz with B } \\
\text { cell depletion to ensure long- } \\
\text { lasting improvement }\end{array}$ \\
\hline $\begin{array}{l}\text { Everly et al. } \\
\text { [44] }\end{array}$ & $\begin{array}{l}\text { Six renal transplant } \\
\text { recipients with refractory } \\
\text { AMR }\end{array}$ & $\begin{array}{l}1.3 \mathrm{mg} / \mathrm{m}^{2} \\
\text { - One cycle of Btz (days } 1 \text {, } \\
4,8,11 \text { ) } \\
\text { - PE and Rtx were } \\
\text { sometimes used as } \\
\text { adjuvant therapy }\end{array}$ & $\begin{array}{l}\text { Reversion of transplant rejection, } \\
\text { amelioration of the clinical } \\
\text { condition, and reduction of allo- } \\
\text { antibody titers. Effects were } \\
\text { sustained for at least five months. } \\
\text { No severe side effects reported }\end{array}$ \\
\hline $\begin{array}{l}\text { Walsh et al. } \\
\text { [58] }\end{array}$ & $\begin{array}{l}30 \text { renal transplant } \\
\text { recipients with AMR. } 13 \text { had } \\
\text { early onset AMR (< six } \\
\text { months post-transplant) } \\
\text { and } 17 \text { had late onset AMR } \\
\text { (> six months post- } \\
\text { transplant) }\end{array}$ & $\begin{array}{l}1.3 \mathrm{mg} / \mathrm{m}^{2} \\
\text { - One cycle of Btz (days } 1 \text {, } \\
4,8,11 \text { ) } \\
\text { - PE and a single dose of } \\
\text { Rtx were used as adjuvant } \\
\text { therapies }\end{array}$ & $\begin{array}{l}\text { Btz improved renal function and } \\
\text { reduced allo-antibody titers in } \\
\text { both early and late AMR, but more } \\
\text { so in early than late AMR. } \\
\text { Peripheral neuropathy was } \\
\text { observed more frequently in late- } \\
\text { onset AMR. There were no reports } \\
\text { of severe cases (grades } 3 \text { or } 4 \text { ) }\end{array}$ \\
\hline $\begin{array}{l}\text { Sberro- } \\
\text { Soussan et } \\
\text { al. [51] }\end{array}$ & $\begin{array}{l}\text { Four renal transplant } \\
\text { recipients with AMR }\end{array}$ & $\begin{array}{l}1.3 \mathrm{mg} / \mathrm{m}^{2} \\
\text { - One cycle of Btz (days } 1 \text {, } \\
4,8,11 \text { ) plus maintenance } \\
\text { immunosuppressive } \\
\text { treatment }\end{array}$ & $\begin{array}{l}\text { After five months' follow-up, no } \\
\text { reductions in allo-antibody or IgG } \\
\text { levels were observed. } \\
\text { Bilateral conjunctivitis and } \\
\text { prolonged fatigue were reported } \\
\text { as severe side effects }\end{array}$ \\
\hline
\end{tabular}


Table 4.2. Continued

\begin{tabular}{|c|c|c|c|}
\hline Reference & Patients & Btz dose and schedule(s) & Main findings \\
\hline $\begin{array}{l}\text { Diwan et al. } \\
\text { [49] }\end{array}$ & $\begin{array}{l}\text { Eight sensitized renal- } \\
\text { transplant candidates, with } \\
\text { high anti-HLA antibody } \\
\text { titers }\end{array}$ & $\begin{array}{l}1.3 \mathrm{mg} / \mathrm{m}^{2} \\
\text { - One or four cycles of Btz } \\
\text { (4 or } 16 \text { doses) }\end{array}$ & $\begin{array}{l}\text { Monotherapy with Btz significantly } \\
\text { reduced the number of both } \\
\text { tetanus-specific and anti-HLA PC in } \\
\text { the bone marrow of patients. Total } \\
\text { PC numbers were also reduced by } \\
\text { Btz, but not significantly. } \\
\text { Treatment with Btz prolonged the } \\
\text { reduction of anti-HLA antibodies } \\
\text { by PE. } \\
\text { No randomized paired-control } \\
\text { group of bone marrow aspirates } \\
\text { was included on this study }\end{array}$ \\
\hline $\begin{array}{l}\text { Everly et al. } \\
\text { [50] }\end{array}$ & $\begin{array}{l}13 \text { renal transplant } \\
\text { recipients with refractory } \\
\text { AMR }\end{array}$ & $\begin{array}{l}1.3 \mathrm{mg} / \mathrm{m}^{2} \\
\text { - One or two cycles of Btz } \\
\text { - PE and methylprednisone } \\
\text { were used as adjuvant } \\
\text { therapies }\end{array}$ & $\begin{array}{l}\text { Anti-HLA antibody levels were } \\
\text { reduced by } \geq 50 \% \text { after one month } \\
\text { of treatment; after one year, } \\
\text { antibody titers were still low. } \\
\text { Total IgG, antibodies against } \\
\text { measles and tetanus toxoid } \\
\text { remained unchanged, and at } \\
\text { protective levels, at one year post- } \\
\text { treatment. } \\
\text { The authors suggest that the lower } \\
\text { antibody production of protective } \\
\text { PC makes them less susceptible to } \\
\text { proteasome inhibition }\end{array}$ \\
\hline $\begin{array}{l}\text { Waiser et al. } \\
\text { [52] }\end{array}$ & $\begin{array}{l}10 \text { renal transplant } \\
\text { recipients with AMR }\end{array}$ & $\begin{array}{l}1.3 \mathrm{mg} / \mathrm{m}^{2} \\
\text { - One cycle of Btz (days } 1 \text {, } \\
4,8,11 \text { ) } \\
\text { - PE and IVIg were used as } \\
\text { adjuvant therapies }\end{array}$ & $\begin{array}{l}\text { Outcomes were compared to a } \\
\text { historical group of patients treated } \\
\text { with the same adjuvant therapy } \\
\text { but with one single dose of Rtx } \\
\text { instead of Btz. At } 18 \text { months post- } \\
\text { treatment, graft survival was } \\
\text { superior in Btz-treated patients. } \\
\text { Both Btz and Rtx significantly } \\
\text { reduced peak anti-HLA antibody } \\
\text { levels during the follow-up period, } \\
\text { but neither eradicated existing } \\
\text { allo-antibodies }\end{array}$ \\
\hline
\end{tabular}

AMR, antibody-mediated transplant rejection; Btz, bortezomib; Dx, dexamethasone; IVIg, intravenous immunoglobulin; PC, plasma cell; PE, plasma exchange; Rtx, rituximab; SLE, systemic lupus erythematosus.

\section{Proteasome inhibitors for myasthenia gravis patients?}

Generally speaking, chronic autoimmune diseases such as MG can seriously affect quality of life because of persistence of clinical symptoms and/or side effects of long-term 
medication (e.g., diabetes, hypertension and osteoporosis caused by glucocorticoids [60]). Broad-spectrum immunosuppressive drugs, such as prednisone and azathioprine, ameliorate the symptoms in most MG patients. However, there is typically a long delay (six to eight weeks for steroids [60] and up to 18 months for azathioprine [61]) before autoantibody titers decline and muscles strengthen significantly. That might well be because of treatment-resistant plasma cells. If so, their specific elimination could represent a novel and promising approach for treating MG. In time, we hope that there will be biomarkers to predict which MG patients will respond rapidly to standard immunosuppressants and which will need adjunctive plasma cell depletion to achieve earlier improvements, whether in acute severe or chronic refractory cases.

An important limitation in using bortezomib in nonmalignant diseases is the concern about development of PN, which is a serious but generally reversible side effect [62] that seems to depend on reaching a cumulative bortezomib-dose threshold during the first five cycles of treatment [63]. Whereas current regimens were designed for multiple myelomas (which are notoriously hard to treat), lower doses and short courses might be sufficient to deplete autoreactive plasma cells significantly, e.g., in MG. For instance, Diwan et al. showed that four cycles of bortezomib were already sufficient to significantly deplete bone marrow plasma cells in transplant recipients [49]. In a large clinical trial in myeloma patients, single weekly doses proved as effective as the established twice weekly schedule, with significantly lower risks of both any-grade PN (35\% vs. $51 \%$ ) and grade $3 / 4$ PN ( $8 \%$ vs. $28 \%$ ) [32]. In addition, using the recently FDAapproved subcutaneous (instead of intravenous) route reduced the incidence and severity of PN (any grade PN 38\% vs. 53\%; grade 3/4 PN 6\% vs. 16\%) [31]. Furthermore, secondgeneration proteasome inhibitors are now approved (carfilzomib) or being developed (some of them are already in use in clinical trials); they seem to be more selective than bortezomib and potentially less neurotoxic $[34,64]$. Another interesting possibility is to combine bortezomib with other drugs now being used for treating myelomas. These include the immunomodulatory drugs thalidomide and lenalidomide, drugs blocking the interactions that maintain plasma cells in their survival niches in the bone marrow (natalizumab [65] against VLA-4, tocilizumab [66] or siltuximab [67] against IL-6, and 
plerixafor [68] against CXCR4), or drugs reactive with plasma cells directly (elotuzumab [69] against CS1, daratumumab [70] against CD38, or nBT062 [71] against CD138).

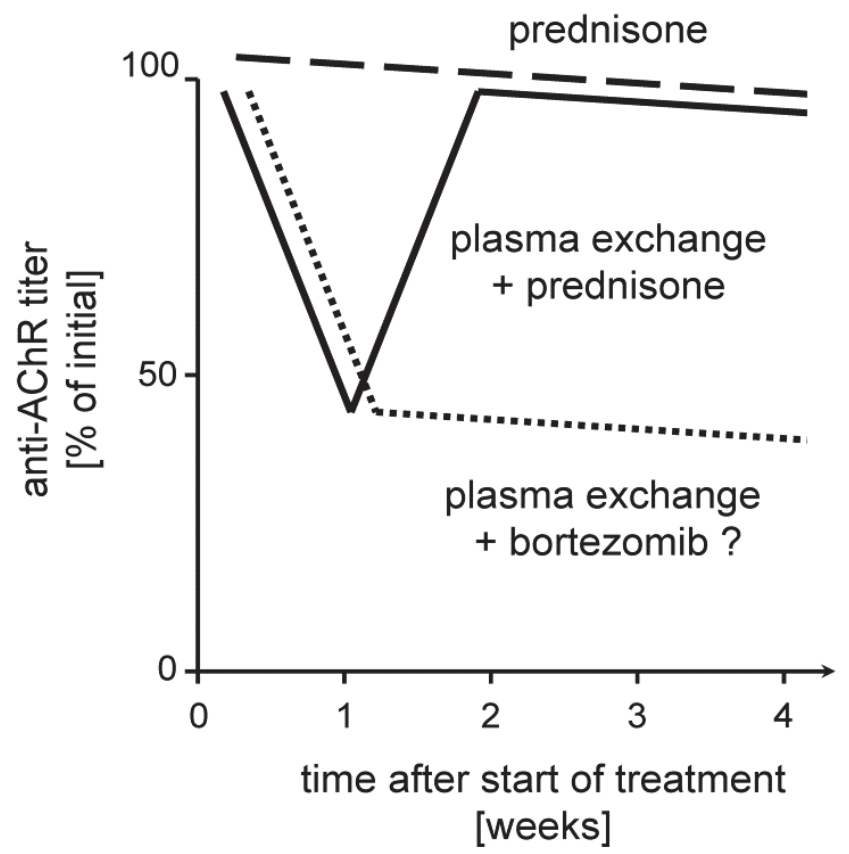

Figure 4.2. Schematic representation of predicted changes in anti-AChR antibody titers following different immunosuppressive treatments. Initial treatment with prednisone only (dashed line) normally requires several weeks to reduce autoantibody titers significantly. Plasma exchange (solid line) reduces them rapidly, but - even in patients also taking prednisone and other immunosuppressive drugs - titers return almost to their initial levels within the next few weeks [72]. The combination of plasma exchange with bortezomib (dotted line) could induce a more lasting reduction in antibody titers, based on results of such a treatment in organ transplant recipients [50].

\section{Conclusions}

In conclusion, proteasome inhibition has significant potential as an effective induction therapy, in combination with plasma exchange, for MG patients with high autoantibody titers and/or acute severe weakness. Removing autoreactive plasma cells should lead to more sustained reductions in autoantibody titers after plasma exchange (Fig. 4.2), a procedure which, by itself, leads to only temporary reductions in autoantibodies in the plasma [72]. Additional immunosuppression with glucocorticoids (at lower than normal doses), azathioprine, MMF, or rituximab would probably be necessary to prevent 
generation of new autoreactive plasma cells - by when bortezomib will have served its purpose. Moreover, it might prove valuable in refractory MG.

To summarize, we consider that proteasome inhibition represents a promising new approach for MG treatment. Experience from animal models, from in vitro settings and from transplant recipients convincingly supports the potential of bortezomib for targeting plasma cells, the main antibody-producing cells. Naturally, future work is needed to confirm the potential of proteasome inhibition in antibody-mediated autoimmune diseases.

\section{Acknowledgements}

We thank Mr H. Duimel and Dr F. Verheyen for their help in preparing the electron micrographs, Mr J. Hummel and Dr. K. Vrolix for their help with the thymic cell cultures and Dr M.E. Hill, Prof. H. Kaminski, Prof. A. Melms and Prof. A.L. Goldberg for helpful discussions. A.M.G. was supported by a Marie-Curie fellowship from the European Union and a grant from the Prinses Beatrix Fonds (Project WAR08-12); P.M.-M. by grants from the Association Française contre les Myopathies and Genmab; N.W. by the UK Medical Research Council; M.L. by a Veni fellowship of The Netherlands Organization for Scientific Research and a fellowship of the Brain Foundation of the Netherlands. The authors declare no conflicts of interest. 


\section{$\underline{\text { References }}$}

1. Lindstrom, J.M., Seybold, M.E., Lennon, V.A., Whittingham, S., Duane, D.D. 1976. Antibody to acetylcholine receptor in myasthenia gravis. Prevalence, clinical correlates, and diagnostic value. Neurology, 26: 1054-9.

2. Hoch, W., McConville, J., Helms, S., Newsom-Davis, J., Melms, A., Vincent, A. 2001. Autoantibodies to the receptor tyrosine kinase MuSK in patients with myasthenia gravis without acetylcholine receptor antibodies. Nat Med, 7: 365-8.

3. Higuchi, O., Hamuro, J., Motomura, M., Yamanashi, Y. 2011. Autoantibodies to low-density lipoprotein receptor-related protein 4 in myasthenia gravis. Ann Neurol, 69: 418-22.

4. Leite, M.I., Jones, M., Strobel, P., Marx, A., Gold, R., Niks, E., Verschuuren, J.J., BerrihAknin, S., Scaravilli, F., Canelhas, A. et al. 2007. Myasthenia gravis thymus: complement vulnerability of epithelial and myoid cells, complement attack on them, and correlations with autoantibody status. Am J Pathol, 171: 893-905.

5. Hill, M.E., Shiono, H., Newsom-Davis, J., Willcox, N. 2008. The myasthenia gravis thymus: a rare source of human autoantibody-secreting plasma cells for testing potential therapeutics. J Neuroimmunol, 201-202: 50-6.

6. Leite, M.I., Strobel, P., Jones, M., Micklem, K., Moritz, R., Gold, R., Niks, E.H., Berrih-Aknin, S., Scaravilli, F., Canelhas, A. et al. 2005. Fewer thymic changes in MuSK antibody-positive than in MuSK antibody-negative MG. Ann Neurol, 57: 444-8.

7. Klooster, R., Plomp, J.J., Huijbers, M.G., Niks, E.H., Straasheijm, K.R., Detmers, F.J., Hermans, P.W., Sleijpen, K., Verrips, A., Losen, M. et al. 2012. Muscle-specific kinase myasthenia gravis IgG4 autoantibodies cause severe neuromuscular junction dysfunction in mice. Brain, 135: 1081-101.

8. Gomez, A.M., Van Den Broeck, J., Vrolix, K., Janssen, S.P., Lemmens, M.A., Van Der Esch, E., Duimel, H., Frederik, P., Molenaar, P.C., Martinez-Martinez, P. et al. Antibody effector mechanisms in myasthenia gravis-pathogenesis at the neuromuscular junction. Autoimmunity, 43: 353-70.

9. Diaz-Manera, J., Martinez-Hernandez, E., Querol, L., Klooster, R., Rojas-Garcia, R., SuarezCalvet, X., Munoz-Blanco, J.L., Mazia, C., Straasheijm, K.R., Gallardo, E. et al. 2012. Longlasting treatment effect of rituximab in MuSK myasthenia. Neurology, 78: 189-93.

10. Lifter, J., Kincade, P.W., Choi, Y.S. 1976. Subpopulations of chicken B lymphocytes. J Immunol, 117: 2220-5.

11. Miller, J.J., 3rd. 1964. An Autoradiographic Study of the Stability of Plasma Cell Ribonucleic Acid in Rats. J Immunol, 93: 250-4.

12. Manz, R.A., Thiel, A., Radbruch, A. 1997. Lifetime of plasma cells in the bone marrow. Nature, 388: 133-4.

13. Slifka, M.K., Antia, R., Whitmire, J.K., Ahmed, R. 1998. Humoral immunity due to long-lived plasma cells. Immunity, 8: 363-72.

14. Radbruch, A., Muehlinghaus, G., Luger, E.O., Inamine, A., Smith, K.G., Dorner, T., Hiepe, F. 2006. Competence and competition: the challenge of becoming a long-lived plasma cell. Nat Rev Immunol, 6: 741-50.

15. DiLillo, D.J., Hamaguchi, Y., Ueda, Y., Yang, K., Uchida, J., Haas, K.M., Kelsoe, G., Tedder, T.F. 2008. Maintenance of long-lived plasma cells and serological memory despite mature and memory B cell depletion during CD20 immunotherapy in mice. J Immunol, 180: 36171.

16. Ahuja, A., Anderson, S.M., Khalil, A., Shlomchik, M.J. 2008. Maintenance of the plasma cell pool is independent of memory B cells. Proc Natl Acad Sci U S A, 105: 4802-7.

17. Belnoue, E., Tougne, C., Rochat, A.F., Lambert, P.H., Pinschewer, D.D., Siegrist, C.A. 2012. 
Homing and adhesion patterns determine the cellular composition of the bone marrow plasma cell niche. J Immunol, 188: 1283-91.

18. Minges Wols, H.A. 2002. Plasma Cells. In Encyclopedia of life sciences. Nature Pub. Group, London; New York.

19. Iwakoshi, N.N., Lee, A.H., Vallabhajosyula, P., Otipoby, K.L., Rajewsky, K., Glimcher, L.H. 2003. Plasma cell differentiation and the unfolded protein response intersect at the transcription factor XBP-1. Nat Immunol, 4: 321-9.

20. Shaffer, A.L., Shapiro-Shelef, M., Iwakoshi, N.N., Lee, A.H., Qian, S.B., Zhao, H., Yu, X., Yang, L., Tan, B.K., Rosenwald, A. et al. 2004. XBP1, downstream of Blimp-1, expands the secretory apparatus and other organelles, and increases protein synthesis in plasma cell differentiation. Immunity, 21: 81-93.

21. Hoyer, B.F., Moser, K., Hauser, A.E., Peddinghaus, A., Voigt, C., Eilat, D., Radbruch, A., Hiepe, F., Manz, R.A. 2004. Short-lived plasmablasts and long-lived plasma cells contribute to chronic humoral autoimmunity in NZB/W mice. J Exp Med, 199: 1577-84.

22. Szyszko, E.A., Skarstein, K., Jonsson, R., Brokstad, K.A. 2011. Distinct phenotypes of plasma cells in spleen and bone marrow of autoimmune NOD.B10.H2b mice. Autoimmunity, 44: 415-26.

23. Teng, Y.O., Wheater, G., Hogan, V.E., Stocks, P., Levarht, E.N., Huizinga, T.W., Toes, R.E., van Laar, J.M. 2012. Induction of long-term B-cell depletion in refractory rheumatoid arthritis patients preferentially affects autoreactive more than protective humoral immunity. Arthritis Res Ther, 14: R57.

24. Merrill, J.T., Neuwelt, C.M., Wallace, D.J., Shanahan, J.C., Latinis, K.M., Oates, J.C., Utset, T.O., Gordon, C., Isenberg, D.A., Hsieh, H.J. et al. 2010. Efficacy and safety of rituximab in moderately-to-severely active systemic lupus erythematosus: the randomized, doubleblind, phase II/III systemic lupus erythematosus evaluation of rituximab trial. Arthritis Rheum, 62: 222-33.

25. Hiepe, F., Dorner, T., Hauser, A.E., Hoyer, B.F., Mei, H., Radbruch, A. 2011. Long-lived autoreactive plasma cells drive persistent autoimmune inflammation. Nat Rev Rheumatol, 7: 170-8.

26. Miller, J.J., Cole, L.J. 1967. The radiation resistance of long-lived lymphocytes and plasma cells in mouse and rat lymph nodes. J Immunol, 98: 982-90.

27. Perry, D.K., Burns, J.M., Pollinger, H.S., Amiot, B.P., Gloor, J.M., Gores, G.J., Stegall, M.D. 2009. Proteasome inhibition causes apoptosis of normal human plasma cells preventing alloantibody production. Am J Transplant, 9: 201-9.

28. Miller, J.J., 3rd, Cole, L.J. 1967. Resistance of long-lived lymphocytes and plasma cells in rat lymph nodes to treatment with prednisone, cyclophosphamide, 6-mercaptopurine, and actinomycin D. J Exp Med, 126: 109-25.

29. Kane, R.C., Farrell, A.T., Sridhara, R., Pazdur, R. 2006. United States Food and Drug Administration approval summary: bortezomib for the treatment of progressive multiple myeloma after one prior therapy. Clin Cancer Res, 12: 2955-60.

30. Goldberg, A.L. 2011. Bortezomib's Scientific Origins and Its Tortuous Path to the Clinic. In Bortezomib in the Treatment of Multiple Myeloma. Ghobrial, I.M., Richardson, P.G., Anderson, K.C., eds. Birkhäuser Basel, pp. 1-27.

31. Moreau, P., Pylypenko, H., Grosicki, S., Karamanesht, I., Leleu, X., Grishunina, M., Rekhtman, G., Masliak, Z., Robak, T., Shubina, A. et al. 2011. Subcutaneous versus intravenous administration of bortezomib in patients with relapsed multiple myeloma: a randomised, phase 3, non-inferiority study. Lancet Oncol, 12: 431-40.

32. Bringhen, S., Larocca, A., Rossi, D., Cavalli, M., Genuardi, M., Ria, R., Gentili, S., Patriarca, F., Nozzoli, C., Levi, A. et al. 2010. Efficacy and safety of once-weekly bortezomib in multiple myeloma patients. Blood, 116: 4745-53. 
33. Vij, R., Siegel, D.S., Jagannath, S., Jakubowiak, A.J., Stewart, A.K., McDonagh, K., Bahlis, N., Belch, A., Kunkel, L.A., Wear, S. et al. 2012. An open-label, single-arm, phase 2 study of single-agent carfilzomib in patients with relapsed and/or refractory multiple myeloma who have been previously treated with bortezomib. Br J Haematol.

34. Arastu-Kapur, S., Anderl, J.L., Kraus, M., Parlati, F., Shenk, K.D., Lee, S.J., Muchamuel, T., Bennett, M.K., Driessen, C., Ball, A.J. et al. 2011. Nonproteasomal targets of the proteasome inhibitors bortezomib and carfilzomib: a link to clinical adverse events. Clin Cancer Res, 17: 2734-43.

35. Obeng, E.A., Carlson, L.M., Gutman, D.M., Harrington, W.J., Jr., Lee, K.P., Boise, L.H. 2006. Proteasome inhibitors induce a terminal unfolded protein response in multiple myeloma cells. Blood, 107: 4907-16.

36. Hideshima, T., Chauhan, D., Richardson, P., Mitsiades, C., Mitsiades, N., Hayashi, T., Munshi, N., Dang, L., Castro, A., Palombella, V. et al. 2002. NF-kappa B as a therapeutic target in multiple myeloma. J Biol Chem, 277: 16639-47.

37. Meister, S., Schubert, U., Neubert, K., Herrmann, K., Burger, R., Gramatzki, M., Hahn, S., Schreiber, S., Wilhelm, S., Herrmann, M. et al. 2007. Extensive immunoglobulin production sensitizes myeloma cells for proteasome inhibition. Cancer Res, 67: 1783-92.

38. Neubert, K., Meister, S., Moser, K., Weisel, F., Maseda, D., Amann, K., Wiethe, C., Winkler, T.H., Kalden, J.R., Manz, R.A. et al. 2008. The proteasome inhibitor bortezomib depletes plasma cells and protects mice with lupus-like disease from nephritis. Nat Med, 14: 74855.

39. Gomez, A.M., Vrolix, K., Martinez-Martinez, P., Molenaar, P.C., Phernambucq, M., van der Esch, E., Duimel, H., Verheyen, F., Voll, R.E., Manz, R.A. et al. 2011. Proteasome inhibition with bortezomib depletes plasma cells and autoantibodies in experimental autoimmune myasthenia gravis. J Immunol, 186: 2503-13.

40. Vogelbacher, R., Meister, S., Guckel, E., Starke, C., Wittmann, S., Stief, A., Voll, R., Daniel, C., Hugo, C. 2010. Bortezomib and sirolimus inhibit the chronic active antibody-mediated rejection in experimental renal transplantation in the rat. Nephrol Dial Transplant, $25:$ 3764-73.

41. Meslier, Y., Andre, S., Dimitrov, J.D., Delignat, S., Bayry, J., Kaveri, S.V., Lacroix-Desmazes, S. 2011. Bortezomib delays the onset of factor VIII inhibitors in experimental hemophilia A, but fails to eliminate established anti-factor VIII IgG-producing cells. J Thromb Haemost, 9: 719-28.

42. Ichikawa, H.T., Conley, T., Muchamuel, T., Jiang, J., Lee, S., Owen, T., Barnard, J., Nevarez, S., Goldman, B.I., Kirk, C.J. et al. 2012. Beneficial effect of novel proteasome inhibitors in murine lupus via dual inhibition of type I interferon and autoantibody-secreting cells. Arthritis Rheum, 64: 493-503.

43. Bontscho, J., Schreiber, A., Manz, R.A., Schneider, W., Luft, F.C., Kettritz, R. 2011. Myeloperoxidase-specific plasma cell depletion by bortezomib protects from antineutrophil cytoplasmic autoantibodies-induced glomerulonephritis. J Am Soc Nephrol, 22: 336-48.

44. Everly, M.J., Everly, J.J., Susskind, B., Brailey, P., Arend, L.J., Alloway, R.R., Roy-Chaudhury, P., Govil, A., Mogilishetty, G., Rike, A.H. et al. 2008. Bortezomib provides effective therapy for antibody- and cell-mediated acute rejection. Transplantation, 86: 1754-61.

45. Willcox, H.N., Newsom-Davis, J., Calder, L.R. 1984. Cell types required for antiacetylcholine receptor antibody synthesis by cultured thymocytes and blood lymphocytes in myasthenia gravis. Clin Exp Immunol, 58: 97-106.

46. Willcox, H.N., Newsom-Davis, J., Calder, L.R. 1983. Greatly increased autoantibody production in myasthenia gravis by thymocyte suspensions prepared with proteolytic enzymes. Clin Exp Immunol, 54: 378-86. 
47. Richardson, P.G., Sonneveld, P., Schuster, M.W., Irwin, D., Stadtmauer, E.A., Facon, T., Harousseau, J.L., Ben-Yehuda, D., Lonial, S., Goldschmidt, H. et al. 2005. Bortezomib or high-dose dexamethasone for relapsed multiple myeloma. N Engl J Med, 352: 2487-98.

48. Carson, K.R., Beckwith, L.G., Mehta, J. 2010. Successful treatment of IgM-mediated autoimmune hemolytic anemia with bortezomib. Blood, 115: 915.

49. Diwan, T.S., Raghavaiah, S., Burns, J.M., Kremers, W.K., Gloor, J.M., Stegall, M.D. 2011. The impact of proteasome inhibition on alloantibody-producing plasma cells in vivo. Transplantation, 91: 536-41.

50. Everly, M.J., Terasaki, P.I., Hopfield, J., Trivedi, H.L., Kaneku, H. 2010. Protective immunity remains intact after antibody removal by means of proteasome inhibition. Transplantation, 90: 1493-8.

51. Sberro-Soussan, R., Zuber, J., Suberbielle-Boissel, C., Candon, S., Martinez, F., Snanoudj, R., Rabant, M., Pallet, N., Nochy, D., Anglicheau, D. et al. 2010. Bortezomib as the sole postrenal transplantation desensitization agent does not decrease donor-specific anti-HLA antibodies. Am J Transplant, 10: 681-6.

52. Waiser, J., Budde, K., Schutz, M., Liefeldt, L., Rudolph, B., Schonemann, C., Neumayer, H.H., Lachmann, N. 2012. Comparison between bortezomib and rituximab in the treatment of antibody-mediated renal allograft rejection. Nephrol Dial Transplant, 27: 1246-51.

53. Danchaivijitr, P., Yared, J., Rapoport, A.P. 2011. Successful treatment of IgG and complement-mediated autoimmune hemolytic anemia with bortezomib and low-dose cyclophosphamide. Am J Hematol, 86: 331-2.

54. van der Heijden, J.W., Oerlemans, R., Lems, W.F., Scheper, R.J., Dijkmans, B.A., Jansen, G. 2009. The proteasome inhibitor bortezomib inhibits the release of NFkappaB-inducible cytokines and induces apoptosis of activated $\mathrm{T}$ cells from rheumatoid arthritis patients. Clin Exp Rheumatol, 27: 92-8.

55. Frohlich, K., Holle, J.U., Aries, P.M., Gross, W.L., Moosig, F. 2011. Successful use of bortezomib in a patient with systemic lupus erythematosus and multiple myeloma. Ann Rheum Dis, 70: 1344-5.

56. Woodle, E.S., Alloway, R.R., Girnita, A. 2011. Proteasome inhibitor treatment of antibodymediated allograft rejection. Curr Opin Organ Transplant, 16: 434-8.

57. Walsh, R.C., Everly, J.J., Brailey, P., Rike, A.H., Arend, L.J., Mogilishetty, G., Govil, A., RoyChaudhury, P., Alloway, R.R., Woodle, E.S. 2010. Proteasome inhibitor-based primary therapy for antibody-mediated renal allograft rejection. Transplantation, 89: 277-84.

58. Walsh, R.C., Brailey, P., Girnita, A., Alloway, R.R., Shields, A.R., Wall, G.E., Sadaka, B.H., Cardi, M., Tevar, A., Govil, A. et al. 2011. Early and late acute antibody-mediated rejection differ immunologically and in response to proteasome inhibition. Transplantation, 91: 1218-26.

59. Hiepe, F., Hoyer, B.F., Tobias, A., Taddeo, A., Voll, R.E., Radbruch, A. 2011. Therapeutic inhibition of proteasomes in systemic lupus erythematosus. Journal of Translational Medicine, 9(Suppl 2): 19.

60. Sanders, D.B., Evoli, A. 2010. Immunosuppressive therapies in myasthenia gravis. Autoimmunity, 43: 428-35.

61. Palace, J., Newsom-Davis, J., Lecky, B. 1998. A randomized double-blind trial of prednisolone alone or with azathioprine in myasthenia gravis. Myasthenia Gravis Study Group. Neurology, 50: 1778-83.

62. Richardson, P.G., Xie, W., Mitsiades, C., Chanan-Khan, A.A., Lonial, S., Hassoun, H., Avigan, D.E., Oaklander, A.L., Kuter, D.J., Wen, P.Y. et al. 2009. Single-agent bortezomib in previously untreated multiple myeloma: efficacy, characterization of peripheral neuropathy, and molecular correlations with response and neuropathy. J Clin Oncol, 27: 
3518-25.

63. Cavaletti, G., Jakubowiak, A.J. 2010. Peripheral neuropathy during bortezomib treatment of multiple myeloma: a review of recent studies. Leuk Lymphoma, 51: 1178-87.

64. Kirk, C.J. 2012. Discovery and development of second-generation proteasome inhibitors. Semin Hematol, 49: 207-14.

65. Podar, K., Zimmerhackl, A., Fulciniti, M., Tonon, G., Hainz, U., Tai, Y.T., Vallet, S., Halama, N., Jager, D., Olson, D.L. et al. 2011. The selective adhesion molecule inhibitor Natalizumab decreases multiple myeloma cell growth in the bone marrow microenvironment: therapeutic implications. Br J Haematol, 155: 438-48.

66. Matsuyama, Y., Nagashima, T., Honne, K., Kamata, Y., Iwamoto, M., Okazaki, H., Sato, K., Ozawa, K., Minota, S. 2011. Successful treatment of a patient with rheumatoid arthritis and IgA-kappa multiple myeloma with tocilizumab. Intern Med, 50: 639-42.

67. Hunsucker, S.A., Magarotto, V., Kuhn, D.J., Kornblau, S.M., Wang, M., Weber, D.M., Thomas, S.K., Shah, J.J., Voorhees, P.M., Xie, H. et al. 2011. Blockade of interleukin-6 signalling with siltuximab enhances melphalan cytotoxicity in preclinical models of multiple myeloma. Br J Haematol, 152: 579-92.

68. Lor, K.W., Helmons, P.J., Belew, H., Lane, J.R., Ball, E.D. 2012. Plerixafor as First- and Second-Line Strategies for Autologous Stem Cell Mobilization in Patients with NonHodgkin's Lymphoma or Multiple Myeloma. Pharmacotherapy, 32: 596-603.

69. Lonial, S., Vij, R., Harousseau, J.L., Facon, T., Moreau, P., Mazumder, A., Kaufman, J.L., Leleu, X., Tsao, L.C., Westland, C. et al. 2012. Elotuzumab in combination with lenalidomide and low-dose dexamethasone in relapsed or refractory multiple myeloma. $J$ Clin Oncol, 30: 1953-9.

70. de Weers, M., Tai, Y.T., van der Veer, M.S., Bakker, J.M., Vink, T., Jacobs, D.C., Oomen, L.A., Peipp, M., Valerius, T., Slootstra, J.W. et al. 2011. Daratumumab, a novel therapeutic human CD38 monoclonal antibody, induces killing of multiple myeloma and other hematological tumors. J Immunol, 186: 1840-8.

71. Ikeda, H., Hideshima, T., Fulciniti, M., Lutz, R.J., Yasui, H., Okawa, Y., Kiziltepe, T., Vallet, S., Pozzi, S., Santo, L. et al. 2009. The monoclonal antibody nBT062 conjugated to cytotoxic Maytansinoids has selective cytotoxicity against CD138-positive multiple myeloma cells in vitro and in vivo. Clin Cancer Res, 15: 4028-37.

72. Hawkey, C.J., Newsom-Davis, J., Vincent, A. 1981. Plasma exchange and immunosuppressive drug treatment in myasthenia gravis: no evidence for synergy. $J$ Neurol Neurosurg Psychiatry, 44: 469-75. 


\section{Chapter 5}

\section{Proteasome inhibition with bortezomib depletes plasma cells and autoantibodies in experimental autoimmune myasthenia gravis}

Alejandro M. Gomez, Kathleen Vrolix, Pilar Martínez-Martínez, Peter C. Molenaar, Marko Phernambucq, Eline van der Esch, Hans Duimel, Fons Verheyen, Reinhard E. Voll, Rudolf A. Manz, Marc H. De Baets, and Mario Losen

The Journal of Immunology (2011); 186 (4):2503-13. 


\section{Abstract}

Bortezomib, an inhibitor of proteasomes, has been reported to reduce autoantibody titers and to improve clinical condition in mice suffering from lupus-like disease. Bortezomib depletes both short- and long-lived plasma cells; the latter normally survive the standard immunosuppressant treatments targeting $T$ and $B$ cells. These findings encouraged us to test whether bortezomib is effective for alleviating the symptoms in the experimental autoimmune myasthenia gravis (EAMG) model for myasthenia gravis, a disease that is characterized by autoantibodies against the acetylcholine receptor (AChR) of skeletal muscle. Lewis rats were immunized with saline (control, $n=36$ ) or Torpedo AChR (EAMG, $n=54$ ) in complete Freund's adjuvant (CFA) in the first week of an experimental period of eight weeks. After immunization, rats received twice a week subcutaneous injections of bortezomib $(0.2 \mathrm{mg} / \mathrm{kg}$ in saline) or saline injections. Bortezomib induced apoptosis in bone marrow cells and reduced the amount of plasma cells in the bone marrow by up to 81\%. In the EAMG animals, bortezomib efficiently reduced the rise of anti-AChR autoantibody titers, prevented ultrastructural damage of the postsynaptic membrane, improved neuromuscular transmission, and decreased myasthenic symptoms. This study thus underscores the potential of the therapeutic use of proteasome inhibitors to target plasma cells in antibody-mediated autoimmune diseases. 


\section{Introduction}

The resistance of long-lived plasma cells against immunosuppressive medication poses a serious problem for the treatment of antibody-mediated autoimmune diseases. Currently used immunosuppressive drugs, including corticosteroids, mitomycin C, cyclosporine $A$, azathioprine, and cyclophosphamide, affect mainly activated and dividing B and/or T cells [1]. Plasma cells are the terminally differentiated, non-dividing effector cells of the B cell lineage that have lost many surface markers. In their survival niches in the spleen and in particular in the bone marrow [2], resident long-lived plasma cells are resistant to most therapies including immunosuppressive drugs and anti-CD20 antibodies that are aimed to inhibit the activation and/or proliferation of lymphocytes or to deplete certain lymphocyte subpopulations $[3,4]$. Thus, resistance to available therapies might be due to persistent long-lived plasma cells that continue to produce autoantibodies notwithstanding immunosuppressive treatment [5].

However, because of their high rate of immunoglobulin production, both shortand long-lived plasma cells are particularly sensitive to inhibition of the proteasome [6, 7]. Indeed, proteasome inhibition causes accumulation of non-degraded, misfolded proteins within the endoplasmic reticulum (ER) of plasma cells and, subsequently, to activation of the terminal unfolded protein response, ultimately leading to apoptosis [8]. The proteasome inhibitor bortezomib, also known under the trade name Velcade, is a boronic acid dipeptide (phenylalanine-leucine) derivative, which binds reversibly to the $26 \mathrm{~S}$ proteasome [9]. After injection, bortezomib is distributed widely and quickly to the blood and most tissues [10]. Currently, bortezomib is approved for the treatment of multiple myeloma and mantle cell lymphoma. In addition to the treatment of B cell malignancies, proteasome inhibition could be a useful therapeutic strategy for antibody mediated autoimmunity such as lupus [7].

In the present study we tested the effect of proteasome inhibition in a model for myasthenia gravis (MG), a well-characterized disease that is found to be critically dependent on the level of autoantibodies against the acetylcholine receptors (AChRs) of muscle. In $85 \%$ of MG patients the disease is caused by autoantibodies against the muscle 
AChR [11]. The remaining patients have autoantibodies against the muscle specific kinase (MuSK) [12] ( 5\% of all MG patients) or no detectable autoantibodies (idiopathic MG, accounting for $\sim 10 \%$ of all patients) [13]. Both AChR and MuSK proteins are located in the postsynaptic membrane of the neuromuscular junction (NMJ), which is specialized to respond to the neurotransmitter acetylcholine released from the overlying nerve ending. These proteins are thus essential for muscle contraction, and MG is potentially fatal, since autoantibodies can cause respiratory failure by impairing neuromuscular transmission. In such an event of acute myasthenic crisis, the first choice of treatment is plasma exchange, mechanical ventilation [14], and intravenous treatment with high doses of IgG [15]. Plasma exchange typically leads to significant improvement or remission within a few days in most patients, including those with the idiopathic MG, but the effect is, of course, not long-lasting. Immunosuppressive drugs such as prednisone and azathioprine are generally used for long-term therapy [1, 16-18]. Because these depend mostly on preventing the activation, proliferation, and differentiation of developing $B$ and $T$ cells, the autoantibody titers only drop over a period of months. Using an established immunotherapy protocol with prednisone and azathioprine, it may take as much as 18 months before patients improve [16]. For the intermediate time interval, during which plasma cells continue to produce autoantibodies, proteasome inhibition might be a useful therapy. Moreover, because some MG patients do not respond well to any currently available treatment in terms of poor reduction of autoantibodies or the occurrence of side effects, proteasome inhibition might provide a therapeutic alternative.

In the experimental autoimmune myasthenia gravis (EAMG) model the disease is induced by immunizing rats with the AChR from the electric organ of the electric ray Torpedo californica [19, 20]. A small proportion of antibodies against the Torpedo AChR cross-reacts with the AChR of the muscle [21]. As in human MG with anti-AChR autoantibodies, the disease symptoms in EAMG are caused by antibody-mediated destruction of the NMJ $[22,23]$.

In this study, we examined the effect of bortezomib in EAMG rats using two different treatment regimes. The first treatment consisted of bortezomib injections for eight weeks, starting directly after immunization (herein referred to as $8 w-B z$ ). For the 
second treatment regime, rats were injected with bortezomib starting only four weeks after immunization, when autoantibody titers were already detectable, until eight weeks after immunization $(4 \mathrm{w}-\mathrm{Bz})$. Using this setup we investigated the potential therapeutic effect of bortezomib after onset of the disease. The results show that both treatment regimes reduce autoantibody levels by depleting bone marrow plasma cells, but only the 8-week bortezomib-treatment led to a significant improvement of the clinical condition of the EAMG rats and to a reduction of postsynaptic damage.

\section{Materials and Methods}

\section{$\underline{\text { Animals }}$}

Inbred female Lewis rats $(n=90)$ were obtained from the Department of Experimental Animal Services, Maastricht University (The Netherlands). Permission to perform this experiment was granted by the Committee on Animal Welfare, according to Dutch governmental rules. At 6 weeks of age, animals were weighed and divided into six experimental groups (Table 5.1) with an equal average weight.

\section{Induction of EAMG}

EAMG was induced in 7-week-old rats $(n=54)$ by active immunization with AChR purified from the electric organ of $T$. californica (tAChR) in complete Freund's adjuvant (CFA). In brief, $20 \mu \mathrm{g}$ of tAChR [20] was dissolved in $100 \mu \mathrm{L}$ of phosphate-buffered saline (PBS) and emulsified with an equal volume of CFA with $0.1 \%$ of Mycobacterium tuberculosis H37 (Difco Laboratories, Detroit, MI). Animals were initially anesthetized in a cylindrical tube through which $5 \%$ isoflurane in air was supplied. Subsequently, $3 \%$ isoflurane was supplied by a cap over the head and $200 \mu \mathrm{L}$ CFA/tAChR emulsion was injected subcutaneously at the base of the tail at three different spots, as described by Lennon and colleagues [24]. Control animals ( $n=36$ ) were injected with an equal volume of emulsified PBS and CFA. Rats were sacrificed eight weeks after immunization or earlier, if they had reached the humane endpoints as described below. They were sacrificed by inhalation of $\mathrm{CO}_{2}$ in air and subsequent cervical dislocation. 


\section{Experimental design and administration of drugs}

Bortezomib was purchased as a lyophilized powder (Velcade, Janssen-Cilag B.V., Beerse, Belgium) and dissolved in sterile saline solution at a final concentration of $0.1 \mathrm{mg} / \mathrm{mL}$. Two weekly doses of $0.2 \mathrm{mg} / \mathrm{kg}$ bortezomib solution were administered subcutaneously, which is considered the highest dose to use without having increased mortality rates or severe side effects in rats $[10,25,26]$. Control and EAMG groups were subdivided into three treatment regimes each (Table 5.1). "Saline" groups received two weekly subcutaneous injections of $0.9 \% \mathrm{NaCl}$ solution $(2 \mathrm{~mL} / \mathrm{kg}$ ) at the neck for eight weeks. The $4 \mathrm{w}$ - $\mathrm{Bz}$ groups received two weekly saline injections for the first four weeks after immunization (by which time autoantibody levels were highly elevated in the plasma) and subsequently two weekly injections of bortezomib for another four weeks. The $8 \mathrm{w}-\mathrm{Bz}$ groups received two weekly injections of bortezomib for eight weeks, starting directly after immunization.

For practical reasons the experiment was conducted three times in sets of 30 animals each, including an equal number of all the aforementioned groups. The animals' tissues were analyzed using electron microscopy (EM), electromyography (EMG), immunofluorescence (IF), and fluorescence activated cell sorting (FACS), and the number of animals used for each method is indicated in Table 5.1.

Table 5.1. Treatment groups

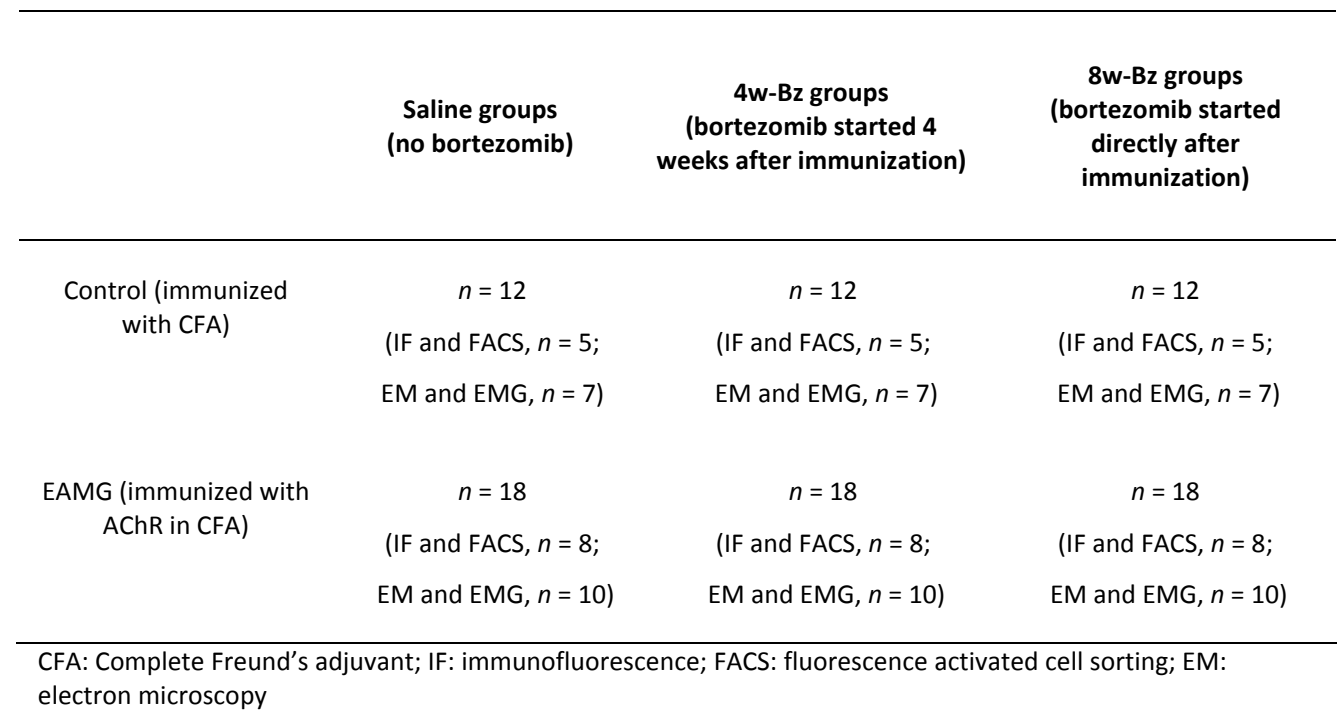




\section{Weight and clinical scoring}

The weights of animals were measured on a weekly basis as a general indicator of health and for dose calculations. The severity of clinical signs of EAMG was scored weekly by measuring muscular weakness by two blinded investigators (A.M.G. and M.P.). The animals' muscle strength and fatigability was assessed by their ability to grasp and lift repeatedly a 300-g metal rack from the table, while suspended manually by the base of the tail for 30 seconds [27-29]. Clinical scoring was based on the presence of tremor, hunched posture, muscle strength, and fatigability. Disease severity was expressed as follows: 0 , no obvious abnormalities; 1 , no abnormalities before testing, but reduced strength at the end; 2, clinical signs present before testing, that is, tremor, head down, hunched posture, weak grip, difficulty in breathing; 3 , severe clinical signs present before testing, no grip, moribund [24].

Animals that reached a clinical score of level 3 , or lost more than $20 \%$ of their weight in the course of one week, were sacrificed within $24 \mathrm{~h}$.

\section{$\underline{\text { Tissue preparation }}$}

For EM analysis, bone marrow was extracted from the femurs by cutting off their upper and lower endings and flushing the shaft with $10 \mathrm{~mL}$ sterile saline solution through the bone marrow cavity using a syringe with a 25-gauge needle. For FACS analysis of bone marrow, PBS containing $2 \%$ fetal calf serum and $0.1 \% \mathrm{NaN}_{3}$ (FACS buffer) was used instead. Thymus and spleen tissue were entirely removed from the animals by dissection and the organ weight was measured. Single cell suspensions were prepared using a gentleMACS tissue dissociator (Miltenyi Biotec, Bergisch Gladbach, Germany) according to the manufacturer's instructions. Cells of different tissues were resuspended in FACS buffer and run through a 70- $\mu \mathrm{m}$ nylon cell strainer to remove large cell clumps. Numbers of viable cells were determined by counting trypan blue negative cells on hemocytometers. Cells were divided into microcentrifuge tubes $\left(10^{5}\right.$ cells $/ 100 \mu \mathrm{L} /$ tube $)$ and then stained for dead cells, $T$ cells, and $B$ cells.

Heparinized blood samples were taken from the vena saphena weekly, starting 
on the week before immunization (week 0) until the last week of experiment (week 8). Peripheral blood mononuclear cells (PBMCs) were isolated by lysing red blood cells using FACS lysing buffer (BD Biosciences). PBMCs from $80 \mu \mathrm{L}$ blood were divided into microcentrifuge tubes in a ratio of $20 / 20 / 40 \mu \mathrm{L}$ to stain for dead cells, T cells, and B cells, respectively.

\section{Proteasome activity assay}

The proteolytic activity of the proteasome was evaluated in whole blood [30] by means of a 20 S proteasome activity kit (APT 280; Millipore), as described by the manufacturer. Taking into account the pharmacokinetic and pharmacodynamic profiles of subcutaneous bortezomib administration [31], blood samples were obtained between 3 and $6 \mathrm{~h}$ after administration of bortezomib or saline. In brief, $80 \mu \mathrm{g}$ whole blood protein extract was incubated in the provided buffer with $3.8 \mu \mathrm{g}$ fluorophore-linked peptide substrate (LLVY-7amino-4-methylcoumarin [AMC]) for $120 \mathrm{~min}$ at 37으. Proteasome activity was measured by quantification of relative fluorescent units from the release of the fluorescent cleaved product AMC using a 380/460 nm filter set in a fluorometer (Victor X3 multilabel reader, PerkinElmer). A solution of the $20 \mathrm{~S}$ proteasome subunit and the proteasome inhibitor lactacystin were used as controls for the assay.

\section{Autoantibody titers}

Antibody titers against rat AChR were measured in plasma samples with an immunoprecipitation radioimmunoassay (RIA). In brief, $2.5 \mu \mathrm{L}$ of plasma was incubated at 4으 Covernight with $100 \mu \mathrm{L}$ rat muscle cell-membrane extract (containing $\sim 5 \mathrm{nmol} / \mathrm{L} \mathrm{AChR}$;

isolated from denervated rat muscles). The AChR was labeled with an excess of $\left[{ }^{125} I\right]-\alpha-$ bungarotoxin (NEX126, $5 \mathrm{TBq} / \mathrm{mmol}$; PerkinElmer). The immune-complexes were precipitated by addition of $150 \mu \mathrm{L}$ goat anti-rat IgG serum and incubation for $4 \mathrm{~h}$ at 4 으. Pellets were washed three times in PBS with 0.5\% Triton X-100 and centrifuged at 25,000 $X \mathrm{~g}$ for $5 \mathrm{~min}$. Radioactivity was measured on an automatic gamma counter (2470 Wizard2; PerkinElmer). Autoantibody titers were expressed as nanomoles of $\alpha$ bungarotoxin binding sites per liter. 


\section{Total IgG ELISA}

A sandwich ELISA was used to measure total IgG content in plasma samples. Briefly, ELISA plates (Microlon 655092, Greiner Bio-One, Frickenhausen, Germany) were coated with 50 $\mu \mathrm{L}$ catching antibody (goat Ig anti-rat IgG, ab6252, Abcam, Cambridge, U.K.), diluted 1:200 in coating buffer (50 mM sodium carbonate $[\mathrm{pH} 9.6])$, for one $\mathrm{h}$ at $37^{\circ} \mathrm{C}$. Plates were washed with PBS containing 0.05\% Tween 20 and blocked for 30 min with $100 \mu \mathrm{L} 4 \%$ nonfat dry milk in PBS (blotting grade blocker, catalogue no. 1706404; Bio-Rad). Afterwards, $50 \mu \mathrm{L}$ plasma samples, diluted 1:20,000 in incubation buffer (PBS plus 1\% BSA plus $0.02 \%$ Tween 20 ), were incubated for $1 \mathrm{~h}$ at $37^{\circ} \mathrm{C}$. A standard curve was made using serially diluted samples of purified rat IgG (catalogue no. 18015; Sigma-Aldrich). After washing, $50 \mu \mathrm{L}$ HRP-conjugated antibody (ab6257; Abcam), diluted 1:5000 in incubation buffer, was added and plates were incubated for another $h$ at $37^{\circ} \mathrm{C}$. Following a washing step, $100 \mu \mathrm{L}$ tetramethylbenzidine substrate solution (s(HS)TMB; SDT Reagents, Baesweiler, Germany) was used to develop HRP-labeled antibodies bound to the plates. The color reaction was allowed to develop for $10 \mathrm{~min}$ and stopped with $50 \mu \mathrm{L} 2 \mathrm{M}$ sulphuric acid. The optical density was measured at $450 \mathrm{~nm}$ filter using a microplate reader (Victor X3 multilabel reader). Results were expressed as milligrams of total IgG per milliliter of plasma.

\section{Apoptosis assays}

Early apoptotic and dead cells were identified by flow cytometric analysis according to surface binding of FITC-labeled annexin $\mathrm{V}$ to exposed membrane phosphatidylserine and propidium iodide (PI) staining (annexin V-FITC apoptosis detection kit; BD Biosciences, Breda, The Netherlands). The cells $\left(10^{5} / 100 \mu \mathrm{L}\right)$ were washed with annexin V-binding buffer and incubated with $5 \mu \mathrm{L}$ annexin $\mathrm{V}$ and $5 \mu \mathrm{L}$ of PI for $15 \mathrm{~min}$ at room temperature. Without washing, cells were immediately measured. Annexin $\mathrm{V}^{+} / \mathrm{PI}^{-}$cells were regarded as early apoptotic, while annexin $\mathrm{V}^{+} / \mathrm{PI}^{+}$cells were considered dead cells.

\section{Extracellular staining for T cell markers}

The cells were washed once with FACS buffer by centrifugation at $250 \times g$ at 4 으 and 
incubated for $30 \mathrm{~min}$ at $4{ }^{\circ} \mathrm{C}$ with antibodies directed against CD3 (FITC-labeled), CD4 (PElabeled), and CD8 (PerCP-labeled) (all from BD Biosciences), diluted 1:50 in FACS buffer. The samples were washed twice and kept at $4{ }^{\circ} \mathrm{C}$ in the dark until measurement within $2 \mathrm{~h}$.

\section{Intracellular staining for B cell markers}

Cells were washed once with FACS buffer by centrifugation at $250 \times g$ at 4 으 and incubated with PE-conjugated antibody against CD45RA (BD Biosciences), diluted 1:20 in FACS buffer. After one washing step, cells were fixed with $2 \%$ paraformaldehyde in FACS buffer for $10 \mathrm{~min}$ at $37^{\circ} \mathrm{C}$. After two more washing steps, cells were permeabilized with cold $90 \%$ methanol for 30 min on ice. Cells were washed twice and incubated with FITCconjugated antibody directed against intracellular immunoglobulin kappa (IgK) (BD Biosciences), diluted 1:20 in FACS buffer. The samples were washed twice and kept at 4으 in the dark until measurement within 2 h. Because no appropriate CD markers were available to specifically detect rat plasma cells, we measured rat plasma cells by using high levels of intracellular Igk expression.

\section{$\underline{\text { FACS analysis }}$}

All cytofluorometric analyses were performed on a FACSCalibur (BD Biosciences) and analyzed using the CellQuest software (BD Biosciences). Forward and sideward light angle scatters were collected. Using these plots, samples were gated to exclude cell debris and cellular aggregates for further analysis. For each marker, the percentage of positive cells stained above background was measured for all gated cells. The cutoff was defined using unstained cells processed alongside the experimental samples.

\section{Plasma cell quantification by EM}

Bone marrow cell suspensions were fixed by mixing with an equal volume of $5 \%$ glutaraldehyde in PBS and then centrifuged at $800 \times \mathrm{g}$. Pellets were resuspended in PBS and embedded in $10 \%$ gelatin, then centrifuged again at $1000 \times \mathrm{g}$ to form a compact pellet. Cell pellets were postfixed with $1 \%$ osmium tetroxide in $0.1 \mathrm{M}$ phosphate buffer (pH 7.4) dehydrated through a graded ethanol series and embedded in Epon 812 (Electron Microscopy Sciences, Fort Washington, PA). Ultrathin sections from whole pellets were 
contrasted with uranyl acetate and lead citrate and viewed with a Philips CM 100 electron microscope. Plasma cell recognition was based on morphological features that are particular to this cell type, such as the typical 'cartwheel' chromatin configuration in the nucleus and the presence of extensive rough ER in the cytoplasm, indicative of an intense protein production. Quantification was performed at six different portions of the sample to have a systematic representation of the cell gradient in the sample that resulted from the centrifugation. Results are expressed as percentage of plasma cells; a total of 800 bone marrow cells were counted per sample.

\section{Electromyography}

Animals were initially anesthetized as described above and subsequently intubated in the trachea. Anesthesia was maintained with $3 \%$ isoflurane in air. Compound muscle action potential (CMAP) decrement was measured in the tibialis anterior muscle using the EMG system Viking IV (Nicolet Biomedicals, Madison, WI) at the end of the experimental period. For stimulation, two small monopolar needle electrodes were used. The cathode was inserted near the peroneal nerve at the level of the knee and the anode more proximal and lateral at a distance of 3-4 $\mathrm{mm}$. For recording, a third monopolar needle electrode was inserted subcutaneously over the tibialis anterior muscle. The reference electrode was inserted subcutaneously near the ankle. A ring electrode around the tail served as ground electrode. To detect a decremental response of the CMAP, series of eight supramaximal stimuli were given at $3 \mathrm{~Hz}$ with $0.2 \mathrm{~ms}$ duration. The test was considered positive for decrement when both the amplitude and the area of the CMAPnegative peak showed a decrease of at least 10\% [32]. To demonstrate reproducibility, at least three consecutive decrement recordings were made of all investigated muscles. During the measurements, skin temperature was kept between $35^{\circ} \mathrm{C}$ and $37^{\circ} \mathrm{C}$ by means of an infrared heating lamp. If initially no decrement was present in the tibialis anterior muscle, neuromuscular transmission was challenged by a continuous intravenous infusion of curare [(+)-tubocurarine, T2379; Sigma-Aldrich]. A solution of $20 \mu \mathrm{g} / \mathrm{mL}$ curare was injected into the vena saphena using a Terfusion syringe pump (model STC-521; Terumo, Tokyo, Japan) at a rate of $1 \mathrm{~mL} / \mathrm{h}(0.33 \mu \mathrm{g}$ curare/min). During curare infusion, CMAP 
measurements were repeated with intervals of 1 min until a repeated decrement was observed. The resistance against curare was used as an indirect, albeit nonlinear, measure for the safety factor of neuromuscular transmission and thus for the performance of neuromuscular transmission [33, 34].

\section{EM of muscle tissue}

Electron micrographs were taken from endplates of the tibialis anterior muscles. Anesthetized rats were transcardially perfused as previously described [21, 32]. Ultrathin sections were viewed with a Philips CM 100 electron microscope. At least five endplate regions were photographed from each muscle. Quantitative morphometry of the folding index (length of postsynaptic membrane/length of presynaptic membrane) was performed as previously described [34, 35]. For the analysis, the following number of animals was used per group: control saline $(n=3)$; EAMG saline $(n=4)$; EAMG $4 \mathrm{w}-\mathrm{Bz}(n=4)$; EAMG $8 \mathrm{w}$ $\mathrm{Bz}(n=4)$. Between 5 and 25 endplate regions were analyzed per animal.

\section{$\underline{\text { Statistics }}$}

GraphPad Prism 4 was used to perform statistical analyses. Comparison between normally distributed values was performed using one- or two-way ANOVA, wherever appropriate. Bonferroni post hoc tests were used to compare groups to each other. A two-sided probability value of 0.05 or lower was considered significant. Values are expressed as means \pm standard error of the mean (SEM) unless stated otherwise. Clinical scores were analyzed by the Chi square $\left(\chi^{2}\right)$ test for trend, and survival was analyzed using the log-rank test.

\section{$\underline{\text { Results }}$}


To investigate whether proteasome inhibition affects plasma cells in vivo, rats were injected with bortezomib or saline. Subcutaneous injections of bortezomib significantly reduced the proteasome activity in rat whole blood (Fig. 5.1). The effect of bortezomib on plasma cells from the bone marrow was analyzed by EM and by FACS. In the bone marrow of bortezomib-treated rats, plasma cells with altered morphology were frequently observed (Fig. 5.2), which was characterized by a vesicular appearance of the rough ER cisternae or pronounced dilatation of the rough ER. The percentage of plasma cells in bone marrow was markedly reduced in bortezomib-treated groups (Fig. 5.3A). Animals that received bortezomib only between 4 and 8 weeks after immunization showed a significant decrease in their percentage of bone marrow plasma cells $(57 \%$ reduction in the $4 \mathrm{w}-\mathrm{Bz}$ control group $[p<0.05]$ and $82 \%$ reduction in the $4 \mathrm{w}-\mathrm{Bz}$ EAMG group $[p<0.01]$ compared with the corresponding saline-treated groups). Rats in the 8w-Bz EAMG group also showed a strong and significant depletion of bone marrow plasma cells $(p<0.05 ; 70 \%$ reduction compared to the saline-treated EAMG group). Very similar results were obtained by FACS analysis using intracellular staining of the Igk light chain in bone marrow cells (Fig. 5.3B).

Figure 5.1. Proteasome activity in blood lysates. Samples were incubated with a labeled peptide substrate (LLVY-7amino-4-methylcoumarin [AMC]) and the amount of cleaved fluorophore AMC was measured in a fluorometer. $(A)$ Proteasome activities at 4 weeks after immunization were normalized using the average relative fluorescence units (RFU) value of the control saline group at week 4 . (B) Proteasome activities at 8 weeks after immunization were normalized using the average RFU value of the control saline group at week 8. One-way ANOVA and Bonferroni post hoc testing were used for statistical analyses.
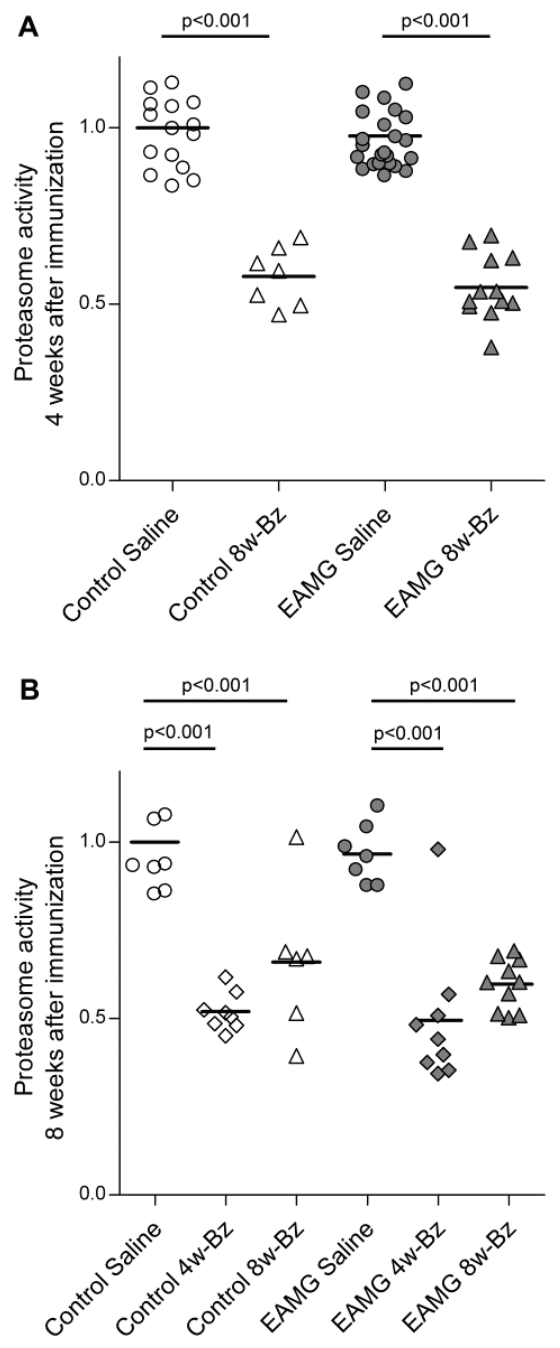


\section{Bortezomib affects the lymphoid organs}

We investigated the overall effect of bortezomib treatment on the immune system by measuring the weight of thymus and spleen tissue and analyzing the proportions of B cells and T cell subsets in the thymus, spleen, blood and bone marrow by FACS (Table 5.2).

Control

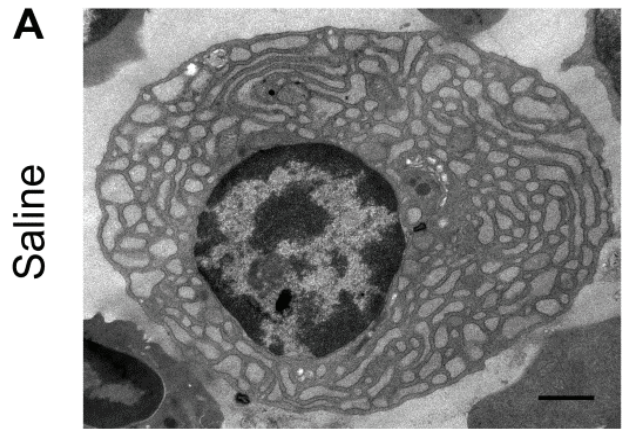

B

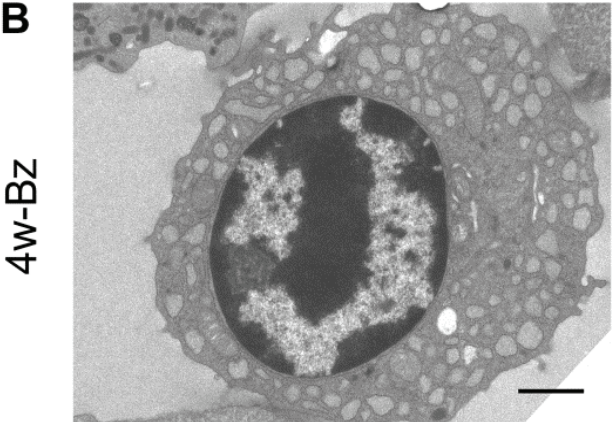

\section{EAMG}
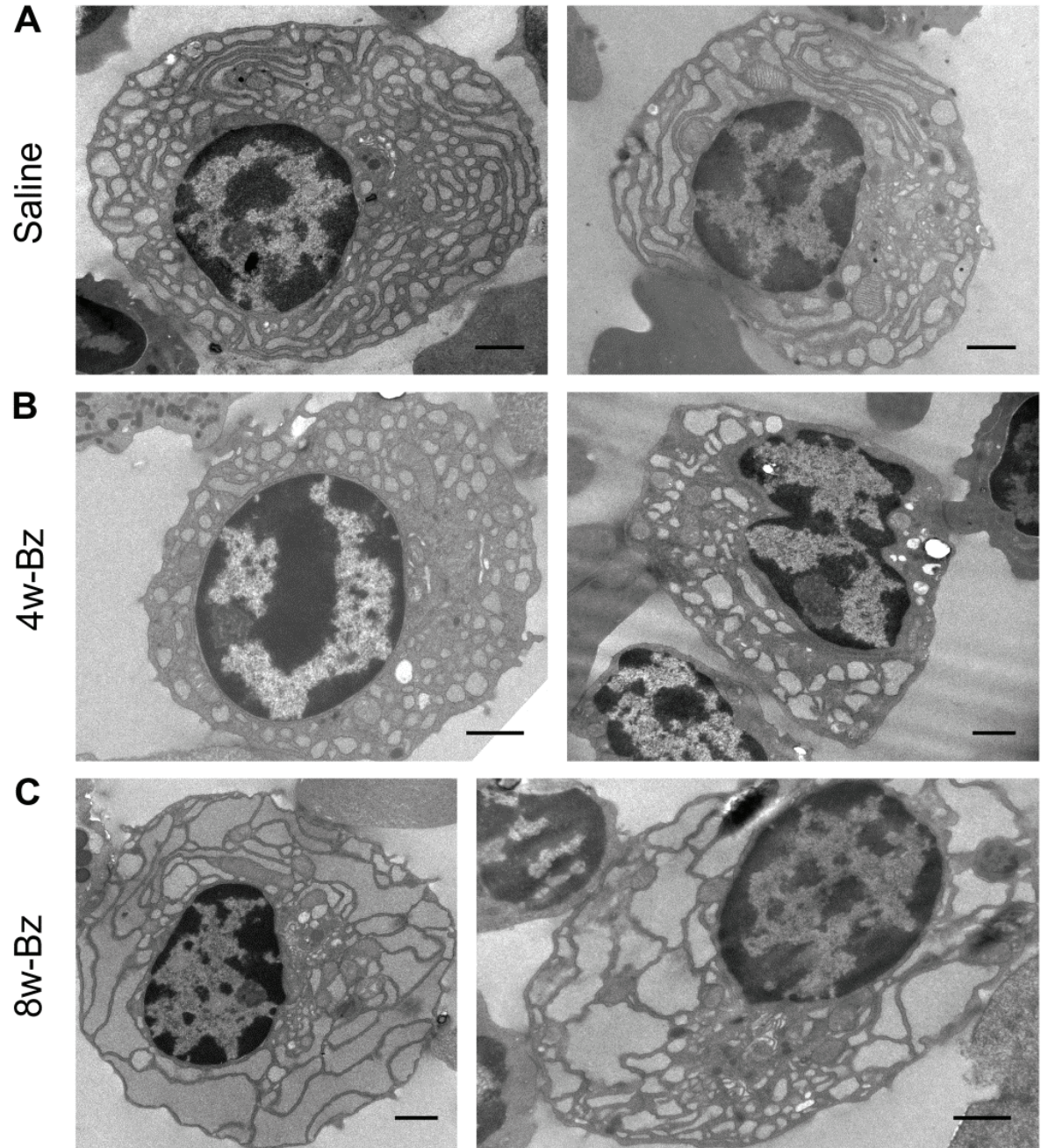

Figure 5.2. Electron micrographs of bone marrow plasma cells. After 4 weeks of bortezomib treatment, the rough endoplasmic reticulum (ER) cisternae have a vesicular appearance; after 8 weeks of treatment, pronounced dilatation of the rough ER is visible. Cells were stained with osmium tetroxide and contrasted with uranyl acetate and lead citrate. Scale bars, $1 \mu \mathrm{m}$. 


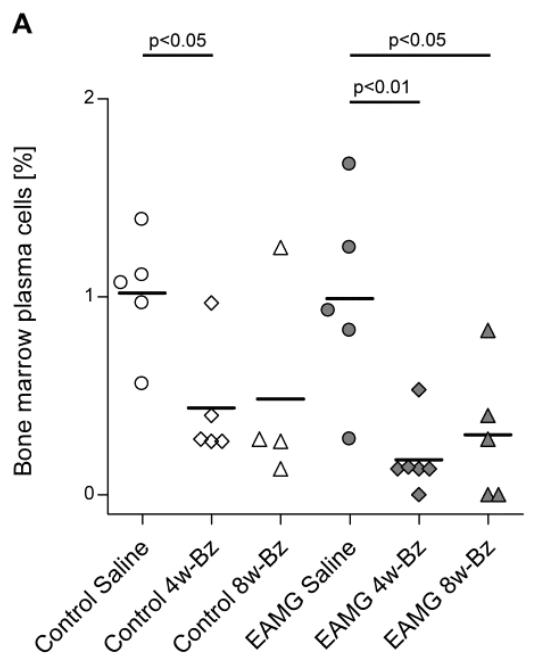

B

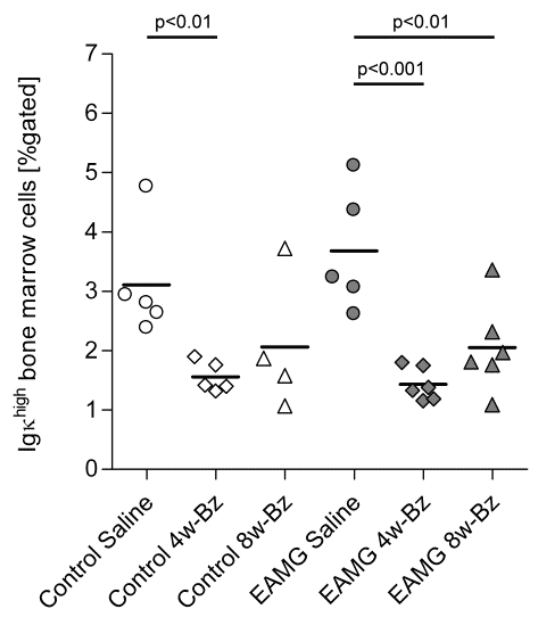

Figure 5.3. Analysis of plasma cells in the bone marrow 8 weeks after immunization. $(A)$ Electron microscopical analysis. Bortezomib treatment decreases the number of plasma cells in the bone marrow. (B) Flow cytometric analyses of Igk ${ }^{\text {high }}$ cells. Data are shown as percentages of cells with respect to gated living bone marrow cells. The proportion of Igk ${ }^{\text {high }}$ cells was significantly lower in $4 \mathrm{w}-\mathrm{Bz}$ and $8 \mathrm{w}-\mathrm{Bz}$ groups compared with the corresponding saline-treated groups. Horizontal bars represent the mean percentage of each group. Two-way ANOVA and Bonferroni post hoc testing were used for statistical analyses.

\section{Bortezomib treatment}

significantly reduced the mean thymus weight, both in the $4 \mathrm{w}-\mathrm{Bz} \quad(46 \%$ reduction; $p<0.01$ ) and $8 \mathrm{w}-\mathrm{Bz}$ groups (50\% reduction; $p<0.01$ ), compared with the saline group (data not shown). In contrast, the mean spleen weight significantly increased by bortezomib treatment in both $4 \mathrm{w}-\mathrm{Bz}$ (36\% increase; $p$ $<0.05)$ and $8 w-B z$ groups (32\% increase; $p<0.05)$ compared to the corresponding saline-treated groups (data not shown). No significant difference was observed between control and EAMG animals.

To assess the effects of

bortezomib treatment on the leukocyte viability, we measured the proportion of early apoptotic (annexin $\mathrm{V}^{+} / \mathrm{PI}^{-}$) and dead cells (annexin $\mathrm{V}^{+} / \mathrm{PI}^{+}$).

In the spleen, thymus, and bone marrow, a trend toward a higher proportion of early apoptotic and dead cells after bortezomib administration could be observed, but the differences did not reach statistical significance. However, the lymphocyte subpopulation in the bone marrow contained a significantly increased number of apoptotic or dead cells after bortezomib-treatment (data not shown). 
Table 5.2. FACS analysis of lymphoid organs

\begin{tabular}{|c|c|c|c|c|}
\hline & Tissue & Saline & $4 w-B z$ & $8 w-B z$ \\
\hline \multirow[t]{4}{*}{ Dead cells, $\mathrm{Ann}^{+} / \mathrm{PI}^{+}$} & Thymus & $11.25 \pm 1.43$ & $13.63 \pm 1.17$ & $14.19 \pm 1.94$ \\
\hline & Spleen & $25.38 \pm 2.34$ & $28.00 \pm 3.28$ & $31.26 \pm 4.25$ \\
\hline & Bone Marrow & $12.93 \pm 0.86$ & $14.57 \pm 1.20$ & $15.82 \pm 1.16$ \\
\hline & PBMC & $5.72 \pm 0.66$ & $2.84 \pm 0.17^{* * *}$ & $2.92 \pm 0.18^{* * *}$ \\
\hline \multirow[t]{4}{*}{ Early apoptotic cells, $\mathrm{Ann}^{+} / \mathrm{PI}^{-}$} & Thymus & $8.23 \pm 0.96$ & $12.11 \pm 0.63$ & $10.22 \pm 1.60$ \\
\hline & Spleen & $17.02 \pm 1.27$ & $16.36 \pm 1.62$ & $15.80 \pm 1.63$ \\
\hline & Bone Marrow & $12.40 \pm 1.76$ & $10.40 \pm 1.19$ & $13.08 \pm 1.56$ \\
\hline & PBMC & $2.25 \pm 0.18$ & $1.23 \pm 0.12 * * *$ & $1.91 \pm 0.22$ \\
\hline \multirow[t]{4}{*}{$\mathrm{CD} 45 \mathrm{RA}^{+} / \operatorname{lgK}^{+}$} & Thymus & $0.48 \pm 0.05$ & $0.89 \pm 0.12$ & $0.63 \pm 0.10$ \\
\hline & Spleen & $19.85 \pm 0.36$ & $15.85 \pm 1.05^{*}$ & $16.13 \pm 1.24^{*}$ \\
\hline & Bone Marrow & $4.16 \pm 0.16$ & $2.56 \pm 0.30 * *$ & $2.44 \pm 0.33^{* * *}$ \\
\hline & PBMC & $5.64 \pm 0.43$ & $3.16 \pm 0.26 * * *$ & $2.57 \pm 0.18^{* * *}$ \\
\hline \multirow[t]{4}{*}{$\mathrm{CD}^{+} / \mathrm{CD}^{+} \mathrm{CD}^{-}$} & Thymus & $7.72 \pm 0.39$ & $10.53 \pm 0.65^{* *}$ & $9.62 \pm 0.61$ \\
\hline & Spleen & $39.44 \pm 0.25$ & $43.92 \pm 1.53^{*}$ & $44.72 \pm 0.71^{*}$ \\
\hline & Bone Marrow & $1.27 \pm 0.22$ & $1.27 \pm 0.31$ & $1.49 \pm 0.29$ \\
\hline & PBMC & $56.52 \pm 0.68$ & $63.21 \pm 0.63^{* * *}$ & $62.18 \pm 0.79 * * *$ \\
\hline \multirow[t]{4}{*}{$\mathrm{CD}^{+} / \mathrm{CD}^{+} \mathrm{CD}^{-}$} & Thymus & $1.78 \pm 0.11$ & $3.49 \pm 0.30^{* * *}$ & $2.80 \pm 0.31^{*}$ \\
\hline & Spleen & $12.89 \pm 0.26$ & $9.82 \pm 0.39 * * *$ & $9.13 \pm 0.63 * * *$ \\
\hline & Bone Marrow & $1.67 \pm 0.30$ & $0.82 \pm 0.08^{*}$ & $1.29 \pm 0.20$ \\
\hline & PBMC & $19.48 \pm 0.40$ & $20.91 \pm 0.47$ & $20.85 \pm 0.43$ \\
\hline \multirow[t]{4}{*}{$\mathrm{CD}^{+} / \mathrm{CD}^{+}$} & Thymus & $83.57 \pm 1.24$ & $77.41 \pm 1.87^{*}$ & $78.99 \pm 1.38$ \\
\hline & Spleen & $1.33 \pm 0.06$ & $1.27 \pm 0.07$ & $1.46 \pm 0.07$ \\
\hline & Bone Marrow & $1.60 \pm 0.39$ & $1.03 \pm 0.11$ & $0.99 \pm 0.12$ \\
\hline & PBMC & $1.39 \pm 0.12$ & $1.62 \pm 0.13$ & $2.16 \pm 0.19 * *$ \\
\hline
\end{tabular}

Using flow cytometry, the effects of bortezomib treatment on apoptosis and on lymphocytes were measured in the thymus, spleen, bone marrow, and peripheral blood. Results are shown as average percentages \pm SEM. Oneway ANOVA analysis and Bonferroni post hoc testing were utilized for statistical analysis. For analyzing the effect of bortezomib treatment, the data of control and EAMG groups were combined since no significant differences were observed between them in any of the parameters studied.

${ }^{*} p<0.05, * * p<0.01$ and ${ }^{* * *} p<0.001$. Ann, annexin V.

In the peripheral blood, unexpectedly, bortezomib treatment significantly decreased the proportion of dead cells in PBMCs in the $4 \mathrm{w}-\mathrm{Bz}$ and $8 \mathrm{w}-\mathrm{Bz}$ groups compared 
to the saline groups. The proportion of early apoptotic cells in PBMCs was significantly lower in the $4 \mathrm{w}-\mathrm{Bz}$ groups $(p<0.001)$ but not in the $8 \mathrm{w}-\mathrm{Bz}$ groups.

In the spleen, the bone marrow, and the blood, the proportion of $\mathrm{CD}_{4} 5 \mathrm{RA}^{+} / \operatorname{lgk}^{+} \mathrm{B}$ cells was significantly decreased after bortezomib treatment (Table 5.2), both in the $4 \mathrm{w}-\mathrm{Bz}$ and the $8 w-B z$ groups.

After treatment with bortezomib, the proportion of immature $\mathrm{CD} 4^{+} / \mathrm{CD} 8^{+}$cells in the thymus was decreased whereas the proportion of $\mathrm{CD}^{+} / \mathrm{CD}^{+} / \mathrm{CD} 8^{-} \mathrm{T}$ helper cells and cytotoxic $\mathrm{CD}^{+} / \mathrm{CD}^{+} / \mathrm{CD} 4^{-}$T cells were increased.

In the blood and the spleen, $\mathrm{CD}^{+} / \mathrm{CD}^{+} / \mathrm{CD}^{-}$cells were significantly increased; the proportion of $\mathrm{CD}^{+} / \mathrm{CD}^{+} / \mathrm{CD}^{-}$cells was significantly decreased in the spleen and bone marrow of bortezomib-treated rats.

In general, the two bortezomib treatment regimes led to similar changes of the rat immune system, with the exception of the proportion of apoptotic cells, as aforementioned.

\section{$\underline{\text { Total IgG concentration is decreased by bortezomib }}$}

The effect of bortezomib on total IgG content in plasma samples was measured by ELISA (Fig. 5.4A). In comparison with the saline-treated group, total IgG at week 8 was significantly reduced in both the $4 \mathrm{w}-\mathrm{Bz}$ and the $8 \mathrm{w}$-Bz group $(p<0.001)$. Importantly, this immunosuppressive effect of bortezomib was observed in both control and EAMG animals, although IgG reduction was more pronounced in $8 \mathrm{w}$-Bz EAMG animals than in the $4 \mathrm{~W}-\mathrm{Bz}$ EAMG rats $(p<0.05)$. A slightly but significantly higher concentration of IgG was observed in all EAMG groups in comparison with the corresponding control groups. Compared to the saline-treated groups, a highly significant reduction in IgG concentrations $(p<0.001)$ was already achieved after 4 weeks of bortezomib treatment in the $8 \mathrm{w}-\mathrm{Bz}$ group (data not shown).

\section{Bortezomib reduces autoantibody titers in EAMG}

The plasma concentration of autoantibodies to the rat AChR was measured by RIA. Autoantibodies were detectable 4 weeks after immunization in all EAMG animals and reached very high levels after 8 weeks (Fig. 5.4B). The variability of autoantibody levels 
between animals is typical for the EAMG model, but it should be borne in mind that already a titer of $1 \mathrm{nM}$ of autoantibodies is sufficient to cause substantial damage to the NMJ [33]. As expected, no anti-AChR antibody titers could be detected in sham/CFAimmunized animals (control group; data not shown). On the other hand, animals that received bortezomib injections from the moment of immunization showed a significantly
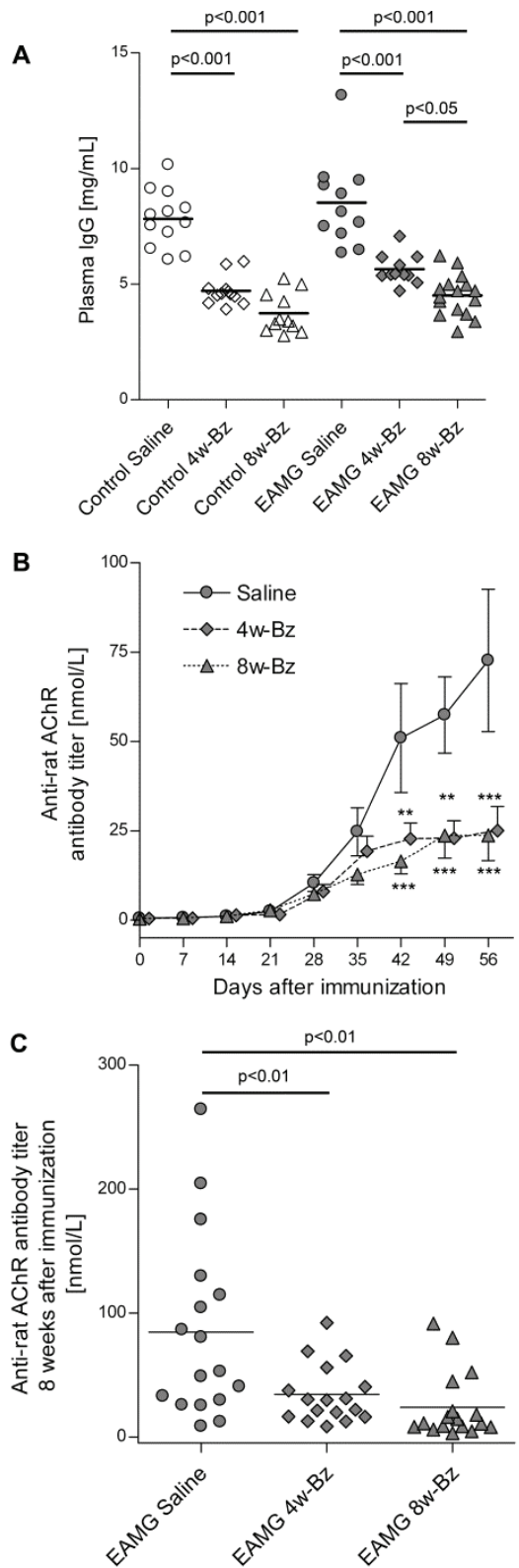

lower production of autoantibodies $(p<$ 0.01 ; corresponding to a $72 \%$ reduction of average autoantibody titer) compared with the saline treated EAMG group 8 weeks after immunization (Fig. 5.4C). Interestingly, rats that received bortezomib 4 weeks after immunization had an autoantibody production profile similar to that observed in the $8 w-B z$ group. After injection of bortezomib, the production of anti-AChR antibodies was reduced significantly compared with saline-treated animals (corresponding to a $60 \%$ reduction; $p<0.01$ ). This demonstrated that bortezomib effectively diminished antibody production not only when administrated at the moment of immunization but also once the immune response was already ongoing.

Figure 5.4. Total IgG and autoantibody titers in plasma. (A) Plasma IgG titers 8 weeks after immunization. Bortezomib significantly reduced plasma IgG levels. Two-way ANOVA and Bonferroni post hoc testing were used for statistical analyses. (B) Average anti-rat AChRtiter; error bars correspond to the SEM. Stars indicate significant differences compared to the saline-treated groups. ${ }^{* *} p<0.01 ;{ }^{* * *} p<0.001$ compared with the saline-treated groups. Autoantibody titers of the $4 w-B z$ and the $8 \mathrm{w}-\mathrm{Bz}$ groups were not significantly different from each other at any time point. (C) Anti-rat AChR titers 8 weeks after immunization with tAChR. One-way 
ANOVA and Bonferroni post hoc testing were used forstatistical analyses.

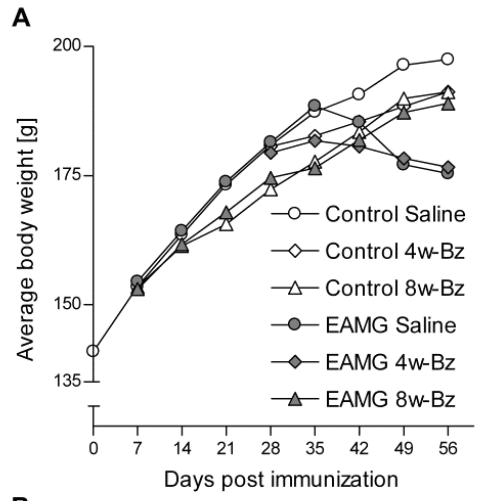

B
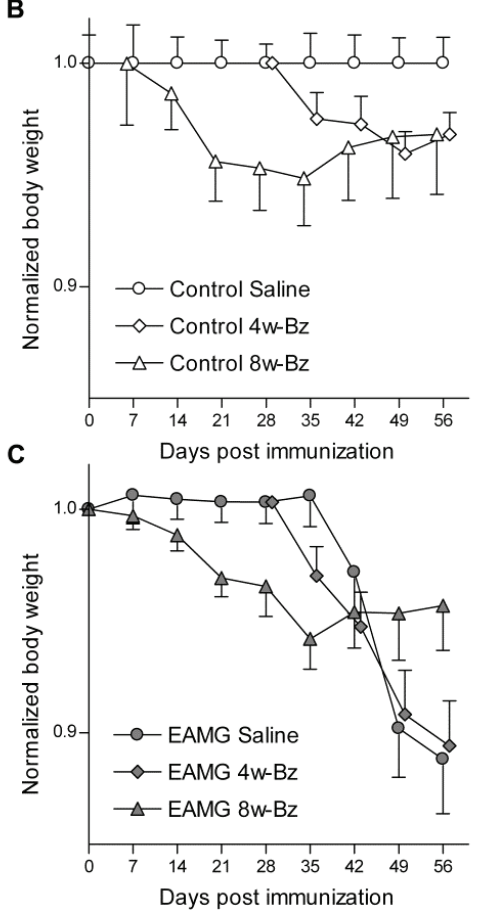

Figure 5.5. Average rat weights. $(A)$ Body weights of bortezomib-treated animals increased slower compared with saline-treated animals. Weight loss occurred frequently in EAMG animals. $(B, C)$ Normalized weights were calculated using the average weight of the saline-treated control group. Error bars correspond to the SEM.

\section{Bortezomib ameliorates clinical conditions in EAMG}

To assess the effect of bortezomib on the overall condition of experimental animals, we weighed them and scored their clinical status on a weekly basis. During the first 5 weeks of treatment, control animals that had received bortezomib from the moment of immunization ( $8 w-B z$ group) showed a slower increase in their total body weight compared to saline-treated control animals (Figure $5.5 A$ and $B ; p<0.001$ ). After 5 weeks, the growth of these animals normalized again. A similar reduction of growth was observed 4 weeks later in the $4 \mathrm{w}-\mathrm{Bz}$ control group. At the end of the experiment there were no significant differences between the average weights of the $4 w-B z$ and the $8 w-B z$ control groups. As expected, control animals did not present muscle weakness or any other clinical sign of EAMG. 


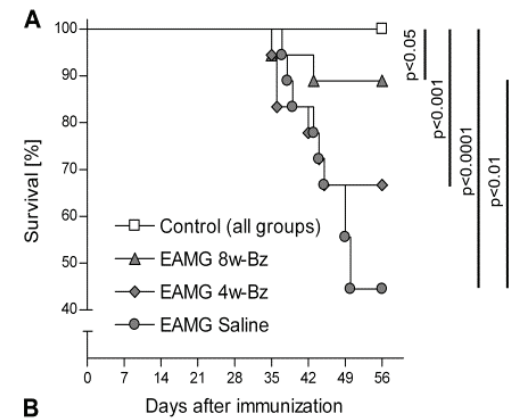

Figure 5.6. MG symptoms and muscle function. (A) Survival. $(B)$ Clinical scores of muscle weakness. Each group contained 18 animals (indicated with 100\%). (C) EMG after curare infusion. The curare dose that induces at least $10 \%$ decrement of the CMAP was used as a measure of the neuromuscular safety factor.

Animals immunized with Torpedo AChR developed clinical symptoms of EAMG starting 5 weeks after immunization, when antibody titers

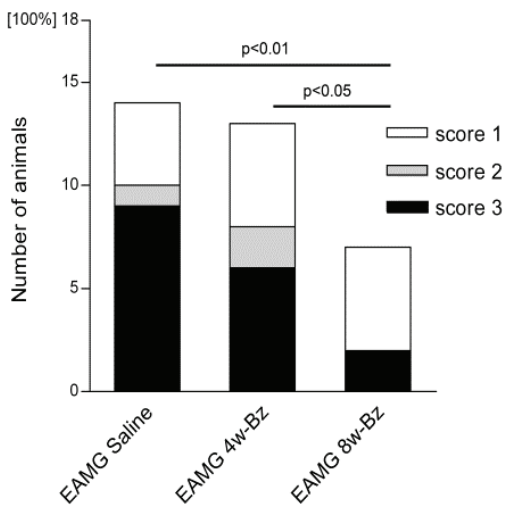
reached considerable levels. Frequently, weight loss preceded the observation of other myasthenic symptoms in EAMG animals, indicating weakness of bulbar muscles and difficulties in chewing and swallowing.

The disease in some of these animals progressed rapidly to score 3 within two days and they had to be sacrificed (Fig. 5.6A). By the

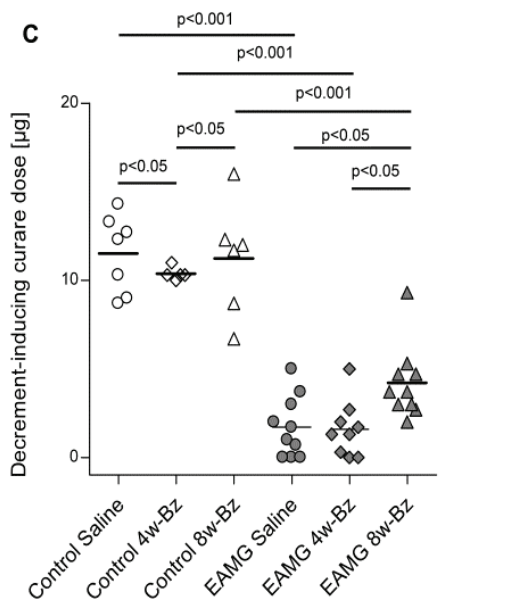
end of the experiment $50 \%$ of animals (9 of 18) treated with saline solution reached a clinical score of 3 or lost $>20 \%$ body weight and had to be sacrificed for ethical reasons. This percentage was reduced to $33 \%$ ( 6 of 18 ) in the $4 w-B z$ group and to $11 \%$ ( 2 of 18 ) in the $8 w-B z$ group (Fig. $5.6 B)$. The survival rate of the $8 w-B z$ EAMG group was significantly higher compared with the saline-treated EAMG group $(p<0.01$; Fig. $5.6 A)$.

From the AChR-immunized animals, $78 \%$ developed muscle weakness in the saline-treated EAMG group, $72 \%$ in the $4 \mathrm{w}-\mathrm{Bz}$ EAMG group, and $39 \%$ in the $8 \mathrm{w}-\mathrm{Bz}$ EAMG group. The clinical score of the 8w-Bz EAMG group was significantly lower compared with the $4 \mathrm{w}-\mathrm{Bz}$ group $(p<0.05)$ and the saline-treated EAMG group ( $p<0.01$; Fig. 5.6B). 
Despite the reduced amount of autoantibodies, the muscle weakness and the survival rate of the $4 w-B z$ EAMG group were not significantly different from the saline-treated EAMG group. The onset of weight loss in the $4 \mathrm{w}-\mathrm{Bz}$ EAMG group even occurred somewhat earlier compared to the saline-treated EAMG group (Fig. 5.5C), indicating that weight loss was partly caused by the (side) effects of bortezomib.

We evaluated the safety factor of neuromuscular transmission, which is a function of the postsynaptic density of AChRs, by performing EMG studies in the presence of the AChR-blocking agent (+)-tubocurarine (curare). The amount of curare needed to induce a decrement in CMAP is related to the safety factor of neuromuscular transmission. Bortezomib had slight effects on the curare sensitivity of the NMJ in control animals in the $4 \mathrm{w}$-Bz group (Fig. 5.6C). The neuromuscular transmission was significantly impaired in all EAMG groups compared with the corresponding control groups. In the 8wBz EAMG group, neuromuscular transmission was significantly improved compared with the saline-treated and the $4 \mathrm{w}-\mathrm{Bz}$ EAMG groups $(p<0.05)$.

Ultrastructural analysis of the NMJ revealed damage of the postsynaptic membrane morphology, with degenerating or absent secondary clefts in EAMG animals (Fig. 5.7). The damage in endplates of animals with low titers in the $8 \mathrm{w}$-Bz group (Fig. 5.7F) was less severe compared with animals with higher titers (Fig. 5.7D, E, G). Quantitative morphometric analysis of the synapse ultrastructure was performed to measure the loss of postsynaptic folds (Fig. 5.8). The folding index was significantly reduced in the salinetreated EAMG animals compared with the saline-treated control animals (a reduction of $55 \%, p<0.001)$. In the $8 \mathrm{w}-\mathrm{Bz}$ EAMG animals only a $20 \%$ reduction of the folding index compared with saline-treated control animals was observed, and a considerable proportion of the endplates had a relatively high folding index. Compared to the salinetreated EAMG group, the folding index in the $8 \mathrm{w}-\mathrm{Bz}$ group was significantly higher $(p<$ 0.001). However, this treatment effect was not observed in the $4 \mathrm{w}-\mathrm{Bz}$ group. In conclusion, bortezomib could not improve synaptic ultrastructure if treatment was started 4 weeks after immunization, but it efficiently prevented damage of the postsynaptic membrane when administrated for 8 weeks starting directly after immunization. 

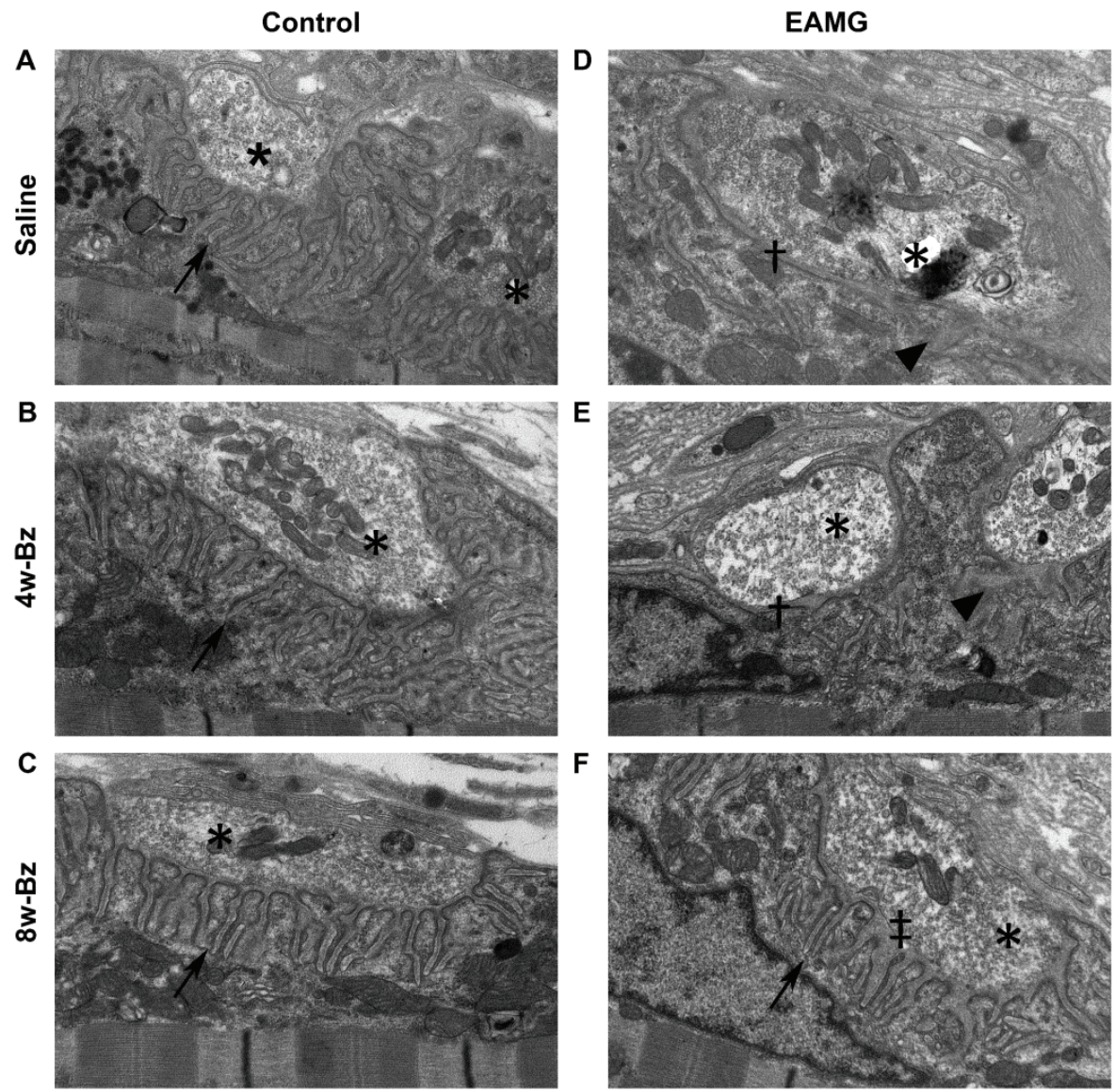

$2 \mu \mathrm{m}$

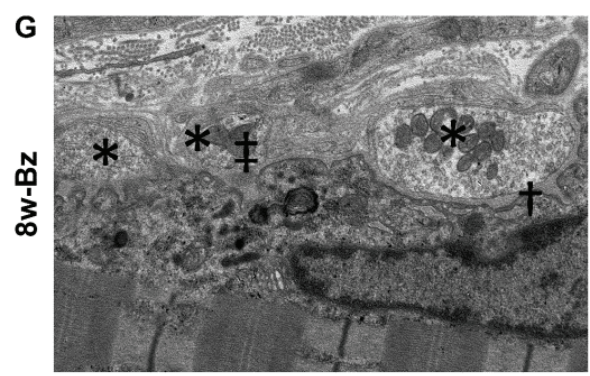

Figure 5.7. Electron micrographs of synaptic boutons of the NMJ. Nerve terminals are indicated by asterisks. In control animals $(A-C)$, the postsynaptic membrane contains secondary clefts (postsynaptic folds), which are indicated by arrows. In EAMG animals $(D-G)$, pathologic changes of the postsynaptic membrane are indicated: degenerating folds (arrowhead), simplified and without folds (dagger), and widening of the primary and secondary synaptic clefts (double dagger). The postsynaptic damage of an animal with an anti-AChR titer of $3 \mathrm{nM}$ $(F)$ was mild compared to an animal with a titer of $20 \mathrm{nM}(G)$. The muscle tissue was stained with osmium tetroxide and contrasted with uranyl acetate and lead citrate. 


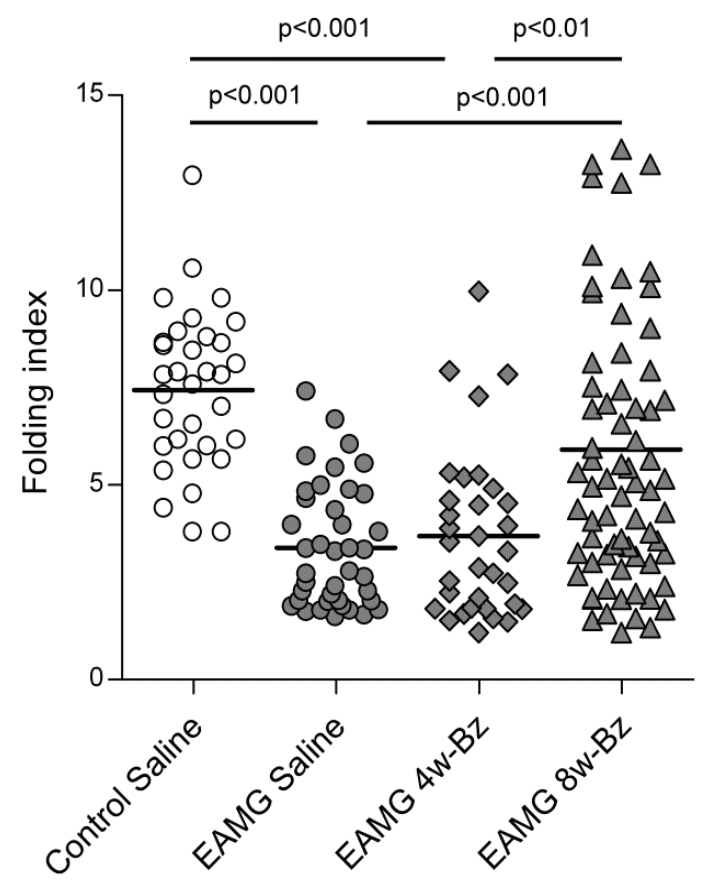

Figure 5.8. Analysis of folding index (length of postsynaptic membrane/length of presynaptic membrane) by quantitative morphometry of electron micrographs. Each point represents one endplate region with one or two synaptic boutons as shown in Fig. 5.7. Due to loss of postsynaptic folds, the folding index is significantly reduced in EAMG saline animals compared with control saline animals. In the EAMG $8 \mathrm{w}-\mathrm{Bz}$, the reduction of postsynaptic folding was prevented by bortezomib. One-way ANOVA and Bonferroni post hoc testing were used for statistical analyses.

\section{Discussion}

In this study we analyzed the effect of proteasome inhibition on the autoimmune response in the EAMG model for MG. Bortezomib reduced the amount of plasma cells, leading to a significant reduction of total serum IgG and autoantibody levels and caused an amelioration of myasthenic symptoms compared with a saline-treated EAMG group. Both the 4- and 8-week bortezomib treatment regimes ( $4 \mathrm{w}-\mathrm{Bz}$ and $8 \mathrm{w}$-Bz) were generally well tolerated, but some side effects were noticed, that are discussed below. There were no significant differences in autoantibody production between the $4 \mathrm{w}-\mathrm{Bz}$ and the $8 \mathrm{w}-\mathrm{Bz}$ group. Because bortezomib in the $4 \mathrm{w}$-Bz group was only administered starting 4 weeks 
after immunization with autoantigen, this suggests that mainly the late (effector) phase of the autoimmune response is affected by proteasome inhibition.

In the EAMG model, the production of antibodies against the muscle AChR is induced by immunization with tAChR. EAMG in Lewis rats is characterized by chronic muscle weakness starting 5 weeks after immunization. A transient acute phase of muscle weakness starting 1 week after immunization is seen in EAMG models using CFA with Bordetella pertussis [20]. In the immunization protocol used in this study with CFA containing $M$. tuberculosis, the acute phase of muscle weakness does not occur [20]. Therefore, we could investigate both a therapeutic as well as a preventive treatment regimen. Bortezomib efficiently reduced the production of autoantibodies and also ameliorated MG symptoms in the $8 \mathrm{w}-\mathrm{Bz}$ group. The average levels of anti-AChR autoantibodies in this study were high, comparable to a previous study using the same protocol with $20 \mu \mathrm{g}$ tAChR $[36,37]$ and much higher than another study using $10 \mu \mathrm{g} \mathrm{tAChR}$ [33], ranging between 3 and $80 \mathrm{nM}$ even in the $8 \mathrm{w}$-Bz groups. Because $1 \mathrm{nM}$ serum antimuscle AChR-antibodies can already reduce the amount of total muscle AChR by $50 \%$ in rats [33], the limited improvement of muscle strength in this study is understandable. It is therefore conceivable that if we could have used EAMG animals with a lower titer, the effects of bortezomib would have been more pronounced. Nevertheless, the resistance against curare, and thus the amount of functional AChR at the NMJ and the folding index of the postsynaptic membrane, was significantly increased by bortezomib in the $8 \mathrm{w}-\mathrm{Bz}$ treatment group, resulting in higher survival rates. In human MG patients, an autoantibody titer reduction of $50 \%$ after plasma exchange is generally sufficient to achieve clinical remission [38,39], and therefore in this respect the bortezomib-induced reduction of autoantibody production by $>65 \%$ within 4 weeks is therapeutically promising.

However, despite the reduced autoantibody levels, the $4 \mathrm{w}$-Bz treatment did not result in a significant improvement of health in EAMG animals, in contrast to the $8 \mathrm{w}-\mathrm{Bz}$ treatment, where bortezomib caused amelioration in the condition of the animals. Two side effects of bortezomib might have influenced this result. First, bortezomib negatively affected body weight during the first 4 weeks of administration in control animals and 
presumably also in EAMG animals. In the 4w-Bz EAMG group, this coincided with the weight loss as a result of muscle weakness and the resulting problems with eating and drinking. Because a $20 \%$ weight loss was chosen as a criterion to sacrifice animals for ethical reasons, the bortezomib treatment could have reduced survival time to some extent. Second, we observed a mild impairment of neuromuscular transmission in the $4 \mathrm{w}$ $\mathrm{Bz}$ Control group (but not in the $8 \mathrm{w}-\mathrm{Bz}$ control group) in comparison with the salinetreated control group. This effect possibly indicates transient nerve damage similar to the bortezomib-induced polyneuropathy $[26,40]$. Arguably, the weight loss in control animals was caused by an effect of proteasome inhibition on the gastrointestinal tract, which has been seen in patients [41]. However, our study was not designed for investigating the side effects of bortezomib, and therefore we cannot conclusively attribute the effect on weight to any particular side effect. In the $8 \mathrm{w}-\mathrm{Bz}$ Control group, weight gain, neuromuscular transmission and apoptosis were normalized 8 weeks after immunization, suggesting that by that time compensatory mechanisms limited these adverse effects of bortezomib.

Despite comparable autoantibody titers, the ultrastructural postsynaptic damage of the $4 w-B z$ EAMG group was significantly higher compared with the $8 w-B z$ EAMG group. Because the repair of the postsynaptic membrane takes at least 10 days [42], it seems possible that the observed loss of postsynaptic folding in the $4 \mathrm{w}$-Bz group is the result of earlier damage, in particular in the period between 4 and 7 weeks after immunization, when titers were higher compared with the 8w-Bz EAMG group.

Apart from the intended killing of plasma cells, bortezomib affected the immune system in a more general fashion. In particular, the thymus was affected by bortezomib; an effect that might not be harmful, since thymectomy is a frequently used treatment in MG, albeit with unproven efficacy so far. In this respect it is relevant that in human thymocyte cultures from thymectomized MG patients we observed that bortezomib induced cell death and reduction of autoantibody production (A. Gomez, K. Vrolix, and M. Losen, unpublished observations). Similar to a previous study in mice [43], we found in our rat model that bortezomib mainly affects immature thymocytes. In the spleen, bone marrow, and the blood of rats, the proportion of $\mathrm{CD} 45 \mathrm{RA}^{+} / \operatorname{IgK}^{+} \mathrm{B}$ cells was significantly decreased, whereas the proportion of $\mathrm{CD}^{+} \mathrm{T}$ cells of total lymphocytes was increased. 
There was a trend for increased proportion of dead and apoptotic cells in the thymus, bone marrow, and spleen of bortezomib-treated animals. In contrast, bortezomib induced a significant reduction of apoptotic cells in the blood. Because the PBMCs only represent a minor proportion of leukocytes, this effect could be attributed to migration of cells into other lymphoid organs, for example, the spleen, which was significantly enlarged in bortezomib-treated rats.

In the past the EAMG model has been instrumental for testing the efficacy of new therapies that are now used for the treatment of MG [reviewed by 44], for example, cyclophosphamide [45], pixantrone [46], linomide [47], azathioprine, and hydrocortisone [48]. Also, mycophenolate mofetil efficiently reduces autoantibodies in a rat model of EAMG [33]. This study now indicates that bortezomib might be useful to complement these drugs for the treatment of MG since it can additionally target plasma cells that produce autoantibodies. Because of the observed plasma cell reduction in rats, it is reasonable to presume that a course of bortezomib treatment might well eliminate shortand long-lived plasma cells also in humans and therefore induce a long-lasting treatment response in antibody-mediated autoimmune diseases.

\section{Acknowledgements}

We thank Joost Van den Broeck, Caroline Hammels, Jo Stevens and Jonas Hummel for valuable help and Pauline Wouters, Richard Frijnts and Rik Tinnemans for excellent technical assistance and for performing the animal experiments. This work was supported by the European Union Sixth Framework Program (FP6) MYASTAID LSHM-CT-2006037833. A.M.G. was supported by a Marie-Curie fellowship by the European Union and a grant from the Prinses Beatrix Fonds (project WAR08-12). PM-M was supported by grants from the Prinses Beatrix Fonds (project: MAR03-0115), L'Association Française contre les Myopathies and Genmab. M.L. was supported by a Veni fellowship of NWO and a fellowship of the Brain Foundation of the Netherlands.

Conflicts of interest: R.A.M. and R.E.V. have applied for a patent on the use of proteasome inhibitors for plasma cell depletion. The other authors have no financial 
conflicts of interest. 


\section{$\underline{\text { References }}$}

1. Sanders, D.B., Evoli, A. 2010. Immunosuppressive therapies in myasthenia gravis. Autoimmunity, 43: 428-35.

2. Shapiro-Shelef, M., Calame, K. 2005. Regulation of plasma-cell development. Nat Rev Immunol, 5: 230-42.

3. Miller, J.J., 3rd, Cole, L.J. 1967. Resistance of long-lived lymphocytes and plasma cells in rat lymph nodes to treatment with prednisone, cyclophosphamide, 6-mercaptopurine, and actinomycin D. J Exp Med, 126: 109-25.

4. DiLillo, D.J., Hamaguchi, Y., Ueda, Y., Yang, K., Uchida, J., Haas, K.M., Kelsoe, G., Tedder, T.F. 2008. Maintenance of long-lived plasma cells and serological memory despite mature and memory B cell depletion during CD20 immunotherapy in mice. J Immunol, 180: 36171.

5. Arce, S., Cassese, G., Hauser, A., Dorner, T., Odendahl, M., Manz, R., Radbruch, A., Hiepe, F. 2002. The role of long-lived plasma cells in autoimmunity. Immunobiology, 206: 558-62.

6. Meister, S., Schubert, U., Neubert, K., Herrmann, K., Burger, R., Gramatzki, M., Hahn, S., Schreiber, S., Wilhelm, S., Herrmann, M. et al. 2007. Extensive immunoglobulin production sensitizes myeloma cells for proteasome inhibition. Cancer Res, 67: 1783-92.

7. Neubert, K., Meister, S., Moser, K., Weisel, F., Maseda, D., Amann, K., Wiethe, C., Winkler, T.H., Kalden, J.R., Manz, R.A. et al. 2008. The proteasome inhibitor bortezomib depletes plasma cells and protects mice with lupus-like disease from nephritis. Nat Med, 14: 74855.

8. Obeng, E.A., Carlson, L.M., Gutman, D.M., Harrington, W.J., Jr., Lee, K.P., Boise, L.H. 2006. Proteasome inhibitors induce a terminal unfolded protein response in multiple myeloma cells. Blood, 107: 4907-16.

9. Groll, M., Berkers, C.R., Ploegh, H.L., Ovaa, H. 2006. Crystal structure of the boronic acidbased proteasome inhibitor bortezomib in complex with the yeast $20 \mathrm{~S}$ proteasome. Structure, 14: 451-6.

10. Hemeryck, A., Geerts, R., Monbaliu, J., Hassler, S., Verhaeghe, T., Diels, L., Verluyten, W., van Beijsterveldt, L., Mamidi, R.N., Janssen, C. et al. 2007. Tissue distribution and depletion kinetics of bortezomib and bortezomib-related radioactivity in male rats after single and repeated intravenous injection of 14 C-bortezomib. Cancer Chemother Pharmacol, 60: 777-87.

11. Vrolix, K., Fraussen, J., Molenaar, P.C., Losen, M., Somers, V., Stinissen, P., De Baets, M.H., Martinez-Martinez, P. 2010. The auto-antigen repertoire in myasthenia gravis. Autoimmunity, 43: 380-400.

12. Hoch, W., McConville, J., Helms, S., Newsom-Davis, J., Melms, A., Vincent, A. 2001. Autoantibodies to the receptor tyrosine kinase MuSK in patients with myasthenia gravis without acetylcholine receptor antibodies. Nat Med, 7: 365-8.

13. Vrolix, K., Niks, E.H., Le Panse, R., van Ostaijen-ten Dam, M.M., Muris, A.-H., Jol-van der Zijde, C.M., van Tol, M.J., Losen, M., Molenaar, P.C., van Zoelen, E.J.J. et al. 2010. Reduced thymic expression of ErbB receptors without auto-antibodies against synaptic ErbB in myasthenia gravis. J Neuroimmunol, In press.

14. Gajdos, P., Chevret, S., Toyka, K. 2002. Plasma exchange for myasthenia gravis. Cochrane Database Syst Rev: CD002275.

15. Gajdos, P., Chevret, S., Toyka, K. 2008. Intravenous immunoglobulin for myasthenia gravis. Cochrane Database Syst Rev: CD002277.

16. Palace, J., Newsom-Davis, J., Lecky, B. 1998. A randomized double-blind trial of prednisolone alone or with azathioprine in myasthenia gravis. Myasthenia Gravis Study 
Group. Neurology, 50: 1778-83.

17. Skeie, G.O., Apostolski, S., Evoli, A., Gilhus, N.E., Illa, I., Harms, L., Hilton-Jones, D., Melms, A., Verschuuren, J., Horge, H.W. Guidelines for treatment of autoimmune neuromuscular transmission disorders. Eur J Neurol.

18. Trivedi, J.R., Wolfe, G.I. 2010. Myasthenia gravis therapy and thymectomy. In Myasthenia gravis - disease mechanisms and immune intervention. Christadoss, P., ed. Linus Publications, Deer Park, NY, pp. 55-79.

19. De Baets, M., Stassen, M., Losen, M., Zhang, X., Machiels, B. 2003. Immunoregulation in experimental autoimmune myasthenia gravis--about $\mathrm{T}$ cells, antibodies, and endplates. Ann N Y Acad Sci, 998: 308-17.

20. Lindstrom, J. 1980. Experimental autoimmune myasthenia gravis. I Neurol Neurosurg Psychiatry, 43: 568-76.

21. Martinez-Martinez, P., Losen, M., Duimel, H., Frederik, P., Spaans, F., Molenaar, P., Vincent, A., De Baets, M.H. 2007. Overexpression of rapsyn in rat muscle increases acetylcholine receptor levels in chronic experimental autoimmune myasthenia gravis. Am J Pathol, 170: 644-57.

22. Gomez, A.M., Van Den Broeck, J., Vrolix, K., Janssen, S.P., Lemmens, M.A., Van Der Esch, E., Duimel, H., Frederik, P., Molenaar, P.C., Martinez-Martinez, P. et al. 2010. Antibody effector mechanisms in myasthenia gravis-Pathogenesis at the neuromuscular junction. Autoimmunity, 43: 353-70.

23. Losen, M., Martinez-Martinez, P., Phernambucq, M., Schuurman, J., Parren, P.W., De Baets, M.H. 2008. Treatment of myasthenia gravis by preventing acetylcholine receptor modulation. Ann N Y Acad Sci, 1132: 174-9.

24. Lennon, V.A., Lindstrom, J.M., Seybold, M.E. 1975. Experimental autoimmune myasthenia: A model of myasthenia gravis in rats and guinea pigs. J Exp Med, 141: 1365-75.

25. Sinn, D.I., Lee, S.T., Chu, K., Jung, K.H., Kim, E.H., Kim, J.M., Park, D.K., Song, E.C., Kim, B.S., Yoon, S.S. et al. 2007. Proteasomal inhibition in intracerebral hemorrhage: neuroprotective and anti-inflammatory effects of bortezomib. Neurosci Res, 58: 12-8.

26. Cavaletti, G., Gilardini, A., Canta, A., Rigamonti, L., Rodriguez-Menendez, V., Ceresa, C., Marmiroli, P., Bossi, M., Oggioni, N., D'Incalci, M. et al. 2007. Bortezomib-induced peripheral neurotoxicity: a neurophysiological and pathological study in the rat. Exp Neurol, 204: 317-25.

27. Verschuuren, J.J., Spaans, F., De Baets, M.H. 1990. Single-fiber electromyography in experimental autoimmune myasthenia gravis. Muscle Nerve, 13: 485-92.

28. Hoedemaekers, A., Graus, Y., van Breda Vriesman, P., de Baets, M. 1997. Age- and sexrelated resistance to chronic experimental autoimmune myasthenia gravis (EAMG) in Brown Norway rats. Clin Exp Immunol, 107: 189-97.

29. Hoedemaekers, A.C., Verschuuren, J.J., Spaans, F., Graus, Y.F., Riemersma, S., van Breda Vriesman, P.J., De Baets, M.H. 1997. Age-related susceptibility to experimental autoimmune myasthenia gravis: immunological and electrophysiological aspects. Muscle Nerve, 20: 1091-101.

30. Lightcap, E.S., McCormack, T.A., Pien, C.S., Chau, V., Adams, J., Elliott, P.J. 2000. Proteasome inhibition measurements: clinical application. Clin Chem, 46: 673-83.

31. Moreau, P., Coiteux, V., Hulin, C., Leleu, X., van de Velde, H., Acharya, M., Harousseau, J.L. 2008. Prospective comparison of subcutaneous versus intravenous administration of bortezomib in patients with multiple myeloma. Haematologica, 93: 1908-11.

32. Losen, M., Stassen, M.H., Martinez-Martinez, P., Machiels, B.M., Duimel, H., Frederik, P., Veldman, H., Wokke, J.H., Spaans, F., Vincent, A. et al. 2005. Increased expression of rapsyn in muscles prevents acetylcholine receptor loss in experimental autoimmune myasthenia gravis. Brain, 128: 2327-37. 
33. Janssen, S.P., Phernambucq, M., Martinez-Martinez, P., De Baets, M.H., Losen, M. 2008. Immunosuppression of experimental autoimmune myasthenia gravis by mycophenolate mofetil. J Neuroimmunol, 201-202: 111-20.

34. Martinez-Martinez, P., Phernambucq, M., Steinbusch, L., Schaeffer, L., Berrih-Aknin, S., Duimel, H., Frederik, P., Molenaar, P., De Baets, M.H., Losen, M. 2009. Silencing rapsyn in vivo decreases acetylcholine receptors and augments sodium channels and secondary postsynaptic membrane folding. Neurobiol Dis, 35: 14-23.

35. Engel, A.G., Santa, T. 1971. Histometric analysis of the ultrastructure of the neuromuscular junction in myasthenia gravis and in the myasthenic syndrome. Ann N Y Acad Sci, 183: 4663.

36. Manz, R.A., Hauser, A.E., Hiepe, F., Radbruch, A. 2005. Maintenance of serum antibody levels. Annu Rev Immunol, 23: 367-86.

37. Slifka, M.K., Ahmed, R. 1998. Long-lived plasma cells: a mechanism for maintaining persistent antibody production. Curr Opin Immunol, 10: 252-8.

38. Hawkey, C.J., Newsom-Davis, J., Vincent, A. 1981. Plasma exchange and immunosuppressive drug treatment in myasthenia gravis: no evidence for synergy. $J$ Neurol Neurosurg Psychiatry, 44: 469-75.

39. Olarte, M.R., Schoenfeldt, R.S., Penn, A.S., Lovelace, R.E., Rowland, L.P. 1981. Effect of plasmapheresis in myasthenia gravis 1978-1980. Ann N Y Acad Sci, 377: 725-8.

40. Bruna, J., Udina, E., Ale, A., Vilches, J.J., Vynckier, A., Monbaliu, J., Silverman, L., Navarro, $X$. Neurophysiological, histological and immunohistochemical characterization of bortezomib-induced neuropathy in mice. Exp Neurol, 223: 599-608.

41. Kane, R.C., Bross, P.F., Farrell, A.T., Pazdur, R. 2003. Velcade: U.S. FDA approval for the treatment of multiple myeloma progressing on prior therapy. Oncologist, 8: 508-13.

42. Engel, A.G., Sakakibara, H., Sahashi, K., Lindstrom, J.M., Lambert, E.H., Lennon, V.A. 1979. Passively transferred experimental autoimmune myasthenia gravis. Sequential and quantitative study of the motor end-plate fine structure and ultrastructural localization of immune complexes (IgG and C3), and of the acetylcholine receptor. Neurology, 29: 179-88.

43. Maseda, D., Meister, S., Neubert, K., Herrmann, M., Voll, R.E. 2008. Proteasome inhibition drastically but reversibly impairs murine lymphocyte development. Cell Death Differ, 15: 600-12.

44. Souroujon, M.C., Brenner, T., Fuchs, S. 2010. Development of novel therapies for MG: Studies in animal models. Autoimmunity, 43: 446-60.

45. Pestronk, A., Drachman, D.B., Teoh, R., Adams, R.N. 1983. Combined short-term immunotherapy for experimental autoimmune myasthenia gravis. Ann Neurol, 14: 235-41.

46. Ubiali, F., Nava, S., Nessi, V., Longhi, R., Pezzoni, G., Capobianco, R., Mantegazza, R., Antozzi, C., Baggi, F. 2008. Pixantrone (BBR2778) reduces the severity of experimental autoimmune myasthenia gravis in Lewis rats. J Immunol, 180: 2696-703.

47. Karussis, D.M., Lehmann, D., Brenner, T., Wirguin, I., Mizrachi-Koll, R., Sicsic, C., Abramsky, O. 1994. Immunomodulation of experimental autoimmune myasthenia gravis with linomide. J Neuroimmunol, 55: 187-93.

48. Abramsky, O., Tarrab-Hazdai, R., Aharonov, A., Fuchs, S. 1976. Immunosuppression of experimental autoimmune myasthenia gravis by hydrocortisone and azathioprine. J Immunol, 117: 225-8. 


\section{Chapter

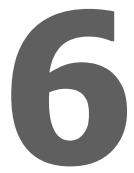

Proteasome inhibition with bortezomib depletes plasma cells and specific autoantibody production in primary thymic cell cultures from early-onset myasthenia gravis patients

Alejandro M. Gomez, Nick Willcox, Kathleen Vrolix, Jonas Hummel, Hans Duimel, Fons Verheyen, Peter C. Molenaar, Wim A. Buurman, Pilar Martinez-Martinez, Marc H. De Baets, and Mario Losen 


\section{Abstract}

Bortezomib is a potent inhibitor of proteasomes currently used to eliminate malignant plasma cells in multiple myeloma patients. It is also effective in depleting both alloreactive plasma cells in acute antibody-mediated transplant rejection and their autoreactive counterparts in animal models of lupus and myasthenia gravis (MG).

In this study, we demonstrate that bortezomib killed long-lived plasma cells in cultured thymus cells from early-onset MG patients - even at $10-250 \mathrm{nM}$ - and halted their spontaneous production not only of autoantibodies against the acetylcholine receptor but also of total IgG. Bortezomib-treated plasma cells showed ultrastructural changes characteristic of endoplasmic reticulum stress after 8 hours, and were no longer detectable at 24 hours. Bortezomib therefore appears promising for treating MG and possibly other antibody-mediated autoimmune or allergic disorders, especially if given in short courses at modest doses before the standard immunosuppressive drugs have taken effect. 


\section{Introduction}

Myasthenia gravis (MG) with antibodies against the muscle acetylcholine receptor ( $\mathrm{AChR}$ ) is one of the best understood of the numerous autoimmune neurological diseases now recognized [1]. It is generally agreed that the patients' autoantibodies are pathogenic, as they decrease AChR numbers by antigenic modulation and complement-mediated damage $[2,3]$. Patients with early-onset MG (EOMG; before age 45) are an unusually well defined subgroup, with strong female and HLA-B8 biases [4], and characteristic lymph node-like infiltrates in the thymic medulla [5-7].

Treatment of MG relies primarily on glucocorticoids, often combined with broadspectrum immunosuppressants such as azathioprine or mycophenolate mofetil (MMF), or rituximab (anti-CD20 mAb) [8]. However, their efficacy and side-effects vary greatly between patients and they reduce autoantibody titers and restore muscle strength only after delays as long as $4-15$ months $[9,10]$. In addition, drug-resistant AChR-MG patients treated with rituximab showed no reduction in either anti-AChR antibody titers or IgG levels, despite complete elimination of circulating B-cells [10]. In such patients, long-lived plasma cells, which are CD20 negative, are likely to be the main producers of the autoantibodies. Moreover, they are probably responsible for the delayed responses of most MG patients to immunosuppressants, which mainly act by preventing generation of new plasma cells from B-cells and impairing the activation and proliferation of T-helper cells [11-13].

Plasma cells are terminally differentiated high-rate antibody-secreting cells $[>10,000$ molecules per cell per second $[14,15]]$ which do not divide; among the B-cell lineage, they are uniquely radio-resistant. Whereas some are short-lived, others persist for many months (or even years) [16] in special survival niches in bone marrow [17] and lymphoid tissues [18]. They are the main producers of circulating IgG, and are clearly major contributors in chronic antibody-mediated autoimmune diseases. Their resistance to both standard immunosuppressants and rituximab, therefore, necessitates a different pharmacological approach. Proteasome inhibitors are a promising new class of drugs for targeting plasma cells [reviewed in: 18, 19, 20]. Bortezomib was the first clinically 
approved proteasome inhibitor and is used for treating multiple myelomas (MM), neoplasms of plasma cells. In addition, bortezomib is now used to prevent acute antibodymediated rejection of solid organ transplants [21]. It is also showing promise in antibodymediated autoimmune diseases such as systemic lupus erythematosus (SLE) and thrombotic thrombocytopenic purpura (TTP) [18, 22]. In autoimmune animal models of SLE, ANCA-induced glomerulonephritis and MG, it depleted both plasma cells and autoantibodies [23-25].

Partly because of their high rate of protein synthesis and dependence on protective unfolded protein responses, MM cells are very susceptible to proteasome inhibitors [26]. These rapidly induce apoptosis by activating the terminal unfolded protein response [27] and inhibiting the transcription factor NF-KB [28]. Proteasome inhibition has similar effects on non-neoplastic plasma cells in vivo [24].

Non-neoplastic plasma cells may also be susceptible to other anti-myeloma drugs, for example, the thalidomide derivative lenalidomide, which is frequently combined with dexamethasone in non-pregnant MM patients, and appears relatively safe. Lenalidomide inhibits the proliferation of several MM cell lines and disrupts the stromal support in their survival niches [29]. Since it reduces IgM and IgG responses to pokeweed mitogen (PWM)-stimulated B-cells [30], it must affect earlier B-lineage cells too.

In most EOMG patients, the thymic infiltrates include numerous germinal centers [5], many of them AChR-specific, and autoreactive T- and B-cells along with terminal plasma cells [31]. In primary cultures of cells from EOMG but not control thymi, autoreactive plasma cells spontaneously secrete AChR autoantibodies, with titers and fine specificities very similar to those in the patients' sera [31, 32]. They do so for several weeks (at least) - even after irradiation [32], implying that many of them are long-lived. The resilience of these plasma cells contrasts strikingly with the majority of thymic subsets, e.g. immature thymocytes and T-cells, which have a very high turnover in vivo $[33,34]$ and die rapidly in culture [35].

Thymectomy is part of standard management of EOMG in many centers. Thus the tissue removed is an almost uniquely accessible source of long-lived human autoimmune plasma cells. Here, we have for the first time tested the hypothesized potential of 
bortezomib and lenalidomide to target such plasma cells.

\section{Patients, Materials and Methods}

\section{$\underline{\text { Patients }}$}

The MG patients (MG 1 - 3) were thymectomized 6 - 30 months after MG onset in London (UK), and were all young females with typical EOMG (onset-ages, 16, 20 and 24 years) but no steroid pre-treatment. They were recruited with informed consent and Ethics Committee approval, and selected only because of recent MG-onset, high serum antiAChR titers $(180,270$ and 1,000 nM), correspondingly high productivity of these antibodies by their thymic cells in culture [32], and availability of irradiated cells. To assess total cell survival after administration of drugs, we used thymus cells from a fourth patient (MG onset-age 36 years, i.e. 13 months before thymectomy; anti-AChR titer 24 nM).

\section{Cell culture and experimental design}

Thymic cells were cultured as described [36]. Briefly, fresh thymic tissue was dispersed enzymatically, washed (and some aliquots irradiated with 1,250 rads from a ${ }^{60}$ Co source) and cryo-stored within a few hours; subsequently, they were thawed carefully, and cultured at $6 \times 10^{5}-9 \times 10^{5}$ cells per well in 96 well round-bottomed plates, without added stimulants in $200 \mu \mathrm{L}$ of RPMI medium containing 15\% fetal bovine serum (Bodinco, the Netherlands), $50 \mathrm{U} / \mathrm{mL}$ penicillin, $50 \mathrm{U} / \mathrm{mL}$ streptomycin and $1 \mathrm{mM}$ sodium pyruvate, at $37^{\circ} \mathrm{C}$ in humidified air with $5 \% \mathrm{CO}_{2}$. Every 2 - 3 days, we removed (and stored) $90 \mu \mathrm{L}$ of supernatant from each well, and replaced it with $100 \mu \mathrm{L}$ of fresh medium \pm any test drugs.

We dissolved lyophilized bortezomib (Velcade, Janssen-Cilag B.V., Belgium) in sterile saline, dexamethasone (D4902; Sigma-Aldrich) in absolute ethanol, and lenalidomide (Santa Cruz Biotechnology; sc-218656) in dimethyl sulfoxide.

\section{$\underline{\text { Immunofluorescence staining and enumeration of plasma cells }}$}

Cultured cells $\left(5 \times 10^{4}-5 \times 10^{5}\right)$ were cytocentrifuged onto poly-L-lysine-coated slides (for 5 minutes at 120 g; Cyto-Tek centrifuge model 4332; Sakura Finetek, Japan). Slides were air-dried for 1 hour at $22^{\circ} \mathrm{C}$ and then fixed in $4 \%$ paraformaldehyde at $4{ }^{\circ} \mathrm{C}$ for 10 minutes. 
Subsequently, they were blocked with $2 \%$ bovine serum albumin in PBS and incubated with Hoechst 33342 solution (2 $\mu \mathrm{g} / \mathrm{mL}$, Cat. B2261; Sigma-Aldrich) to stain DNA. Plasma cells were stained with mouse anti-human CD138 mAb (1:250, Clone MI15, Dako), donkey anti-mouse IgG Alexa 594 (1:300, A21203; Molecular Probes-Invitrogen) and goat antihuman IgG Alexa 488 (1:500, A11013; Molecular Probes-Invitrogen). Slides were mounted in $80 \%$ glycerol-TBS and stored at $4{ }^{\circ} \mathrm{C}$ in the dark. All washing and incubation steps were performed with TBS-Triton X-100 (0.03\%). We counted the plasma cells from each well, in a blinded fashion, on a fluorescence microscope (Olympus BX51), identifying them by their distinctive size, shape (extensive cytoplasm and eccentric nuclei), and positive staining for IgG and/or CD138. Results are expressed as the proportion of the initially plated plasma cells that were finally detected in each well (\% survival PC).

\section{Autoantibody and total lgG assays}

In a standard radio-immunoprecipitation assay, we incubated $20 \mu \mathrm{L}$ of supernatant overnight at $4^{\circ} \mathrm{C}$ with $12.5 \mu \mathrm{L}$ of TE671 human rhabdomyosarcoma cell membrane-extract (containing approximately $3 \mathrm{fmol}$ of human AChR). The AChR was labeled with excess ${ }^{125} \mathrm{I}-$ $\alpha$-bungarotoxin ( ${ }^{125} \mathrm{I}-\alpha$-BT, NEX126, $3.4 \mathrm{TBq} / \mathrm{mmol}$; PerkinElmer), and normal human serum was used as carrier. Any immune complexes were precipitated by addition of 150 $\mu \mathrm{L}$ of goat anti-human IgG and incubation for 4 hours at $4^{\circ} \mathrm{C}$. A standard curve was made by serial dilutions of the anti-AChR mAb 637 [37] and processed in parallel to the samples. Results are expressed as nanomoles of $\alpha-B T$ binding sites/L culture medium/day.

We measured total IgG in the culture supernatants with a standard sandwich ELISA as described [23], capturing with goat $F\left(a b^{\prime}\right)_{2}$ anti-human IgG-Fcy (109-006-008; Jackson Immuno-Research; diluted 1:200) and detecting with horseradish peroxidase conjugated goat $\mathrm{F}\left(\mathrm{ab}^{\prime}\right)_{2}$ anti-human IgG-Fcy (109-036-008; Jackson Immuno-Research; diluted 1:20,000). Results were expressed as ng of total IgG secreted per $\mathrm{mL}$ of culture medium/day.

The newly synthesized antibody against the AChR and total IgG was quantitated as its present concentration (in $200 \mu \mathrm{L}$ ) minus the concentration in the previous sample (in $100 \mu \mathrm{L}$ ) / time interval. 


\section{Staining for surface B-and T-cell markers, and membrane integrity}

Cells were incubated for 30 minutes at $4^{\circ} \mathrm{C}$ in FACS buffer ( $2 \%$ fetal calf serum and $0.1 \%$ sodium azide in PBS) with FITC mouse anti-human CD3 (Cat. 555339; BD Biosciences) and PE mouse anti-human CD19 (Cat. 555413, BD Biosciences), all diluted 1:100. The samples were washed twice, kept at $4^{\circ} \mathrm{C}$ in the dark, and analyzed within 2 hours. Dead cells were identified by propidium iodide (PI) counter-staining (Apoptosis detection kit; BD Pharmingen).

We used a FACSCalibur plus CellQuest Software (BD Biosciences) for data acquisition and analyzed results using the Flowing Software (version 2.5.0; Turku Center for Biotechnology, Finland). Samples were gated to exclude cell debris and aggregates, and PI-positive cells.

\section{Electron microscopy}

Cultured thymic cells were collected, pelleted $\left(7 \mathrm{~min}, 220 \mathrm{~g}, 4^{\circ} \mathrm{C}\right)$ and fixed with $3 \%$ glutaraldehyde $+1.4 \%$ sucrose buffered in $0.09 \mathrm{M} \mathrm{KH}_{2} \mathrm{PO}_{4}$ at $\mathrm{pH}$ 7.4. They were then washed in $0.09 \mathrm{M} \mathrm{KH}_{2} \mathrm{PO}_{4}$ buffer with $7.5 \%$ sucrose and transferred to a $1 \% \mathrm{OsO}_{4}+1.5 \%$ ferrocyanide solution buffered with veronal at $\mathrm{pH} 7.4$ for subsequent immersion fixation for 1 hour at $4^{\circ} \mathrm{C}$. After washing in veronal buffer with $7 \%$ sucrose at $\mathrm{pH} 7.4$, dehydration was carried out rapidly in graded ethanol series. Samples were then incubated overnight in propylene oxide and Epon (1:1), and subsequently embedded in Epon. Serial $80 \mathrm{~nm}$ sections were stained with uranyl acetate, lead citrate, and coded. We used a Philips CM100 electron microscope to count plasma cells and examine their ultrastructure in five representative sections for each sample.

\section{$\underline{\text { Statistics }}$}

GraphPad Prism 4 was used for statistical analyses. We compared normally distributed values using 1- or 2-way ANOVA analyses, and Bonferroni post-hoc tests. A two-sided probability value of 0.05 or lower was considered significant. Values are expressed as means \pm standard error of the mean (SEM) unless stated otherwise. We used Spearman (non-parametric) correlation coefficients $(\rho)$. 


\section{Results}

\section{Culturing EOMG thymic cells}

Plasma cells were identified by their characteristic ultra-structural morphology (Fig. 6.1), intense internal IgG staining and surface CD138 expression (Fig. 6.2A). They were frequently found in clumps of 3-5 cells (or sometimes more), in close contact with extracellular matrix and other cell types (Fig. 6.2A), as in their survival niches in the spleen or bone marrow [38].

In the thymus, there is normally a high rate of cell death in vivo [33, 34]. As expected, it was also substantial in our suspension cultures of frozen/thawed thymic cells; $\sim 20 \%$ of the input cells remained viable on day 14 , and even fewer in irradiated samples ( 8\%). To maximize plasma cell recovery/activity, we used cryo-stored cells that had been dispersed with dispase and collagenase $[7,36]$. They appeared highly dependent on cell concentration and on adherent 'feeder' fibroblasts and macrophages [36]. Although microenvironments were probably not optimal in the present cultures, spontaneous autoantibody production was nonetheless relatively consistent in quadruplicate wells (see Figs. 6.2, 6.3). Remarkably, it persisted for at least 2 weeks, even after irradiation (Fig. 6.3), when only occasional viable macrophages and fibroblasts could still be seen (not shown).

\section{Bortezomib rapidly induces apoptosis in plasma cells from EOMG thymi}

We cultured thawed EOMG thymic cells for 3 days before adding bortezomib; the standard concentration of $2.5 \mu \mathrm{M}$ was based on previous in vitro experiments on human plasma cells [39] and the peak concentration measured in MM patients [40].

In all control samples, plasma cell ultrastructure appeared normal, with elaborate endoplasmic reticulum (ER), a well-defined Golgi complex and dense regions of (nuclear) heterochromatin in a typical "cart-wheel" distribution (Fig. 6.1A). They still appeared normal at 2 and 4 hours after addition of bortezomib (at $2.5 \mu \mathrm{M}$; Fig. 6.1B). However, after 8 hours, most surviving plasma cells showed signs of apoptosis (Fig. 6.1C), including condensation of chromatin and distension of the ER [41]. After 24 hours, they were no 
longer detectable in the bortezomib-treated cultures. Results were very similar with bortezomib at $0.25 \mu \mathrm{M}$ (not shown).

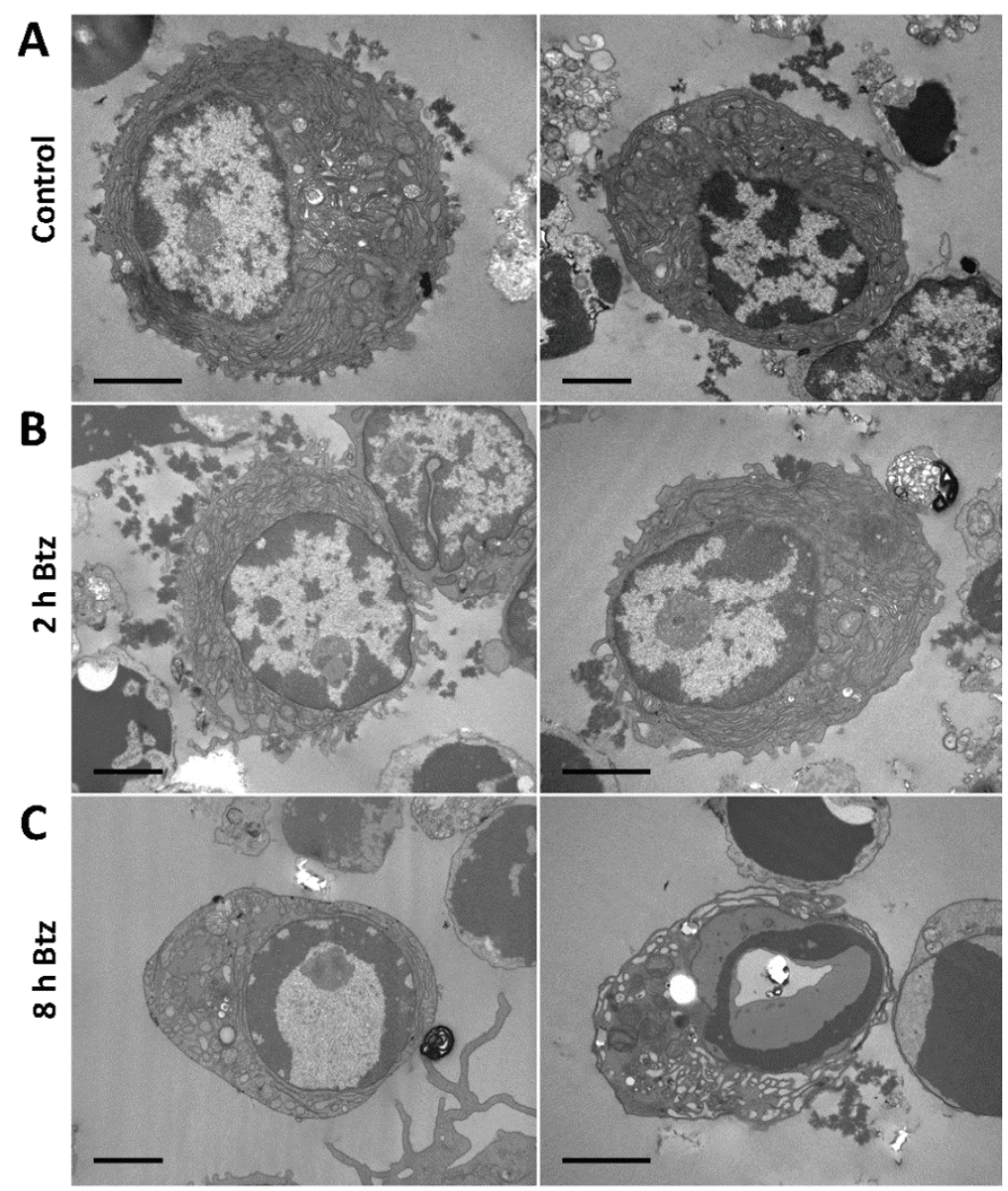

Figure 6.1. Ultrastructural changes in plasma cells incubated with bortezomib. (A) Normal plasma cells in control samples. Note the typical morphology, with an elaborate endoplasmic reticulum (ER) and eccentric nuclei (with a cart-wheel configuration of the heterochromatin). (B) Most plasma cells also appeared normal after 2 hours of treatment with bortezomib. (C) After 8 hours of treatment with $2.5 \mu \mathrm{M}$ bortezomib, most plasma cells appeared apoptotic, with heterochromatin condensed around the perimeter of the nucleus and distension of the ER lumen. 24 hours after treatment with bortezomib, no plasma cells could be detected. Coded cell samples were post-fixed with osmium tetroxide and counter-stained with uranyl acetate and lead citrate. Scale bars are 2 $\mu \mathrm{m}$.

\section{Bortezomib eliminates plasma cells in cultured EOMG thymic cells}

To focus on long-lived plasma cells, we next added bortezomib, lenalidomide or 
dexamethasone on days 7 and 11 of culture, and counted surviving plasma cells on day 14 . Lenalidomide was used at $10 \mu \mathrm{M}$, based on previous in vitro studies [42-44] and peak levels in MM patients [45]. Dexamethasone was tested at $10 \mathrm{nM}$, a level known to inhibit lymphocyte proliferation in susceptible humans $[46,47]$.

Three days after a second dose of bortezomib, plasma cells were almost undetectable $(p<0.001$; Fig. 6.2B). Interestingly, their numbers were not changed by lenalidomide, and only modestly reduced by dexamethasone $(p<0.05)$. In a separate experiment, we confirmed that $10 \mu \mathrm{M}$ lenalidomide suppressed IgG production by PWMstimulated PBMCs (not shown), as previously reported [30].

\section{Proteasome inhibition halts spontaneous secretion of total IgG and AChR}

\section{autoantibodies}

We could already detect significant production of both anti-AChR antibody and total IgG at 48 hours of culture onwards; both increased further from days 9 - 14 in the control and lenalidomide cultures (Fig. 6.2C, E). In striking contrast, production of both anti-AChR antibody and total IgG declined sharply after the first dose of bortezomib, and further still after the second $(p<0.001)$. Notably, dexamethasone merely prevented their rise after day 9, which correlated with the mild reduction in plasma cell survival observed by day 14 .

With irradiated cells from the same thymi, overall plasma cell survival and antiAChR and total IgG productivity (see Fig. 6.3A-C) largely paralleled those from the untreated cells (Fig. 6.2B-F). Antibody production was generally lower, but was completely unaffected by dexamethasone, whereas it was again inhibited almost completely by bortezomib, as was total IgG production (Fig. 6.3B, C).

When all results were combined, numbers of plasma cells (whether irradiated or not) correlated strongly with spontaneous secretion of total IgG $(\rho=0.89 ; p<0.0001)$ and AChR antibodies ( $\rho=0.79 ; p<0.0001)$. 
A DNA IgG CD138

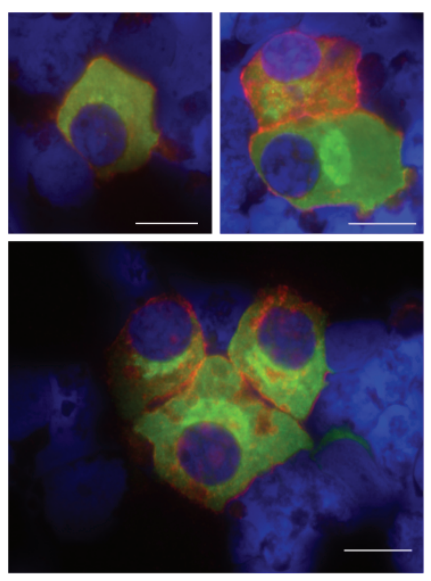

B $\quad$ MG $1 \square \quad$ MG $2 \square \quad$ MG 3

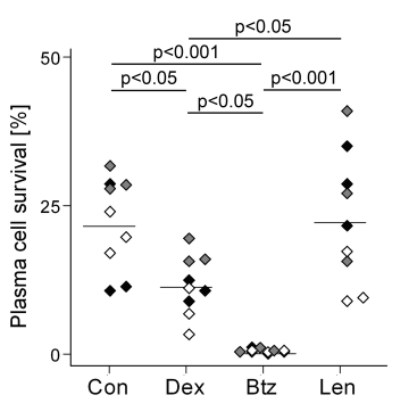

C

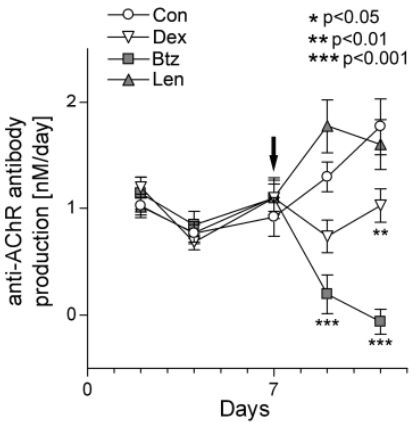

E

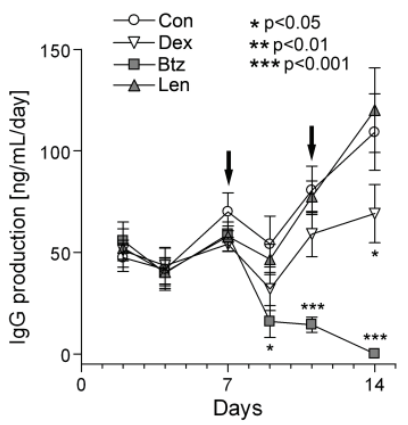

Figure 6.2. Changes in plasma cell numbers and functions after addition of bortezomib (2.5 $\mu \mathrm{M})$, lenalidomide $(10 \mu \mathrm{M})$ or dexamethasone $(10 \mathrm{nM})$ on days 7 and 11, and collected on day 14. (A) Representative plasma cells from cytocentrifuged thymic cells. They were readily identified by their staining for IgG (green) and CD138 (red; DNA is blue), and typical morphological features, including: relatively large size, abundant cytoplasm with positive staining for immunoglobulins and eccentric nuclei. Frequently, plasma cells were found in clumps of 2-3 or more cells together, as shown in the lower panel. Scale bars are $10 \mu \mathrm{m}$. (B) Survival of plasma cells in cell cultures, expressed as a percentage of the input plasma cell numbers. Each point represents an individual well (3 per patient) and results correspond to day $14 .(C, D)$ Spontaneous secretion of antiAChR antibodies in vitro, measured with an immunoprecipitation radioimmunoassay and expressed as nmol of newly synthesized antiAChR antibody/L/day. Results in $D$ correspond to day 11. $(E, F)$ Spontaneous secretion of total $\lg \mathrm{G}$ in vitro. The IgG-content in the supernatant was quantified by a sandwich ELISA and results are expressed as ng of newly synthesized $\mathrm{IgG} / \mathrm{mL}$ medium/day. Results in $F$ are for day 14 . Arrows indicate the days of drug addition. Each point represents the average of samples from all patients (4 per patient; $C, E$ ) or an individual well $(B, D, F)$, and error bars (in $C, E$ ) correspond to the SEM; horizontal bars $(B, D, F)$ represent the average of the group. One way $(B, D, F)$ or two-way $(C, E)$ ANOVA and Bonferroni post-hoc testing were used for statistical analysis. 


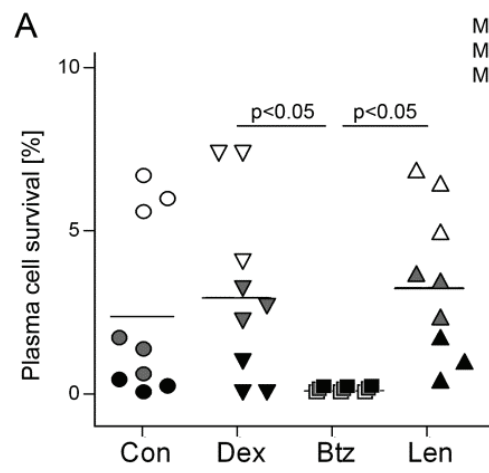

B

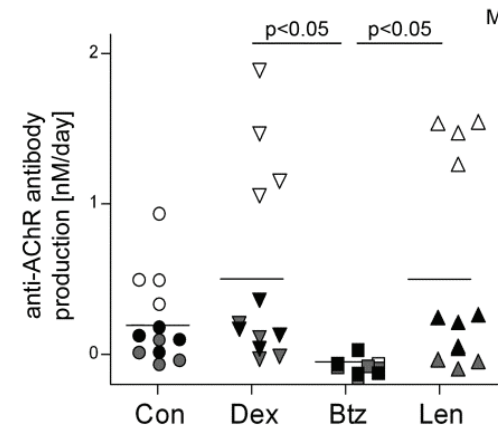

C

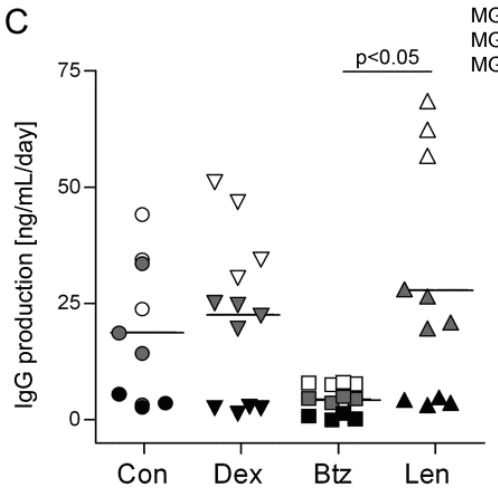

Figure 6.3. Susceptibility of irradiated cells to experimental drugs. Thymic cells were irradiated and subsequently cultured for two weeks. Drugs were added on days 7 and 11 (bortezomib - $2.5 \mu \mathrm{M}$, lenalidomide -10 $\mu \mathrm{M}$, dexamethasone - $10 \mathrm{nM}$ ) and samples were collected and analyzed as for Fig. 6.2 at day 14. (A) Plasma cell survival. Although it was generally lower than with their unirradiated counterparts (Fig. 6.2A), the surviving plasma cells were still resistant to dexamethasone and lenalidomide, but clearly sensitive to bortezomib. (B) AChR autoantibody secretion. (C) IgG secretion. Each point represents an individual well. Grey shades indicate from which patient the sample originates. Horizontal bars represent the average of the group. One-way ANOVA and Bonferroni post-hoc testing were used for statistical analysis.

To test for effects on other cell types, we next stained unirradiated cultured cells for CD3 and CD19. Both dexamethasone (at 10 $\mathrm{nM}$ ) and bortezomib (at $2.5 \mu \mathrm{M}$ ) reduced the numbers of T- and B-cells after the first dose (day $7 ; p<0.001$ ) - and to a similar extent (Fig. $6.4 D, F)$, although dexamethasone had much less effect than bortezomib on antibody levels. By contrast, lenalidomide (at $10 \mu \mathrm{M}$ ) had no significant effect on either cell numbers or anti-AChR antibody/ total IgG production (Fig. $6.4 D, F)$. Together with the strong correlation between total IgG production and plasma cell survival, these results deeply implicate plasma cells, rather than B-cells, in the spontaneous antibody production that we observed in vitro.

\section{Dose-dependence of bortezomib and dexamethasone effects on total IgG production}

\section{and plasma cell survival}

We next tested broader concentration ranges of dexamethasone and bortezomib. Total 
IgG productivity and plasma cell survival were both minimal in the presence of $100 \mathrm{nM}$ $10 \mu \mathrm{M}$ bortezomib (Fig. 6.5A, B). In sharp contrast, dexamethasone had no significant effects, even at $1 \mu \mathrm{M}$. Subsequently, we tested lower concentrations of bortezomib to estimate its minimum effective dose. As illustrated in Fig. 6.5C-D, it eliminated plasma cells and their IgG production even at $10 \mathrm{nM}$. As above, plasma cell survival correlated strongly with IgG production in these experiments.

A

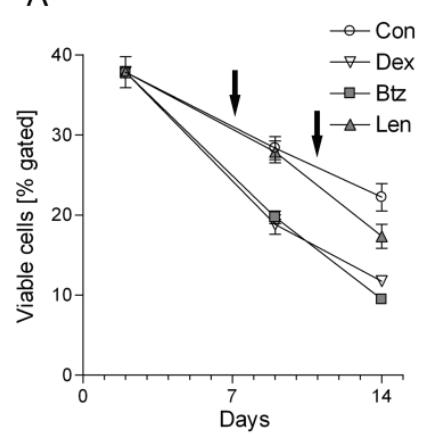

C

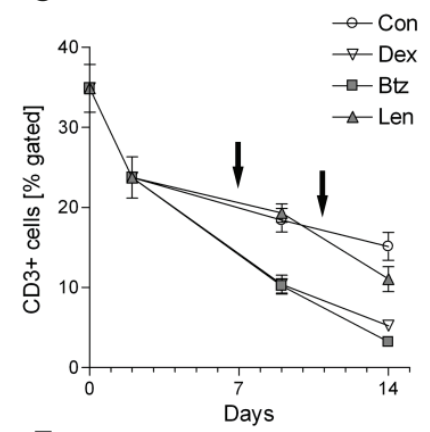

E

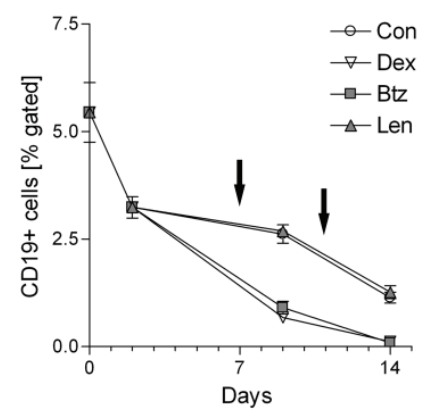

B

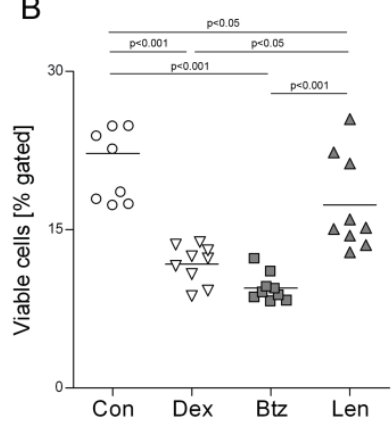

D

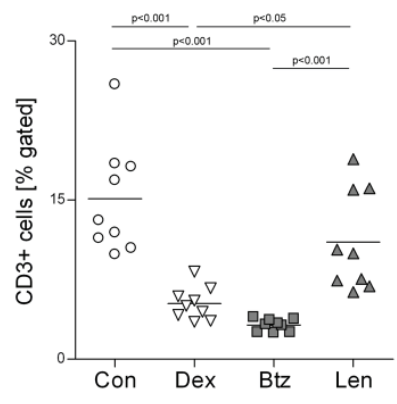

F

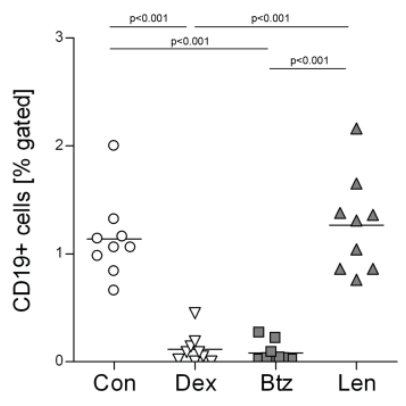

Figure 6.4. Quantitative overview of the drug effects on B- and T-lymphocytes. Thymic cells were cultured for 2 weeks and drugs were added on days 7 and 11 (indicated by arrows). Cells were collected and labeled for FACS analysis on days 0 , 2, 9 and 14. Samples were gated to exclude cell debris, selected for PI-negative cells (viable cells) and for either CD3 or CD19. Results in panels $B, D$ and $F$ are for day 14. Each point represents the average of samples from all patients ( 3 per patient; A, C, E) or an individual well (B, D, $F$ ), and error bars (in $A, C, E$ ) correspond to the SEM; horizontal bars (B, D, F) represent the average of the group. One-way ANOVA and Bonferroni post hoc testing were used for statistical analysis. 
A

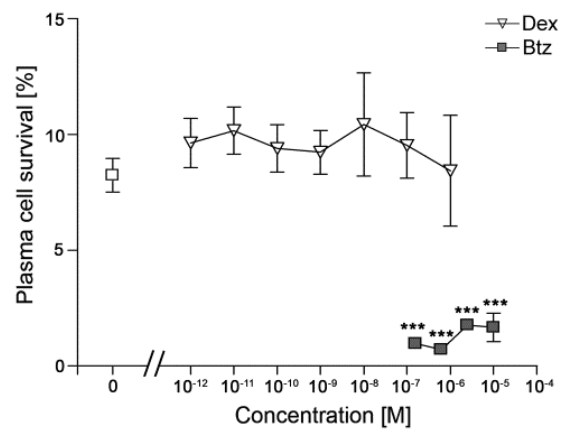

C

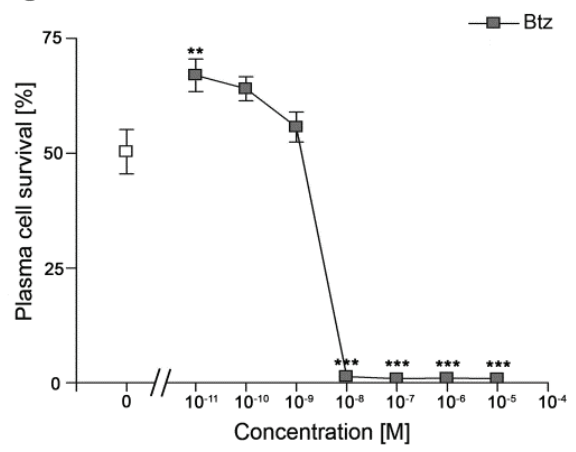

B

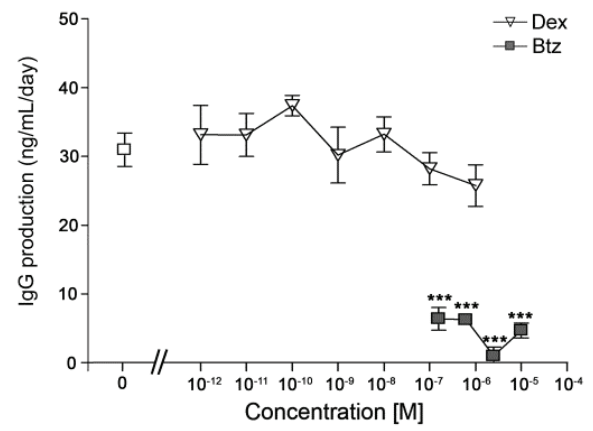

$\mathrm{D}$

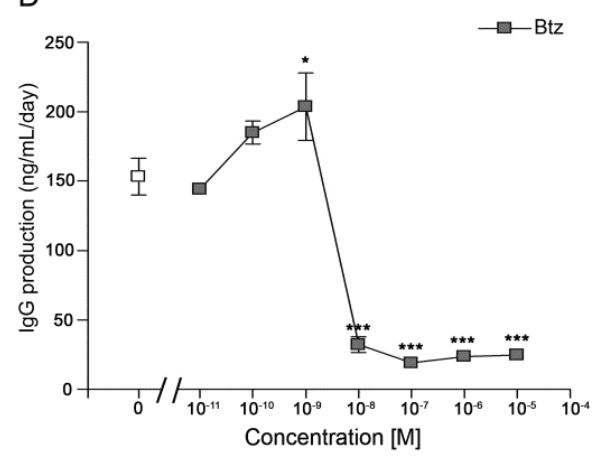

Figure 6.5. Dose-response curves for plasma cell survival (A, C) and total IgG secretion (B, D), after addition of drugs on day 4 and assay on day 7. Thymic cells from MG-1 were used in A and B; cells from MG-3 in C and D. Each point represents the average of 4 replicates and error bars the SEM. One-way ANOVA and Bonferroni posthoc testing were used for statistical analysis. ${ }^{*} \mathrm{p}<0.05 ;{ }^{* *} \mathrm{p}<0.01 ;{ }^{* * *} \mathrm{p}<0.001$, compared with the control samples (white square).

To assess their general toxicity, we sampled cultures at earlier times after addition of these drugs. Cells collected at 6,24 and $48 \mathrm{~h}$ showed no significant differences in overall viability. At day 7, viabilities were reduced more by dexamethasone at $1 \mu \mathrm{M}$ than $10 \mathrm{nM}$; still more by bortezomib at $2.5 \mu \mathrm{M}$, but not significantly at $10 \mathrm{nM}$, where its effects were more selective for plasma cells (Fig. 6.1S). Surprisingly, lenalidomide inhibited IgG production only at $1 \mathrm{mM}$, when it also reduced total cell viability by an extra $40 \%$ (not shown). 


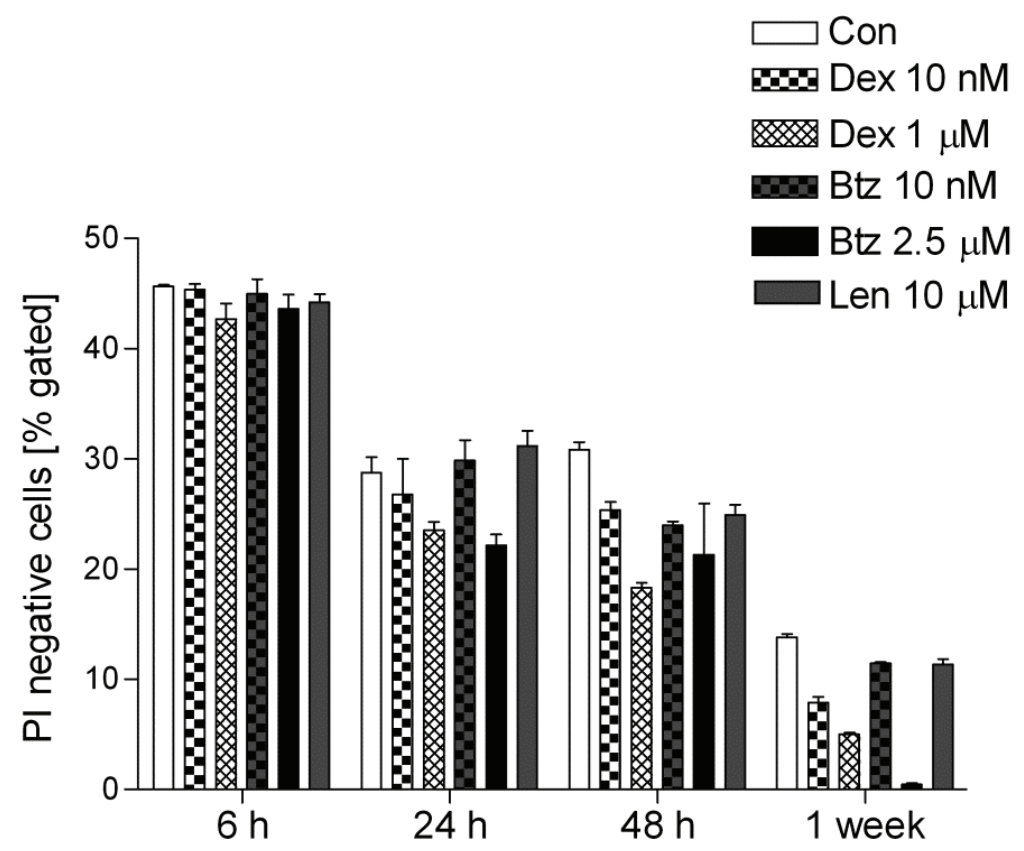

Figure 6.1S. General toxicity of the experimental drugs on thymic cells. Thymic cells from patient MG 4 were cultured for 1 week in the presence of different concentrations of the experimental drugs. Cell viability was evaluated at $6 \mathrm{~h}, 24 \mathrm{~h}, 48 \mathrm{~h}$ and 1 week by measuring propidium iodide (PI) incorporation by flow cytometry; samples were gated in the FSC-SSC dot-plot to exclude membrane debris. Cell viability decreased with time in all the conditions and was particularly low after 1 week exposure to dexamethasone (10 nM and $1 \mu \mathrm{M})$ and bortezomib $2.5 \mu \mathrm{M}$, but not bortezomib $(10 \mathrm{nM})$ or lenalidomide $(10 \mu \mathrm{M})$. Each bar represents the average of 3 replicates and error bars the SEM.

\section{Discussion}

In this study we demonstrate that bortezomib selectively eliminates long-lived autoimmune plasma cells in cultures of thymus cells from EOMG patients. Their spontaneous AChR autoantibody and total IgG production were completely halted, even at $10 \mathrm{nM}$. At 0.25 and $2.5 \mu \mathrm{M}$ - and within 8 hours - it led to ultra-structural changes in plasma cells that are characteristic not only of ER stress but also of apoptosis, as seen in vivo too [23]. These are the first demonstrations of its efficacy directly on pathogenic autoantibody-producing human plasma cells. Since bortezomib clearly triggers apoptosis 
in non-neoplastic plasma cells, even after a single dose, short low-dose regimens might be sufficient to rapidly reduce their numbers and antibody levels in patients with autoimmune disorders, thus 'buying time' during induction of immunosuppression with standard drugs.

In our cultures, plasma cells seemed almost entirely responsible for production of both autoantibody and total IgG, which correlated strongly with their survival. Moreover, it was maintained despite the depletion of B-cells by the addition of dexamethasone (Fig. $6.4 E, F)$ - which evidently contributed minimally in untreated cultures (if at all). Indeed, we have rarely found signs of mitogen-stimulable production of anti-AChR antibodies in EOMG thymi [32]. These data, together with the antibodies' highly mutated heavy and light chain $\mathrm{V}$ region sequences, suggest that native $\mathrm{AChR}$ - which is continuously available in the thymus [31] - is driving most antibody-producing cells to the terminal plasma cell stage. We saw very similar behavior in remnant thymus tissue adjacent to thymomas [31], implying that our findings are not unique to EOMG.

In previous studies, plasma cells from recently immunized mice died after only 4 days in suspension cultures [48]. In sharp contrast, their Ig production was sustained in vitro for 2 - 4 weeks in primary cultures from human tonsils and gut-associated lymphoid tissue, and was enhanced by feeder cells and especially in whole organ cultures $[49,50]$. It seems unlikely that equivalent survival niches were reconstituted efficiently in our cultures of cryostored, and especially irradiated, thymic cells. We suggest that the remarkable survival of the long-lived plasma cells shown here is due to their co-clustering (Fig. 6.2A) and/ or to some degree of resilience or 'self-sufficiency'. Their radio-resistance clearly shows that they are well established in many EOMG thymi and scarcely replaced in culture. Importantly, since bortezomib (but not dexamethasone) reduced their numbers and antibody production to baseline in irradiated samples, its targets must include longlived plasma cells.

In sharp contrast with our results with bortezomib, but in agreement with previous in vivo findings $[24,51]$, we found only marginal effects of dexamethasone on plasma cell survival or function, even when added twice at $1 \mu \mathrm{M}$, and only on unirradiated cells. Evidently, most of the thymic plasma cells are dexamethasone- as well as radio- 
resistant; indeed, neither treatment completely eliminated them in any of our cultures. In theory, both treatments might also affect their supporting cells, and/ or damage other short-lived plasma cells or plasmablasts. In vivo, however, their precursors may be steroidinsensitive too; we noted no obvious decrease in PWM-stimulated IgG responses by (radio-sensitive) B-cells from prednisone-pretreated patients - rather, they appeared to be enriched [52].

The even smaller effects on plasma cells of the immunomodulatory drug lenalidomide may seem surprising in view of its clear benefits in MM patients [53]. One possible explanation is that its toxicity for MM cells is mainly related to the activation of tumor suppressor genes and caspases that trigger apoptosis in transformed cells [54-56], but probably not in their non-neoplastic counterparts. Moreover, since lenalidomide disrupts the survival niches required by $\mathrm{MM}$ and plasma cells, such toxic effects may be under-estimated in our cultures. In addition, it is well-known for its disparate immunomodulatory properties, e.g., inhibiting Ig production by cultured PBMCs [30], but also augmenting antibody responses to vaccination [57], and inducing proliferation and activation of T-cells $[29,58]$. Taken together, our in vitro results indicate that, unlike MM cells, non-neoplastic plasma cells are not directly killed by lenalidomide. However, its possible effects on their niches in vivo might valuably complement the direct actions of bortezomib in patients [42].

Both bortezomib (at higher concentrations) and dexamethasone reduced CD19 and CD3 lymphocytes in our cultures. This is in line with the reported effects of bortezomib on activated human B-cells [59] and total circulating B-cells in EAMG rats [23]. Moreover, bortezomib influences T-cell subset distributions, inducing apoptosis in activated CD4 T-cells, preventing the activation of memory T-cells [60], but preserving resting and regulatory T-cells [61-63], and promoting their de novo generation [63]. Additional effects of bortezomib on activated B- and T-cells, or on antigen-presenting Bcells, could be an advantage in treating MG patients, e.g., in preventing the generation of new auto-reactive plasma cells while also eliminating the existing long-lived subset.

Although bortezomib is clearly effective in treating MM, SLE, TTP and acute antibody-mediated transplant rejection, there are serious concerns about such side- 
effects as thrombocytopenia and, especially, peripheral neuropathy. These may well correlate with the long courses and high doses $\left(1.3 \mathrm{mg} / \mathrm{m}^{2}\right.$; resulting in plasma levels of $C_{\max }=600 \mathrm{nM}[40]$ of bortezomib and other chemotherapeutics needed to eliminate as many MM cells as possible in patients. MM and related leukemia cell lines are susceptible to bortezomib with an $\mathrm{IC}_{50}$ of $12 \mathrm{nM}$ in vitro [64] which is comparable to the $10 \mathrm{nM}$ that proved effective here. Since even partial elimination of autoimmune plasma cells might be sufficient to treat MG, the side-effects might be avoided in autoimmune patients by using shorter courses and/ or lower doses of bortezomib, e.g., in combination with plasma exchange $[65,66]$. Our results suggest that these should rapidly deplete plasma cells/ reduce antibody levels in the short-term - as now seen in prevention of hyper-acute antibody-mediated transplant rejection $[21,67]$. Indeed, adverse effects were significantly fewer with such 'light-touch' regimens [40, 65, 66]. Finally, some second generation proteasome inhibitors have equal or greater potency but lower neurotoxicity than bortezomib, and are already being tested in clinical trials [68].

In conclusion, our study using EOMG thymic cells, in combination with our previous results in the EAMG model [23], gives proof-of-principle for using proteasome inhibitors for the elimination of non-neoplastic plasma cells in autoantibody-mediated disorders. This therapeutic strategy could have potential applications in AChR-MG, especially for rapidly reducing autoantibody titers and so temporizing while standard immunosuppressants start to take effect, and/ or in treatment-refractory patients. However, these potential benefits in MG or other antibody-mediated diseases still need to be balanced very carefully against their side-effects.

\section{Acknowledgements}

We are very grateful to Dr. H. Kaminski and Dr ME Hill for helpful discussions, to the patients for their samples and to Sr E Goodger and the late Prof John Newsom-Davis for access to them.

This work was supported by a Marie-Curie fellowship from the European Union to A.M.G; grants from the Prinses Beatrix Fonds (Project WAR08-12) and the Association Française contre les Myopathies to P.M.-M; grants from the UK Medical Research Council 
to NW; a Veni fellowship of the Netherlands Organization for Scientific Research and a fellowship of the Brain Foundation of the Netherlands to M.L. 


\section{$\underline{\text { References }}$}

1. Irani, S., Lang, B. 2008. Autoantibody-mediated disorders of the central nervous system. Autoimmunity, 41: 55-65.

2. Sahashi, K., Engel, A.G., Lambert, E.H., Howard, F.M., Jr. 1980. Ultrastructural localization of the terminal and lytic ninth complement component (C9) at the motor end-plate in myasthenia gravis. J Neuropathol Exp Neurol, 39: 160-72.

3. Heinemann, S., Merlie, J., Lindstrom, J. 1978. Modulation of acetylcholine receptor in rat diaphragm by anti-receptor sera. Nature, 274: 65-8.

4. Compston, D.A., Vincent, A., Newsom-Davis, J., Batchelor, J.R. 1980. Clinical, pathological, HLA antigen and immunological evidence for disease heterogeneity in myasthenia gravis. Brain, 103: 579-601.

5. Le Panse, R., Bismuth, J., Cizeron-Clairac, G., Weiss, J.M., Cufi, P., Dartevelle, P., De Rosbo, N.K., Berrih-Aknin, S. 2010. Thymic remodeling associated with hyperplasia in myasthenia gravis. Autoimmunity, 43: 401-12.

6. Castleman, B., Norris, E.H. 1949. The pathology of the thymus in myasthenia gravis; a study of 35 cases. Medicine (Baltimore), 28: 27-58.

7. Willcox, H.N., Newsom-Davis, J., Calder, L.R. 1984. Cell types required for antiacetylcholine receptor antibody synthesis by cultured thymocytes and blood lymphocytes in myasthenia gravis. Clin Exp Immunol, 58: 97-106.

8. Gold, R., Hohlfeld, R., Toyka, K.V. 2008. Progress in the treatment of myasthenia gravis. Ther Adv Neurol Disord, 1: 36-51.

9. Hehir, M.K., Burns, T.M., Alpers, J., Conaway, M.R., Sawa, M., Sanders, D.B. 2010. Mycophenolate mofetil in AChR-antibody-positive myasthenia gravis: outcomes in 102 patients. Muscle Nerve, 41: 593-8.

10. Diaz-Manera, J., Martinez-Hernandez, E., Querol, L., Klooster, R., Rojas-Garcia, R., SuarezCalvet, X., Munoz-Blanco, J.L., Mazia, C., Straasheijm, K.R., Gallardo, E. et al. 2012. Longlasting treatment effect of rituximab in MuSK myasthenia. Neurology, 78: 189-93.

11. Cupps, T.R., Gerrard, T.L., Falkoff, R.J., Whalen, G., Fauci, A.S. 1985. Effects of in vitro corticosteroids on B cell activation, proliferation, and differentiation. J Clin Invest, 75: 75461.

12. Ashwell, J.D., Lu, F.W., Vacchio, M.S. 2000. Glucocorticoids in T cell development and function*. Annu Rev Immunol, 18: 309-45.

13. Brown, T.E., Ahmed, A., Filo, R.S., Knudsen, R.C., Sell, K.W. 1976. The immunosuppressive mechanism of azathioprine. I. In vitro effect on lymphocyte function in the baboon. Transplantation, 21: 27-35.

14. Helmreich, E., Kern, M., Eisen, H.N. 1961. The secretion of antibody by isolated lymph node cells. J Biol Chem, 236: 464-73.

15. Hibi, T., Dosch, H.M. 1986. Limiting dilution analysis of the B cell compartment in human bone marrow. Eur J Immunol, 16: 139-45.

16. Amanna, I.J., Carlson, N.E., Slifka, M.K. 2007. Duration of humoral immunity to common viral and vaccine antigens. N EnglJ Med, 357: 1903-15.

17. Manz, R.A., Hauser, A.E., Hiepe, F., Radbruch, A. 2005. Maintenance of serum antibody levels. Annu Rev Immunol, 23: 367-86.

18. Hiepe, F., Dorner, T., Hauser, A.E., Hoyer, B.F., Mei, H., Radbruch, A. 2011. Long-lived autoreactive plasma cells drive persistent autoimmune inflammation. Nat Rev Rheumatol, 7: 170-8.

19. Fierabracci, A. 2012. Proteasome inhibitors: a new perspective for treating autoimmune diseases. Curr Drug Targets, 13: 1665-75. 
20. Gomez, A.M., Willcox, N., Molenaar, P.C., Buurman, W., Martinez-Martinez, P., De Baets, M.H., Losen, M. 2012. Targeting plasma cells with proteasome inhibitors: possible roles in treating myasthenia gravis? Ann N Y Acad Sci, 1274: 48-59.

21. Woodle, E.S., Alloway, R.R., Girnita, A. 2011. Proteasome inhibitor treatment of antibodymediated allograft rejection. Curr Opin Organ Transplant, 16: 434-8.

22. Shortt, J., Oh, D.H., Opat, S.S. 2013. ADAMTS13 antibody depletion by bortezomib in thrombotic thrombocytopenic purpura. N Engl J Med, 368: 90-2.

23. Gomez, A.M., Vrolix, K., Martinez-Martinez, P., Molenaar, P.C., Phernambucq, M., van der Esch, E., Duimel, H., Verheyen, F., Voll, R.E., Manz, R.A. et al. 2011. Proteasome inhibition with bortezomib depletes plasma cells and autoantibodies in experimental autoimmune myasthenia gravis. J Immunol, 186: 2503-13.

24. Neubert, K., Meister, S., Moser, K., Weisel, F., Maseda, D., Amann, K., Wiethe, C., Winkler, T.H., Kalden, J.R., Manz, R.A. et al. 2008. The proteasome inhibitor bortezomib depletes plasma cells and protects mice with lupus-like disease from nephritis. Nat Med, 14: 74855.

25. Bontscho, J., Schreiber, A., Manz, R.A., Schneider, W., Luft, F.C., Kettritz, R. 2011. Myeloperoxidase-specific plasma cell depletion by bortezomib protects from antineutrophil cytoplasmic autoantibodies-induced glomerulonephritis. J Am Soc Nephrol, 22: 336-48.

26. Obeng, E.A., Carlson, L.M., Gutman, D.M., Harrington, W.J., Jr., Lee, K.P., Boise, L.H. 2006. Proteasome inhibitors induce a terminal unfolded protein response in multiple myeloma cells. Blood, 107: 4907-16.

27. Meister, S., Schubert, U., Neubert, K., Herrmann, K., Burger, R., Gramatzki, M., Hahn, S., Schreiber, S., Wilhelm, S., Herrmann, M. et al. 2007. Extensive immunoglobulin production sensitizes myeloma cells for proteasome inhibition. Cancer Res, 67: 1783-92.

28. Hideshima, T., Richardson, P., Chauhan, D., Palombella, V.J., Elliott, P.J., Adams, J., Anderson, K.C. 2001. The proteasome inhibitor PS-341 inhibits growth, induces apoptosis, and overcomes drug resistance in human multiple myeloma cells. Cancer Res, 61: 3071-6.

29. Davies, F., Baz, R. 2010. Lenalidomide mode of action: linking bench and clinical findings. Blood Rev, 24 Suppl 1: S13-9.

30. Shannon, E., Sandoval, F., Greig, N., Stagg, P. 2012. Lenalidomide alone or lenalidomide plus dexamethasone significantly inhibit IgG and IgM in vitro... A possible explanation for their mechanism of action in treating multiple myeloma. Int Immunopharmacol, 12: 441-6.

31. Shiono, H., Roxanis, I., Zhang, W., Sims, G.P., Meager, A., Jacobson, L.W., Liu, J.L., Matthews, I., Wong, Y.L., Bonifati, M. et al. 2003. Scenarios for autoimmunization of $T$ and B cells in myasthenia gravis. Ann N Y Acad Sci, 998: 237-56.

32. Hill, M.E., Shiono, H., Newsom-Davis, J., Willcox, N. 2008. The myasthenia gravis thymus: a rare source of human autoantibody-secreting plasma cells for testing potential therapeutics. J Neuroimmunol, 201-202: 50-6.

33. Bai, M., Doukas, M., Papoudou-Bai, A., Barbouti, A., Stefanaki, K., Galani, V., Kanavaros, P. 2013. Immunohistological analysis of cell cycle and apoptosis regulators in thymus. Ann Anat, 195: 159-65.

34. Le, P.T., Maecker, H.T., Cook, J.E. 1995. In situ detection and characterization of apoptotic thymocytes in human thymus. Expression of bcl-2 in vivo does not prevent apoptosis. $J$ Immunol, 154: 4371-8.

35. Purton, J.F., Boyd, R.L., Cole, T.J., Godfrey, D.I. 2000. Intrathymic T cell development and selection proceeds normally in the absence of glucocorticoid receptor signaling. Immunity, 13: 179-86.

36. Willcox, H.N., Newsom-Davis, J., Calder, L.R. 1983. Greatly increased autoantibody production in myasthenia gravis by thymocyte suspensions prepared with proteolytic 
enzymes. Clin Exp Immunol, 54: 378-86.

37. van der Neut Kolfschoten, M., Schuurman, J., Losen, M., Bleeker, W.K., Martinez-Martinez, P., Vermeulen, E., den Bleker, T.H., Wiegman, L., Vink, T., Aarden, L.A. et al. 2007. Antiinflammatory activity of human IgG4 antibodies by dynamic Fab arm exchange. Science, 317: 1554-7.

38. Tokoyoda, K., Hauser, A.E., Nakayama, T., Radbruch, A. 2010. Organization of immunological memory by bone marrow stroma. Nat Rev Immunol, 10: 193-200.

39. Perry, D.K., Burns, J.M., Pollinger, H.S., Amiot, B.P., Gloor, J.M., Gores, G.J., Stegall, M.D. 2009. Proteasome inhibition causes apoptosis of normal human plasma cells preventing alloantibody production. Am J Transplant, 9: 201-9.

40. Moreau, P., Pylypenko, H., Grosicki, S., Karamanesht, I., Leleu, X., Grishunina, M., Rekhtman, G., Masliak, Z., Robak, T., Shubina, A. et al. 2011. Subcutaneous versus intravenous administration of bortezomib in patients with relapsed multiple myeloma: a randomised, phase 3, non-inferiority study. Lancet Oncol, 12: 431-40.

41. Hacker, G. 2000. The morphology of apoptosis. Cell Tissue Res, 301: 5-17.

42. Chauhan, D., Singh, A.V., Ciccarelli, B., Richardson, P.G., Palladino, M.A., Anderson, K.C. 2010. Combination of novel proteasome inhibitor NPI-0052 and lenalidomide trigger in vitro and in vivo synergistic cytotoxicity in multiple myeloma. Blood, 115: 834-45.

43. Qian, Z., Zhang, L., Cai, Z., Sun, L., Wang, H., Yi, Q., Wang, M. 2011. Lenalidomide synergizes with dexamethasone to induce growth arrest and apoptosis of mantle cell lymphoma cells in vitro and in vivo. Leuk Res, 35: 380-6.

44. Matsuoka, A., Tochigi, A., Kishimoto, M., Nakahara, T., Kondo, T., Tsujioka, T., Tasaka, T., Tohyama, Y., Tohyama, K. 2010. Lenalidomide induces cell death in an MDS-derived cell line with deletion of chromosome $5 q$ by inhibition of cytokinesis. Leukemia, 24: 748-55.

45. Hofmeister, C.C., Yang, X., Pichiorri, F., Chen, P., Rozewski, D.M., Johnson, A.J., Lee, S., Liu, Z., Garr, C.L., Hade, E.M. et al. 2011. Phase I trial of lenalidomide and CCl-779 in patients with relapsed multiple myeloma: evidence for lenalidomide-CCI-779 interaction via Pglycoprotein. J Clin Oncol, 29: 3427-34.

46. De, A., Blotta, H.M., Mamoni, R.L., Louzada, P., Bertolo, M.B., Foss, N.T., Moreira, A.C., Castro, M. 2002. Effects of dexamethasone on lymphocyte proliferation and cytokine production in rheumatoid arthritis. J Rheumatol, 29: 46-51.

47. Hearing, S.D., Norman, M., Smyth, C., Foy, C., Dayan, C.M. 1999. Wide variation in lymphocyte steroid sensitivity among healthy human volunteers. J Clin Endocrinol Metab, 84: 4149-54.

48. Cassese, G., Arce, S., Hauser, A.E., Lehnert, K., Moewes, B., Mostarac, M., Muehlinghaus, G., Szyska, M., Radbruch, A., Manz, R.A. 2003. Plasma cell survival is mediated by synergistic effects of cytokines and adhesion-dependent signals. J Immunol, 171: 1684-90.

49. van Laar, J.M., Melchers, M., Teng, Y.K., van der Zouwen, B., Mohammadi, R., Fischer, R., Margolis, L., Fitzgerald, W., Grivel, J.C., Breedveld, F.C. et al. 2007. Sustained secretion of immunoglobulin by long-lived human tonsil plasma cells. Am J Pathol, 171: 917-27.

50. Mesin, L., Di Niro, R., Thompson, K.M., Lundin, K.E., Sollid, L.M. 2011. Long-lived plasma cells from human small intestine biopsies secrete immunoglobulins for many weeks in vitro. J Immunol, 187: 2867-74.

51. Miller, J.J., 3rd, Cole, L.J. 1967. Resistance of long-lived lymphocytes and plasma cells in rat lymph nodes to treatment with prednisone, cyclophosphamide, 6-mercaptopurine, and actinomycin D. J Exp Med, 126: 109-25.

52. Willcox, N., Schluep, M., Sommer, N., Campana, D., Janossy, G., Brown, A.N., NewsomDavis, J. 1989. Variable corticosteroid sensitivity of thymic cortex and medullary peripheral-type lymphoid tissue in myasthenia gravis patients: structural and functional effects. Q J Med, 73: 1071-87. 
53. Dimopoulos, M.A., Richardson, P.G., Brandenburg, N., Yu, Z., Weber, D.M., Niesvizky, R., Morgan, G.J. 2012. A review of second primary malignancy in patients with relapsed or refractory multiple myeloma treated with lenalidomide. Blood, 119: 2764-7.

54. Gandhi, A.K., Kang, J., Capone, L., Parton, A., Wu, L., Zhang, L.H., Mendy, D., Lopez-Girona, A., Tran, T., Sapinoso, L. et al. 2010. Dexamethasone synergizes with lenalidomide to inhibit multiple myeloma tumor growth, but reduces lenalidomide-induced immunomodulation of T and NK cell function. Curr Cancer Drug Targets, 10: 155-67.

55. Verhelle, D., Corral, L.G., Wong, K., Mueller, J.H., Moutouh-de Parseval, L., JensenPergakes, K., Schafer, P.H., Chen, R., Glezer, E., Ferguson, G.D. et al. 2007. Lenalidomide and CC-4047 inhibit the proliferation of malignant B cells while expanding normal CD34+ progenitor cells. Cancer Res, 67: 746-55.

56. Mitsiades, N., Mitsiades, C.S., Poulaki, V., Chauhan, D., Richardson, P.G., Hideshima, T., Munshi, N.C., Treon, S.P., Anderson, K.C. 2002. Apoptotic signaling induced by immunomodulatory thalidomide analogs in human multiple myeloma cells: therapeutic implications. Blood, 99: 4525-30.

57. Noonan, K., Rudraraju, L., Ferguson, A., Emerling, A., Pasetti, M.F., Huff, C.A., Borrello, I. 2012. Lenalidomide-induced immunomodulation in multiple myeloma: impact on vaccines and antitumor responses. Clin Cancer Res, 18: 1426-34.

58. Gorgun, G., Calabrese, E., Soydan, E., Hideshima, T., Perrone, G., Bandi, M., Cirstea, D., Santo, L., Hu, Y., Tai, Y.T. et al. 2010. Immunomodulatory effects of lenalidomide and pomalidomide on interaction of tumor and bone marrow accessory cells in multiple myeloma. Blood, 116: 3227-37.

59. Heidt, S., Roelen, D.L., Vergunst, M., Doxiadis, II, Claas, F.H., Mulder, A. 2009. Bortezomib affects the function of human B cells: possible implications for desensitization protocols. Clin Transpl: 387-92.

60. Kim, J.S., Lee, J.I., Shin, J.Y., Kim, S.Y., Shin, J.S., Lim, J.H., Cho, H.S., Yoon, I.H., Kim, K.H., Kim, S.J. et al. 2009. Bortezomib can suppress activation of rapamycin-resistant memory $T$ cells without affecting regulatory T-cell viability in non-human primates. Transplantation, 88: 1349-59.

61. Berges, C., Haberstock, H., Fuchs, D., Miltz, M., Sadeghi, M., Opelz, G., Daniel, V., Naujokat, C. 2008. Proteasome inhibition suppresses essential immune functions of human CD4+ T cells. Immunology, 124: 234-46.

62. Heider, U., Rademacher, J., Kaiser, M., Kleeberg, L., von Metzler, I., Sezer, O. 2010. Decrease in CD4+ T-cell counts in patients with multiple myeloma treated with bortezomib. Clin Lymphoma Myeloma Leuk, 10: 134-7.

63. Blanco, B., Perez-Simon, J.A., Sanchez-Abarca, L.I., Caballero-Velazquez, T., GutierrezCossio, S., Hernandez-Campo, P., Diez-Campelo, M., Herrero-Sanchez, C., RodriguezSerrano, C., Santamaria, C. et al. 2009. Treatment with bortezomib of human CD4+ T cells preserves natural regulatory $\mathrm{T}$ cells and allows the emergence of a distinct suppressor $\mathrm{T}$ cell population. Haematologica, 94: 975-83.

64. Horton, T.M., Gannavarapu, A., Blaney, S.M., D'Argenio, D.Z., Plon, S.E., Berg, S.L. 2006. Bortezomib interactions with chemotherapy agents in acute leukemia in vitro. Cancer Chemother Pharmacol, 58: 13-23.

65. Everly, M.J. 2009. A summary of bortezomib use in transplantation across 29 centers. Clin Transpl: 323-37.

66. Bringhen, S., Larocca, A., Rossi, D., Cavalli, M., Genuardi, M., Ria, R., Gentili, S., Patriarca, F., Nozzoli, C., Levi, A. et al. 2010. Efficacy and safety of once-weekly bortezomib in multiple myeloma patients. Blood, 116: 4745-53.

67. Diwan, T.S., Raghavaiah, S., Burns, J.M., Kremers, W.K., Gloor, J.M., Stegall, M.D. 2011. The impact of proteasome inhibition on alloantibody-producing plasma cells in vivo. 
Transplantation, 91: 536-41.

68. Kirk, C.J. 2012. Discovery and development of second-generation proteasome inhibitors. Semin Hematol, 49: 207-14. 


\section{General Discussion}

Alejandro M. Gomez 


\section{Plasma cells and autoantibody titers in myasthenia gravis}

Although it is widely accepted that MG is mediated by autoantibodies directed against postsynaptic proteins of the NMJ (the AChR, in most cases), the correlation between autoantibody titers and severity of symptoms has remained controversial to demonstrate in large cohorts of patients [1-4]. Nonetheless, it is generally acknowledged that the fluctuations in anti-AChR titers do correlate with the severity of symptoms for a given individual patient, implying that they could represent a valuable tool for evaluating responses to treatment, in addition to the MGFA score [5]. One possible explanation for these discrepancies relies on the differential specificities or affinities of anti-AChR antibodies among MG patients. In this regard, it has been shown that most MG patients produce autoantibodies directed against the main immunogenic region of the AChR (antiMIR antibodies), though such anti-MIR antibody titers do not correlate well with disease severity [4]. However, it has been recently reported in a large cohort of MG patients that anti-MIR antibody titers do have a positive correlation with clinical factors typical of generalized and severe MG, and a negative correlation with those of ocular MG, rendering them useful for differential diagnosis between ocular and generalized MG [6]. Thus, even though several elements are involved in the severity of symptoms in MG (e.g. complement, response of the muscle to the autoimmune attack, cytokine levels), autoantibody titers seem to be one of the most directly related to disease severity and, consequently, their reduction remains an essential therapeutic goal in MG. Accordingly, it has been demonstrated by several studies that reductions of about $50-75 \%$ in autoantibody titers correlate well with clinical improvement for a given patient $[1,7,8]$.

There are several immunosuppressive therapies currently available that will eventually reduce autoantibody titers in most of MG patients. However, they usually require a prolonged induction period (e.g. azathioprine and, to a lesser extent, corticosteroids), which increases morbidity and the chances for undesired side-effects. A rapid reduction of autoantibody titers becomes particularly important during a myasthenic crisis and, until now, there are no better alternatives to achieve this rapid reduction than plasma exchange or IVIg; which offer only temporary relief. Moreover, 
some MG patients are refractory to most of the standard treatments available (even to new ones such as the anti-CD20 monoclonal antibody rituximab), and are thus in need of novel treatment alternatives. As discussed in Chapter 4, targeting plasma cells (particularly the long-lived plasma cells, which can resist most of the immunosuppressive drugs [9-11] and even irradiation [10]), could offer a novel and valuable approach for both rapidly reducing autoantibody titers and for treating refractory MG patients.

Following this idea, I demonstrated in Chapter 5 that the proteasome inhibitor bortezomib significantly depletes bone marrow plasma cells in the EAMG model [12], leading to a rapid and significant reduction of autoantibody titers. Since the bone marrow is considered to be the main site for homing of long-lived plasma cells [13-15], depletion of bone marrow plasma cells by bortezomib is likely to reflect effects on the long-lived subpopulation. In that study, EAMG-rats were treated with bortezomib twice a week for 8 weeks in two treatment schemes: one starting directly after immunization with Torpedo acetylcholine receptor (tAChR) $(8 \mathrm{w}-\mathrm{Bz})$; and the other 4 weeks after immunization ( $4 \mathrm{w}$ $\mathrm{Bz}$ ), once autoantibodies against the AChR were already present in serum. After 8 weeks of treatment, a significant reduction in both plasma cells numbers and autoantibody titers was observed in bortezomib-treated rats in comparison with saline-treated animals and, importantly, no differences were observed between the $8 w-B z$ and $4 w-B z$ treatment schemes. Therefore, proteasome inhibition could both prevent the development of EAMG and also significantly reduce autoantibody titers once the immune response has already started. This rapid reduction of antibody titers correlated well with the significant depletion of plasma cells observed after treatment with bortezomib in both $4 \mathrm{w}$ - and $8 \mathrm{w}$ Bz groups, indicating that indeed killing the plasma cells can rapidly reduce antibody titers (i.e. in less than 4 weeks). Lower autoantibody titers led to improved clinical status for most of $8 w-B z$ animals. The clinical scoring of $4 w-B z$ animals, however, was not significantly improved despite their significant autoantibody reduction, which was comparable to that of $8 \mathrm{w}-\mathrm{Bz}$ animals. This is most likely explained by transient acute side effects of bortezomib administration (weight loss and possible direct effects on neuromuscular transmission) that occurred earlier in $8 \mathrm{w}-\mathrm{Bz}$ animals and, consequently, affected less their clinical symptoms at the endpoint than in $4 \mathrm{w}-\mathrm{Bz}$ animals. Also, the NMJ 
in $4 \mathrm{w}-\mathrm{Btz}$ animals was probably severely affected by the time of bortezomib administration and, considering that it requires several weeks for the NMJ to fully recover after an autoimmune attack [16], the mild clinical recovery after 4 weeks of treatment was possibly due to a yet incomplete repair of NMJs. Had I treated these animals for a longer period, I might have found greater improvements in their clinical condition.

The toxic effects of proteasome inhibition on plasma cells were confirmed and further characterized in thymic cell cultures from EAMG patients that underwent thymectomy (Chapter 6). I demonstrated that bortezomib, but not corticosteroids or lenalidomide, can virtually eliminate human autoimmune plasma cells cultured in vitro in less than $24 \mathrm{~h}$. This results in a complete blockade of autoantibody and total IgG production in these cultures, even at lower concentrations than those normally used in in vitro studies or the peak values found in patient's sera. Moreover, ultrastructural alterations suggestive of apoptosis were found in plasma cells by electron microscopy as early as $8 \mathrm{~h}$ after administration of bortezomib, corroborating qualitative observations in our in vivo study (Chapter 5). Even though these findings are in vitro and, most likely, the in vivo kinetics and efficacy of bortezomib-induced plasma cell death might be different, as already suggested in Chapter 5, they certainly support the notion that killing plasma cells leads to a rapid and effective reduction in autoantibody production.

Moreover, bortezomib had toxic effects on lymphocytes in both the EAMG model and in cultured EOMG thymic cells (Chapters 5 and 6, respectively). I found a reduction in circulating B-cells in bortezomib-treated rats (both $4 \mathrm{w}-\mathrm{Bz}$ and $8 \mathrm{w}-\mathrm{Bz}$ ) and a significant depletion of both T- and B-cells in thymic cell cultures $48 \mathrm{~h}$ after administration of bortezomib. In this regard, previous studies had shown that bortezomib affects the dynamics of different lymphocyte populations: it induces apoptosis in activated CD4+ Tcells, but preserves inactive and regulatory T-cells [17-19]; it promotes the generation of new T-suppressor cells [19]; it also prevents the activation of memory T-cells [20]; and it induces apoptosis in activated B-cells [21]. At present, it is quite accepted that mature, and even memory, B-cells are not crucial for the maintenance of antibody levels once long-lived plasma cell have been generated [15, 22]. However, additional effects of bortezomib on activated (and memory) B- and T-cells could be an advantage in treating 
MG patients, since this can help to prevent the generation of new auto-reactive plasma cells while also eliminating the existing long-lived subset.

Generally speaking, our results neatly complement observations from trials of rituximab in MG patient sub-groups [23] and in SLE [24], where autoantibody titers remained constant for at least one year after complete depletion of circulating B-cells, probably because of ongoing production by long-lived plasma cells. In this regard, the reduction in bone marrow plasma cells in bortezomib-treated animals ( $\sim 60 \%)$ correlated well with the reduction in autoantibody titers ( 72\%) and total IgG $(\sim 50 \%)$ in the animals' serum (Chapter 5), which further supports the hypothesis of the (largely) long-lived bone marrow plasma cells as major contributors to (auto-) antibody levels in AChR-MG. By contrast, contributions from B-cells and short-lived plasma cells are apparently greater in the minority of MG patients with anti-MuSK antibodies, where rituximab treatment led to both long-lasting clinical improvements and sharp reductions in antibody titers [23]. Evidently, the underlying responses differ greatly in these two distinct autoimmune disorders, although both finally lead to myasthenia. Indeed, the thymus is scarcely involved in MuSK-MG [25], where pathogenic autoantibodies are mainly IgG4, in contrast with the IgG1 and IgG3 in EOMG. The predominantly-lgG4 autoantibody response in MuSK-MG is apparently sustained mostly by short-lived plasma cells that are continuously regenerated from autoreactive $\mathrm{CD}_{2} \mathrm{O}^{+}$B-cells [23], whereas long-lived plasma cells may play a more dominant role in AChR-MG.

\section{Models to explain humoral immunological memory}

Humoral immunological memory is fundamental for the survival of higher vertebrates and it has probably evolved as a tool to avoid re-infection with previously encountered pathogens and to cope with the host's microbiota [26, 27]. The concept of immunological memory has been implicitly known for centuries: already in the $10^{\text {th }}$ century Chinese practitioners inoculated dried scabs from smallpox pustules in the nostrils of naïve recipients to prevent infection (variolation). However, its mechanisms and regulation have remained largely unknown. Only recently the scientific community started to genuinely study the biology of immunological memory, the types of cells involved, the dynamics of 
vaccination protocols, etc. For instance, such a basic concept as the duration of antibody responses upon infection or vaccination was not seriously addressed until the 2000's. In a longitudinal analysis of antibody titers to vaccination antigens in the general population, Amanna et al. estimated the half-life of antibody responses to range from 11 years (for tetanus toxoid) up to centuries (for measles and mumps) [28]; implying that the humoral immune system is able to provide protection against re-infections, at least for certain antigens, for a lifetime.

Traditionally, humoral immunological memory was thought to rely on the generation and re-activation of memory B-cells upon re-encounter with an antigen. These models, however, started to be challenged in the 1990's since they could not fully explain the duration and kinetics of antibody responses. Memory B-cell-based models explain prolonged antibody production in terms of persistent antigens (chronic viral infections), repeated exposure to antigen (re-infection or booster vaccination), cross-reactivity and polyclonal activations [29], among others. However, for most of these assumptions, there are solid arguments that point against memory B-cell-only sustained antibody responses. First, a clear correlation between frequency of memory B-cells and antibody titers have been difficult to demonstrate for several antigens $[28,30]$. Second, reactivation of latent chronic viruses such as the varicella zoster (shingles) increases antibody titers for the virus, but they will subsequently decrease back to basal pre-reactivation levels in the following years, which is also the case for antibody titers after booster vaccination $[28,31]$. This suggests that there is a physiological threshold for the production of antibodies to a certain antigen that helps to keep "basal" antibody levels relatively constant in time [29]. Third, complete elimination of circulating B-cells with an anti-CD20 mAb scarcely affects total IgG levels or antibody levels against vaccination or previously encountered antigens $[11,32]$. Fourth, the half-life of antigens in antigen-presenting cells is about 2 months [33] and, consequently, antigen-driven constant B-cell re-activation cannot explain sustained antibody production for several years. And finally, booster vaccination has little to no effect on antibody titers to other antigens, indicating that random polyclonal activations of memory B-cells are not likely to replenish the pool of plasma cells and, thereby, maintain antibody titers for longer periods of time $[28,29]$. It seemed thus, that a piece of 
the puzzle was missing in these models in order to comprehensively understand humoral immunological memory: the long-lived plasma cells.

Long-lived plasma cells are nowadays considered as a fundamental and largely memory B-cell independent compartment of immunological memory, with its own homeostasis and regulatory mechanisms [11, 22, 34, 35]. One of the most widely accepted models of long-lived plasma cell survival proposes that, in order to be long-lived, plasma cells must occupy special survival niches in immune organs such as the bone marrow or the spleen $[36,37]$. Since the number of such niches is limited, newly-generated plasma cells have to displace older plasma cells from their niches in order to survive. Thus, such model predicts that, for every new immune response against a certain antigen that produces a wave of plasma cells, there will be decays in the antibody levels to previous antigens as a consequence of displaced long-lived plasma cells. This, however, does not seem to be the case based on a study that followed antibody responses for decades and showed very constant antibody levels against various antigens; even at old ages, when the number of survival niches available is believed to be significantly reduced [28]. More recently, a new complimentary model was proposed in which plasma cells would be imprinted with the capacity for long-term survival ("competence to compete"), though they still must reach a survival niche in order to survive ("competition for survival") [38, 39]. Such imprinted capacity is believed to be acquired at the moment of B-cell activation, prompted by interactions with T-helper cells at the germinal center. Under this new concept, immunological memory to a certain antigen due to long-lived plasma cells would be the result of both how efficient is the immune response to elicit a substantial number of long-lived imprinted plasma cells, and how successful are they in homing to survival niches; either by displacing previously-generated plasma cells or by occupying (or perhaps even inducing) new survival niches. The advantage of this model is that only immune responses that occur with substantial T-helper cell intervention in the finely-regulated environment of the germinal center can provide long-lived plasma cells [29]. This process would allow for a "fine-tuning" in the selection of valuable antibody responses, ensuring that not every plasma cell that is generated can occupy survival niches and, thus, maintain an antibody response against antigens that are not likely to be relevant in the future. 


\section{Long-lived plasma cells in myasthenia gravis}

Given their fundamental role in the maintenance of long-term antibody responses, and their well-known resistance to most of the immunomodulatory treatments currently available, long-lived plasma cells have become a promising therapeutic target in autoimmune diseases [40-42]. It is certainly possible that autoimmune responses generate long-lived plasma cells that, once in their survival niches at the bone marrow, can perpetuate the production of autoantibodies. This was clearly demonstrated, for instance, in a mice model of systemic lupus erythematosus in which autoantibody production was shown to be driven by both short- and long-lived anti-DNA splenic plasma cells [43]. Also in inflammatory autoimmune diseases, inflamed tissues can provide new survival niches that can accommodate (long-lived) auto-reactive plasma cells generated in situ [44], as it was suggested for the synovial tissue of rheumatoid arthritis patients [45] and demonstrated for the kidney of NZW/B lupus mice [46].

Since plasma cells - especially the long-lived subset - are thought to be highly dependent on special niches in the bone marrow and lymphoid tissues, it is remarkable that they survived and secreted so well even in our suspension cultures of cryostored cells (Chapter 6). Their frequent appearance in clusters (Chapter 6, Fig. 2A) may imply some reconstitution of these niches, but it was unlikely to have been optimal, especially with irradiated cells. Previous studies have shown that primary cultures of plasma cells from human lymphoid organs, such as tonsils and the small intestine gut-associated lymphoid tissue (GALT), can sustain antibody production in vitro for up to 2 or 4 weeks, respectively $[47,48]$; a feature that was enhanced by the presence of feeder cells and, even more, by maintaining the intact tissue in culture. In our samples, plasma cells could still survive and spontaneously produce antibodies for at least two weeks (and up to 4 weeks, data not shown) despite disruption of the normal tissue architecture, which implies that the supportive cells required for plasma cell survival were still active after enzymatic disruption, and even after irradiation.

Several cellular and molecular components of the survival niches have been proven to contribute to plasma cell survival (e.g. stromal cells, eosinophils, monocytes, 
macrophages, IL-5, IL-6, TNF- $\alpha$, SDF-1 $\alpha$, hyaluronic acid, APRIL, CXCL12, BAFF) [34, 37, 49, 50], while most of them primarily act by synergistic effects and no single mediator seems to be per se essential for plasma cell survival (their function is many times redundant). Furthermore, plasma cells have been shown to induce other cell types in their vicinity to secrete pro-survival cytokines (e.g. stromal cells to produce IL-6 [51]), in what could be a feedback system for the generation and maintenance of survival niches [52] . Thus, the sustained presence of long-lived plasma cells in our cultures might be explained by this apparently flexible nature of the survival niches, since the potential loss of redundant prosurvival signaling (i.e. loss of supportive cell types or cytokines due to tissue disruption or irradiation) can be probably compensated by other cell types remaining in EOMG thymus cultures.

As mentioned, the generation of long-lived imprinted plasma cells is highly dependent on interactions between the antigen, the B-cell receptor and T-cells in the context of the germinal center [52]. Depending on the nature of the antigen and, therefore, the degree of T-helper co-stimulation, short- or long-lived antibody responses will be generated. On the one hand, if the antigen has no repetitive epitopes to cross-link the B-cell receptor and induces none or poor T-cell activation, then the immune response is likely to remain short-lived ( $<3$ years). On the other hand, if the antigen has repetitive epitopes that can cross-react the B-cell receptor, and also activates $\mathrm{T}$ - helper cells, then the immune response has the potential of producing a substantial number of long-lived plasma cells [29]. In antibody-mediated autoimmune diseases such as MG this might well be the case, at least for some patients. For instance, the sustained autoantibody titers in refractory AChR-MG patients depleted from B-cell with long-term Rtx treatment is likely to be produced mainly by long-lived plasma cells [23], as previously discussed. Also, the enrichment of anti-AChR T-cells and B-cells in the PBMCs of MG patients $[53,54]$ clearly indicates that auto-reactive germinal center can be formed, leading to affinity maturation of autoantibodies and generation of potentially long-lived plasma cells.

Accordingly, one of the hallmarks of MG-thymus is the presence of active germinal centers $[55,56]$, which are normally absent in control thymi, and that contain all the ingredients to generate long-lived autoimmune plasma cells: anti-AChR T- and B-cells, 
and the locally-expressed AChR in myoid and thymic epithelial cells $[57,58]$. Indeed, antiAChR germinal centers and plasma cells are frequently found in the thymus of EOMG patients and, once in culture, the latter can substantially secrete pathological autoantibodies for several weeks [59] (Chapter 6), suggesting that they are long-lived. Consequently, the loss of these thymic autoimmune long-lived plasma cells and/or thymic auto-reactive germinal centers after thymectomy could be an explanation for the reduction of anti-AChR titers, improvement of clinical condition, or even remission of some thymectomized MG-patients [60-65].

\section{The muscle's response to an autoimmune attack: implications for disease severity}

As explained in Chapter 1 , the pathophysiology of AChR-MG is well characterized and the pathogenic role of anti-AChRs has been clearly demonstrated. Still, an important feature of MG patients is their substantial heterogeneity of symptoms and variability in clinical severity [66]. Although these characteristics have been widely acknowledged in several studies and are well categorized $[67,68]$, up to date, their underlying causes remain poorly understood. As previously discussed, differences in anti-AChR antibodies specificity, affinity, or titers could offer an explanation to the variability in severity among MG patients but these correlations have, for the most part, remained controversial and, therefore, inconclusive $[1-3,5,6]$. Alternatively, differences in the response of the muscle, in particular of the NMJ, to the autoimmune attack might account for the variability in disease severity in MG. Such intrinsic differences in the muscle's response, in combination with the variability of the autoimmune response, could provide a more comprehensive explanation to the differential development of symptoms in MG; for instance, they most certainly account for the involvement of certain muscles (e.g. ocular muscles) in preference to others [69]. Moreover, it was reported that about half of MG patients in clinical remission (absence of symptoms without therapy) have still electrophysiological abnormalities and sustained presence of anti-AChR antibodies [70]; suggesting that, so far, unknown factors in these patients (e.g. intrinsic properties of the muscle, variability in the complement system, or in regulators of complement activation such as DAF) might 
account for this lack of symptoms despite the presence of pathological abnormalities. In addition, understanding the response of the muscle in MG could offer new insights into potential therapeutic options to increase the tolerance of the NMJ to an autoimmune attack.

To study the proteins involved in the response of the muscle to an autoimmune attack, I analyzed the proteome of rat tibialis anterior muscles that have been chronically challenged by anti-AChR antibodies in the EAMG model (Chapter 2). In this study, I observed that most of the differentially-expressed muscle proteins were cytoplasmic and related to metabolic pathways, cellular-stress responses or contractile proteins. Generally speaking, there was a reduction in the glycolytic capacity of the muscle and a shift towards expression of slow-twitch fiber isoforms of contractile proteins. Together, these findings indicated that the muscle in EAMG animals is either preferentially losing fast-twitch fibers or is actively switching to slow-type fibers, or a combination of both. In this regard, it has been described that muscle biopsies from MG patients have also preferential atrophy of fast-twitch fibers [71-73].

Since fast-twitch fibers rely primarily on anaerobic ATP generation through glycolysis, in contrast to aerobic mitochondrial ATP generation in slow-twitch fibers, they are more prone to fatigue than their slow-type counterparts [74]. Additionally, intrinsic contractile properties of fast-twitch fibers (e.g. differential expression of heavy chain myosin isoforms) also renders them susceptible to fatigue [75]. Taking into consideration that functional denervation of muscle fibers typically results in preferential atrophy of fast-twitch fibers [76] one possibility is that, in both MG and EAMG, the impairment in neuromuscular transmission is less tolerated by fast-twitch fibers and, consequently, these fibers are preferentially lost. This phenomenon could be attributed to an increased sensitivity to inactivity or higher neurotrophic dependence of fast-twitch fibers [77, 78], though this has not been clearly demonstrated yet [79]. Alternatively, since muscles with a majority of slow-twitch fibers are more resistant to fatigue [80], the preferential loss of fast-twitch fibers might be a response of the tissue to counteract the muscle fatigability that results from poor neuromuscular transmission. In MuSK-MG patients, for instance, it has been reported that fast-twitch muscles are preferentially affected [81], suggesting 
that they are more prone to experience weakness and fatigability in the event of poor neuromuscular transmission than slow-twitch muscles. Also, the peculiar fiber composition, mechanical properties, and myosin heavy chain expression of extraocular muscles are, arguably, the main reasons behind their preferential affection in MG [69]; which further implies intrinsic muscle properties as fundamental factors for the development of symptoms.

Unexpectedly, I could not detect any NMJ-protein differentially expressed in EAMG muscles by a 2D-DIGE proteomics approach (Chapter 2). On the one hand, given the well-known loss of $A C h R$ and AChR-related proteins in EAMG, this was rather counterintuitive. On the other hand, technical limitations of 2D-DIGE proteomics for detecting membrane-bound proteins (i.e. poor solubility of these proteins in buffers used for isoelectric focusing) [82], and the fact that NMJ proteins represent a very small fraction of the muscle's proteome, can possibly explain their absence in our analysis. In this regard, NMJ proteins were also not satisfactorily detected in more comprehensive studies that characterized the whole muscle's proteome with more sensitive technological approaches [83]. Possibly, in the near future, novel techniques such as shotgun proteomics, subcellular fractionation, free-flow electrophoresis, and others, might overcome the limitations for detecting membrane-bound proteins in proteomics studies [84] and, consequently, provide better tools for investigating the response of the NMJ to an autoimmune attack.

Upon binding of anti-AChR antibodies at the NMJ, complement is locally activated and loss of AChRs and AChR-associated proteins occurs (reviewed in Chapter 1). In EAMG models, a reduction in extracellular AChR-associated proteins such as utrophin [85] and MuSK (unpublished observations), in addition to intracellular proteins such as rapsyn [86], have been reported. These proteins are all implicated in the clustering and maintenance of AChRs at the adult NMJ, and their loss could contribute to delay the repair processes of the endplate after an autoimmune attack (reviewed in Chapter 1). In this regard, I studied the effects of down-regulating the expression of Dok-7, the most recently described member of the AChR clustering pathway, in the recovery from and susceptibility to the EAMG model (Chapter 3).

Dok-7 is an intracellular adaptor protein that is required for full activation of 
MuSK, the central kinase in the organization of the muscle's postsynaptic apparatus, and its presence is fundamental for the fetal development of neuromuscular synapses. Contrary to my expectations, silencing of Dok-7 expression did not significantly delay the recovery from the damage caused by $20 \mathrm{pmol}$ mAb35/100 g body weight (anti-AChR antibody), probably because I underestimated the time needed for a full functional recovery of the NMJ (Chapter 3). However, Dok-7 silencing did increase the susceptibility to EAMG, when it was induced with a subclinical dose of mAb35 (5 pmol/100g body weight), suggesting that an impaired clustering machinery renders the NMJ more prone to AChR loss in the case of an autoantibody attack. These findings are in accordance with the clinical characteristics of patients with CMS due to Dok-7 mutations, since they have generalized muscle weakness and smaller, more disorganized, endplate regions [87-89]; a feature that I also observed in C2C12 myotubes silenced for Dok-7 expression (Chapter 3). In addition to a lack of MuSK activation, a reduction in Dok-7 levels might also influence downstream signaling cascades independently from MuSK signaling, since it was recently demonstrated that Dok-7 can bind Crk and Crk-L in its C-terminal upon phosphorylation [90]. These adaptor proteins are able to link the postsynaptic apparatus with the actin remodeling system and AChR clustering, thereby acting as integrating factors for multiple pathways [90].

A deeper understanding of the functioning of the AChR clustering machinery and the muscle's response to the autoantibody attack could prove useful for symptomatic treatment of MG patients. Overexpression of the anchoring protein rapsyn, for instance, has been shown to increase the resistance of the NMJ to the damage inflicted by autoantibodies in the passive-transfer EAMG model [91] and might even reverse the loss of AChRs in ongoing chronic EAMG [85]. Also, administration of a fast-skeletal-troponin activator (CK-2017357) was shown to increase muscle force in response to sub-optimal nerve signaling and, thereby, improve muscle strength in the passive-transfer EAMG model [92]. These studies are clear examples on how manipulations of muscle proteins can increase the tissue's tolerance to the autoimmune attack in MG and, consequently, they provide novel options for symptomatic treatment other than the traditionally used acetylcholinesterase inhibitors. Additionally, regulating the expression of NMJ proteins 
with gene therapy, or modulating their activity with synthetic agents, might eventually be used to treat not only MG, but also CMS. Although rather experimental treatments such as gene therapy are still far from being a common practice in the clinic, much progress has been made during the past decades and several gene-therapy clinical trials have proven successful to treat human diseases [93-95]. Keeping these therapeutic options in mind, a more detailed knowledge about the repair and maintenance of adult NMJs is likely to be fundamental for the development of more targeted treatments for MG and CMS in the future.

\section{Conclusions}

The development of symptoms in MG results from the fine balance between the autoimmune response against the NMJ and the capacity of this synapse to resist an autoimmune attack, or repair itself after it. Traditionally, the treatment of MG has relied heavily on immunomodulatory agents that block the autoimmune response rather unspecifically and on acetylcholinesterase inhibitors (the only symptomatic treatment available). In this thesis, I have investigated new therapeutic strategies for targeting two of the pathophysiological components of MG that are most directly involved in the development of symptoms, and that have not been frequently taken into consideration so far: the plasma cells and the muscle.

Plasma cells are relevant in MG primarily because they are the main antibodyproducing cell of the immune system and they resist most of the currently available treatments. I have shown in both the EAMG model and primary thymic cell cultures from MG patients that depletion of plasma cells rapidly and efficiently reduces autoantibody production, providing a strong proof of principle for its future use in patients. A characterization of the muscle's response to the autoimmune attack was also performed, in an attempt to analyze individual proteins involved in resistance or repair mechanisms at the NMJ. Despite the lack of NMJ-proteins differentially-expressed in the proteomics study of EAMG muscles, I found protein changes suggestive of a switch in muscle fiber composition, in what could represent compensatory mechanisms of the muscle to prevent weakness and fatigability. In addition, I have shown that reduced levels of the adaptor 
protein Dok-7, involved in AChR-clustering, increases the susceptibility to passive transfer EAMG and, consequently, I provide a demonstration that levels of AChR-associated proteins can also influence disease severity in EAMG.

Expanding the treatment options for MG by focusing on traditionally neglected therapeutic targets might eventually prove beneficial for MG patients in the near future, particularly those who are refractory to the currently available therapies. Additionally, given that these treatment strategies are relatively restricted to target only components directly involved in the development of symptoms (autoantibodies and the NMJ), they can also be valuable to prevent undesired side-effects of the more unspecific therapies commonly used. As a consequence, the therapeutic strategies discussed in this thesis are, in a way, a step forward towards developing more specific therapies for MG and, on the whole, they have the potential of becoming valuable tools for the management of MG patients in the future. 


\section{$\underline{\text { References }}$}

1. Besinger, U.A., Toyka, K.V., Homberg, M., Heininger, K., Hohlfeld, R., Fateh-Moghadam, A. 1983. Myasthenia gravis: long-term correlation of binding and bungarotoxin blocking antibodies against acetylcholine receptors with changes in disease severity. Neurology, 33: 1316-21.

2. Howard, F.M., Jr., Lennon, V.A., Finley, J., Matsumoto, J., Elveback, L.R. 1987. Clinical correlations of antibodies that bind, block, or modulate human acetylcholine receptors in myasthenia gravis. Ann N Y Acad Sci, 505: 526-38.

3. Lindstrom, J.M., Seybold, M.E., Lennon, V.A., Whittingham, S., Duane, D.D. 1998. Antibody to acetylcholine receptor in myasthenia gravis: prevalence, clinical correlates, and diagnostic value. 1975. Neurology, 51: 933 and 6 pages following.

4. Tzartos, S.J., Seybold, M.E., Lindstrom, J.M. 1982. Specificities of antibodies to acetylcholine receptors in sera from myasthenia gravis patients measured by monoclonal antibodies. Proc Natl Acad Sci U S A, 79: 188-92.

5. Meriggioli, M.N., Sanders, D.B. 2012. Muscle autoantibodies in myasthenia gravis: beyond diagnosis? Expert Rev Clin Immunol, 8: 427-38.

6. Masuda, T., Motomura, M., Utsugisawa, K., Nagane, Y., Nakata, R., Tokuda, M., Fukuda, T., Yoshimura, T., Tsujihata, M., Kawakami, A. 2012. Antibodies against the main immunogenic region of the acetylcholine receptor correlate with disease severity in myasthenia gravis. J Neurol Neurosurg Psychiatry, 83: 935-40.

7. Newsom-Davis, J., Pinching, A.J., Vincent, A., Wilson, S.G. 1978. Function of circulating antibody to acetylcholine receptor in myasthenia gravis: investigation by plasma exchange. Neurology, 28: 266-72.

8. Seybold, M.E., Lindstrom, J.M. 1981. Patterns of acetylcholine receptor antibody fluctuation in myasthenia gravis. Ann N Y Acad Sci, 377: 292-306.

9. Perry, D.K., Burns, J.M., Pollinger, H.S., Amiot, B.P., Gloor, J.M., Gores, G.J., Stegall, M.D. 2009. Proteasome inhibition causes apoptosis of normal human plasma cells preventing alloantibody production. Am J Transplant, 9: 201-9.

10. Miller, J.J., 3rd, Cole, L.J. 1967. Resistance of long-lived lymphocytes and plasma cells in rat lymph nodes to treatment with prednisone, cyclophosphamide, 6-mercaptopurine, and actinomycin D. J Exp Med, 126: 109-25.

11. DiLillo, D.J., Hamaguchi, Y., Ueda, Y., Yang, K., Uchida, J., Haas, K.M., Kelsoe, G., Tedder, T.F. 2008. Maintenance of long-lived plasma cells and serological memory despite mature and memory B cell depletion during CD20 immunotherapy in mice. J Immunol, 180: 36171.

12. Gomez, A.M., Vrolix, K., Martinez-Martinez, P., Molenaar, P.C., Phernambucq, M., van der Esch, E., Duimel, H., Verheyen, F., Voll, R.E., Manz, R.A. et al. 2011. Proteasome inhibition with bortezomib depletes plasma cells and autoantibodies in experimental autoimmune myasthenia gravis. J Immunol, 186: 2503-13.

13. Slifka, M.K., Matloubian, M., Ahmed, R. 1995. Bone marrow is a major site of long-term antibody production after acute viral infection. J Virol, 69: 1895-902.

14. Manz, R.A., Thiel, A., Radbruch, A. 1997. Lifetime of plasma cells in the bone marrow. Nature, 388: 133-4.

15. Slifka, M.K., Antia, R., Whitmire, J.K., Ahmed, R. 1998. Humoral immunity due to long-lived plasma cells. Immunity, 8: 363-72.

16. Engel, A.G., Sakakibara, H., Sahashi, K., Lindstrom, J.M., Lambert, E.H., Lennon, V.A. 1979. Passively transferred experimental autoimmune myasthenia gravis. Sequential and 
quantitative study of the motor end-plate fine structure and ultrastructural localization of immune complexes (IgG and C3), and of the acetylcholine receptor. Neurology, 29: 179-88.

17. Berges, C., Haberstock, H., Fuchs, D., Miltz, M., Sadeghi, M., Opelz, G., Daniel, V., Naujokat, C. 2008. Proteasome inhibition suppresses essential immune functions of human CD4+ T cells. Immunology, 124: 234-46.

18. Heider, U., Rademacher, J., Kaiser, M., Kleeberg, L., von Metzler, I., Sezer, O. 2010. Decrease in CD4+ T-cell counts in patients with multiple myeloma treated with bortezomib. Clin Lymphoma Myeloma Leuk, 10: 134-7.

19. Blanco, B., Perez-Simon, J.A., Sanchez-Abarca, L.I., Caballero-Velazquez, T., GutierrezCossio, S., Hernandez-Campo, P., Diez-Campelo, M., Herrero-Sanchez, C., RodriguezSerrano, C., Santamaria, C. et al. 2009. Treatment with bortezomib of human CD4+ T cells preserves natural regulatory $\mathrm{T}$ cells and allows the emergence of a distinct suppressor $\mathrm{T}$ cell population. Haematologica, 94: 975-83.

20. Kim, J.S., Lee, J.I., Shin, J.Y., Kim, S.Y., Shin, J.S., Lim, J.H., Cho, H.S., Yoon, I.H., Kim, K.H., $\mathrm{Kim}$, S.J. et al. 2009. Bortezomib can suppress activation of rapamycin-resistant memory $T$ cells without affecting regulatory T-cell viability in non-human primates. Transplantation, 88: 1349-59.

21. Heidt, S., Roelen, D.L., Vergunst, M., Doxiadis, II, Claas, F.H., Mulder, A. 2009. Bortezomib affects the function of human $B$ cells: possible implications for desensitization protocols. Clin Transpl: 387-92.

22. Ahuja, A., Anderson, S.M., Khalil, A., Shlomchik, M.J. 2008. Maintenance of the plasma cell pool is independent of memory B cells. Proc Natl Acad Sci U S A, 105: 4802-7.

23. Diaz-Manera, J., Martinez-Hernandez, E., Querol, L., Klooster, R., Rojas-Garcia, R., SuarezCalvet, X., Munoz-Blanco, J.L., Mazia, C., Straasheijm, K.R., Gallardo, E. et al. 2012. Longlasting treatment effect of rituximab in MuSK myasthenia. Neurology, 78: 189-93.

24. Merrill, J.T., Neuwelt, C.M., Wallace, D.J., Shanahan, J.C., Latinis, K.M., Oates, J.C., Utset, T.O., Gordon, C., Isenberg, D.A., Hsieh, H.J. et al. 2010. Efficacy and safety of rituximab in moderately-to-severely active systemic lupus erythematosus: the randomized, doubleblind, phase II/III systemic lupus erythematosus evaluation of rituximab trial. Arthritis Rheum, 62: 222-33.

25. Leite, M.I., Strobel, P., Jones, M., Micklem, K., Moritz, R., Gold, R., Niks, E.H., Berrih-Aknin, S., Scaravilli, F., Canelhas, A. et al. 2005. Fewer thymic changes in MuSK antibody-positive than in MuSK antibody-negative MG. Ann Neurol, 57: 444-448.

26. Hsu, E. 1998. Mutation, selection, and memory in B lymphocytes of exothermic vertebrates. Immunol Rev, 162: 25-36.

27. McFall-Ngai, M. 2007. Adaptive immunity: care for the community. Nature, 445: 153.

28. Amanna, I.J., Carlson, N.E., Slifka, M.K. 2007. Duration of humoral immunity to common viral and vaccine antigens. N Engl J Med, 357: 1903-15.

29. Amanna, I.J., Slifka, M.K. 2010. Mechanisms that determine plasma cell lifespan and the duration of humoral immunity. Immunol Rev, 236: 125-38.

30. Nanan, R., Heinrich, D., Frosch, M., Kreth, H.W. 2001. Acute and long-term effects of booster immunisation on frequencies of antigen-specific memory B-lymphocytes. Vaccine, 20: 498-504.

31. Hammarlund, E., Lewis, M.W., Hansen, S.G., Strelow, L.I., Nelson, J.A., Sexton, G.J., Hanifin, J.M., Slifka, M.K. 2003. Duration of antiviral immunity after smallpox vaccination. Nat Med, 9: 1131-7.

32. Teng, Y.K., Wheater, G., Hogan, V.E., Stocks, P., Levarht, E.W., Huizinga, T.W., Toes, R.E., van Laar, J.M. 2012. Induction of long-term B-cell depletion in refractory rheumatoid arthritis patients preferentially affects autoreactive more than protective humoral immunity. Arthritis Res Ther, 14: R57. 
33. Tew, J.G., Mandel, T.E. 1979. Prolonged antigen half-life in the lymphoid follicles of specifically immunized mice. Immunology, 37: 69-76.

34. Tangye, S.G. 2011. Staying alive: regulation of plasma cell survival. Trends Immunol, 32: 595-602.

35. Manz, R.A., Lohning, M., Cassese, G., Thiel, A., Radbruch, A. 1998. Survival of long-lived plasma cells is independent of antigen. Int Immunol, 10: 1703-11.

36. Manz, R.A., Arce, S., Cassese, G., Hauser, A.E., Hiepe, F., Radbruch, A. 2002. Humoral immunity and long-lived plasma cells. Curr Opin Immunol, 14: 517-21.

37. Tokoyoda, K., Hauser, A.E., Nakayama, T., Radbruch, A. 2010. Organization of immunological memory by bone marrow stroma. Nat Rev Immunol, 10: 193-200.

38. Radbruch, A., Muehlinghaus, G., Luger, E.O., Inamine, A., Smith, K.G., Dorner, T., Hiepe, F. 2006. Competence and competition: the challenge of becoming a long-lived plasma cell. Nat Rev Immunol, 6: 741-50.

39. Elgueta, R., de Vries, V.C., Noelle, R.J. 2010. The immortality of humoral immunity. Immunol Rev, 236: 139-50.

40. Winter, O., Dame, C., Jundt, F., Hiepe, F. 2012. Pathogenic long-lived plasma cells and their survival niches in autoimmunity, malignancy, and allergy. J Immunol, 189: 5105-11.

41. Tarlinton, D.M., Hodgkin, P.D. 2004. Targeting plasma cells in autoimmune diseases. J Exp Med, 199: 1451-4.

42. Neves, M., Alves, J.D. 2011. Factors implicated in the generation and persistence of longlived plasma cell-mediated autoimmunity. Autoimmun Rev, 10: 375-82.

43. Hoyer, B.F., Moser, K., Hauser, A.E., Peddinghaus, A., Voigt, C., Eilat, D., Radbruch, A., Hiepe, F., Manz, R.A. 2004. Short-lived plasmablasts and long-lived plasma cells contribute to chronic humoral autoimmunity in NZB/W mice. J Exp Med, 199: 1577-84.

44. Hiepe, F., Dorner, T., Hauser, A.E., Hoyer, B.F., Mei, H., Radbruch, A. 2011. Long-lived autoreactive plasma cells drive persistent autoimmune inflammation. Nat Rev Rheumatol, 7: 170-8.

45. Kim, H.J., Krenn, V., Steinhauser, G., Berek, C. 1999. Plasma cell development in synovial germinal centers in patients with rheumatoid and reactive arthritis. J Immunol, 162: 305362.

46. Cassese, G., Lindenau, S., de Boer, B., Arce, S., Hauser, A., Riemekasten, G., Berek, C., Hiepe, F., Krenn, V., Radbruch, A. et al. 2001. Inflamed kidneys of NZB / W mice are a major site for the homeostasis of plasma cells. Eur J Immunol, 31: 2726-32.

47. van Laar, J.M., Melchers, M., Teng, Y.K., van der Zouwen, B., Mohammadi, R., Fischer, R., Margolis, L., Fitzgerald, W., Grivel, J.C., Breedveld, F.C. et al. 2007. Sustained secretion of immunoglobulin by long-lived human tonsil plasma cells. Am J Pathol, 171: 917-27.

48. Mesin, L., Di Niro, R., Thompson, K.M., Lundin, K.E., Sollid, L.M. 2011. Long-lived plasma cells from human small intestine biopsies secrete immunoglobulins for many weeks in vitro. J Immunol, 187: 2867-74.

49. Cassese, G., Arce, S., Hauser, A.E., Lehnert, K., Moewes, B., Mostarac, M., Muehlinghaus, G., Szyska, M., Radbruch, A., Manz, R.A. 2003. Plasma cell survival is mediated by synergistic effects of cytokines and adhesion-dependent signals. J Immunol, 171: 1684-90.

50. Belnoue, E., Tougne, C., Rochat, A.F., Lambert, P.H., Pinschewer, D.D., Siegrist, C.A. 2012. Homing and adhesion patterns determine the cellular composition of the bone marrow plasma cell niche. J Immunol, 188: 1283-91.

51. Minges Wols, H.A., Underhill, G.H., Kansas, G.S., Witte, P.L. 2002. The role of bone marrow-derived stromal cells in the maintenance of plasma cell longevity. J Immunol, 169: 4213-21.

52. Yoshida, T., Mei, H., Dorner, T., Hiepe, F., Radbruch, A., Fillatreau, S., Hoyer, B.F. 2010. Memory B and memory plasma cells. Immunol Rev, 237: 117-39. 
53. Newsom-Davis, J., Harcourt, G., Sommer, N., Beeson, D., Willcox, N., Rothbard, J.B. 1989. T-cell reactivity in myasthenia gravis. J Autoimmun, 2 Suppl: 101-8.

54. Link, H., Olsson, O., Sun, J., Wang, W.Z., Andersson, G., Ekre, H.P., Brenner, T., Abramsky, O., Olsson, T. 1991. Acetylcholine receptor-reactive T and B cells in myasthenia gravis and controls. J Clin Invest, 87: 2191-6.

55. Berrih-Aknin, S., Morel, E., Raimond, F., Safar, D., Gaud, C., Binet, J.P., Levasseur, P., Bach, J.F. 1987. The role of the thymus in myasthenia gravis: immunohistological and immunological studies in 115 cases. Ann N Y Acad Sci, 505: 50-70.

56. Castleman, B., Norris, E.H. 1949. The pathology of the thymus in myasthenia gravis; a study of 35 cases. Medicine (Baltimore), 28: 27-58.

57. Roxanis, I., Micklem, K., McConville, J., Newsom-Davis, J., Willcox, N. 2002. Thymic myoid cells and germinal center formation in myasthenia gravis; possible roles in pathogenesis. $J$ Neuroimmunol, 125: 185-97.

58. Shiono, H., Roxanis, I., Zhang, W., Sims, G.P., Meager, A., Jacobson, L.W., Liu, J.L., Matthews, I., Wong, Y.L., Bonifati, M. et al. 2003. Scenarios for autoimmunization of $T$ and B cells in myasthenia gravis. Ann N Y Acad Sci, 998: 237-56.

59. Hill, M.E., Shiono, H., Newsom-Davis, J., Willcox, N. 2008. The myasthenia gravis thymus: a rare source of human autoantibody-secreting plasma cells for testing potential therapeutics. J Neuroimmunol, 201-202: 50-6.

60. Nieto, I.P., Robledo, J.P., Pajuelo, M.C., Montes, J.A., Giron, J.G., Alonso, J.G., Sancho, L.G. 1999. Prognostic factors for myasthenia gravis treated by thymectomy: review of 61 cases. Ann Thorac Surg, 67: 1568-71.

61. Bartoccioni, E., Scuderi, F., Scoppetta, C., Evoli, A., Tonali, P., Guidi, L., Bartoloni, C., Terranova, T. 1980. Myasthenia gravis, thymectomy, and antiacetycholine receptor antibody. J Neurol, 224: 9-15.

62. Vincent, A., Newsom-Davis, J., Newton, P., Beck, N. 1983. Acetylcholine receptor antibody and clinical response to thymectomy in myasthenia gravis. Neurology, 33: 1276-82.

63. Seybold, M.E., Baergen, R.N., Nave, B., Lindstrom, J.M. 1978. Anti-acetylcholine-receptor antibody concentrations after thymectomy in patients with myasthenia gravis. Br Med J, 2: 1051-3.

64. Tindall, R.S. 1980. Humoral immunity in myasthenia gravis: effect of steroids and thymectomy. Neurology, 30: 554-7.

65. Vincent, A. 1980. Immunology of acetylcholine receptors in relation to myasthenia gravis. Physiol Rev, 60: 756-824.

66. Pal, J., Rozsa, C., Komoly, S., Illes, Z. 2011. Clinical and biological heterogeneity of autoimmune myasthenia gravis. J Neuroimmunol, 231: 43-54.

67. Verschuuren, J.J., Palace, J., Gilhus, N.E. 2010. Clinical aspects of myasthenia explained. Autoimmunity, 43: 344-52.

68. Meriggioli, M.N., Sanders, D.B. 2009. Autoimmune myasthenia gravis: emerging clinical and biological heterogeneity. Lancet Neurol, 8: 475-90.

69. Yu Wai Man, C.Y., Chinnery, P.F., Griffiths, P.G. 2005. Extraocular muscles have fundamentally distinct properties that make them selectively vulnerable to certain disorders. Neuromuscul Disord, 15: 17-23.

70. Mano, K., Takegami, T., Okamoto, S., Takahashi, A. 1993. Remission of myasthenia gravis: clinical, electrophysiological and immunological studies. Nagoya J Med Sci, 55: 103-13.

71. Coers, C., Telerman-Toppet, N. 1976. Morphological and histochemical changes of motor units in myasthenia. Ann N Y Acad Sci, 274: 6-19.

72. Martignago, S., Fanin, M., Albertini, E., Pegoraro, E., Angelini, C. 2009. Muscle histopathology in myasthenia gravis with antibodies against MuSK and AChR. Neuropathol Appl Neurobiol, 35: 103-10. 
73. Zamecnik, J., Vesely, D., Jakubicka, B., Cibula, A., Pitha, J., Schutzner, J., Mazanec, R. 2009. Atrophy of type II fibres in myasthenia gravis muscle in thymectomized patients: steroidinduced change with prognostic impact. J Cell Mol Med, 13: 2008-18.

74. Scott, W., Stevens, J., Binder-Macleod, S.A. 2001. Human skeletal muscle fiber type classifications. Phys Ther, 81: 1810-6.

75. Fitts, R.H. 1994. Cellular mechanisms of muscle fatigue. Physiol Rev, 74: 49-94.

76. Li, Z.B., Lehar, M., Samlan, R., Flint, P.W. 2005. Proteomic analysis of rat laryngeal muscle following denervation. Proteomics, 5: 4764-76.

77. Syrovy, I., Gutmann, E., Melichna, J. 1971. Differential response of myosin--ATPase activity and contraction properties of fast and slow rabbit muscles following denervation. Experientia, 27: 1426-7.

78. Niederle, B., Mayr, R. 1978. Course of denervation atrophy in type I and type II fibres of rat extensor digitorum longus muscle. Anat Embryol (Berl), 153: 9-21.

79. Midrio, M. 2006. The denervated muscle: facts and hypotheses. A historical review. Eur J Appl Physiol, 98: 1-21.

80. Fuchs, A.F., Binder, M.D. 1983. Fatigue resistance of human extraocular muscles. J Neurophysiol, 49: 28-34.

81. Farrugia, M.E., Robson, M.D., Clover, L., Anslow, P., Newsom-Davis, J., Kennett, R., HiltonJones, D., Matthews, P.M., Vincent, A. 2006. MRI and clinical studies of facial and bulbar muscle involvement in MuSK antibody-associated myasthenia gravis. Brain, 129: 1481-92.

82. Santoni, V., Molloy, M., Rabilloud, T. 2000. Membrane proteins and proteomics: un amour impossible? Electrophoresis, 21: 1054-70.

83. Hojlund, K., Yi, Z., Hwang, H., Bowen, B., Lefort, N., Flynn, C.R., Langlais, P., Weintraub, S.T., Mandarino, L.J. 2008. Characterization of the human skeletal muscle proteome by one-dimensional gel electrophoresis and HPLC-ESI-MS/MS. Mol Cell Proteomics, 7: 257-67.

84. Tan, S., Tan, H.T., Chung, M.C. 2008. Membrane proteins and membrane proteomics. Proteomics, 8: 3924-32.

85. Martinez-Martinez, P., Losen, M., Duimel, H., Frederik, P., Spaans, F., Molenaar, P., Vincent, A., De Baets, M.H. 2007. Overexpression of rapsyn in rat muscle increases acetylcholine receptor levels in chronic experimental autoimmune myasthenia gravis. $\mathrm{Am} \mathrm{J}$ Pathol, 170: 644-57.

86. Martinez-Martinez, P., Phernambucq, M., Steinbusch, L., Schaeffer, L., Berrih-Aknin, S., Duimel, H., Frederik, P., Molenaar, P., De Baets, M.H., Losen, M. 2009. Silencing rapsyn in vivo decreases acetylcholine receptors and augments sodium channels and secondary postsynaptic membrane folding. Neurobiol Dis, 35: 14-23.

87. Slater, C.R., Fawcett, P.R., Walls, T.J., Lyons, P.R., Bailey, S.J., Beeson, D., Young, C., Gardner-Medwin, D. 2006. Pre- and post-synaptic abnormalities associated with impaired neuromuscular transmission in a group of patients with 'limb-girdle myasthenia'. Brain, 129: 2061-76.

88. Muller, J.S., Herczegfalvi, A., Vilchez, J.J., Colomer, J., Bachinski, L.L., Mihaylova, V., Santos, M., Schara, U., Deschauer, M., Shevell, M. et al. 2007. Phenotypical spectrum of DOK7 mutations in congenital myasthenic syndromes. Brain, 130: 1497-506.

89. Beeson, D., Higuchi, O., Palace, J., Cossins, J., Spearman, H., Maxwell, S., Newsom-Davis, J., Burke, G., Fawcett, P., Motomura, M. et al. 2006. Dok-7 mutations underlie a neuromuscular junction synaptopathy. Science, 313: 1975-8.

90. Hallock, P.T., Xu, C.F., Park, T.J., Neubert, T.A., Curran, T., Burden, S.J. 2010. Dok-7 regulates neuromuscular synapse formation by recruiting Crk and Crk-L. Genes Dev, 24: 2451-61.

91. Losen, M., Stassen, M.H., Martinez-Martinez, P., Machiels, B.M., Duimel, H., Frederik, P., Veldman, H., Wokke, J.H., Spaans, F., Vincent, A. et al. 2005. Increased expression of 
rapsyn in muscles prevents acetylcholine receptor loss in experimental autoimmune myasthenia gravis. Brain, 128: 2327-37.

92. Russell, A.J., Hartman, J.J., Hinken, A.C., Muci, A.R., Kawas, R., Driscoll, L., Godinez, G., Lee, K.H., Marquez, D., Browne, W.F.t. et al. 2012. Activation of fast skeletal muscle troponin as a potential therapeutic approach for treating neuromuscular diseases. Nat Med, 18: 452-5.

93. Alexander, B.L., Ali, R.R., Alton, E.W., Bainbridge, J.W., Braun, S., Cheng, S.H., Flotte, T.R., Gaspar, H.B., Grez, M., Griesenbach, U. et al. 2007. Progress and prospects: gene therapy clinical trials (part 1). Gene Ther, 14: 1439-47.

94. Aiuti, A., Bachoud-Levi, A.C., Blesch, A., Brenner, M.K., Cattaneo, F., Chiocca, E.A., Gao, G., High, K.A., Leen, A.M., Lemoine, N.R. et al. 2007. Progress and prospects: gene therapy clinical trials (part 2). Gene Ther, 14: 1555-63.

95. Edelstein, M.L., Abedi, M.R., Wixon, J. 2007. Gene therapy clinical trials worldwide to 2007--an update. J Gene Med, 9: 833-42. 
Summary 
This thesis is aimed at investigating new strategies for a more comprehensive treatment of MG, a well characterized autoimmune disease of the NMJ that leads to muscle weakness and fatigability, which is typically treated by a combination of wide-range immunomodulatory agents. To address this issue, I focused on two factors that are not usually taken into account as therapeutic targets and that are directly involved in the development of symptoms: the plasma cells (the main producers of autoantibodies) and the response of the muscle to an autoimmune attack.

Chapter 1 explains the structure and functioning of the NMJ, emphasizing its electrophysiological and structural characteristics, and the corresponding pathological changes associated with MG. Particular interest is paid to the pathological mechanisms of the different subclasses of autoantibodies in the main subsets of MG: AChR-MG (predominantly pro-inflammatory subtypes IgG1 and IgG3) and MuSK-MG (predominantly anti-inflammatory IgG4). The ability to bind and activate complement, undergo Fab exchange, increase the antigenic modulation of AChRs, or functionally block the AChR is thoroughly explained for these IgG subtypes. In addition, the loss of several AChRassociated proteins which are important for neuromuscular synaptogenesis (utrophin, rapsyn, MuSK, Dok-7, Lrp4, Tid1) is discussed for both MG and CMS, and the concept of loss of AChR-associated proteins as a possible contributor to disease severity in MG is introduced. Finally, the main animal models of MG and the relative contribution of different IgG subtypes to these models are described.

Chapter 2 studies the response of the muscle to an autoimmune attack mediated by anti-AChR antibodies in the chronic EAMG rat model. A two-dimensional difference ingel electrophoresis (2D-DIGE) was utilized to analyze the muscle's proteomic profile at different stages of EAMG. A total of 22 differentially expressed proteins, mainly related to metabolic and stress-response pathways, were identified. NMJ proteins were not found to be differentially expressed, most likely due to the relative low abundance of these proteins in the whole muscle's proteome and also because of technical limitations of 2DDIGE for detecting membrane-bound proteins. Interestingly, the changes in differentially expressed proteins were suggestive of a switch of muscle fiber type towards more fatigueresistant slow-twitch fibers, or a preferential loss of fatigue-prone fast-twitch fibers. This 
phenotype has also been associated with other contraction-impairing muscle pathologies (e.g. inclusion body myositis), which suggests a similar response of the muscle to such conditions.

Chapter 3 investigates the role of the adaptor NMJ protein Dok-7, crucial for the embryonic development of NMJs and the full activation of MuSK, in a passive-transfer EAMG model. Since Dok-7 is the most recently described member of the AChR clustering machinery, and its mutations are one of the leading causes of CMS, it was hypothesized that reduced levels of Dok-7 at the NMJ increases the susceptibility to develop EAMG and impairs recovery after the antibody attack. To test this hypothesis, shRNAs targeting Dok-7 were transfected into the tibialis anterior muscle of adult rats by in vivo electroporation and EAMG was induced 35 days later. Silencing of Dok-7 significantly impaired neuromuscular transmission and reduced AChR levels at the NMJ in EAMG animals that received a subclinical dose of mAb35 (5 pmol/100g body weight). By contrast, silencing Dok-7 had no effects either on control animals or in the recovery from the autoantibody attack up to 14 days after induction of EAMG. At this time-point, however, the NMJ had still not fully recovered its functionality, unexpectedly. Additionally, no evident morphological abnormalities were observed by electron microscopy in Dok-7-silenced NMJs. These results suggest that a reduced Dok-7 expression is not essential for the recovery of the NMJ after damage but may play a role in the susceptibility to EAMG, probably by rendering AChR clusters less resistant to the autoantibody attack.

Chapter 4 discusses the potential therapeutic applications of plasma cell depletion with the proteasome inhibitor bortezomib in MG. This chapter elaborates on the relative contribution of plasma cells, the main antibody producing immune cells, to autoimmunity, and particularly of the long-lived plasma cell subset. Such cells can survive for several months (if not years) producing (auto-) antibodies and are resistant to most of the immunomodulatory therapies used in MG, thus representing promising therapeutic targets. Moreover, the in vitro, in vivo and clinical experience with bortezomib in antibody-mediated autoimmune diseases and organ transplantation is carefully reviewed, with emphasis on the effects on the plasma cell population. Taking this information into account, I proposed and discussed the rationale and relative advantages of bortezomib's 
treatment in certain subsets of MG patients, mainly severely-affected or refractory ones. Such patients could indeed benefit from a rapid reduction in autoantibody titers, though bortezomib's side-effects must be carefully taken into consideration when evaluating plasma cell depletion as an autoantibody-reducing therapy.

Chapter 5 demonstrates that plasma cell depletion with bortezomib reduces antiAChR and IgG levels in the chronic EAMG model, ameliorating the animal's clinical condition concomitantly. The proteasome inhibitor bortezomib has been previously shown to eliminate plasma cells and improve the clinical condition in a mice model of lupus erythematosus. To investigate such effects in MG, bortezomib was tested in a rat EAMG model for an experimental period of eight weeks. One group of rats received bortezomib twice a week subcutaneously right after immunization ( $8 \mathrm{w}-\mathrm{Bz})$, and another group received it 4 weeks after immunization ( $4 \mathrm{w}-\mathrm{Bz})$, while the control group received saline injections. Bortezomib induced apoptosis in bone marrow plasma cells and reduced the amount of plasma cells in the bone marrow by up to $81 \%$. In the EAMG animals, bortezomib efficiently reduced the rise of anti-AChR autoantibody titers and IgG levels. In the $8 \mathrm{w}-\mathrm{Bz}$ animals, it prevented ultrastructural damage of the postsynaptic membrane, improved neuromuscular transmission, and decreased myasthenic symptoms. These outcomes, however, were not significantly improved in $4 \mathrm{w}-\mathrm{Bz}$ animals despite their significant autoantibody reduction, which was comparable to that of $8 \mathrm{w}-\mathrm{Bz}$ animals. This was probably due to transient side-effects of bortezomib and the relatively short-course of treatment, which did not allow for a complete recovery of the NMJ.

Chapter 6 evaluates the effects of proteasome inhibition with bortezomib in primary cultures of human thymic cells from EOMG patients. Frequently, the thymus of EOMG patients is enriched in plasma cells that, after mechanical and enzymatic disruption of the tissue, can produce anti-AChR antibodies in culture for several weeks. The duration of auto-antibody production, its radio-resistance, and its independence from mitogenic stimulation strongly implies plasma cells, primarily the long-lived ones, as the main autoantibody producing cells in these cultures. In this study, it was demonstrated that bortezomib, but not corticosteroids or lenalidomide, killed long-lived plasma cells in cultured thymus cells from EOMG patients and halted their spontaneous production not 
only of autoantibodies but also of total IgG. Bortezomib-treated plasma cells showed ultrastructural changes characteristic of endoplasmic reticulum stress after $8 \mathrm{~h}$, and were no longer detectable at $24 \mathrm{~h}$. Consequently, in this chapter it was corroborated that bortezomib is toxic for human autoimmune plasma cells and that its administration, even at 60 times lower doses than the peak values measured in multiple myeloma patients, can lead to a rapid and sustained reduction of autoantibody production.

In conclusion, this thesis explored novel strategies for treating MG and demonstrated that there is still room for improvement in the management of this autoimmune disease, particularly for treatment-refractory patients and those with high autoantibody titers. In this regard, I have shown that long-lived plasma cells are promising therapeutic targets in MG and depleting them is likely to be fundamental for rapidly and significantly reducing autoantibody titers in MG, and possibly other antibody-mediated diseases. Additionally, I investigated the response of the muscle to the autoimmune challenge in MG and provided supporting evidence on how NMJ proteins (such as Dok-7) can influence the susceptibility to MG, which could have potential therapeutic applications in the future. Thus, these findings provide a stepping stone for developing a more comprehensive treatment strategy for MG, both by expanding the therapeutics options for refractory patients and by focusing on muscle-specific aspects of the disease. 


\section{Samenvatting}


Het doel van dit proefschrift was nieuwe strategieën te bestuderen voor de behandeling van myasthenia gravis (MG), een goed gekarakteriseerde auto-immuunziekte van de neuromusculaire overgang (neuromuscular junction, NMJ) die leidt tot spierzwakte en vermoeibaarheid van skeletspieren; MG wordt gewoonlijk behandeld met een combinatie van breed-spectrum immunosuppressiva. In mijn onderzoek heb ik mij geconcentreerd op twee factoren die gewoonlijk niet beschouwd worden als therapeutische targets en die direct betrokken zijn bij de ontwikkeling van de symptomen: de plasmacellen (die het merendeel van de antistoffen produceren) en de reactie van de spier zelf op de autoimmuunaanval.

In Hoofdstuk 1 wordt de structuur en het functioneren van de NMJ verklaard, waarbij de nadruk wordt gelegd op de karakteristieke eigenschappen van elektrofysiologie en structuur, en de daarmee corresponderende pathologische veranderingen die geassocieerd zijn met MG. In het bijzonder wordt aandacht besteed aan de pathologische mechanismen van de verschillende sub-klassen van auto-antistoffen in de hoofdgroepen van MG: AChR-MG (acetylcholinereceptor-MG; hoofdzakelijk pro-inflammatoire sub-typen IgG1 en IgG3) en MuSK-MG (hoofdzakelijk anti-inflammatoir IgG4). Van deze IgG subtypen wordt het vermogen om complement te binden en te activeren uitgelegd, alsmede het vermogen van de Fab-arm uitwisseling, de toename van antigene modulatie van AChRs of een functionele blokkade. Daarbij wordt het verlies van meerdere AChRgeassocieerde eiwitten besproken die van belang zijn voor de synaptogenese van de NMJ in MG en CMS (congenital myasthenic syndromes) (utrophin, rapsyne, MuSK, Dok-7, Lrp4, Tid1) en het principe van het verlies van AChR-geassocieerde eiwitten als een mogelijke factor die de ernst van MG kan beïnvloeden. Ten slotte worden de voornaamste modellen besproken van MG en de relatieve bijdragen van de verschillende IgG sub-typen op deze modellen.

Hoofdstuk 2 behandelt de reactie van de spier op een auto-immuun aanval die wordt gemedieerd door anti-AChR antistoffen in het chronische EAMG-model (experimental autoimmune myasthenia gravis). Een twee-dimensionaal difference in-gel electrophoresis (2D-DIGE) techniek werd toegepast om het proteomisch profiel in verschillende stadia van EAMG te bestuderen. In totaal werden 22 eiwitten gevonden die 
differentieel tot expressie werden gebracht, hoofdzakelijk gerelateerd aan metabole en stress-response pathways. NMJ eiwitten die differentieel tot expressie kwamen werden niet gevonden, hetgeen waarschijnlijk het gevolg was van het feit dat deze eiwitten een zeer klein onderdeel uitmaken van het arsenaal aan eiwitten in het proteoom van de hele spier en ook vanwege de technische beperking dat de 2D-DIGE techniek niet in staat is membraan-gebonden eiwitten te detecteren. Interessant was dat de differentieel tot expressie gebrachte eiwitten suggereren dat er een switch was opgetreden van het spiervezel type naar de meer vemoeidheid-resistente slow-twitch vezels, of een preferentieel verlies van de gemakkelijk vermoeibare fast-twitch vezels. Dit fenotype is eerder geassocieerd met andere vormen van spierpathologie met een verslechterde contractiekracht (bijv. inclusion body myositis), hetgeen suggereert dat de spier in beide omstandigheden een soortgelijke reactie geeft, nl. switch van fast naar slow-twitch vezels.

In hoofdstuk 3 wordt in een passief transfer EAMG-model de rol bestudeerd van Dok-7, een eiwit dat essentieel is voor de embryonale ontwikkeling van NMJs en de volledige activering van MuSK. Aangezien Dok-7 het nieuwste lid is van de familie van eiwitten die betrokken zijn bij de clustering van AChRs, en ook aangezien mutatie in Dok-7 één van de belangrijkste oorzaken is van CMS, werd de hypothese geformuleerd dat een gereduceerde hoeveelheid van Dok-7 in de NMJ de drempel om EAMG te ontwikkelen verlaagt en het herstel remt na een aanval van antistoffen. Om deze hypothese te testen werden anti-Dok-7 shRNA's getransfecteerd in de tibialis anterior spier van volwassen ratten middels electroporatie en werd EAMG 35 dagen later opgewekt. Het silencen van Dok-7 veroorzaakte een significante verslechtering van de neuromusculaire transmissie en bracht een vermindering teweeg van de hoeveelheid AChRs in de NMJ van EAMG dieren die behandeld waren geweest met een subklinische dosis van mAb35 (5 pmol/100 g lichaamsgewicht). In tegenstelling hiermee had de silencing van Dok-7 geen effect op de controle dieren of op het herstel van de auto-immuun aanval tot 14 dagen na het opwekken van EAMG. Echter op dit tijdstip was de NMJ onverwachts nog niet volledig functioneel hersteld. Verder werden geen evidente abnormaliteiten in de morfologie van de NMJs waargenomen met de electronenmiscroscoop na silencing van Dok-7. Dit suggereert dat een gereduceerd niveau van Dok-7 niet kritisch van invloed is voor het 
herstel van de NMJ na schade maar wel dat een reductie ervan een rol zou kunnen spelen in de drempel om EAMG te kunnen opwekken, waarschijnlijk door de clusters van AChRs minder resistent te maken tegen aanval met antistof.

In hoofdstuk 4 worden de mogelijke therapeutische toepassingen besproken van de depletie van plasmacellen middels applicatie van de proteasoomremmer bortezomib in MG. Dit hoofdstuk gaat in op de bijdrage van plasmacellen, die van alle immuuncellen de meeste antistof produceren, aan het fenomeen auto-immuniteit en in het bijzonder de subset van lang-levende plasmacellen. Dit type cellen kunnen gedurende maanden (zo niet jaren) overleven terwijl ze antistoffen produceren die resistent blijken tegen de meeste immunosuppressie-therapieën in MG. Lang-levende plasmacellen zijn derhalve veelbelovende doelwitten voor therapie. Verder worden de in vivo en in vitro data en de klinische ervaring met bortezomib in antistof-gemedieerde auto-immuunziekten en orgaantransplantatie onderworpen aan een zorgvuldige, genuanceerde beschouwing, met nadruk op de effecten op de populatie van plasmacellen. Deze informatie in beschouwing nemende, heb ik op rationele gronden voorgesteld dat behandeling met bortezomib relatieve voordelen zou kunnen bieden in subsets van MG patiënten, namelijk die hetzij ernstig zijn aangedaan hetzij refractair zijn. Dit type patiënten zouden inderdaad baat kunnen hebben bij vermindering van antistoftiters, alhoewel benadrukt moet worden dat rekening gehouden moet worden met de bijwerkingen van bortezomib wanneer wordt overwogen om door middel van bortezomib het niveau van auto-antistoffen te doen dalen via reductie van plasmacellen.

In hoofdstuk 5 wordt aangetoond dat depletie van plasma cellen onder invloed van bortezomib de niveau's van anti-AChR antistoffen en IgG verlagen in het chronische EAMG- model, waardoor de klinische conditie van het dier dienovereenkomstig wordt verbeterd. Eerder was aangetoond dat de proteasoomremmer bortezomib tot eliminatie leidt van plasmacellen en ook de klinische conditie verbetert van muizen in een model voor lupus erythematosus. Om dergelijke effecten in MG te onderzoeken, werd bortezomib getest in een rat EAMG-model gedurende een periode van acht weken. Eén groep ratten kreeg tweemaal per week subcutaan bortezomib onmiddellijk na immunisatie $(8 \mathrm{w}-\mathrm{Bz})$ en een tweede groep kreeg het geneesmiddel 4 weken na 
immunisatie (4w-Bz); de controlegroep kreeg injecties met fysiologisch zout. Bortezomib veroorzaakte apoptosis in plasmacellen van het beenmerg en veroorzaakte een vermindering in het aantal plasmacellen in het beenmerg tot $81 \%$. In EAMG dieren leidde toediening van bortzeomib tot een vermindering van de toename van anti-AChR antistoftiters en niveau van het IgG. In de groep van $8 w-B z$ dieren verhinderde het de ultrastructurele schade van het postsynaptisch membraan, verbeterde het de neuromusculaire transmissie en verminderde het de myasthene symptomen. Deze effecten werden echter niet significant verbeterd in de groep van $4 \mathrm{w}$-Bz dieren ondanks het feit dat er een significante daling was in de titer van auto-antistof die van dezelfde grootte was als die in de $8 w-B z$ dieren. Waarschijnlijk was dit het gevolg van voorbijgaande neveneffecten van bortezomib en de relatieve korte duur van de behandeling die niet toereikend was voor een volledig herstel van de NMJ.

In hoofdstuk 6 worden de effecten geëvalueerd van proteasoomremming met bortezomib in primaire culturen van humane thymuscellen afkomstig van EOMGpatiënten (early-onset MG). In veel gevallen is de thymus van EOMG-patiënten verrijkt in plasmacellen die, na mechanische en enzymatische disruptie van het weefsel, het vermogen hebben tot productie van anti-AChR antistoffen gedurende enkele weken in weefselkweek. De duur van auto-antistofproductie, de ongevoeligheid voor bestraling en de weerstand tegen mitogene stimulatie geven een sterke aanwijzing dat plasmacellen, en in het bijzonder het lang-levende type, de voornaamste bron is van auto-antistoffen in deze kweken. In dit onderzoek hebben we aangetoond dat bortezomib, maar niet corticosteroïden of lenalidomide, lethaal was voor lang-levende plasmacellen in thymuscelkweken van EOMG-patiënten en de productie stopzette van auto-antistoffen alsmede die van het totale IgG. Plasmacellen die waren behandeld met bortezomib vertoonden ultrastucturele veranderingen na 8 uur die karakteristiek zijn voor stress van het endoplasmatisch reticulum; cellen waren niet langer detecteerbaar na 24 uur. Dientengevolge is in dit hoofdstuk aannemelijk gemaakt dat bortezomib toxisch is voor humane auto-immuun plasmacellen en dat toediening ervan, zelfs in een concentratie die 60 maal lager is dan de piek concentratie die gevonden was in multipele myeloma patiënten na bortezomib behandeling, kan leiden tot een blijvende vermindering van de 
productie van auto-antistoffen.

Samenvattend is in dit proefschrift een verkenning uitgevoerd voor nieuwe strategieën om MG te behandelen. We hebben hierbij aangetoond dat er nog ruimte voor verbetering is voor de behandeling van deze auto-immuunziekte, in het bijzonder voor de behandeling van patiënten die ongevoelig blijken voor behandeling alsmede patiënten met hoge titers van auto-antistoffen. Wat dit betreft heb ik laten zien dat lang-levende plasmacellen belofte inhouden als therapeutisch target in MG. Het is essentieel om juist deze cellen op te ruimen teneinde het niveau van auto-antistoffen in MG te kunnen reduceren. Deze aanpak zou tevens kunnen werken in andere auto-immuun aandoeningen. Verder heb ik onderzocht wat de response van de spier was op een autoimmuun challenge in MG en daarmee aanvullend bewijs gevonden hoe verlaging van NMJ eiwitten (zoals Dok-7) de vatbaarheid voor MG kan beïnvloeden, hetgeen therapeutisch potentieel voorspelt voor de toekomst. Derhalve, leveren deze data een stepping stone voor de ontwikkeling van een uitgebreide behandelingsstrategie in MG zowel door de therapeutische opties uit te breiden in refractoire patiënten als door te focusseren op spier-specifieke aspecten van deze ziekte. 
Resumen 
Esta tesis tiene como objetivo principal el desarrollo de nuevas estrategias para un tratamiento mas exhaustivo de la enfermedad autoinmune miastenia gravis (MG). MG es una enfermedad autoinmune prototípica que afecta la unión neuromuscular (UNM), causando debilidad muscular y fatigabilidad, y que es tradicionalmente tratada con una combinación de agentes inmunomoduladores de amplia gama. Para cumplir los objetivos de esta tesis, me he enfocado en dos factores que usualmente no se tienen en cuenta como posibles opciones de tratamiento, y que están directamente relacionados en el desarrollo de los síntomas en MG: las células plasmáticas (principales productoras de autoanticuerpos) y la respuesta del músculo ante el ataque de los autoanticuerpos.

El Capitulo 1 explica la estructura y el funcionamiento de la UNM, haciendo hincapié en sus principales características electrofisiológicas y estructurales, y las correspondientes alteraciones patológicas de la misma asociadas con MG. En particular, se explican los mecanismos patológicos de las diferentes subclases de autoanticuerpos en los principales subtipos de MG: MG con anticuerpos hacia el receptor de acetilcolina (AChRMG, predominantemente subclases pro-inflamatorias IgG1 y $\operatorname{lgG} 3$ ) y con autoanticuerpos hacia la quinasa-especifica del músculo (MuSK-MG, predominantemente de la subclase anti-inflamatoria lgG4). Para cada una de estas subclases de inmunoglobulinas se describen exhaustivamente sus capacidades para interaccionar con el sistema del complemento y activarlo, realizar intercambio de brazos Fab, incrementar la modulación antigénica de AChRs, o bloquear funcionalmente el AChR. Además, se elabora sobre la perdida de proteínas asociadas al AChR que son importantes para la sinaptogénesis neuromuscular (utrophin, rapsyn, MuSK, Dok-7, Lrp4, Tid1) tanto en MG como en los síndromes miasténicos congénitos (SMC), y se introduce el concepto de la perdida de proteínas asociadas al AChR como posible factor contribuyente a la severidad de los síntomas en MG. Finalmente, se describen los principales modelos animales de MG, y la contribución relativa de las diferentes subclases de inmunoglobulinas a los cambios patológicos en cada modelo.

El Capitulo 2 estudia la respuesta del músculo ante un ataque autoinmune mediado por anticuerpos contra el AChR (anti-AChR) en el modelo crónico de EAMG (experimental autoimmune myasthenia gravis, por sus siglas en inglés). A fines de analizar 
el perfil proteómico del músculo en diferentes estadios clínicos de EAMG, se utilizo la técnica de electroforesis bidimensional diferencial (2D-DIGE, por sus siglas en inglés). En total se identificaron 22 proteínas expresadas diferencialmente en el músculo, en su mayoría relacionadas con vías metabólicas y de respuesta al estrés celular. Proteínas de la UNM no fueron identificadas entre las proteínas expresadas diferencialmente en músculos de animales con EAMG, probablemente debido a la relativamente baja abundancia de estas proteínas en el proteoma muscular, y también debido a limitaciones técnicas de la 2D-DIGE para detectar proteínas unidas a membranas lipídicas. Es de particular interés el hecho de que estas modificaciones en la expresión de proteínas sugieren un cambio en el tipo de fibras musculares hacia tipos de fibras más resistentes a la fatiga (las fibras de contracción lenta), o bien reflejan una pérdida preferencial de las fibras de contracción rápida (las cuales se fatigan más rápidamente). Este tipo de cambio fenotípico ha sido anteriormente asociado con otras patologías que afectan la contracción muscular (ej. miositis de cuerpos de inclusión), lo que sugiere una respuesta similar del músculo ante este tipo de patologías.

El Capitulo 3 investiga el rol de la proteína adaptadora de la UNM Dok-7, la cual es crucial para el desarrollo embrionario de UNMs y la activación completa de MuSK, en el modelo de transferencia pasiva de EAMG. Teniendo en cuenta que Dok-7 es la proteína de las vías de clustering del AChR más recientemente identificada, y que mutaciones en Dok7 son una de las principales causas de SMC, se hipotetizó que una reducción en los niveles de Dok-7 en la UNM aumenta la susceptibilidad para desarrollar EAMG y afecta la recuperación de la UNM luego del ataque de los autoanticuerpos. Para corroborar esta hipótesis, shARNs (short hairpin ARN, por sus siglas en inglés) específicos para Dok-7 fueron transfectados en el músculo tibialis anterior de ratas adultas mediante electroporación in vivo, y el modelo de EAMG fue inducido 35 días mas tarde. La silenciación de Dok-7 empeoró la transmisión neuromuscular y redujo los niveles de AChR en la UNM en animales con EAMG que recibieron una dosis subclínica de mAb35 (monoclonal antibody 35, por sus siglas en inglés) (5 pmol/100g peso). En contraste, la silenciación de Dok-7 no tuvo efectos significativos tanto en los animales control como en la recuperación de la UNM del ataque de autoanticuerpos en animales con EAMG (14 
pmol/100g peso), hasta 14 días luego de la inducción del modelo. En este estadio del experimento, no obstante, la UNM aún no estaba completamente recuperada en su funcionalidad, lo cual fue inesperado. Adicionalmente, no se observaron claras alteraciones morfológicas por microscopia electrónica en UNMs en las cuales la expresión de Dok-7 fue silenciada. Estos resultados sugieren que una reducción en la expresión de Dok-7 no es esencial para la recuperación de la UNM una vez que ésta esta dañada, aunque sí podría desempeñar un papel importante en la susceptibilidad para desarrollar EAMG, probablemente a causa de una reducción en la resistencia de los clusters de AChR hacia el ataque de autoanticuerpos.

El Capitulo 4 discute las posibles aplicaciones terapéuticas de la depleción de células plasmáticas con el inhibidor del proteasoma bortezomib en el tratamiento de MG. En este capitulo se elabora sobre la contribución relativa de las células plasmáticas, las principales células productoras de anticuerpos del sistema inmune, en enfermedades autoinmunes y, en particular, sobre la importancia del subgrupo de células plasmáticas de larga vida en este tipo de enfermedades. Este subgrupo es capaz de sobrevivir por muchos meses (y quizás años) produciendo (auto-) anticuerpos y son resistentes a la mayoría de las terapias inmunomoduladoras que se utilizan en MG, representando, por lo tanto, nuevas y prometedoras dianas terapéuticas. Además, se provee una revisión bibliográfica meticulosa de la experiencia con bortezomib in vitro, in vivo y en pacientes con enfermedades autoinmunes mediadas por anticuerpos o con transplante de órganos, enfatizando los efectos de esta droga sobre la población de células plasmáticas. Teniendo en cuenta esta información, yo propongo los principios, y discuto las ventajas relativas, del uso de bortezomib en el tratamiento de ciertos subgrupos de pacientes con MG, principalmente aquellos con síntomas severos o refractarios al tratamiento estándar. Estos subgrupos de pacientes podrían beneficiarse enormemente de una reducción rápida en los niveles de autoanticuerpos, aunque los efectos adversos de bortezomib deben tenerse cuidadosamente en consideración cuando se evalúa la reducción de células plasmáticas con este medicamento como una posible terapia para reducir autoanticuerpos.

El Capitulo 5 demuestra que la depleción de células plasmáticas con bortezomib 
reduce los niveles de anticuerpos anti-AChR y de IgG en el modelo crónico de EAMG, concomitantemente mejorando el estado clínico de los animales. Previamente, se había demostrado que el inhibidor del proteasoma bortezomib elimina células plasmáticas y mejora la condición clínica en un modelo murino de lupus eritematoso sistémico. A fines de investigar éstos efectos en MG, bortezomib fue testado en un modelo de EAMG en ratas durante un periodo de ocho semanas. Un grupo de ratas recibió bortezomib dos veces por semana de forma subcutánea inmediatamente después de la inmunización (8w$\mathrm{Bz}$, por sus siglas en inglés), y otro grupo lo recibió cuatro semanas después de la inmunización ( $4 \mathrm{w}-\mathrm{Bz}$ ), en tanto que el grupo control recibió inyecciones de solución salina fisiológica. Bortezomib indujo apoptosis en las células plasmáticas de la médula ósea y redujo la cantidad de células plasmáticas en este tejido en hasta un $81 \%$. En los animales con EAMG, bortezomib redujo eficientemente el incremento en los niveles de autoanticuerpos anti-AChR y de IgG. En los animales del grupo 8w-Bz, previno el daño estructural de la membrana post-sináptica, mejoró la transmisión neuromuscular, y redujo los síntomas miasténicos. Sin embargo, éstos parámetros no fueron significativamente mejorados en los animales del grupo $4 \mathrm{w}-\mathrm{Bz}$, a pesar de la significativa reducción en sus niveles de autoanticuerpos, que era comparable con la reducción observada en animales del grupo $8 \mathrm{w}$-Bz. Esto fue probablemente debido a efectos secundarios transitorios de bortezomib y al relativamente breve período de tratamiento con esta droga, el cual no permitió una recuperación completa de la UNM.

El Capitulo 6 evalúa los efectos de la inhibición del proteasoma con bortezomib en cultivos primarios de células tímicas de pacientes con MG de aparición temprana (EOMG, early-onset MG, por sus siglas en inglés). Frecuentemente, el timo de pacientes con EOMG contiene células plasmáticas que, luego de la disrupción mecánica y enzimática del tejido para su cultivo, pueden producir anticuerpos anti-AChR in vitro por varias semanas. La prolongada producción de autoanticuerpos, la radio-resistencia de la misma, y su independencia de la estimulación mitogénica, implican vehementemente a las células plasmáticas, principalmente las de larga vida, como las mayores productoras de autoanticuerpos en estos cultivos celulares. En este estudio se demostró que bortezomib, pero no los corticoides o lenalidomide, elimina las células plasmáticas de larga vida en 
cultivos de células tímicas de pacientes con EOMG y detiene la producción espontánea, no solo de autoanticuerpos, sino que también de IgGs. Las células plasmáticas tratadas con bortezomib presentaron cambios ultra-estructurales característicos de estrés en el retículo endoplasmático y apoptosis luego de 8 horas en presencia de bortezomib y, luego de 24 horas, ya no pudieron ser detectadas. Consecuentemente, en este capitulo se corroboró que bortezomib es tóxico para células plasmáticas autoinmunes de origen humano y que su administración, aún en dosis 60 veces menores a los valores máximos observados en pacientes con mieloma múltiple, podría conducir a una rápida y sostenida reducción en la producción de autoanticuerpos.

Para concluir, esta tesis exploró nuevas estrategias para tratar la MG y demostró que aún existen oportunidades para mejorar el manejo de esta enfermedad autoinmune, particularmente en el tratamiento de pacientes refractarios y aquellos con altos niveles de autoanticuerpos. En este sentido, yo he demostrado que las células plasmáticas de larga vida son prometedoras dianas terapéuticas en MG y que su depleción probablemente sea fundamental para rápida y significativamente reducir los niveles de autoanticuerpos en MG, y posiblemente también en otras enfermedades mediadas por anticuerpos. Adicionalmente, he investigado la respuesta del músculo ante el ataque autoinmune en MG y he encontrado evidencia sustentable de cómo proteínas de la UNM (e.g. Dok-7) pueden influir la susceptibilidad para el desarrollo de MG, lo cual podría tener potenciales aplicaciones terapéuticas en el futuro. Por consiguiente, estos descubrimientos proveen un punto de partida para el desarrollo de una estrategia de tratamiento más comprensiva para MG, tanto por la expansión de las opciones terapéuticas para pacientes refractarios como por el novedoso enfoque en aspectos músculo-específicos de la enfermedad. 
About the author 


\section{Curriculum vitae}

Alejandro Martin Gomez was born on the $30^{\text {th }}$ May 1983 in Concordia, Argentina. In 2000 he obtained his High School Degree with specialization in Biological Sciences at the Instituto Nuestra Señora de Los Angeles (Concordia, Argentina), with distinctions for his marks in Biology and Laboratory Work. He was also recognized for his five-year participation at the Science Club of the abovementioned institute, an extracurricular activity for conducting and guiding science projects at the high school level. In 2001 he started his higher education studies at the Universidad Nacional del Litoral (UNL, Santa Fe, Argentina) and obtained his degree in Biochemistry in 2007, with the highest grade point average of his class. In 2005, he was awarded with a scholarship from the Santander Central Hispano Undergraduate Exchange Program to study one semester of the Biochemistry Specialization at the Universidad Autónoma de Madrid (Madrid, Spain). Between 2006 and 2007, he conducted his final research internship at the laboratory of Metabolic and Nutrition Related Diseases (UNL, Santa Fe, Argentina), under the supervision of Prof. Yolanda B. de Lombardo. His final project was entitled "Effects of Soya Protein in Rats with Lipids Disorder and Glucose Intolerance", which explored the effects of a soya protein-based diet in a rat model of metabolic syndrome. In 2007, he worked as medical technologist at the Clinical Biochemistry Laboratory of Rawson Clinic and the Jose Maria Cullen Hospital in Santa Fe, Argentina. In 2008, he obtained a Marie-Curie Fellowship that allowed him to start his PhD at the division Neuroscience in Maastricht University (The Netherlands), under the supervision of Prof. Dr. Marc H. De Baets, Mario Losen and Pilar Martinez-Martinez. In his PhD project, he investigated pathological mechanisms and potential new therapies for the neuromuscular autoimmune disease myasthenia gravis. The results of his work are described on this thesis. 


\section{Peer-reviewed publications}

- Gomez, A.M., * Van Den Broeck, * J., Vrolix, K., ${ }^{*}$ Janssen, S.P., Lemmens, M.A., Van Der Esch, E., Duimel, H., Frederik, P., Molenaar, P.C., Martinez-Martinez, P., De Baets, M.H., Losen, M. Antibody effector mechanisms in myasthenia gravis-pathogenesis at the neuromuscular junction. Autoimmunity (2010), 43: 353-70.

- Gomez, A.M., Vrolix, K., Martinez-Martinez, P., Molenaar, P.C., Phernambucq, M., van der Esch, E., Duimel, H., Verheyen, F., Voll, R.E., Manz, R.A., De Baets, M.H., Losen, M. Proteasome inhibition with bortezomib depletes plasma cells and autoantibodies in experimental autoimmune myasthenia gravis. J Immunol (2011), 186: 2503-13.

- Gomez, A.M., Willcox, N., Molenaar, P.C., Buurman, W., Martinez-Martinez, P., De Baets, M.H., Losen, M. Targeting plasma cells with proteasome inhibitors: possible roles in treating myasthenia gravis? Ann N Y Acad Sci (2012), 1274: 48-59.

- Verschuuren, J.J., Huijbers, M.G., Plomp, J.J., Niks, E.H., Molenaar, P.C., MartinezMartinez, P., Gomez, A.M., De Baets, M.H., Losen, M. Pathophysiology of myasthenia gravis with antibodies to the acetylcholine receptor, muscle-specific kinase and lowdensity lipoprotein receptor-related protein 4. Autoimmun Rev (2013), 12: 918-23.

- Gomez, A.M., ${ }^{*}$ Vanheel, A., ${ }^{*}$ Losen, M., Molenaar, P.C., De Baets, M.H., Noben, J.P., Hellings, N., Martinez-Martinez, P. Proteomic analysis of rat tibialis anterior muscles at different stages of experimental autoimmune myasthenia gravis. J Neuroimmunol (2013), 10.1016/j.jneuroim.2013.05.008.

* These authors contributed equally to this work

\section{Manuscripts in preparation}

- Gomez, A.M., Willcox, N., Vrolix, K., Hummel, J., Duimel, H., Verheyen, F., Molenaar, P.C., Buurman, W.A., Martinez-Martinez, P., De Baets, M.H., Losen, M. Proteasome inhibition with bortezomib depletes plasma cells and specific autoantibody production in primary thymic cell cultures from early-onset myasthenia gravis patients. Submitted to J Immunol (in revision).

- Gomez, A.M., Stevens, J., Losen, M., Molenaar, P.C., Duimel, H., Verheyen, F., De Baets, M.H., Martinez-Martinez, P. Silencing of Dok-7 in adult rat muscle increases susceptibility to experimental autoimmune myasthenia gravis. Manuscript in preparation. 


\section{Book chapter}

- Van den Broeck, J., Gomez, A., Vrolix, K., Martínez-Martínez, P., Molenaar, P. C., De Baets, M. H., Losen, M. Effector Functions of IgG Isotypes in Myasthenia Gravis. In: Myasthenia Gravis: Disease Mechanisms and Immune Intervention. 2010, Linus Publications, Inc. (USA).

\section{Conference Abstracts}

\section{Oral presentations}

* Gomez, A.M., Stevens, J., Molenaar, P., Losen, M., De Baets, M.H., Martinez-Martinez, P. Repair mechanisms at the neuromuscular junction - the role of Dok-7.

$-3^{\text {rd }}$ Marie Curie Fellow Meeting. March $25^{\text {th }}, 2009$, Maastricht (The Netherlands)

- $3^{\text {rd }}$ Aachen-Maastricht Neuromuscular Research Meeting. October 2009, Maastricht (The Netherlands)

- $4^{\text {th }}$ Aachen-Maastricht Neuromuscular Research Meeting. November 2010, Aachen (Germany)

* Gomez, A.M., Vrolix, K., Phernambucq, M., Martinez-Martinez, P., De Baets, M.H., Losen, M. Bortezomib as a new treatment for myasthenia gravis.

$-13^{\text {th }}$ Euron PhD Days. October $1^{\text {st }}-2^{\text {nd }}, 2009$, Nijmegen (The Netherlands)

- $3^{\text {rd }}$ Aachen-Maastricht Neuromuscular Research Meeting. October 2009, Maastricht (The Netherlands)

- $2^{\text {nd }}$ Joint Meeting Belgian-Dutch Neuromuscular Study Club and German Reference Center for Neuromuscular Diseases of the DGNN. April $23^{\text {rd }}-24^{\text {th }}, 2010$, Vaals (The Netherlands)

* Gomez, A.M., Vrolix, K., Martinez-Martinez, P., Molenaar, P.C., Phernambucq, M., Van Der Esch, E., Duimel, H., Verheyen, F., Voll, R.E., Manz, R.A., De Baets, M.H., Losen, M. Proteasome inhibition with bortezomib depletes plasma cells and autoantibodies in experimental autoimmune myasthenia gravis. 
- ESF Research Conference on B Cells and Protection: Back to Basics. $12^{\text {th }}-17^{\text {th }}$ June, 2011, Sant Feliu de Guixols (Spain)

* Gomez, A.M., Willcox, N., Vrolix, K., Hummel, J., Duimel, H., Verheyen, F., Molenaar, P.C., Buurman, W., Martinez-Martinez, P., De Baets, M.H., Losen, M. Proteasome inhibition with bortezomib eliminates plasma cells in cultured thymic cells from myasthenia gravis patients.

- $12^{\text {th }}$ International Conference on Myasthenia Gravis and Related Disorders. $21^{\text {st }}-23^{\text {rd }}$ May, 2012, New York (USA)

$-16^{\text {th }}$ Euron PhD Days. September $27^{\text {th }}-28^{\text {th }}, 2012$, Maastricht (The Netherlands)

- $100^{\text {th }}$ AAI Annual Meeting Immunology 2013. May $3^{\text {rd }}-7^{\text {th }}, 2013$, Honolulu (USA)

\section{Poster presentations}

* Gomez, A.M., Vrolix, K., Phernambucq, M., Martinez-Martinez, P., De Baets, M.H., Losen, M. Bortezomib as a novel treatment for experimental autoimmune myasthenia gravis.

- International Conference on Myasthenia (EuroMyasthenia Network). December 1-2, 2009, Paris (France)

- Final Marie Curie Fellow Meeting. March $16^{\text {th }}, 2010$, Maastricht (The Netherlands)

- $3^{\text {rd }}$ MHeNS Research Day. March $17^{\text {th }}, 2010$, Maastricht (The Netherlands)

$-7^{\text {th }}$ International Congress on Autoimmunity. May $5^{\text {th }}-9^{\text {th }}, 2010$, Ljubljana (Slovenia)

$-10^{\text {th }}$ International Congress of Neuroimmunology. October $26^{\text {th }}-30^{\text {th }}, 2010$, Sitges (Spain)

* Gomez, A.M., Stevens, J., Molenaar, P., Losen, M., De Baets, M.H., Martinez-Martinez, P. Repair mechanisms at the neuromuscular junction - the role of Dok-7.

$-15^{\text {th }}$ Euron PhD Days. September $22^{\text {nd }}-23^{\text {rd }}, 2011$, Bad Honnef (Germany)

- $12^{\text {th }}$ International Conference on Myasthenia Gravis and Related Disorders. $21^{\text {st }}-23^{\text {rd }}$ May, 2012, New York (USA)

$-6^{\text {th }}$ MHeNS Research Day. June $6^{\text {th }}, 2013$, Maastricht (The Netherlands)

- Myasthenia 2013. $1^{\text {st }}-2^{\text {nd }}$ July, 2013, Paris (France) 
* Gomez, A.M., Vanheel, A., Losen, M., Molenaar, P.C., De Baets, M.H., Noben, J.P., Hellings, N., Martinez-Martinez, P. Proteomic analysis of rat tibialis anterior muscles at different stages of experimental autoimmune myasthenia gravis

- Myasthenia 2013. $1^{\text {st }}-2^{\text {nd }}$ July, 2013, Paris (France)

\section{$\underline{\text { Travel awards }}$}

- Young Investigator Travel Fellowship. (Myasthenia Gravis Foundation of America),

$12^{\text {th }}$ International Conference on Myasthenia Gravis and Related Disorders, May 2012, New York (NY) (1250 USD).

- Trainee Abstract Award. $100^{\text {th }}$ Annual Meeting of the American Association of Immunologists (AAI) - Immunology 2013. May 2013, Honolulu (HI) (750 USD).

- Travel Fellowship. Myasthenia 2013. July 2013, Paris (France) (300 EUR)

\section{Courses \& Internships}

- Euron Course Neuroimmunology. May 2008, Hasselt University, Belgium.

- Course on Laboratory Animal Science. September 2008, Division of Laboratory Animal Science, Utrecht University.

- Dutch Course, Module 1 (NL-9A1). September - December 2008, Language Centre, Maastricht University.

- Course on Radiological Protection, Level 5b. February - March 2009, Department of Radiological Laboratories, Maastricht University.

- Dutch Course, Module 2 (NL-9A2). April - June 2009, Language Centre, Maastricht University.

- Basic Course for Tutors in Problem-Based Learning. June 2009, Institute for Education (FHML), Maastricht University.

- Academic Visit to David Beeson's Lab at the Department of Clinical Neurology, University of Oxford. February 2010, Oxford, UK.

- Dutch Course, Module 3 (NL-9B1-). February - May 2010, Language Centre, Maastricht 
University.

- $10^{\text {th }}$ Course of the European School of Neuroimmunology (ESNI). October $26^{\text {th }}, 2010$, Sitges, Spain.

- Course in Academic Writing for PhD's (PhD-1). October - November 2010, Language Centre, Maastricht University.

- PhD Presentations Course (PhD-4). March - May 2012, Language Centre, Maastricht University.

- Course in Academic Writing for Biomedical Sciences (PhD-2). September - October 2012, Language Centre, Maastricht University. 


\section{Affiliations of co-authors}


Buurman, Wim A.

Baets De, Marc H.

Duimel, Hans

Frederik, Peter

Hellings, Niels

Janssen, Sofie P.

Losen, Mario

Manz, Rudolf A.

Martínez-Martínez, Pilar

Molenaar, Peter C.
Gomez, Alejandro M.

Division Neuroscience, School for Mental Health and Neuroscience, Maastricht University, Maastricht, The Netherlands

Neuroimmunology group, Division Neuroscience, School for Mental Health and Neuroscience, Maastricht University, Maastricht, The Netherlands

School of Life Sciences, Biomedical Research Institute and transnationale Universiteit Limburg, Hasselt University, Diepenbeek, Belgium

Electron Microscopy Unit-CRISP, Department of Molecular Cell Biology, Maastricht University, Maastricht, The Netherlands

Electron Microscopy Unit, Department of Pathology, Maastricht University, Maastricht, The Netherlands

Neuroimmunology group, Division Neuroscience, School for Mental Health and Neuroscience, Maastricht University, Maastricht, The Netherlands

Biomedical Research Institute, Hasselt University and Transnationale Universiteit Limburg, School of Life Sciences, Hasselt, Belgium

Neuroimmunology group, Division Neuroscience, School for Mental Health and Neuroscience, Maastricht University, Maastricht, The Netherlands

Lemmens, Marijke A. M. Division Neuroscience, School for Mental Health and Neuroscience, Maastricht University, Maastricht, The Netherlands

Neuroimmunology group, Division Neuroscience, School for Mental Health and Neuroscience, Maastricht University, Maastricht, The Netherlands

Institute for Systemic Inflammation Research, University of Lübeck, Lübeck, Germany

Neuroimmunology group, Division Neuroscience, School for Mental Health and Neuroscience, Maastricht University, Maastricht, The Netherlands

Neuroimmunology group, Division Neuroscience, School for Mental Health and Neuroscience, Maastricht University, Maastricht, The Netherlands 
Noben, Jean-Paul

Phernambucq, Marko

Stevens, Jo

Van den Broeck, Joost

Van der Esch, Eline

Vanheel, Annelies

Verheyen, Fons

Voll, Reinhard E.

Vrolix, Kathleen

Willcox, Nick
Biomedical Research Institute, Hasselt University and Transnationale Universiteit Limburg, School of Life Sciences, Hasselt, Belgium

Neuroimmunology group, Division Neuroscience, School for Mental Health and Neuroscience, Maastricht University, Maastricht, The Netherlands

Neuroimmunology group, Division Neuroscience, School for Mental Health and Neuroscience, Maastricht University, Maastricht, The Netherlands

Neuroimmunology group, Division Neuroscience, School for Mental Health and Neuroscience, Maastricht University, Maastricht, The Netherlands

Neuroimmunology group, Division Neuroscience, School for Mental Health and Neuroscience, Maastricht University, Maastricht, The Netherlands

Biomedical Research Institute, Hasselt University and Transnationale Universiteit Limburg, School of Life Sciences, Hasselt, Belgium

Electron Microscopy Unit-CRISP, Department of Molecular Cell Biology, Maastricht University, Maastricht, The Netherlands

Department of Internal Medicine 3, Nikolaus Fiebiger-Center of Molecular Medicine, University Hospital Erlangen, Erlangen, Germany

Neuroimmunology group, Division Neuroscience, School for Mental Health and Neuroscience, Maastricht University, Maastricht, The Netherlands

Department of Clinical Neurology, University of Oxford, United Kingdom 
Acknowledgements 
Last, but not least, I would like to thank all the people who, directly or indirectly, contributed to the completion of this thesis and was part of my journey throughout the PhD. As some might say: "Knowledge is in the end based on acknowledgement" (L. Wittgenstein).

First of all, I would like to thank my supervisor Prof. Marc De Baets. Marc: I've learnt a lot from your broad knowledge about myasthenia and other clinical conditions. I particularly enjoyed your way of making precise and relevant scientific questions, this also helped me to guide and improve my research after our several lab-meetings. I also appreciate how you always encouraged me to attend international meetings and improve my professional network, you showed me that science is not only about good results, but also about having the adequate network to support and communicate them. I have good memories of our nice and prolonged dinners with the group or at conferences (always with good wine included, of course). It's nice to know that you can be a successful scientist and still enjoy the good pleasures of life. Moreover, thanks for the amazing Italian espresso machine you gave us! Our scientific output would have been much slower without that fundamental apparatus... And finally, I value a lot your support during the crucial moments of my PhD and the fact that I could rely on you when I had problems. Sincere thanks for that and for your trust in me.

Special thanks also to my co-supervisors, Pilar and Mario. Pilar (as I always called you despite most of people calling you Piluca): thanks for giving me the opportunity to start my PhD in Maastricht. I've always appreciated your courage and determination for choosing me, a random applicant from 11000 km-away Argentina, to start a complex research project under your supervision. I experienced at first-hand how the bureaucracy is more complicated when you want to bring someone from far away to work in the Netherlands, so I honestly appreciate your efforts, trust and good intentions when offering me the chance to start my PhD here. The same determination and enthusiasm also characterizes your way of doing science, many times your input and support decisively helped me to continue working despite problematic results. And it felt good to be able to talk and discuss with you in our mother-tongue Spanish, particularly when you are constantly surrounded by an English-Dutch environment. Mario: I've learnt a lot about 
layouts, data analysis and presentation of results \& figures from you. I value your critical view on the results and manuscripts, and your willingness to help when I was performing busy experiments or I had problems at the microscope. You are somebody who you can freely discuss issues with, I also appreciate this. For the both of you, since you work as a couple, I honestly thank you for the freedom you gave me for conducting my PhD and making decisions about it. Of course, due to our different expectations and approaches to work, we had sometimes more chaotic situations and misunderstandings, but I think we have learned to work together efficiently and we managed to produce decent pieces of scientific work of which I'm proud. Above all, I thank you for your trust, patience and unconditional support during these 5 years of PhD.

I would also like to thank Prof. Harry Steinbusch for taking interest in me and giving me the chance to do my PhD at the School for Mental Health and Neuroscience. Harry: I would particularly like to thank you for your support during my trial-period and my first year and a half as a Marie-Curie fellow, my PhD would not have started so smoothly if it wouldn't be for your help. Many thanks also to Peter Molenaar and Wim Buurman for their scientific advice and valuable help for correcting manuscripts.

This thesis would not have been legally completed without the help of Lisa Pizzuto, who dealt with all the letters, legal documents and emails that are required to officially process a PhD thesis. Thanks a lot for always being ready to help me with a big smile. Also thanks to Marie-Therese Moers, Nicole Senden and the financial department (Ankie Hochstenbach and Laurent Louwies) for guiding me through the various administrative procedures that are usually part of doing a PhD at MHeNS. Special thanks to the Knowledge Centre for International Staff, particularly to Marjo Zwanenburg and Martine Berghof, for their valuable and efficient help in the quite complex bureaucracy behind work permits, unemployment and visas.

I would also like to thank the technician's team (Hellen, Denise, Marjan, Eline and Jorike) for their help at various stages of this thesis. In particular to Denise and Marjan for their help with my experiments and for being always available for my questions about broken machines, missing or empty lab reagents and, most importantly, for providing me with lab material from the sacred storage room (even when I was asking for it outside the 
legal allocated time for this). I would also like to thank the CPV employees that help me through the design and approval of DECs, and their various modifications, in particular to Richard; and also to Rik and Inger for their excellent assistance in the animal experiments.

And how to forget my dear office mates! We have had a wonderful time together in our cozy room that smells always like freshly-grinded coffee, is full of mutated basilicums and is covered with postcards from around the world. First of all, Chiara: we started the PhD basically at the same time and we became friends almost immediately, it was great to have your cheerful presence at the office and to have somebody with whom I share a common view on many things, despite being from such distant parts of the world. All the trips that we have done together to escape the tormenting Dutch weather, the exotic dinners to try flavors from around the world and, most importantly, your unconditional friendship in both the good and troubled times made these years in Maastricht a "delicious" experience (:) YY. Kathleen: our Belgian office mate, it has been great fun to work together with you and to be your friend, and even your last-minute paranymph! I will always remember the very "spartan" conference that we attended in Spain, the overnight trips to the Mediterranean through the $160 \mathrm{~km}$-spaced German highways, and the autographed calendar of suicidal bunnies that you gave me to decorate my wall, you know my humor very well $;$. Jo and Gerard, my paranymphs, after being 4 times paranymph myself I know that now it's payback time and revenge will fall on me ; ), but I'm confident that you'll do a fair job... Jo: you were the first student under my supervision and I'm proud to see that you enjoyed so much your stage in our group that you have stayed with us for your Master's and even PhD (or perhaps was it because of your unconditional love for Dok-7?). I've really enjoyed working with you for producing tons of bacteria + DNA and during those eternal hours in the basement of the CPV, and also our trips, dinners, Mario Kart competitions, and experiments with liquid nitrogen. And Gerard: when I first met you, you were a silent and long-haired Master's student with whom I did not interact much, but I soon learned that you only get talkative after the sun comes down and you have consumed several grams of caffeine $: ;$. It was nice to get to know you and to share the office with you, the many trips we have made, watch the Maastricht's sky with your telescope, try the espressos from your extremely-well 
optimized espresso machine, drink good scotch spirits, and help you to survive when you had both arms broken. I'm very glad that you guys (official and unofficial paranymphs) are going to be there next to me at the very end of my PhD!

Many thanks also to the people who were part of the neuroimmunology group at various periods during my PhD. Marko: you are an extremely friendly guy and you were my first "guide" into the lab, the department, and the city. Thanks a lot for your willingness to help and for introducing me to the Dutch culture \& habits, and to the world of paranymphing also! Sofie: thanks for your help during the first months of my PhD and for your efficient way of instruction of laboratory techniques. Joost and Caroline: thanks for your help (and for teaching me some survival Antwerps!), it was nice sharing dinners, trips and lunch with you. Marjorie: thanks for being such a nice colleague. Anne-Hilde: it was very nice having you in our group (even though it was for a brief period) and even nicer to keep you as a friend. Thanks for your kindness, for joining in our several dinners and carnaval celebrations, and for helping me with the FACS in moments of desperation! Jonas: your were my first (unofficial) Master's student and I would like to thank you for your commitment to our side-project (that turned out to be the main one) and the numerous hours you've spent culturing, counting cells and labeling tubes, hope this vast experience will help you now for your own $\mathrm{PhD} \odot$ :

Of course I would like to specially thank all my colleagues at Neuroscience that have shared all these years (and lab space) with me. Marisela: como buen anfitrión fui a buscarte al aeropuerto de Maastricht ni bien llegaste, emocionado por tener a otro latinoamericano en el departamento, y termine estando a tu lado también en tu defensa. Como vos bien dijiste, del principio al fin! Pablo: fue muy bueno tener otro "guey" latino en el departamento con quien poder hacer chistes en español y con quien disfrutar de las buenas cervezas belgas y, de paso, también de un viajecito por Polonia. Yara: la última adición al grupo de hispano-parlantes en Neuroscience, me alegra que hayas podido continuar tu PhD aquí con nosotros y que hayamos disfrutado de varias fiestas hasta el amanecer (como se debe!), del famoso Oktoberfest y de jamón Serrano del bueno. Julie: I'm not going to write in Spanish for you (though I know you understand it, despite your complaints about my accent). It was great having you around all those summers with your 
memorable troupes of New Yorkers, and it was even better to have you as a full Maastricht PhD student this last year. We wouldn't have made so many mud runs, color runs, international dinners, and discussions over the time for lunch if it weren't because of you (:). Maria (or is it Maaaaria?), thanks for your cheerfulness and for joining us in our crazy trip ideas such as chasing volcanoes on isolated islands or sleeping at the desert, you are always a great company! Jochen, thanks for your help in the lab at the beginning of my $\mathrm{PhD}$, when I had absolutely no clue of where things are or what to do, and for your cool musical \& movie/series suggestions. It was very nice to go to good concerts and to travel to sunny destinations together. Sven, one of the May-1983 fellows, thanks for providing the shelter for our $3^{\text {rd }}$ decade celebration, and the bbq's that followed it, l'll always remember that party when I look at my (now) weird finger... And also many thanks to all the PhD students, Bachelor's, Master's, postdocs, and other colleagues from Maastricht University who, in one way or another, were part of my PhD experience: Evi, Rianne, the two Eva's, Prashanth, João, Abhishek, Gisela, Mark, Ramona, Leonidas, Fabien, Eveline, Thibaut, Frank, Natalia, Jos, Fred, Yasin, Daniel, Rinske, Annerieke, Marijke, Ivona, Govert, Lucas, Nick, Niki, Dagmar, Sarah, Wiel, Ali, Youssef, Bert, Nicole, Lisa, Remco, Celine, Ehsan, Lee, Laura, Sonny, Kenrick, Marlien, Tatyana, Tim, Olga, Marlies, Ralf, Els, Ronald, the Bart's, Kimberly, Gunther, Hans, Fons, Marjolein, and to the many others that I'm probably forgetting in this list.

Doing a PhD in Maastricht turned out to be a great experience, and this was largely because of the amazing friends and colleagues I met during these past years. A special recognition goes to Paula, mi vecina germano-brasileña, fue genial conocerte y compartir no sólo salidas, fiestas hasta tarde, comidas exóticas, viajes, postales, basilicos y té del DM, sino que también nuestra querida Herbenusstraat y, lo más importante, la famosa WM!! Aunque no puedas estar en mi defensa, se que estarás presente como paranymph honoraria, pondremos algunos temas de La Pegatina en tu honor durante la fiesta! Sinceros agradecimientos también para Patricia, por tu energía y buena onda, por tu amistad, el buen tequila (y la crema de tequila!), y por escucharme y confiar en mí. Many thanks also to my group of friends from the UM Randwyck campus (and their partners): Rita, Luis, Nuria, Ingo, Raffaele, Tsilla, Mohamed, Mirjam, Erik, Kathelijne and 
Lars. Was great to share so many dinners, birthday celebrations, weddings in sunny locations, walks in the mud (and the sea-mud), and trips to stunning Scandinavian places. The trip to Iceland was one of the best I've done in my life: the recruiting period and interviews with Mo, the super stuffed car, the random camping spots, the quite weird car rental company, the snake and the isolated road, Karl the mechanic, the strange drawings in the logbook of someone, and many other stories. I could not imagine better company that you guys. Special thanks also to the PhD Academy, the social life in Maastricht wouldn't be so intense and exciting if it weren't for your work. Mi tocayo Alejandro, Luciana, Julieta, Agustin, Jenny: los PhD argentinos en Maastricht! Fue buenísimo encontrarlos y no sentirme el único argentino en varios kilómetros a la redonda, poder compartir mates y fernet con cola, escuchar cumbias y cuarteto, comer asados (aunque en versión europea) y hablar con acento argento sin temor a que la gente no me entienda. Many thanks to the PhD Improv people: Jessie, Nevena, Gabri, Fred, Jan, Sanne, Paul, Mehrdad, Nordin, Burcu, Jasper, Ayse, Saba, Nadine, Yeliz, Roxanne, Despina; for their enthusiasm, theme parties and for being the coolest group in town $:-$. I really enjoyed the time spent with you guys. Also many thanks to the rest of the PhD (and UM-related) world in Maastricht: Francesca, Jennifer, Giorgio, Cheng, Joost, Shuan, Martin, Andrea, Emmanuel, Mare, Daan, Francisco, Stefania, Bas, Thom, Johan, Viktor, Thomas, Oscar, Ariano, Nico, Gintare, Amanda, Hendrik, the Irina's, Alexandros, Juan Carlos, Tomás, Verena, Mike, Esther, Josy, Kristine, Eugene, Christian, Ina, Erik, Bart, Maurits and many others. You made my time in Maastricht an unforgettable and enriching experience and helped me to feel truly at home here.

I would also like to thank my friend Maja, you know me basically since I was born though we did not meet until I first came to Europe in 2005. Your three-decade friendship with my mother through letters always amazed me and made my proud, and I was happy to discover that you understood what I wanted to do when I came to Europe. You gave me good advice (and shelter!) and made me feel at home while I was trying to get a PhD here. Many thanks also to Zhaosha, we met casually at that famous animal course in Utrecht and ended up going to Prague together, and later I even attended your big defense. You have always impressed me with your sharp insights and great humor, thanks for your 
friendship! Y sinceros agradecimientos también para Diana, por ser la única no-argentina que verdaderamente comparte mates conmigo, le gustan los alfajores, el dulce de leche y hasta las cumbias! Gracias por mostrarme Amberes, la buena música belga y por tu amistad.

También quisiera agradecer a mis amigos de la UNL Santa Fe que, aunque no estén directamente relacionados con esta tesis, están presentes en los recuerdos de las clases y prácticos interminables (con mate en el laboratorio incluido), la tradicional birra después de los exámenes, las inolvidables fiestas, y los extraños personajes que hemos encontrado en el camino. Me alegró un montón que nos hayamos podido encontrar con varios de ustedes cuando vinieron a Europa por intercambios o de paseo (Maru, Andrés, Berni, Vicky, Alexis, Nico, Ludmila, Sonia, Franco, Fede). Pasamos de tomar Quilmes en el 4 grados a tomar trapistas Belgas en Paris $(;)$, aunque en el fondo seguimos siendo los mismos de siempre, y eso esta genial! Y no quiero olvidarme de agradecer al resto de mis amigos de la UNL (Juan Diego, Vane, Nati, Aye, Victoria, Ana, Vale, Fernán, Félix, Belén) y a mis amigos del CMU (que son muchos como para nombrarlos a todos), pero están siempre presentes de alguna forma u otra en las innumerables historias, asados, salidas, la convivencia, los personajes, etc. Mis años de estudiante en Santa Fe no hubieran sido tan memorables de no ser por ustedes.

Y no podría faltar el agradecimiento a mis amigos del pago Concordiense! Tanto para los que influenciaron mi decisión de estudiar bioquímica y dedicarme a la investigación (Carlos C. y Graciela M.) como para mis amigos de (prácticamente) toda la vida: Vini, Fede, Búfalo, Pepo, José Maria, Marcelo, Mato, Matías M., Jorge, Diego, Nico D., Nico B., Martín L., Martín P., Victoria, Juanjo, Ariel, Mariano, Lucas, Gastón C., Marita B., y muchos más que probablemente me estoy olvidando en esta lista. Volver a Concordia todos los años y encontrarme con ustedes (durante Navidad y Año Nuevo, como para estratégicamente escapar al invierno Holandés) fue la mejor manera de recargar las pilas para empezar con energías renovadas cada año. Inclusive, con algunos de ustedes (Facu, Mariano I., Victoria G., Sabrina), hasta tuve la suerte de verlos aquí en Europa también. Me alegra mucho que, a pesar de los años, sigamos en contacto y haciendo las mismas bol...ces que siempre hacíamos $(-)$. Ir a la costanera a dar la vueltas en auto y tomar algo 
en las pegajosas noches de verano Concordienses, los asados con fernet, los tradicionales cigarros de fin de año, ir a los bares que abren y se ponen de moda sólo por un par de temporadas estivales, saludar a los conocidos en la calle, etc. Concordia no cambia demasiado con el tiempo y volver ahí cada año, a los lugares familiares, la gente que creció conmigo y la familia, fue muy importante para mantener presente mis orígenes. $Y$ esto se vuelve fundamental cuando uno ya no vive en su país hace unos cuantos años.

$\mathrm{Y}$, finalmente, quisiera agradecer en especial a toda mi familia: la familia cordobesa, Marcelo, mis abuelos, mis tíos, mis hermanos y mis viejos; no solo por haberme dado una vida llena de afecto sincero y una educación ejemplar, sino también por su apoyo incondicional en las decisiones que he tomado en mi vida. Les agradezco sinceramente la libertad que me dieron y la confianza que siempre han tenido, y tienen, en mí. Desde el primer momento en que les comente mi idea de irme fuera de Argentina para hacer el doctorado supieron entenderme y me apoyaron incondicionalmente en esto. Sé que en general no les gusta alardear de nuestros logros, pero también sé que por dentro siempre estuvieron orgullosos de lo que hemos logrado en nuestros estudios y profesiones, hay cosas que no se necesitan decir con palabras. Vivir afuera país implica ganar muchas cosas $y$, de alguna forma, perderse otras, pero, sobre todo, sirve para conocerse mejor a uno mismo y entender cuáles son las cosas que realmente importan en la vida. En mi caso, yo entendí que mi familia es lo más importante para mí y, por eso y mucho más, ésta tesis se las dedico a ustedes. 


